RENATA D'AGOSTINO DE MARCHI

\title{
ESTUDO SOBRE A VARIABILIDADE DO MÓDULO DE DEFORMAÇÃO DO CONCRETO ASSOCIADA A FATORES INTRÍNSECOS À PRODUÇÃO DO MATERIAL
}


RENATA D'AGOSTINO DE MARCHI

\title{
ESTUDO SOBRE A VARIABILIDADE DO MÓDULO DE DEFORMAÇÃO DO CONCRETO ASSOCIADA A FATORES INTRÍNSECOS Á PRODUÇÃO DO MATERIAL
}

\author{
Dissertação apresentada à Escola \\ Politécnica da Universidade de São \\ Paulo para obtenção do título de Mestre \\ em Engenharia
}


RENATA D'AGOSTINO DE MARCHI

\title{
ESTUDO SOBRE A VARIABILIDADE DO MÓDULO DE DEFORMAÇÃO DO CONCRETO ASSOCIADA A FATORES INTRÍNSECOS À PRODUÇÃO DO MATERIAL
}

\author{
Dissertação apresentada à Escola \\ Politécnica da Universidade de São Paulo \\ para obtenção do título de Mestre em \\ Engenharia \\ Área de Concentração: \\ Engenharia de Construção Civil e Urbana \\ Orientador: \\ Prof. Dr. Antonio Domingues de Figueiredo
}




\section{DEDICATÓRIA}

Ao meu marido pelo companheirismo e carinho

À minha família pelo incentivo 


\section{AGRADECIMENTOS}

Ao professor e orientador Antonio Domingues de Figueiredo pelo incentivo, orientação e amizade demonstrados durante todo o desenvolvimento deste trabalho. À Universidade de São Paulo pela oportunidade e seus mestres que contribuíram para meu conhecimento e também para o enriquecimento desta dissertação.

Ao meu marido Caio pela compreensão, companheirismo e carinho durante a condução deste trabalho.

À minha família pelo apoio e incentivo constantes.

À banca examinadora composta pelos professores Túlio Nogueira Bittencourt e Cláudio Sbrighi Neto.

À Holcim Brasil S.A. pela cessão dos materiais e de suas instalações para a realização dos ensaios.

Aos amigos do Laboratório do Centro Tecnológico da Holcim que colaboraram na execução do trabalho experimental, especialmente aos Laboratoristas Donizete dos Santos e Fernando Cassiano, demonstrando todo o comprometimento e zelo na realização dos ensaios. Ao amigo Robson Marinho Augusto Espósito pela colaboração nas análises estatísticas. Ao amigo Francisco de Assis Mezzalira pelo incentivo e apoio constantes. Aos demais amigos da Holcim que tanto me incentivaram para seguir adiante.

Aos amigos que souberam entender minha ausência, torceram e me apoiaram para a concretização deste trabalho.

E, sobretudo, a Deus pela força nos momentos mais difíceis. 
"O ato de entender é vida"

Aristóteles

"Livros não mudam o mundo, quem muda o mundo são as pessoas.

Os livros só mudam as pessoas."

Mário Quintana 


\section{RESUMO}

Em função da especificação do módulo de elasticidade ou módulo de deformação do concreto ser cada vez mais frequente, se faz necessário o conhecimento da variabilidade desta propriedade, relacionada ao processo de produção, de modo a tornar mais confiável sua avaliação e que possibilite melhores condições no controle de produção para o atendimento aos requisitos associados a esta propriedade.

Várias pesquisas têm comprovado que a variabilidade das propriedades mecânicas dos materiais de construção obedece a processos aleatórios. Portanto, os métodos de segurança no projeto estrutural devem estar fundamentados no conceito da teoria das probabilidades e não em métodos deterministas. Isso já acontece para a determinação da resistência à compressão, conforme estabelecido pela ABNT NBR 12655 (2006).

A presente dissertação tem como objetivo principal estudar o controle experimental do módulo estático de deformação do concreto, mostrando a influência da variação dos materiais constituintes do concreto, dentro da realidade de uma Central de Concreto.

Também objetiva apresentar uma discussão da aplicabilidade do conceito semiprobabilístico das normas nacionais de projeto, dosagem e controle tecnológico à propriedade módulo de deformação do concreto.

A metodologia da pesquisa envolveu a escolha de uma central dosadora de concreto localizada na cidade de São Paulo, com a avaliação em dois concretos de resistências características $\left(f_{c k}\right)$ de 25 e $30 \mathrm{MPa}$, que são comumente solicitados no mercado em que se insere. Para cada $f_{c k}$ foram realizados ensaios para determinação do módulo de deformação secante, $\mathrm{E}_{\mathrm{cs}}$, três vezes por semana por um período de nove meses.

Em função da precisão observada em pesquisa recente, foi utilizada a instrumentação clip gage para avaliação da propriedade módulo de deformação. Foram realizados ensaios sob o plano de carregamento secante, previsto na ABNT NBR 8522 (2008).

Concluiu-se que, pelo fato do módulo de deformação do concreto ser influenciado pela resistência à compressão, que obedece a uma distribuição probabilística, não 
se pode atribuir à propriedade uma característica determinística, incorrendo no risco de não atendimento da propriedade.

Recomendou-se o estabelecimento de tolerâncias para a especificação do módulo de deformação, uma vez que é uma variável com distribuição de probabilidade de rejeição. Sugeriu-se a discussão de mudança de enfoque no controle do módulo de deformação do concreto, com o controle por valor característico, tal qual ocorre para a resistência à compressão, atribuindo-se um estimador que atribua valores inferiores ao módulo de deformação, considerando-se uma rejeição aceitável. Também pode-se atribuir uma faixa de variação aceitável do valor em torno da média, uma vez que a responsabilidade estrutural do parâmetro módulo de deformação é menor do que o da resistência à compressão. 


\section{ABSTRACT}

The modulus of elasticity requirements for concrete structures is becoming even more frequent. So, the knowledge of the variables involved in the experimental results became more important in order to make more reliable its assessment and enabling better conditions for specifications requirements attendance in relation to this property.

Several studies have shown that the variability of mechanical properties of construction materials is subjected to random processes. Therefore, the security methods in the structural design must be based in the probability theory concept rather than deterministic methods. The randomness of the, compressive strength of concrete is already take in account in the quality control process according to the Brazilian Standard ABNT NBR 12655 (2006).

The present work aims to study the experimental control of static modulus of elasticity of concrete, showing the influence of the constituent materials used in a Concrete Ready Mix Plant. It also intends to present a discussion on the applicability of the semi-probabilistic concept of national design standards in the mix design and production control of concrete in order to attend the elastic modulus requirements.

The research methodology had two main steps: the first one, developed at a Concrete Ready Mix Plant located in São Paulo City, was based on the assessment of two characteristic compressive strength $\left(\mathrm{f}_{\mathrm{ck}}\right)$ of $25 \mathrm{MPa}$ and $30 \mathrm{MPa}$, which are commonly demanded in this market. For each strength class, tests were done to evaluate the variability of static modulus of elasticity of concrete, $E_{c s}$, three times per week, during a period of nine months. On the second step, an analysis of elastic modulos of concretes provided at six different sites, where the characteristic strength was $30 \mathrm{MPa}$, which was made using the same materials used in the first step.

It has been used the clip gage instrumentation for measuring deformation to the assessment of static modulus of elasticity of concrete. It was used due to the precision that has been observed in recent research. The evaluation has been done according to the Brazilian Standard ABNT NBR 8522 (2008).

It was possible to conclude that the modulus of elasticity of concrete is influenced by the compressive strength, so it follows a probabilistic distribution and cannot be associated to a deterministic model of quality control, due to the risk of noncompliance of the requirement. 
It was recommended the establishment of tolerances for the measured modulus of elasticity results, taking in account its random characteristic. The possibility of changing the focus on modulus of elasticity quality control was proposed, turning the deterministic criterion as occurs for the compressive strength, giving an estimator that assigns lower values to the modulus of elasticity, considering an acceptable rejection. It can be also based in a method that allows the acceptance of a concrete that lies within a predetermined tolerance around the average value, because the structural responsibility of modulus of elasticity is lower than the compressive strength. 


\section{LISTA DE FIGURAS}

Figura 2.1 - Comportamento típico tensão- deformação do concreto e suas fases.

Figura 2.2 - Representação do comportamento do concreto sob compressão uniaxial $(\sigma-\varepsilon)$ 26

Figura 2.3 - Perturbação inicial no gráfico $\sigma-\varepsilon$ 28

Figura 3.1 - Detalhe das fibras cristalinas de C-S-H (silicatos de cálcio hidratados) 35

Figura 3.2 - Representação da zona de transição pastaagregado.

Figura 3.3 - Influência da condição de umidade dos corpos-de-prova no módulo de deformação

Figura 3.4 - Fatores que afetam o módulo de deformação do concreto.

Figura 3.5 - Plano de carga para obtenção do módulo de deformação tangente inicial, $E_{c i}-$ Metodologia A - Tensão $\sigma_{a}$ fixa - ABNT NBR 8522 (2008). 45

Figura 3.6 - Plano de carga para obtenção do módulo de deformação tangente inicial, $E_{c i}-$ Metodologia B - Deformação específica $\varepsilon_{a}$ fixa - ABNT NBR 8522 (2008).

Figura 3.7 - Plano de carga para obtenção do módulo de deformação secante, $\mathrm{E}_{\mathrm{cs}}$, a uma tensão indicada $\sigma_{\mathrm{n}}$ - ABNT NBR 8522 (2008). 46

Figura 3.8 - Plano de carga para obtenção do módulo de deformação secante, $E_{c s}$, para o traçado do diagrama tensão-deformação $(\sigma-\varepsilon)$. 46

Figura 3.9 - Princípio de funcionamento dos clip gages 48

Figura 3.10 - Clip gages de contato em lâmina com ligação elástica por anéis de borracha 49

Figura 4.1 - Mudança de centragem média do processo de produção e ensaio do concreto em função do tempo, como decorrência da variação de alguns fatores que influem na resistência à compressão do concreto.

Figura 4.2 - Distribuição Normal de probabilidade da resistência do concreto......... 53

Figura 4.3 - Distribuição estatística dos resultados de resistência à

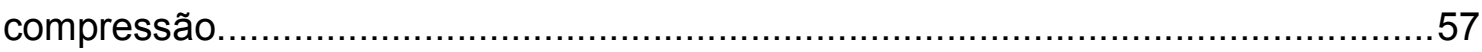

Figura 5.1 - Curvas granulométricas - Areia de quartzo.................................... 66 
Figura 5.2 - Curvas granulométricas - Areia artificial granítica............................. 67

Figura 5.3 - Curvas granulométricas - Agregado miúdo composto..........................67

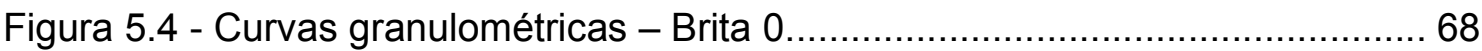

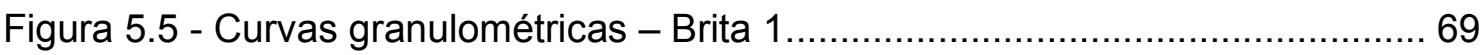

Figura 5.6 - Curvas granulométricas - Agregado graúdo composto........................ 70

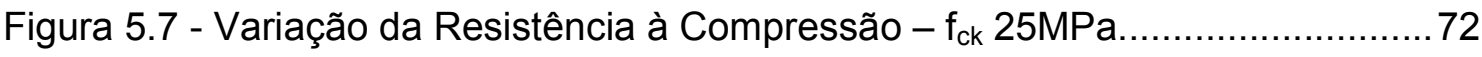

Figura 5.8 - Histograma de frequência para os resultados de resistência à

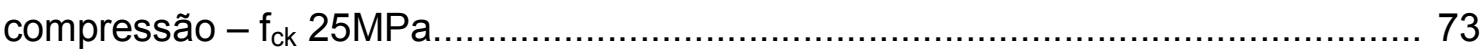

Figura 5.9 - Aderência dos resultados de resistência à compressão - curva Normal de distribuição - $f_{\mathrm{ck}} 25 \mathrm{MPa}$

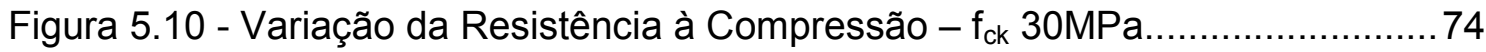

Figura 5.11 - Histograma de frequência para os resultados de resistência à

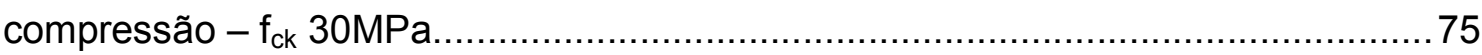

Figura 5.12 - Aderência dos resultados de resistência à compressão - curva Normal

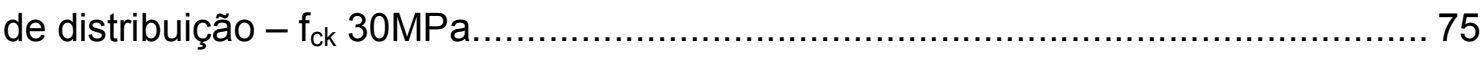

Figura 5.13 - Histograma de frequência para os resultados do módulo de

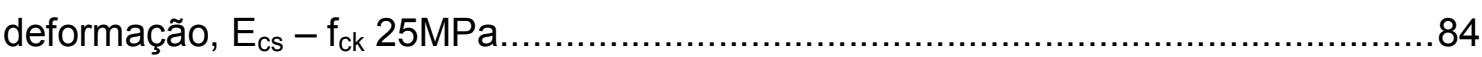

Figura 5.14 - Aderência dos resultados de módulo de deformação secante, $E_{c s}$

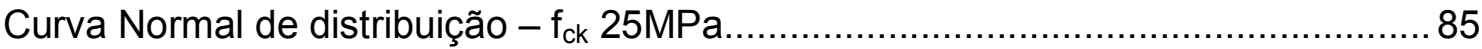

Figura 5.15 - Histograma de frequência para os resultados do módulo de

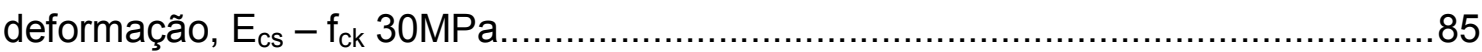

Figura 5.16 - Aderência dos resultados de módulo de deformação secante, $E_{c s}$ Curva Normal de distribuição - fck 30MPa......................................................... 86

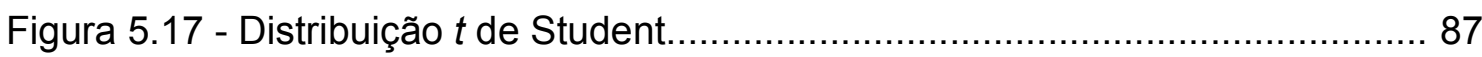

Figura 5.18 - Risco de não atendimento à especificação do módulo de

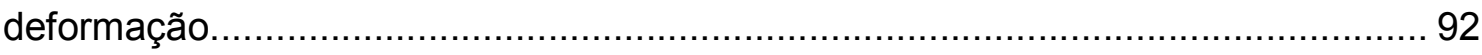




\section{LISTA DE TABELAS}

Tabela 2.1 - Expressões para determinação do módulo de

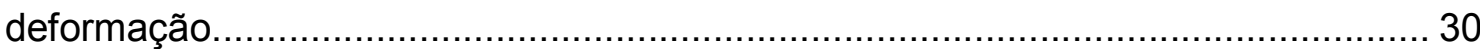

Tabela 3.1 - Módulo de elasticidade dos agregados............................................. 33

Tabela 3.2 - Planos de carregamento para determinação do módulo de deformação estático do concreto - ABNT NBR 8522 (2008)................................................ 44

Tabela 4.1 - Características físicas e mecânicas do cimento CP V ARI RS...............59

Tabela 4.2 - Características químicas do cimento CP V ARI RS..............................59

Tabela 4.3 - Caracterização do agregado miúdo - Areia quartzosa......................... 60

Tabela 4.4 - Caracterização do agregado miúdo - Areia artificial granítica............... 60

Tabela 4.5 - Caracterização do agregado graúdo - Brita 0 ….................................. 61

Tabela 4.6 - Caracterização do agregado graúdo - Brita 1...................................... 61

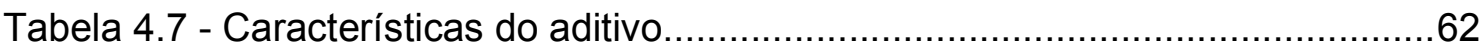

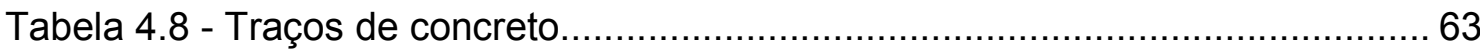

Tabela 5.1 - Caracterização dos agregados - AREIA DE QUARTZO........................6 65

Tabela 5.2 - Caracterização dos agregados - AREIA ARTIFICIAL

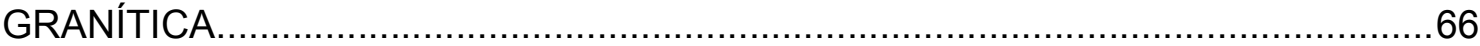

Tabela 5.3 - Caracterização dos agregados - BRITA 0 GRANÍTICA.........................68

Tabela 5.4 - Caracterização dos agregados - BRITA 1 GRANÍTICA.........................69

Tabela 5.5 - Resumo da análise estatística $-f_{\mathrm{ck}} 25 \mathrm{MPa}$...................................... 71

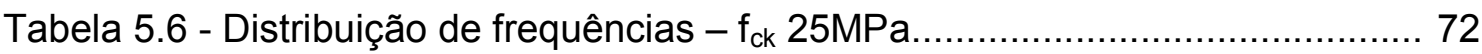

Tabela 5.7 - Resumo da análise estatística - $f_{\mathrm{ck}} 30 \mathrm{MPa}$........................................ 74

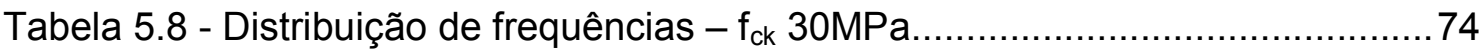

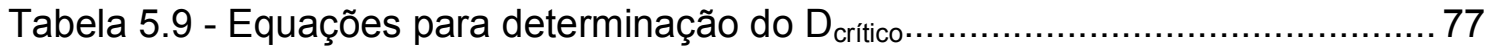

Tabela 5.10 - Resumo - teste de ajustamento de Kolmogorov-Smirnov -

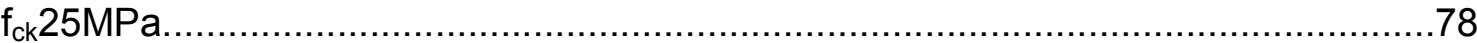

Tabela 5.11 - Resumo - teste de ajustamento de Kolmogorov-Smirnov $\mathrm{f}_{\mathrm{ck}} 30 \mathrm{MPa}$.

Tabela 5.12.a - Módulo de deformação $E_{c s}$ e Resistência à Compressão $f_{c}$ $\mathrm{f}_{\mathrm{ck}} 25 \mathrm{MPa}$.

Tabela 5.12.b - Módulo de deformação $E_{c s}$ e Resistência à Compressão $f_{c}$ $\mathrm{f}_{\mathrm{ck}} 25 \mathrm{MPa}$. 
Tabela 5.13.a - Módulo de deformação $E_{c s}$ e Resistência à Compressão $f_{c}$ $\mathrm{f}_{\mathrm{ck}} 30 \mathrm{MPa}$.

Tabela 5.13.b - Módulo de deformação $E_{c s}$ e Resistência à Compressão $f_{c}$ -

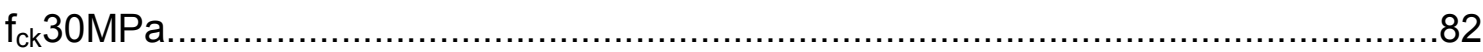

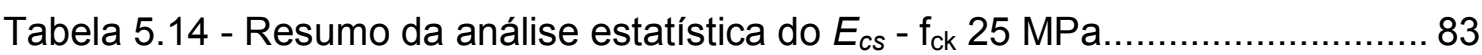

Tabela 5.15 - Distribuição de frequências $-f_{\text {ck }} 25 \mathrm{MPa}$......................................... 83

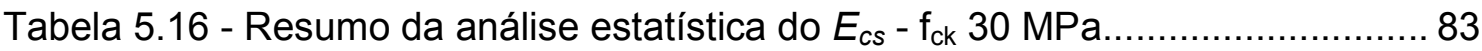

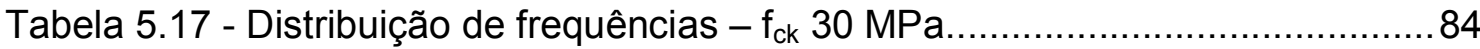

Tabela 5.18 - Módulo de deformação $E_{c s}$ - teste em campo................................... 88

Tabela 5.19 - Teste $t$ : duas amostras presumindo variâncias diferentes................... 89

Tabela 5.20 - Probabilidade de não atendimento ao especificado pela ABNT NBR 6118 (2007) 


\section{SUMÁRIO}

1. INTRODUÇÃO

1.1 Objetivos

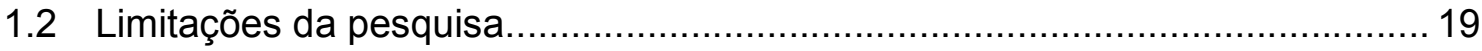

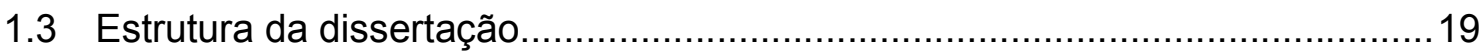

\section{CONCEITOS BÁSICOS SOBRE A DEFORMABILIDADE DAS ESTRUTURAS}

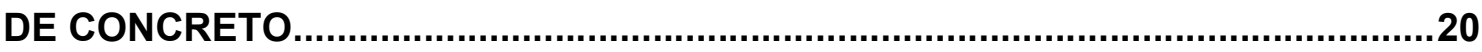

2.1 Evolução dos materiais e métodos empregados...............................................20

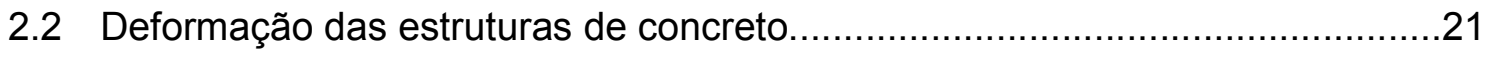

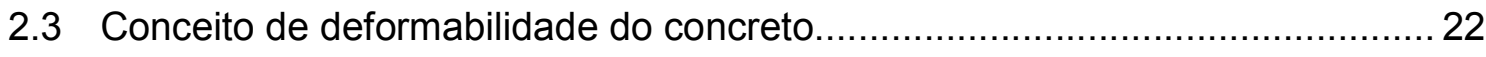

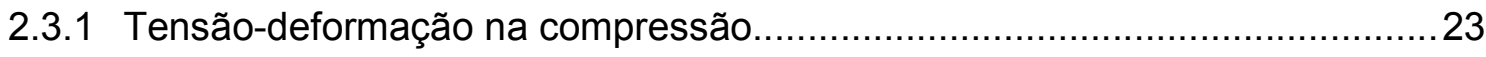

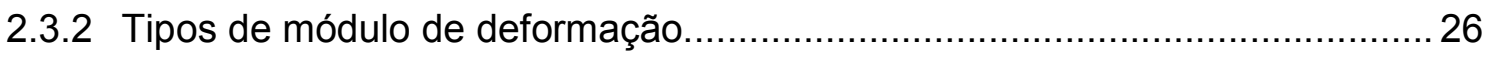

2.3.3 Modelos de previsão do Módulo de Deformação............................................ 28

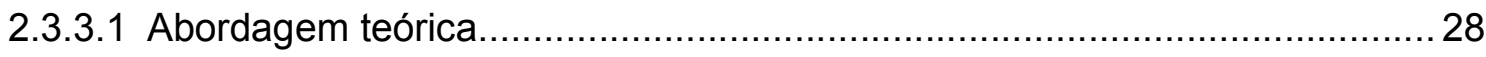

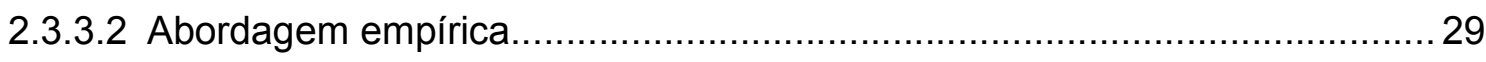

3. FATORES INTERVENIENTES NO MÓDULO DE DEFORMAÇÃO.......................31

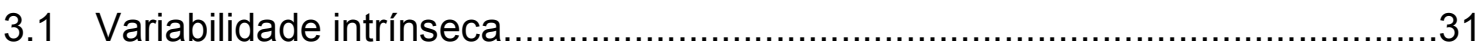

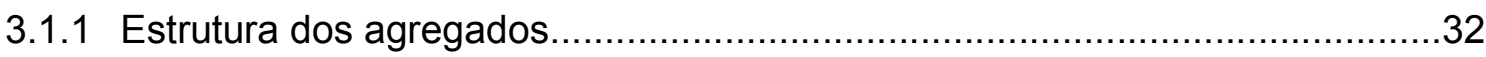

3.1.2 Estrutura da matriz da pasta de cimento..................................................... 34

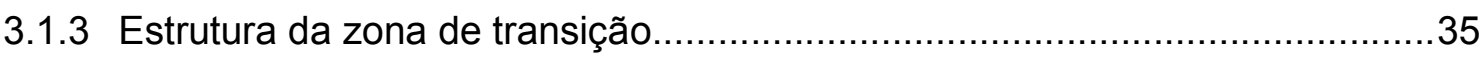

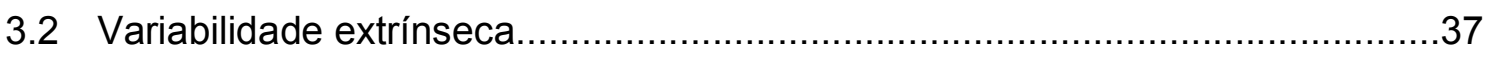

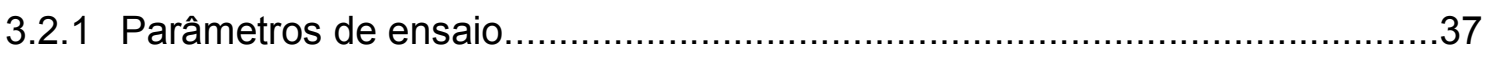

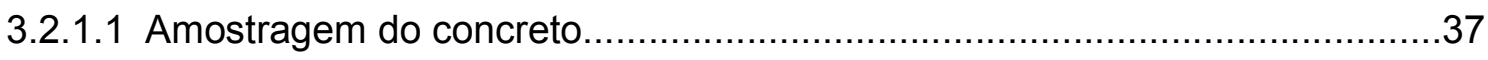

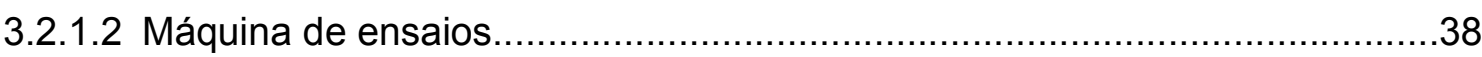

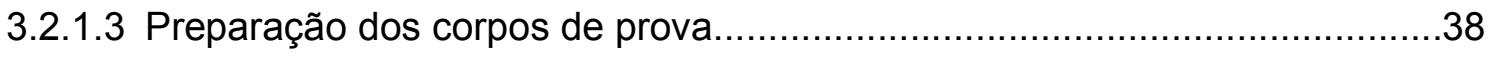

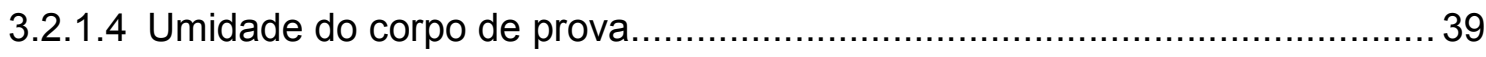


3.2.1.5 Medida da deformação - Instrumentação............................................... 40

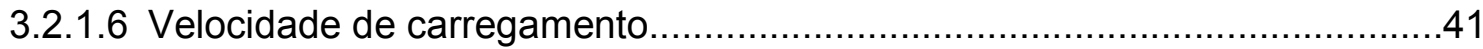

3.2.2 Ensaio para determinação do módulo de deformação do concreto..................41

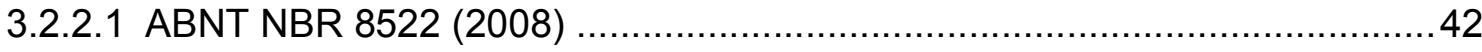

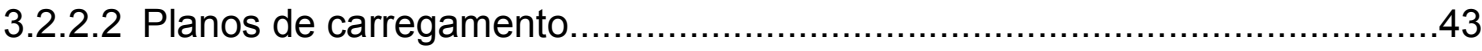

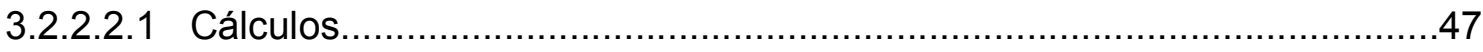

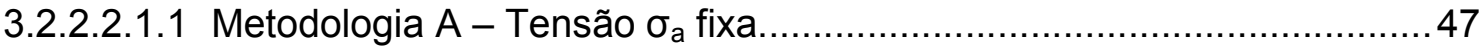

3.2.2.2.1.2 Metodologia B - Deformação específica $\varepsilon_{a}$ fixa.................................... 47

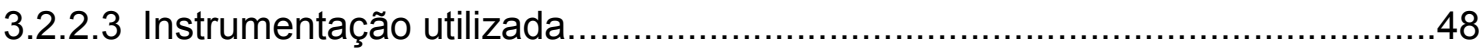

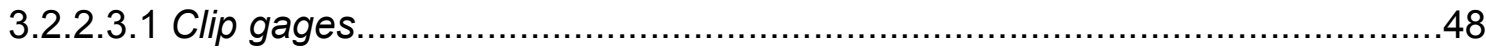

4. METODOLOGIA DA PESQUISA

4.1 Variabilidade da propriedade em função da variabilidade dos materiais...........51

4.2 Conceito semiprobabilístico aplicado ao módulo de deformação........................52

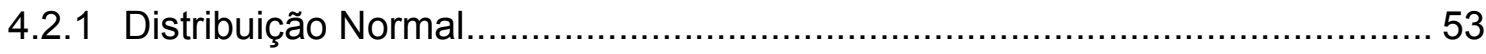

4.3 Conceito semiprobabilístico aplicado ao módulo de deformação.........................54

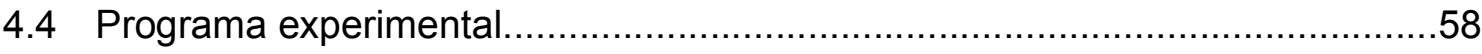

4.4.1 Materiais constituintes do concreto utilizados na pesquisa............................59

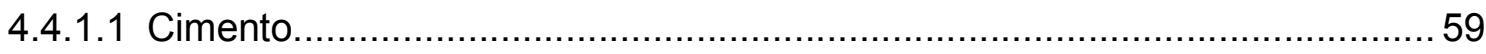

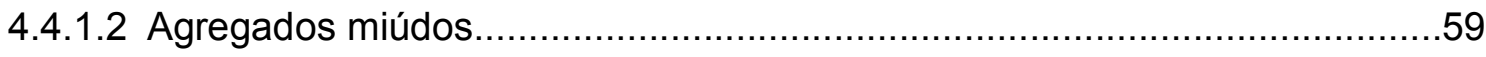

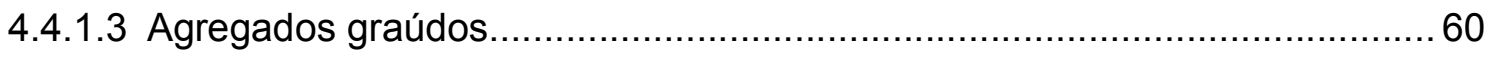

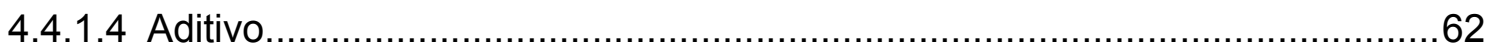

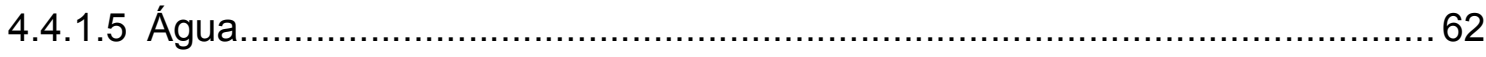

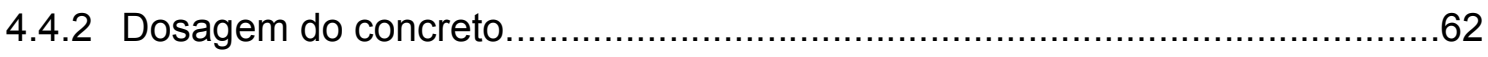

4.4.2.1 Primeira etapa

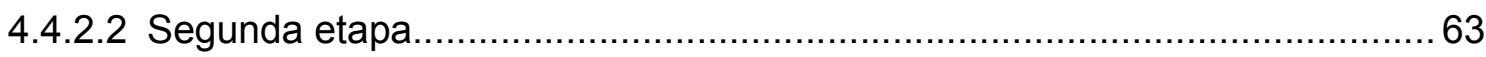

5. APRESENTAÇÃO E ANÁLISE DOS RESULTADOS OBTIDOS..........................64 


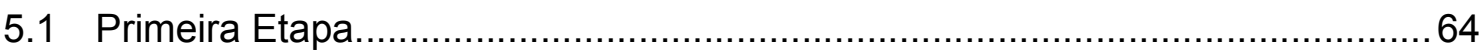

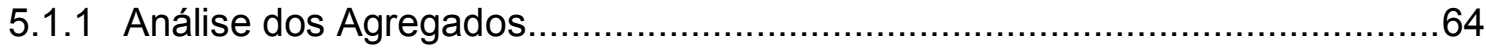

5.1.2 Avaliação da resistência à Compressão dos concretos estudados..................70

5.1.3 Avaliação do módulo de deformação dos concretos estudados...................... 76

5.1.3.1 Análises de distribuição Normal dos resultados..........................................76

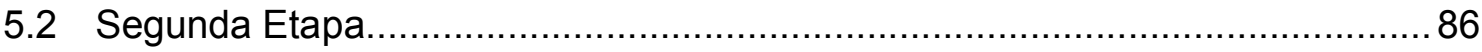

5.3 Conceito semi-probabilístico aplicado ao módulo de deformação......................89

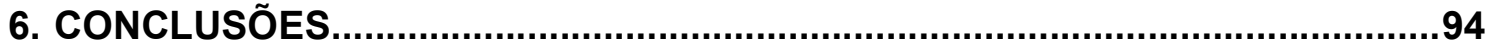

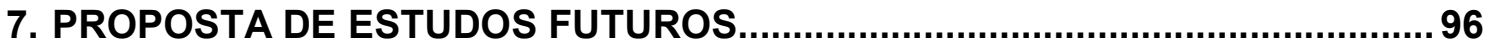

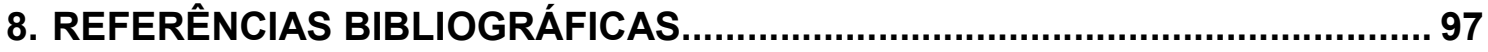

APÊNDICE A - Resultados dos ensaios realizados - Primeira etapa................101

APÊNDICE B - Resultados dos ensaios realizados - Segunda etapa...............121 


\section{INTRODUÇÃO}

Atualmente o risco de haver deformações excessivas nos edifícios em concreto não pode ser ignorado e representa um problema que deve ser analisado com a cautela necessária para se ter confiabilidade na avaliação das deformações.

O dimensionamento das estruturas de concreto baseia-se nas propriedades mecânicas do material, sendo a resistência à compressão o principal parâmetro nesse processo, a qual é determinada através de ensaio padronizado. No entanto, para a avaliação das deformações é necessário o conhecimento do comportamento do material quanto à sua rigidez, o que é parametrizado através da determinação do módulo de elasticidade ou módulo de deformação do concreto. Esta também é uma propriedade determinada através de um ensaio padronizado que carrega em si uma complexidade maior que a determinação da resistência à compressão e que tem elevada variabilidade de resultados experimentais observada pelo meio técnico nacional, conforme mostrado por MONTIJA (2007). A evidência dessa variabilidade excessiva na determinação da propriedade consta dos relatórios interlaboratoriais de abrangência nacional realizados por INÁCIO; ANDRADE e BITTENCOURT (2005) apud MONTIJA (2007).

Pelo fato do setor da construção civil ter uma escala muito grande, gerando um impacto ambiental elevado, um dos maiores desafios é diminuir a intensidade de uso de recursos materiais, que deve ser feita selecionando-se os materiais mais adequados para cada solicitação. A otimização do uso de materiais e recursos só é possível com a redução da variabilidade, como é percebida hoje para o controle da resistência à compressão, onde trabalhamos com valores característicos, baseados na teoria das probabilidades. HELENE (1980) relata que os produtores de concreto acabam por procurar melhorar seu processo de produção e controle, de forma a reduzir o desvio padrão de produção reduzindo, por consequência, o custo do metro cúbicode concreto produzido. Isso já não ocorre para o módulo de deformação do concreto, cujo estimativa e controle hoje realizados ainda são baseados em métodos deterministas. A propriedade normalmente é especificada pelos projetistas que fazem uso de equações empíricas propostas em norma para estimativa da propriedade. Entretanto, esses valores nem sempre são confirmados pelo controle tecnológico realizado em campo, o que pode gerar uma situação bastante problemática nas obras. Uma das razões é o fato de engenheiros tomarem o 
parâmetro estimado como um valor determinístico absoluto. Isso ressalta a importância do controle de qualidade, pois irá fornecer os dados para análise e decisão sobre o atendimento às especificações de projeto, de forma a garantir a otimização no uso de materiais e recursos, gerando menores custos financeiros e ambientais.

Dessa forma, no mercado existe uma série de possibilidades de divergências em função da dificuldade em se considerar a variabilidade do módulo de deformação. Com isso, para que sejam atendidas as exigências do módulo de deformação pelo produtor de concreto, incorre-se no aumento da resistência à compressão média, fazendo com que toda a economia na otimização da dosagem seja perdida. Entretanto, vale considerar que o atendimento do módulo de deformação do concreto não é tão prioritário como o atendimento da resistência à compressão, pois é uma propriedade associada às condições de serviço da obra e não ao seu estado limite último.

Neste contexto, a presente pesquisa visa estudar o controle experimental do módulo estático de deformação do concreto, principalmente sob a influência da variação dos materiais constituintes do concreto, dentro da realidade de uma Central de Concreto.

\subsection{Objetivos}

A presente dissertação tem como objetivo principal contribuir para o controle de produção do concreto, baseado no controle experimental do módulo estático de deformação do concreto, demonstrando assim a influência da variabilidade dos materiais constituintes do concreto, dentro da realidade de uma Central de Concreto.

Contribuir para a aplicação do conceito semiprobabilístico nas normas nacionais de projeto, dosagem e controle tecnológico de estruturas de concreto relacionada ao módulo de deformação do concreto.

Estudo apresentado por MONTIJA (2007) demonstrou a variabilidade da metodologia de ensaio, com foco principalmente àquela originada na instrumentação para a medida das deformações.

BORIN et al (2010) avaliou a variabilidade geral da propriedade em algumas regiões, apresentando um risco elevado de rejeição de concretos devido à não conformidade da propriedade de acordo com as especificações normativas. 
Assim, a presente dissertação pretende inserir-se na verificação da variabilidade da propriedade módulo de deformação do concreto nas condições de produção.

\subsection{Limitações da pesquisa}

Esta pesquisa limita-se a avaliação de dois concretos para produção de resistências características distintas, produzidos em um único laboratório de controle de uma central de concreto, com a utilização de um tipo de equipamento e agregados de mesma origem, com a variação dos operadores para a realização dos ensaios previstos.

\subsection{Estrutura da dissertação}

A estrutura deste trabalho contém no Capítulo 2 uma revisão bibliográfica sobre os conceitos básicos sobre a deformabilidade das estruturas de concreto, com os principais fatores que influenciam o módulo de deformação do concreto. No Capítulo 3 é apresentado o Controle de qualidade com os fatores intervenientes para a variabilidade dos resultados dos ensaios experimentais e, no Capítulo 4, o estudo experimental realizado principalmente sob a influência da variabilidade dos materiais empregados em uma Central Dosadora de Concreto. Por fim, no Capítulo 5 são apresentadas as conclusões deste trabalho e sugestões para investigações futuras. 


\section{CONCEITOS BÁSICOS SOBRE A DEFORMABILIDADE DAS ESTRUTURAS DE CONCRETO}

\subsection{Evolução dos materiais e métodos empregados}

Antigamente as estruturas em concreto apresentavam maior rigidez, em função dos pequenos vãos entre pilares e pelo fato de que a alvenaria trabalhava solidária à estrutura. Assim, a análise das deformações era muitas vezes ignorada. Hoje, com o aumento da resistência do concreto e a execução de estruturas mais esbeltas e com maiores vãos, as mesmas passaram a apresentar deformações bastante elevadas e sua análise se torna cada vez mais importante, para que as construções sejam projetadas e construídas de maneira a se evitar danos aos sistemas de vedações e deformações perceptíveis da estrutura, obtendo-se assim, uma vida útil elevada

Essas deformações excessivas se devem ao desenvolvimento tecnológico dos materiais empregados, como a evolução do processo de fabricação de cimento, com qualidade superior à antigamente encontrada, possibilitando a obtenção de elevados níveis de resistência a idades cada vez menores. Com isso, possibilitou-se a construção de estruturas de forma mais rápida, aumentando-se a produtividade e os lucros para toda a cadeia produtiva. Entretanto, isso também ocasionou um aumento das deformações nas estruturas a idades cada vez menores. Isso se deve ao fato de que o aumento da resistência não implica num aumento proporcional do módulo de deformação do concreto e, com isto, a estrutura não fica mais rígida. CUNHA (2000) relata que, com a evolução dos materiais e métodos, as estruturas dos edifícios tornaram-se mais esbeltas, proporcionando a adoção de vãos cada vez maiores, o que fez com que houvesse diminuição na rigidez do elemento estrutural. Segundo CAVALERA (1991) apud CUNHA (2000), no caso dos elementos planos (lajes) para se elevar a rigidez da peça, a altura útil será aumentada concomitantemente ao aumento dos vãos. FRANÇA (1999) apud CUNHA (2000) comparando flechas em lajes com características físicas e mecânicas adotadas antigamente com as adotadas nos dias atuais, constatou que as lajes atualmente trabalham no Estádio II, caracterizado pela fase de formação de fissuras, e as flechas podem ser até 25 vezes maiores do que as encontradas no passado, onde o regime era predominante era o Estádio I. Portanto, o aumento da altura útil não é 
suficiente para garantir o trabalho da laje no Estádio I, como considerado no passado.

É importante ressaltar que, com o aumento da velocidade na construção de edifícios, passou-se a utilizar concretos mais fluidos que necessitam de fluidez elevada para facilitar o seu lançamento, através de bombeamento, e também nas operações de adensamento e acabamento. SBRIGHI (2005) relata que a evolução dos concretos ocasionou o aumento nos teores de argamassa e, consequentemente, diminuição do teor de agregado graúdo, diminuindo-se a rigidez do material. Essa prática pode levar à produção de concretos mais deformáveis se não houver preocupação com qualidade do agregado graúdo, que tem forte influência na propriedade do módulo de deformação do concreto.

\subsection{Deformação das estruturas de concreto}

A determinação dos esforços solicitantes e a consequente análise do comportamento das estruturas de concreto, estabelecem a importância em se conhecer o seu comportamento sob ação de cargas, fundamentalmente através das relações entre as tensões e deformações. A importância da análise das deformações é reforçada por CUNHA (2000) que afirma que a concepção estrutural adotada será condicionada a deformações convencionadas como limites, dependentes da finalidade de uso da estrutura. Apesar do principal parâmetro a ser atendido ser a resistência à compressão do concreto, fica evidente que não se pode ignorar o controle do módulo de deformação.

MEHTA e MONTEIRO (2008) salientam que as características elásticas de um material são uma medida de sua rigidez, portanto, determinante para o cálculo das deformações a que uma estrutura estará submetida.

Normalmente, estruturas bem dimensionadas e executadas são resistentes e duráveis, conforme explicado por GUIMARÃES et al (2002). Entretanto, ainda segundo os autores, quando se executam elementos fletidos de grandes dimensões, podem surgir deformações excessivas, comprometendo a estabilidade das peças, o que pode colocar em risco seus usuários ou gerar desconforto indesejável em função dessas deformações. Além disso, a deformação exagerada da estrutura 
afeta todos os sistemas e subsistemas solidarizados a ela: vedações e instalações, que podem ser muito prejudicados.

Vale ressaltar que, o quanto um elemento irá deformar sob ação de cargas está diretamente ligado às suas dimensões. CUNHA (2000) cita como fatores condicionantes para a escolha das dimensões dos elementos como: desenvolvimento tecnológico, evolução da tecnologia de concreto, aprimoramento e difusão dos métodos construtivos e computacionais, necessidade de minimizar os custos e mudanças nos padrões construtivos e arquitetônicos.

Para o cálculo das estruturas de concreto, a NBR 6118 (ABNT, 2007) descreve que devem ser contemplados os aspectos relacionados ao colapso, ou a qualquer outra forma de ruína estrutural, que determine a paralisação do uso da estrutura (Estados Limites Últimos-ELU). Também devem ser considerados os aspectos relacionados à durabilidade das estruturas, aparência, conforto ao usuário e à boa utilização funcional da estrutura, seja em relação aos usuários, às máquinas ou aos equipamentos utilizados (Estados Limites de Serviço-ELS).

Assim, para a segurança das estruturas de concreto quanto às deformações excessivas pode-se exigir a verificação do Estado Limite de Deformações Excessivas, de acordo com a NBR 6118 (2007), onde o conhecimento do comportamento do concreto sob ação de cargas será de fundamental importância.

\subsection{Conceito de deformabilidade do concreto}

Em materiais metálicos, o módulo de elasticidade é função da energia de ligação, da mesma forma como ocorre com a temperatura de fusão, segundo CALLISTER (2007). No caso de materiais cerâmicos homogêneos, segundo MEHTA e MONTEIRO (2008), existe uma relação direta entre densidade e módulo de deformação.

SHEHATA (2005) descreve que o comportamento do concreto submetido a tensões abaixo de um determinado nível, pode ser representado aproximadamente pela Lei de Hooke. Neste caso, as relações entre as tensões normais e deformações específicas são definidas pelo módulo de elasticidade. 
O concreto não é um material elástico perfeito e este fato é explicado por MEHTA e MONTEIRO (2008) devido a sua heterogeneidade e influência da microfissuração da zona de transição sob tensão, que será abordado posteriormente.

\subsubsection{Tensão-deformação na compressão}

Segundo MEHTA e MONTEIRO (2008), o módulo de deformação pode ser definido como sendo a relação entre a tensão aplicada e deformação instantânea dentro de um limite de proporcionalidade do material. Em alguns casos, este limite é simplesmente adotado por uma norma que padroniza o ensaio, como acontece na normalização brasileira.

Em materiais metálicos o módulo de elasticidade é função da energia de ligação, da mesma forma como ocorre com a temperatura de fusão. No caso de materiais cerâmicos homogêneos, segundo MEHTA e MONTEIRO (2008), existe uma relação direta entre densidade e módulo de deformação. Já para o concreto, que é uma mistura de compostos cujas ligações químicas são características dos materiais cerâmicos, sendo um material heterogêneo e multifásico, a fração volumétrica, a densidade e o módulo dos principais componentes, além das características da zona de transição na interface, determinam o comportamento elástico do compósito.

Como a densidade é inversamente proporcional à porosidade, os fatores que afetam a porosidade do agregado, da matriz da pasta de cimento e da zona de transição na interface são importantes. No concreto, há um material bem mais rígido, o agregado, e outro bem mais poroso e flexível, a pasta. Assim, o módulo de deformação do conjunto é a resultante da interação destas duas fases, apresentando um valor intermediário entre o módulo de elasticidade do agregado graúdo e o da pasta de cimento que o constitui. Esse comportamento do concreto pode ser observado pelas diferentes curvas típicas de tensão-deformação específica do agregado, pasta endurecida e concreto submetidos à compressão axial, conforme Figura 2.1 de Neville (1997). 


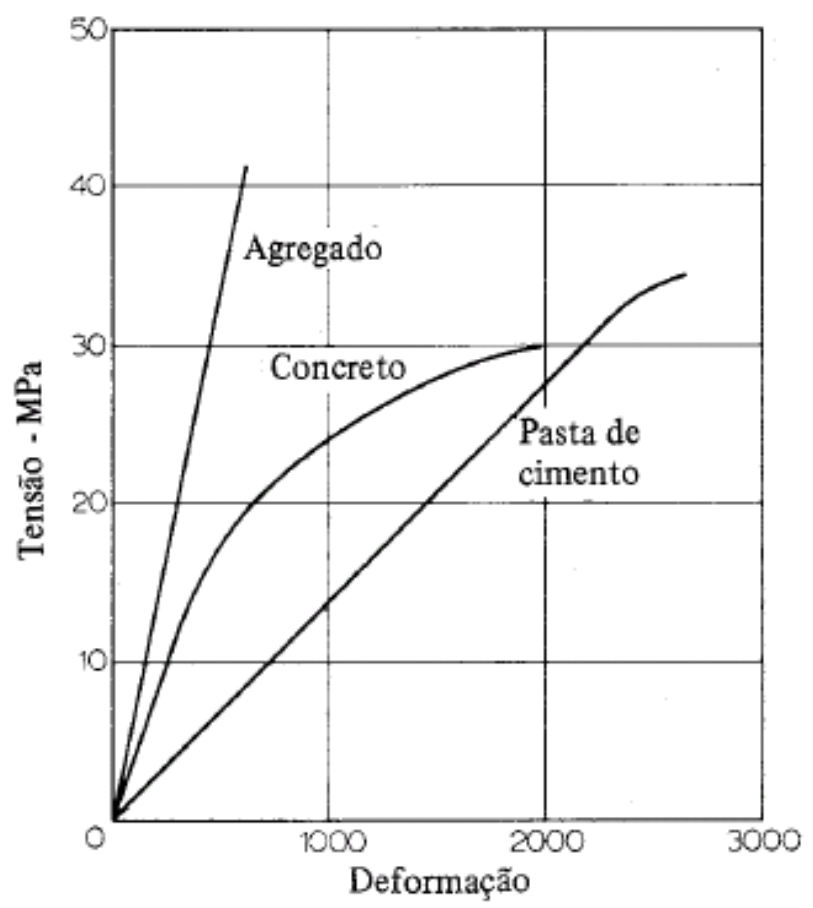

Figura 2.1 - Comportamento típico tensão- deformação do concreto e suas fases, NEVILLE (1997).

Enquanto a pasta de cimento e o agregado têm um comportamento tensãodeformação elástico linear até $80 \%$ do seu limite de resistência, o concreto começa a divergir para um comportamento linear inelástico quando as tensões aplicadas alcançam 40-50\% de sua capacidade. Segundo GLUCKLICH (1968), apud METHA e MONTEIRO (2008), o comportamento não linear do concreto sob tensão pode ser explicado pelo processo de microfissuração progressiva do concreto sob a ação de cargas. Assim, o concreto não apresenta um comportamento perfeitamente elástico e, por essa razão, denomina-se módulo de deformação pela impossibilidade de determinar o módulo de elasticidade no sentido estrito da definição do termo. Ou seja, como o concreto não apresenta um comportamento compatível com a lei de Hooke, não se pode ter determinado o módulo de elasticidade, sem que se defina um nível de tensão do material. A heterogeneidade do concreto constituído de três fases - argamassa, agregado e zona de transição também influenciam este comportamento. O módulo de deformação do concreto também é afetado pelas características da argamassa, agregado graúdo e zona de transição. Para a mesma quantidade de argamassa, tipos diferentes de agregados graúdos com diferentes 
tamanhos, formas, textura, mineralogia e resistência podem resultar em concretos com módulos de deformação diferentes. Isto ocorre em grande parte devido à influência do módulo de deformação do agregado graúdo no módulo de deformação do concreto, conforme demonstrado por DE MARCHI et al (2010). Para concretos com relações água/cimento maiores que 0,40 , a resistência da argamassa e a zona de transição são limitantes da resistência do material.

O comportamento não-linear da curva tensão-deformação na compressão é explicado por NEVILLE (1997) na afirmação de que, antes mesmo de sofrer a aplicação de carga o concreto possui microfissuras principalmente na zona de transição. Essas microfissuras evoluiriam inicialmente dentro da zona de transição com a aplicação da carga, ficando estáveis até um nível em torno de $30 \%$ da resistência à compressão do concreto. Com solicitações acima de $70 \%$ da resistência à compressão, as fissuras se propagariam através da pasta. $\mathrm{O}$ autor ainda cita que, além das microfissuras, o concreto sob tensão constante, apresenta deformação crescente com o tempo, caracterizando o fenômeno da fluência. Ressalta ainda o fato de que o concreto apresenta retração autógena da pasta de cimento que o constitui, estando ou não sujeito a ação de cargas, o que faz com que haja retração e, consequentemente, deformação do compósito.

MEHTA e MONTEIRO (2008) mostraram o comportamento do concreto quando submetido à compressão. Apresenta-se na Figura 2.2 a relação entre ao nível de tensão a que o concreto está submetido e sua microfissuração, divididos em quatro estágios. Em função da diferença entre os módulos de elasticidade das fases que constituem o concreto, aparecem fissuras na zona de transição entre a pasta e o agregado graúdo. Em concretos de resistências normais, abaixo de $30 \%$ da carga última estas fissuras permanecem estáveis e a curva tensão-deformação permanece linear. Com o aumento da tensão, essas microfissuras começam a aumentar em comprimento, abertura e quantidade, fazendo com que a curva tensão-deformação $(\sigma-\varepsilon)$ desvie de uma linha reta. Porém, admite-se um sistema estável de fissuras na zona de transição na interface até $50 \%$ da carga última. Com o aumento da tensão até $75 \%$ da carga última, o sistema de fissuras torna-se instável, aumentando e propagando-se as fissuras por toda a matriz, inclinando a curva $\sigma-\varepsilon$ para o sentido horizontal. Acima de $75 \%$ da carga última, a taxa de liberação de energia de deformação alcança seu nível crítico, fazendo com que as fissuras se desenvolvam 
espontaneamente sob tensão constante e o material se deforme até sua ruptura. Os autores explicam que a ocorrência e o grau de não-linearidade da curva $\sigma-\varepsilon$ depende da taxa de aplicação de carga. A um determinado grau de tensão, o módulo de deformação irá variar em função da taxa de propagação de fissuras, dependente da velocidade em que a carga é aplicada.
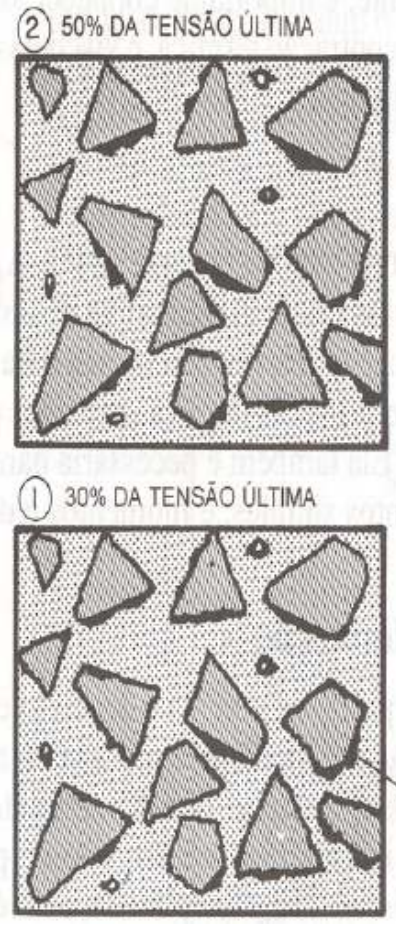

MICROFISSURAS

NA ZONA DE

TRANSIÇÃO

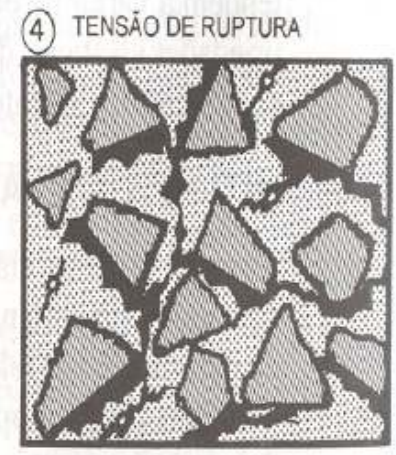

(2)

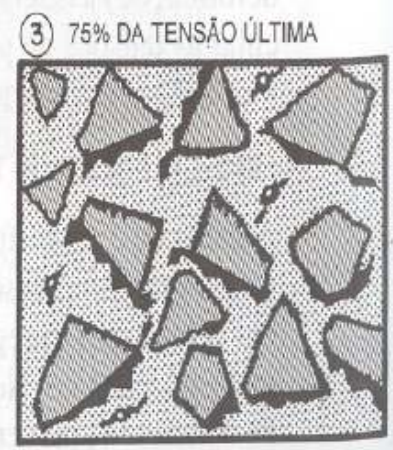

Figura 2.2 - Representação do comportamento do concreto sob compressão uniaxial ( $\sigma-\varepsilon)$, METHA e MONTEIRO (2008).

\subsubsection{Tipos de módulo de deformação}

SHEHATA (2005) destaca que na literatura são citados os módulos de deformação tangente, secante e cordal, mas nem sempre são interpretados corretamente. MEHTA e MONTEIRO (2008) explicam que este fato advém da nãolinearidade da curva $\sigma-\varepsilon$. A seguir são descritos os três tipos de módulo de deformação do concreto na compressão:

Módulo tangente é o coeficiente angular da reta tangente a qualquer ponto da curva $\sigma-\varepsilon$ na compressão, mas quando não for especificado o ponto da curva, refere-se à origem, ou seja, ao módulo tangente inicial $E_{c i}$. 
Módulo secante é dado pela relação entre uma tensão qualquer e a deformação a ela correspondente, ou seja, o coeficiente angular da reta que liga os pontos da curva $\sigma-\varepsilon$ correspondentes a essa tensão e à tensão igual a zero. Entretanto, quando a tensão não é mencionada, infere-se que o módulo secante seja relativo a uma tensão entre 40 e $50 \%$ da resistência à compressão.

Módulo cordal é definido pela reta que liga dois pontos quaisquer da curva $\sigma$ $\varepsilon$.

Normalmente, a determinação do módulo de deformação tangente inicial e o módulo de deformação secante são de difícil observação nos ensaios. Isso porque no início da curva $\sigma-\varepsilon$ existe um pequeno intervalo onde a curva apresenta uma leve concavidade voltada para cima (NEVILLE, 1996). Assim, convenciona-se adotar uma tensão mínima ou deformação específica mínima para iniciar o traçado da curva, desprezando-se a influência da perturbação inicial no início do processo, que é normalmente decorrente das imperfeições dos corpos de prova, da instabilidade das máquinas de ensaio e da acomodação dos corpos de prova ao início do carregamento (Figura 2.3).

Para o presente trabalho, foram realizados ensaios sob o plano de carregamento secante, previsto na ABNT NBR 8522 (2008). Isso porque a ABNT NBR 6118 (2007) preconiza que a propriedade seja controlada através do módulo de deformação tangente inicial, $E_{c i}$. Entretanto, a mesma norma indica a utilização do módulo de deformação secante, $E_{c s}$, para ser aquele utilizado pelos projetistas em análises elásticas de projeto, especialmente para determinação de esforços solicitantes e verificação de estados limites de serviço na avaliação do comportamento de um elemento estrutural ou seção transversal durante o projeto

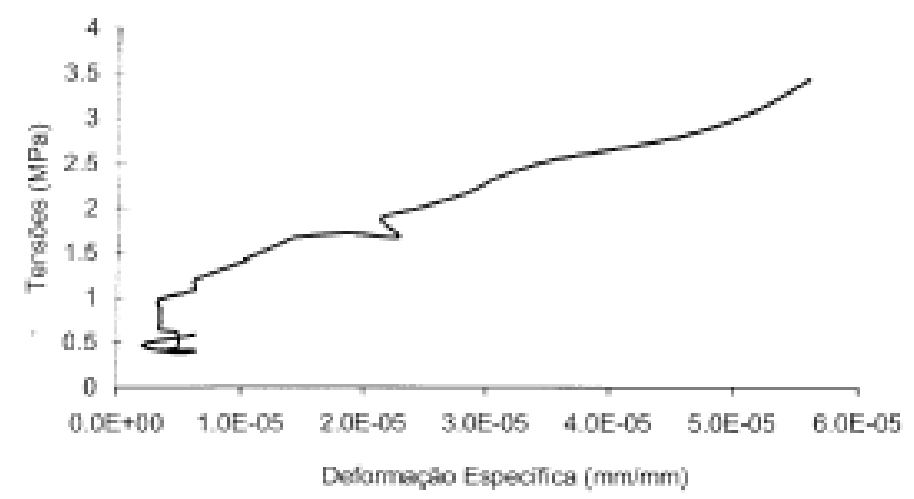

Figura 2.3- Perturbação inicial no gráfico $\sigma-\varepsilon$ - PEREIRA NETO, 1994 


\subsubsection{Modelos de previsão do módulo de deformação}

Apesar de toda a variabilidade intrínseca ao módulo de deformação do concreto, este parâmetro não recebe o mesmo nível de rigor que se utiliza para o controle tecnológico da resistência à compressão do concreto. Isto porque seu grau de responsabilidade para a segurança estrutural é menor que o da resistência do concreto. Assim, a própria norma prevê que se possa estimar o módulo de deformação a partir de modelos empíricos de previsão de comportamento. $\mathrm{Na}$ literatura existem modelos teóricos e empíricos que associam o módulo de deformação do concreto com as propriedades reológicas, além do proporcionamento de seus componentes. Alguns não levam em consideração o tipo de agregado, o que pode acarretar em erros de previsão.

\subsubsection{Abordagem teórica}

Existem diversos modelos teóricos para se determinar o módulo de deformação do concreto associado às suas propriedades reológicas, cuja resposta de deformabilidade do concreto depende da qualidade (de rigidez) individual de suas fases, de seu proporcionamento e de sua interação. Como exemplos, temos os modelos de Voigt, Reuss, Hirsch-Dougill, Popovics, Hashin e Shtrikman, Counto, Hansen e Müller-Hochholz, conforme citado por CUNHA (2000), e MONTIJA (2007).

O inconveniente destes modelos se dá por conta da necessidade de se ensaiar previamente o módulo de elasticidade do agregado e também da pasta de cimento que constitui o concreto.

SegundoAïTCIN (1998), essas expressões fornecem valores limites superior e inferior de um modelo bifásico. Modelos mais complexos que esses já foram propostos, mas seu interesse é apenas acadêmico, pois os parâmetros envolvidos não são normalmente conhecidos e nem sempre levam a resultados adequados. 


\subsubsection{Abordagem empírica}

Por conta da dificuldade em se obter os dados confiáveis para aplicação dos modelos teóricos de estimativa do módulo de deformação, existem fórmulas empíricas que relacionam o módulo de deformação do concreto em função de sua resistência à compressão adotada no projeto estrutural. Estas fórmulas servem como base para inferência do módulo de deformação quando este ainda não foi determinado por ensaio.

Várias fórmulas empíricas têm sido sugeridas para estimar o módulo de deformação tangente e secante, sendo elas só função da resistência à compressão ou desta grandeza e da massa específica ou do tipo de agregado do concreto.

A maioria das fórmulas empíricas adotadas por normas internacionais e também a ABNT NBR 6118 (2007) relacionam o módulo de deformação secante a um nível de tensão de $40 \%$ da resistência característica do concreto.

Na Tabela 2.1 são relacionadas as expressões para determinação do módulo de deformação do concreto constantes nas normas e recomendações técnicas internacionais de projetos de estruturas de concreto. 
Tabela 2.1 - Expressões para determinação do módulo de deformação

\begin{tabular}{|c|c|c|}
\hline Autor & Expressão & Observações \\
\hline NBR 6118/2007 & $E_{c s}=0,85.5600 \sqrt{f c k}$ & $E_{c i}=5600 \sqrt{f c k}$ \\
& & $f_{c k} \leq 50 M P a$ \\
\hline EUROCODE 2/2004 & $E_{c s}=\alpha_{e} 22000\left(\frac{f c m}{10}\right)^{0,3}$ & Módulo secante para $0,4 f c m$ \\
\hline ACI 318/2005 & $E_{c s}=4700 \sqrt{f c^{\prime}}$ & $f_{c}$ é função do tipo de agregado $(0,7$ a 1,2$)$ \\
\hline CEB FIP MC 90 & $E_{c s}=\alpha_{\beta} 18275\left(\frac{f c m}{10}\right)^{1 / 3}$ & Módulo secante para $0,45 f c^{\prime}$ \\
& & $\alpha_{e}$ é função do tipo de agregado $(0,7$ a 1,2$)$ \\
\hline
\end{tabular}

A Prática Recomendada do IBRACON (2004) sugere uma correção na equação do módulo de deformação da NBR 6118 para se levar em conta a consistência do concreto no estado fresco e a influência dos diferentes tipos de agregado. A equação sugerida é:

$E_{c i}=a_{1} \cdot a_{2} \cdot 0,85 \cdot 5600 \sqrt{f c k}$

(Equação 2.1)

Onde:

$a_{1}$ é o índice de correção do módulo do concreto em função da natureza do agregado (varia de 0,7 a 1,2 )

$\boldsymbol{a}_{2}$ é o índice de correção do módulo do concreto em função da consistência do concreto (varia de 0,9 a 1,1 )

Convém citar que esta correção em função da consistência do concreto advém da idéia original que sua mudança era originada do aumento do consumo de água e de argamassa. Hoje pode-se corrigir a consistência com o uso de aditivos e isto não atua como redutor do módulo de deformação do concreto. 


\section{FATORES INTERVENIENTES NO MÓDULO DE DEFORMAÇÃO DO CONCRETO}

Sendo o concreto um material compósito e, devido a sua estrutura heterogênea e multifásica, a fração volumétrica, a densidade e o módulo dos principais componentes (matriz da pasta e agregados), além das características da zona de transição na interface, determinam o seu comportamento elástico. GIACCIO et al. (1992), propõem que a diferença de dureza entre os agregados e a matriz da pasta de cimento seja responsável por concentração de tensões nas interfaces, a qual pode diferir das tensões do material. Podem também ocorrer formações de fissuras no concreto, na argamassa e nas partículas dos agregados. Todos esses efeitos são intensificados com o aumento do tamanho do agregado graúdo (acima de $5 \mathrm{~mm})$.

A zona de transição representa a região interfacial entre as partículas de agregado graúdo e a pasta. É uma camada delgada de 10 a $50 \mu \mathrm{m}$ de espessura ao redor do agregado graúdo, e para o concreto de resistência normal, geralmente, é mais fraca do que a matriz da pasta de cimento e do que os agregados, exercendo influência sobre o comportamento mecânico do concreto.

Cada uma de suas fases é de natureza multifásica, ou seja, cada partícula de agregado pode conter vários minerais, além de microfissuras e vazios. Tanto a matriz da pasta como a zona de transição contém geralmente uma distribuição heterogênea, de diferentes tipos de fases sólidas, poros e microfissuras. Além disso, diferentemente de outros materiais de engenharia, a estrutura do concreto não permanece estável, pois dois componentes constituintes da estrutura, a matriz da pasta e a zona de transição estão sujeitas a modificações ao longo do tempo, umidade e temperatura.

\subsection{Variabilidade intrínseca}

SBRIGHI (2005) salienta o fato de que a microestrutura de qualquer material está diretamente relacionada com suas propriedades. Ainda segundo o autor, no caso dos agregados graúdos, a influência é muito grande na resistência mecânica, na durabilidade e também na estabilidade dimensional do concreto. 
Geralmente, as centrais dosadoras de concreto selecionam seus fornecedores de agregados se, após sua caracterização e verificação ao atendimento aos aspectos normativos, ele apresentar viabilidade técnico-econômica, ou seja, o quanto uma dosagem de concreto pode ser otimizada através da redução do seu custo total por metro cúbico, em função do uso de um ou outro tipo de agregado.

Quando se realizam estudos em concreto para composição das tabelas de dosagem de uma central dosadora de concreto, previamente são caracterizados os materiais para composição dos experimentos laboratoriais. Entretanto, sabe-se que esses materiais sofrerão variabilidade em função da variação em sua origem e/ou produção.

No caso dos agregados, TANGO (2005) afirma a importância de serem mantidas as propriedades inicialmente aprovadas no momento da compra dos mesmos. Isso porque, para os agregados, diferentemente do cimento que possui controle de produção mais rigoroso e a verificação do atendimento aos parâmetros de qualidade internos é realizada quase que diariamente, a variação da rocha matriz pode ser muito grande, o que poderá afetar a propriedade do módulo de deformação do concreto. SBRIGHI (2005) ressalta a importância que as propriedades intrínsecas dos agregados, principalmente os graúdos, têm no módulo de deformação do concreto, sendo um dos principais elementos definidores.

Assim, este estudo tem por objetivo verificar a variabilidade do módulo de deformação associada à própria heterogeneidade intrínseca ao material. Ou seja, determinar a parcela de contribuição da variabilidade natural do agregado e dos demais materiais constituintes na variabilidade total do módulo de deformação do concreto durante a execução do controle da qualidade de produção.

\subsubsection{Estrutura dos agregados}

Os agregados geralmente ocupam cerca de $75 \%$ do volume do concreto, por isso, muitas das propriedades do concreto dependem do tipo de agregado selecionado. Esse constituinte altera significativamente o valor do módulo de deformação do concreto. 
Os agregados mais comumente utilizados na dosagem de concretos estruturais são mais resistentes e menos deformáveis que a pasta de cimento endurecida. SBRIGHI (2005) apresenta os principais tipos de rochas utilizados como agregados para concreto e seus respectivos módulos de elasticidade (Tabela 3.1).

Tabela 3.1 - Módulo de elasticidade dos agregados (SBRIGHI, 2005)

\begin{tabular}{c|c}
\hline Tipo de rocha & $\begin{array}{c}\text { Módulo de elasticidade } \\
(\mathbf{G P a})\end{array}$ \\
\hline Arenito & $20-40$ \\
\hline Basalto & $60-100$ \\
\hline Calcário & $30-50$ \\
\hline Gnaisse & $40-70$ \\
\hline Granito & $40-70$ \\
\hline Quartzito & $50-100$ \\
\hline Xisto & $25-40$ \\
\hline
\end{tabular}

De acordo com METHA e MONTEIRO (2008), entre as características do agregado graúdo que afetam o módulo de deformação do concreto, a porosidade parece ser a mais importante. A porosidade do agregado determina a sua rigidez que, por sua vez, controla a capacidade do agregado de restringir deformações da matriz da pasta de cimento.

Mantendo-se as demais variáveis do concreto constantes, à medida que se aumenta o módulo de elasticidade do agregado, aumenta-se também o módulo de deformação do concreto.

MEHTA e AÏTCIN (1990) investigaram a influência de quatro diferentes tipos de agregados graúdos na resistência à compressão e no comportamento elástico de misturas de concreto de alta resistência $(a / c=0,275)$ e concluíram que as características mineralógicas do agregado graúdo influem significativamente na resistência e no módulo de deformação do concreto.

MONTIJA (2007) ressalta a importância da composição granulométrica dos agregados no arranjo da estrutura do concreto. Segundo o autor, se para a pasta de cimento endurecida a porosidade é de fundamental importância para a definição da rigidez, nos agregados a microporosidade intrínseca à rocha-matriz tende a ser tão 
importante quanto a distribuição granulométrica dos grãos que gerarão a macroporosidade, porque é esta última que a pasta de cimento deverá preencher.

\subsubsection{Estrutura da matriz da pasta de cimento}

MEHTA e MONTEIRO (2008) afirmam que o módulo de elasticidade da pasta de cimento endurecida também é determinado por sua porosidade. Isso está diretamente atrelado à relação água/cimento, teor de ar incorporado, adições minerais e grau de hidratação do cimento. Os autores relacionam os diversos produtos de hidratação do cimento Portland com sua contribuição na rigidez do compósito, que incluem principalmente silicato de cálcio hidratado (C-S-H), hidróxido de cálcio, e os sulfoaluminatos de cálcio (etringita). O C-S-H é um material cristalino e é o principal componente de hidratação que constitui de $50 \%$ a $60 \%$ do volume de pasta hidratada. O C-S-H possui partículas de dimensões coloidais menores do que $1 \mu \mathrm{m}$.

O hidróxido de cálcio $(\mathrm{CH})$ é um material cristalino que ocupa cerca de 20 a $25 \%$ do volume de pasta. Embora MONTEIRO e CHANG (1995) apud MONTIJA (2007), discutiram que a presença deste composto contribui na rigidez do compósito, por tender a formar cristais grandes sob a forma de prismas hexagonais distintos muito maiores que o C-S-H, o que traz um grau de porosidade difícil de ser preenchido, acaba por contribuir menos na rigidez da pasta do que o C-S-H.

A etringita cristaliza-se com o tempo e forma cristais aciculares de tamanho estimado entre 20 e $50 \mathrm{~nm}$, mas menos resistentes que os dos compostos C-S-H. Constitui 10 a $15 \%$ do volume da pasta de cimento, sendo seus vazios importantes componentes da microestrutura da pasta de cimento endurecida. Os vários tipos de vazios na pasta de cimento são classificados como porosidade gel (espaço interlamelar no C-S-H) e porosidade capilar. Os espaços interlamelares estão aproximadamente em uma faixa de 5 a $10 \mathrm{~nm}$ no tamanho, e pode ser reconhecida como fazendo parte do C-S-H, enquanto a porosidade capilar varia de 0,01 a $10 \mu \mathrm{m}$ no tamanho, e representam os espaços não preenchidos pelos componentes sólidos da pasta. O volume da porosidade diminui durante a hidratação. 


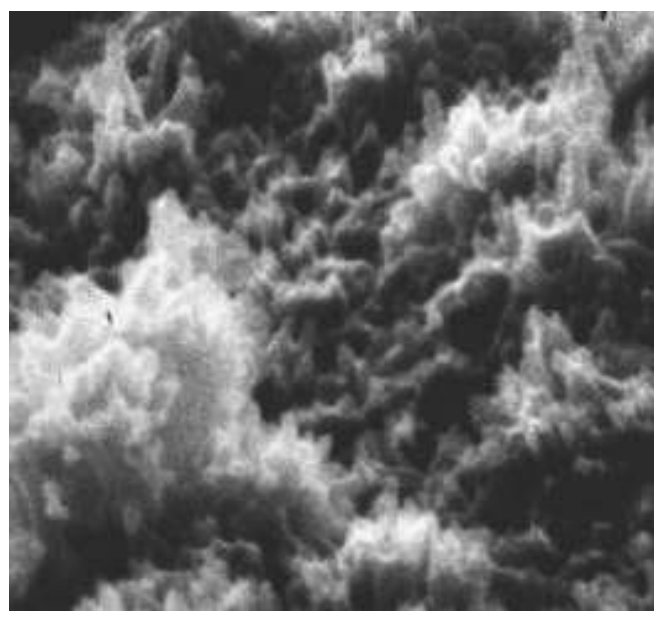

Figura 3.1 Detalhe das fibras cristalinas de C-S-H (silicatos de cálcio hidratados) MONTEIRO, 2007

\subsubsection{Estrutura da zona de transição}

A zona de transição entre a matriz da pasta de cimento e o agregado é normalmente considerada como a parte mais fraca do concreto de resistência normal. Para o concreto de alta resistência, a resistência da argamassa e da zona de transição pode ser comparável com a resistência do agregado graúdo.

Segundo DIAMOND e STRUBLE (1987) apud POMPEU NETO (2004), geralmente uma camada de hidróxido de cálcio $(\mathrm{CH})$ precipita-se no limite físico entre o agregado e a matriz da pasta de cimento. Logo em seguida uma camada livre preferivelmente contendo cristais de hidróxido de cálcio orientados, etringita e C-S-H, tendo uma porosidade muito elevada.

MASO apud MEHTA e MONTEIRO (2008) descreve o comportamento do concreto a partir do seu lançamento: primeiro forma-se um filme de água ao redor das partículas dos agregados graúdos, podendo formar uma relação água-cimento mais elevada nas proximidades do agregado graúdo do que na matriz da pasta de cimento. Os íons de cálcio, sulfato, hidroxila e aluminatos formados pela dissolução dos compostos de sulfato de cálcio e de aluminato de cálcio, combinam-se para formar etringita e hidróxido de cálcio. Devido à relação água/cimento elevada, estes produtos cristalinos vizinhos ao agregado graúdo consistem de cristais relativamente grandes e, consequentemente, formam uma estrutura mais porosa do que na matriz da pasta de cimento ou na matriz da argamassa. Os cristais em formato de placas de hidróxido de cálcio tendem a se formar em camadas orientadas, seguidas de C$\mathrm{S}-\mathrm{H}$ pouco cristalizado e uma segunda geração de cristais menores de etringita e de 
hidróxido de cálcio começam a preencher os espaços vazios entre o reticulado criado pelos cristais grandes de etringita e de hidróxido de cálcio. Isso ajuda a melhorar a densidade e, consequentemente, a resistência da zona de transição na interface.

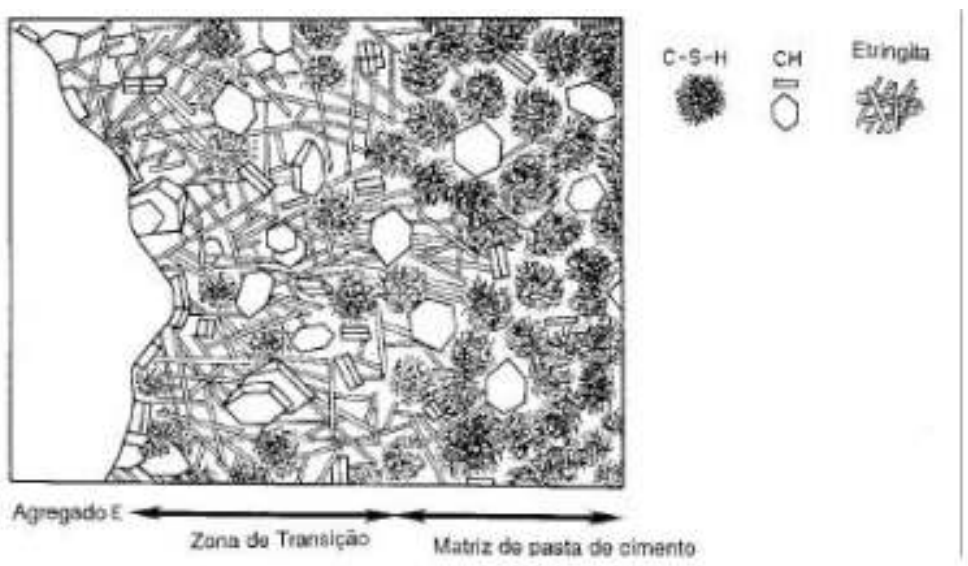

Figura 3.2 - Representação da zona de transição pasta-agregado (MEHTA e MONTEIRO, 2008)

SKALNY e MINDNESS (1984) apud KARIMOV (2002) encontraram que a relação água/cimento na matriz da pasta de cimento é menor do que na zona de transição, fazendo com que a resistência na zona de transição seja menor do que as resistências da matriz de cimento e do agregado, especialmente nos primeiros estágios de hidratação das amostras.

PAULON (2005) descreve que a auréola de zona de transição de maior porosidade que cerca os agregados tem uma espessura da ordem de $50 \mu \mathrm{m}$, sendo uma zona fortemente anisotrópica. Nessa zona interfacial forma-se uma concentração de tensões no concreto sob ação de cargas. Ainda segundo o autor, quanto maiores forem as partículas chatas e alongadas dos agregados, maior será a tendência da água de acumular-se em filmes próximos às partículas, tornando mais fraca a pasta de cimento na região da interface.

STRUBLE (1988) apud KARIMOV (2002) relatou que essa zona de interface é caracterizada por baixa quantidade de grandes grãos de cimento não hidratado com alta porosidade e a presença de vazios de grãos hidratados. A presença de agregados calcários na zona intermediária leva a uma baixa quantidade de hidróxido 
de cálcio, pois ele interage com o calcário produzindo, ao longo do tempo, uma diminuição da espessura da zona de transição.

\subsection{Variabilidade extrínseca}

\subsubsection{Parâmetros de ensaio}

SHEHATA (2005) descreve que, entre os parâmetros influenciadores para o resultado do módulo de deformação relacionados aos corpos-de-prova, encontramse a forma e a dimensão da seção transversal, a relação entre o comprimento e essa dimensão e a direção de concretagem. Já os parâmetros relacionados ao procedimento de ensaio estão o teor de umidade do corpo-de-prova a velocidade de aplicação de tensão, a restrição à deformação nas extremidades do corpo-de-prova causada pela placa de carregamento, o comprimento ao longo do qual se mede a deformação, o diâmetro do prato transmissor de carga e a rigidez da prensa.

ANDRADE (1997) apud MONTIJA (2007) descreve que quanto mais rápida a aplicação da carga, menor a capacidade de propagação das fissuras e acomodação microestrutural das deformações, o que acarreta num módulo de deformação mais elevado. MEHTA e MONTEIRO (2008) citam que para taxas de carregamento muito lentas, as deformações de fluência se sobrepõem às deformações elásticas, fazendo com que o módulo de deformação diminua.

Exceto o módulo de deformação tangente na origem, o módulo diminui com o aumento da tensão. Portanto, para fins práticos, a fixação da tensão é fundamental para se determinar o módulo de deformação do concreto.

\subsubsection{Amostragem do concreto}

Como o módulo de deformação do concreto está associado à quantidade de cada uma das fases que o constitui, o material só será representativo se for corretamente amostrado, devendo seguir os critérios especificados pela NBR 12655 (2006) - "Concreto de cimento Portland - Preparo, controle e recebimento Procedimento". Dessa forma, serão formados lotes de ensaio de maneira racional. A maior possibilidade de erro de amostragem se dá quando da coleta de material com 
deficiência de mistura ou não-representativo do lote misturado, o que irá impactar nos resultados dos ensaios, devendo, portanto, ser descartados para que não se incorra em erros de determinação desta propriedade.

\subsubsection{Máquina de ensaios}

Com o aumento dos valores de resistência dos concretos se fez necessária a utilização de máquinas mais rígidas para execução do ensaio de módulo de deformação, para que a qualidade do ensaio não seja comprometida. Como alternativa de manutenção das máquinas antigas de ensaio, optou-se por diminuir as dimensões dos corpos de prova $(200 \times 100 \mathrm{~mm})$, obedecendo-se a relação $\mathrm{h} / \mathrm{d}$ igual a 2.

Quanto maior a capacidade nominal de carga da máquina de ensaios mais difícil é a obtenção e a estabilização da carga a níveis de tensão tão baixos. Faz-se necessário o uso de células de carga com capacidade de carga menor, obtendo-se, assim, o nível de confiabilidade da medida das tensões e deformações correspondentes.

\subsubsection{Preparação dos corpos de prova}

A moldagem, a cura e o capeamento ou retificação dos corpos de prova são de fundamental importância para a uniformidade dos resultados. A NBR 5738 (2003) - Concreto - Procedimento para moldagem e cura de corpos-de-prova e NBR 5739 (2007) - Concreto - Ensaios de compressão de corpos-de-prova cilíndricos preconizam a metodologia específica. Isso é de fundamental importância, pois o corpo de prova de concreto deve constituir uma amostra de um material isotrópico, sendo uma aproximação profundamente dependente da amostragem bem como de sua preparação. A preparação inclui a moldagem, desforma, o transporte, o armazenamento e preparação final para o ensaio - cura e saturação o mais homogênea possível e a retificação ou capeamento do topo e da base dos corposde-prova - garantindo assim que não haja segregação entre as fases constituintes ou esta seja minimizada. 
SCOVA apud SOBRAL (1983) ressalta que, para se evitar a concentração de tensões durante o ensaio, os topos e bases dos corpos de prova devem ser planos. Se isso não ocorrer, a área de contato entre o corpo de prova e os pratos da máquina de ensaio será reduzida, trazendo como consequência uma concentração de tensões que resultarão em diminuição da resistência.

\subsubsection{Umidade do corpo de prova}

METHA e MONTEIRO (2008), relatam que os corpos de prova ensaiados em condições úmidas apresentam um módulo de deformação cerca de $15 \%$ maior que os corpos de prova testados em condições secas, comportando-se de maneira oposta à resistência à compressão, que é cerca de $15 \%$ maior quando as amostras são ensaiadas em condições secas. Para os autores, a explicação para o fenômeno decorre da secagem do cimento que produz efeito diferente na matriz da pasta de cimento e na zona de transição na interface. A matriz da pasta de cimento ganha em resistência por um aumento na força de atração de Van der Waals nos produtos de hidratação, enquanto que a zona de transição na interface perde resistência devido à microfissuração. Outra explicação seria que, numa pasta de cimento saturada, a água adsorvida no C-S-H é capaz de suportar carga e, portanto, sua presença contribui para o aumentar o módulo de deformação. Entretanto, ao reduzir a força de atração de Van der Waals, a pressão de separação no C-S-H provoca diminuição na resistência.

Entretanto, a explicação mais contundente é feita por NEVILLE (1997) que relata que o fenômeno ocorre por conta da incompressibilidade da água presente nos poros capilares do concreto que, durante a compressão, tende a exercer tensões na direção transversal ao carregamento, contribuindo para o colapso da estrutura mais precocemente, ou seja, a uma tensão menor. Já para o módulo de deformação, a explicação decorre do fato que, ao se substituir o ar, que é um material extremamente flexível por água dentro dos capilares do concreto, há um aumento da rigidez da matriz aumentando, por consequência, a rigidez do compósito, conforme ilustra a Figura 3.3. A ABNT NBR 8522 (2008) preconiza o ensaio na condição saturada. 


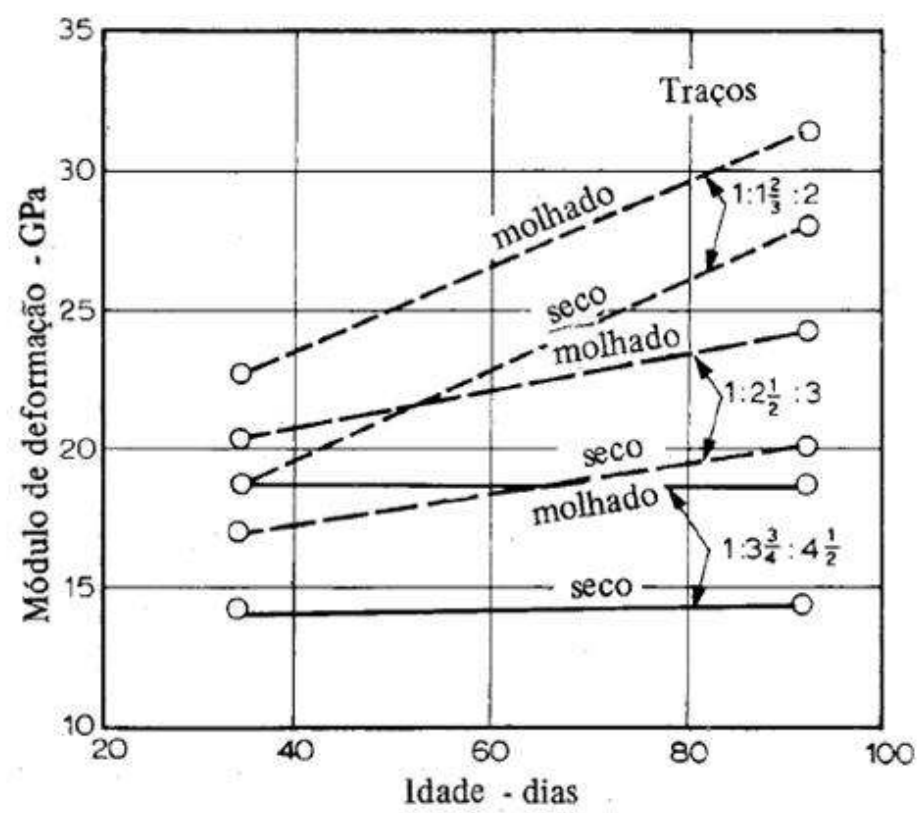

Figura 3.3 - Influência da condição de umidade dos corpos-de-prova no módulo de deformação NEVILLE (1997)

\subsubsection{Medida da deformação - Instrumentação}

O tipo de instrumentação para medição das deformações também constitui fonte de variabilidade, pois tem grande impacto no resultado final, sendo maior até que a variabilidade da resistência à compressão. Isso porque o erro da deformação está embutido no denominador da equação de determinação do módulo de deformação e altera fortemente o resultado final

Existem vários instrumentos para medição das deformações para determinação do módulo de deformação estático do concreto, sendo os mais comuns: compressômetro com relógios comparadores, compressômetro com transdutores de deslocamento indutivos (linear variable differential transformer ou LVDT), transdutores resistivos ou extensômetros elétricos tipo strain gages de colagem superficial, de imersão ou de ancoragem tipo clip gage. Eles são instalados no terço médio do corpo de prova e captam a deformação durante o ensaio de compressão, conforme melhor explicitado no item 3.2.2.3. 


\subsubsection{Velocidade de carregamento}

Pelo fato do concreto não ser uma material perfeitamente elástico, a uniformidade dos resultados de módulo de deformação está diretamente ligada à velocidade de aplicação de carga, conforme relatado por MONTIJA (2007). Assim, quanto mais rápida a aplicação da carga, menor a capacidade de propagação das fissuras e acomodação microestrutural das deformações. Conseqüentemente, o módulo de deformação será maior.

Na Figura 3.4 são apresentados os principais fatores que afetam o módulo de deformação do concreto.

\section{Fatores que influenciam o módulo de deformação do concreto}

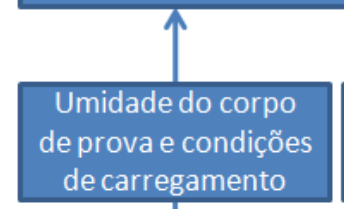

de carregamento

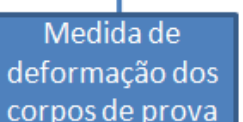

corpos de prova

Nível de

carregamento

Parâmetros

de ensaio
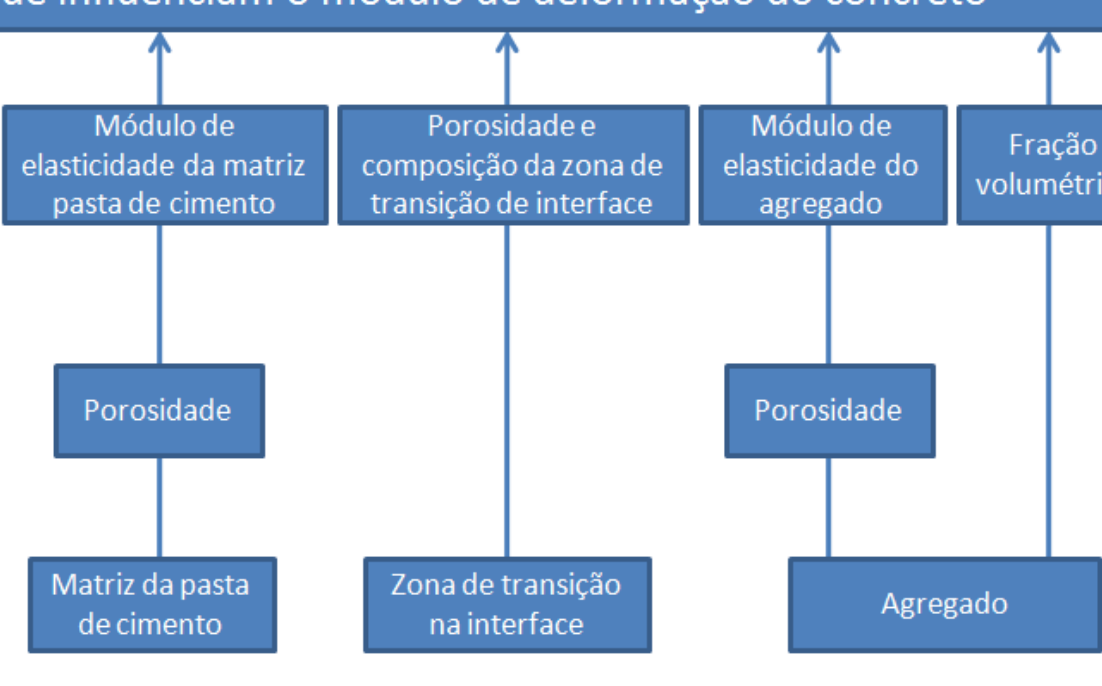

Fração

volumétrica

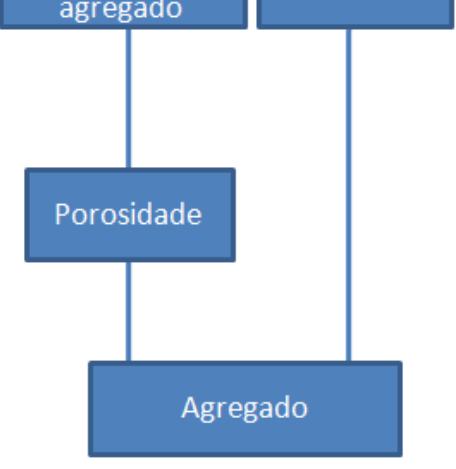

Figura 3.4 - Fatores que afetam o módulo de deformação do concreto. Adaptado de MEHTA e

MONTEIRO, (2008)

\subsubsection{Ensaio para determinação do módulo de deformação do concreto}

MONTIJA (2007) descreve que, por fazer uso de uma aproximação matemática gráfica, este seria um fator interveniente na interpretação do resultado de ensaio do módulo de deformação do concreto. Assim, deve-se garantir que os limites do trecho retilíneo estejam bem definidos e confiáveis. Também são citados pelo autor, como fontes de variabilidade inerentes ao ensaio, a velocidade de aplicação da carga, a definição do plano de carga e o tipo de instrumentação para a medição das deformações. 


\subsubsection{ABNT NBR 8522 (2008)}

De acordo com a ABNT NBR 8522 (2008), antes da realização dos ensaios, o diâmetro e a altura dos corpos de prova devem ser determinadas com a precisão de $0,1 \mathrm{~mm}$.

Para o ensaio de módulo de deformação são necessários 5 corpos de prova cilíndricos, com diâmetro (d) e altura (h) que atenda à condição $h / d=2$, sendo que o diâmetro deva ser no mínimo 4 vezes o tamanho máximo do agregado graúdo. Dois corpos de prova devem ser ensaiados para se obter sua resistência à compressão, de acordo com o que define a ABNT NBR 5739 (2007), para determinar o nível de carregamento a ser aplicado no ensaio de módulo. Os corpos de prova devem ser centralizados nos pratos da prensa e os medidores de deformação devem ser fixados de forma que os pontos de medição fiquem equidistantes dos extremos do corpo de prova. A base de medida das deformações deve ser no mínimo igual a 2/3 do diâmetro do corpo de prova e no máximo igual a esse diâmetro.

Para determinação do módulo tangente inicial, após o posicionamento do corpo de prova é aplicado o carregamento até uma tensão de $30 \%$ de $f_{\mathrm{cmj}}\left(\sigma_{\mathrm{b}}\right)$ a uma velocidade de $(0,25 \pm 0,05) \mathrm{MPa} / \mathrm{s}$. Este nível de carregamento deve ser mantido por 60 segundos e em seguida, reduzido à mesma velocidade do processo de carregamento até o nível de tensão básica $\left(\sigma_{a}=0,5 \pm 0,1 \mathrm{MPa}\right)$. Devem ser realizados mais ciclos de carregamento adicionais, entre $\sigma_{a}$ e $\sigma_{b}$ mantendo-se estas tensões por 60 segundos, como representa a Figura 3.2. Depois do último ciclo de carga são medidas as deformações específicas.

Para determinação do módulo de deformação secante, após o posicionamento do corpo de prova é feita uma compatibilização da deformação das bases de medida, aplicando-se uma carga de até, no máximo, $20 \%$ da carga prevista para ruptura do concreto e verificando-se as deformações registradas pelos medidores. Caso a diferença entre as deformações lidas nesses medidores seja maior que $20 \%$ da maior das leituras feitas, descarrega-se o corpo-de-prova e ajusta-se girando-o. Este procedimento deve ser repetido até que a diferença entre as deformações lidas não seja maior que $20 \%$ da maior deformação. Terminada esta etapa de compatibilização das deformações, aplica-se um carregamento crescente à velocidade $(0,25 \pm 0,05) \mathrm{MPa} / \mathrm{s}$ com pausa de 60 segundos nas tensões 
de 0,5 MPa e on para leitura das respectivas deformações em, no máximo, 30 segundos, conforme Figura 3.3.

Após o término das leituras de deformação, o corpo de prova deve ser carregado até sua ruptura. Se a resistência efetiva à compressão do corpo de prova diferir de $\mathrm{fcm}_{j}$ em mais de $20 \%$, os resultados do corpo de prova devem ser descartados.

\subsubsection{Planos de carregamento}

Os planos de carregamento definem a solicitação da amostra, os níveis de solicitação, os tempos de conservação de carga nos níveis de tensão e as velocidades de carregamento e descarregamento. Eles podem ser divididos entre aqueles que estabelecem a realização de pré-ciclos de carregamento, buscam a obtenção do módulo tangente inicial e aqueles que não estabelecem a realização de pré-ciclos de carregamento determinam o módulo de deformação secante à curva $\sigma$ $\varepsilon$.

A ABNT NBR 8522 (2008) - Determinação do módulo de deformação estático do concreto - apresenta dois planos de carregamento e quando se deve realizar cada um deles, conforme Tabela 3.2. 
Tabela 3.2 - Planos de carregamento para determinação do módulo de deformação estático do concreto - ABNT NBR 8522 (2008).

\begin{tabular}{|c|c|c|}
\hline Tipo de módulo & Plano de carga indicado & Aplicação \\
\hline $\begin{array}{l}\text { Módulo de deformação } \\
\text { ou módulo de } \\
\text { deformação tangente } \\
\text { inicial }\left(\mathrm{E}_{\mathrm{ci}}\right)\end{array}$ & 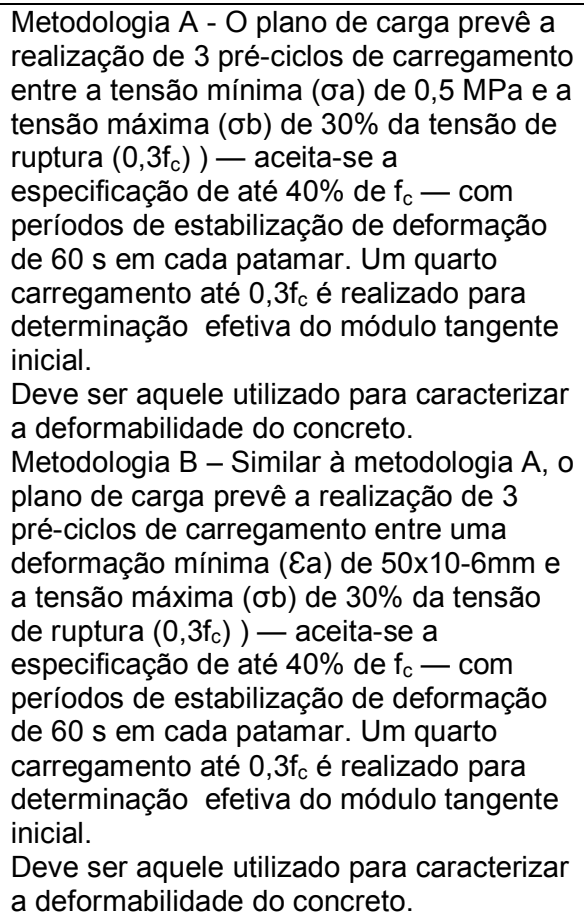 & $\begin{array}{l}\text { A norma NBR } 6118 \text { (2007) indica este } \\
\text { resultado para ser aquele especificado em } \\
\text { projeto e controlado tecnologicamente } \\
\text { pelas obras. Este valor pode ser utilizado } \\
\text { diretamente pelos projetistas na avaliação } \\
\text { do comportamento global de uma estrutura } \\
\text { e para o cálculo de perdas de protensão. }\end{array}$ \\
\hline $\begin{array}{l}\text { Módulo de deformação } \\
\text { secante }\left(\mathrm{E}_{\mathrm{cs}}\right) \text { a uma } \\
\text { tensão indicada ou a } \\
\text { partir do diagrama } \\
\text { tensão-deformação }(\sigma-\varepsilon)\end{array}$ & 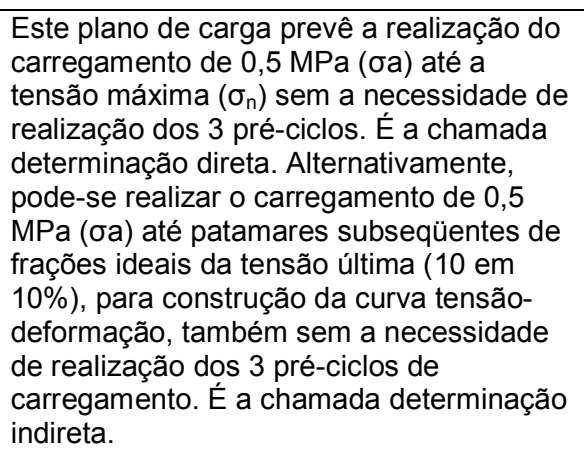 & $\begin{array}{l}\text { Deve ser aquele utilizado quando há } \\
\text { interesse na simulação de uma estrutura } \\
\text { cuja carga permanente prevaleça desde o } \\
\text { primeiro carregamento. } \\
\text { A norma NBR } 6118 \text { (2007) indica este } \\
\text { resultado para ser aquele utilizado pelos } \\
\text { projetistas em análises elásticas de } \\
\text { projeto, especialmente para determinação } \\
\text { de esforços solicitantes e verificação de } \\
\text { estados limites de serviço na avaliação do } \\
\text { comportamento de um elemento estrutural } \\
\text { ou seção transversal durante o projeto. }\end{array}$ \\
\hline \multicolumn{3}{|c|}{$\begin{array}{l}\text { Observações: } \\
\text { a) Se a tensão máxima estiver entre } 30 \text { e } 50 \% \text { de } f_{c} \text {, faculta-se nos dois casos, antes da determinação efetiva, a } \\
\text { realização da centragem das bases do instrumento medidor das deformações (em geral, } 2 \text { bases de medida), através } \\
\text { de cargas de } 20 \% \text { de } f_{c} \text {. } \\
\text { b) Em projeto, de acordo com a NBR } 6118(2007) \text {, ao dispor-se do valor de } E_{c i} \text { pode-se usar a seguinte correlação } \\
\text { para obtenção de } E_{c s}: E_{c s}=0,85 . E_{c i}\end{array}$} \\
\hline
\end{tabular}

As Figuras 3.5 a 3.7 representam os planos de carregamento previstos na ABNT NBR 8522 (2008). Na Figura 3.8 é ilustrado o ensaio sob o plano de carregamento secante que prevê a construção completa da curva tensãodeformação específica. 


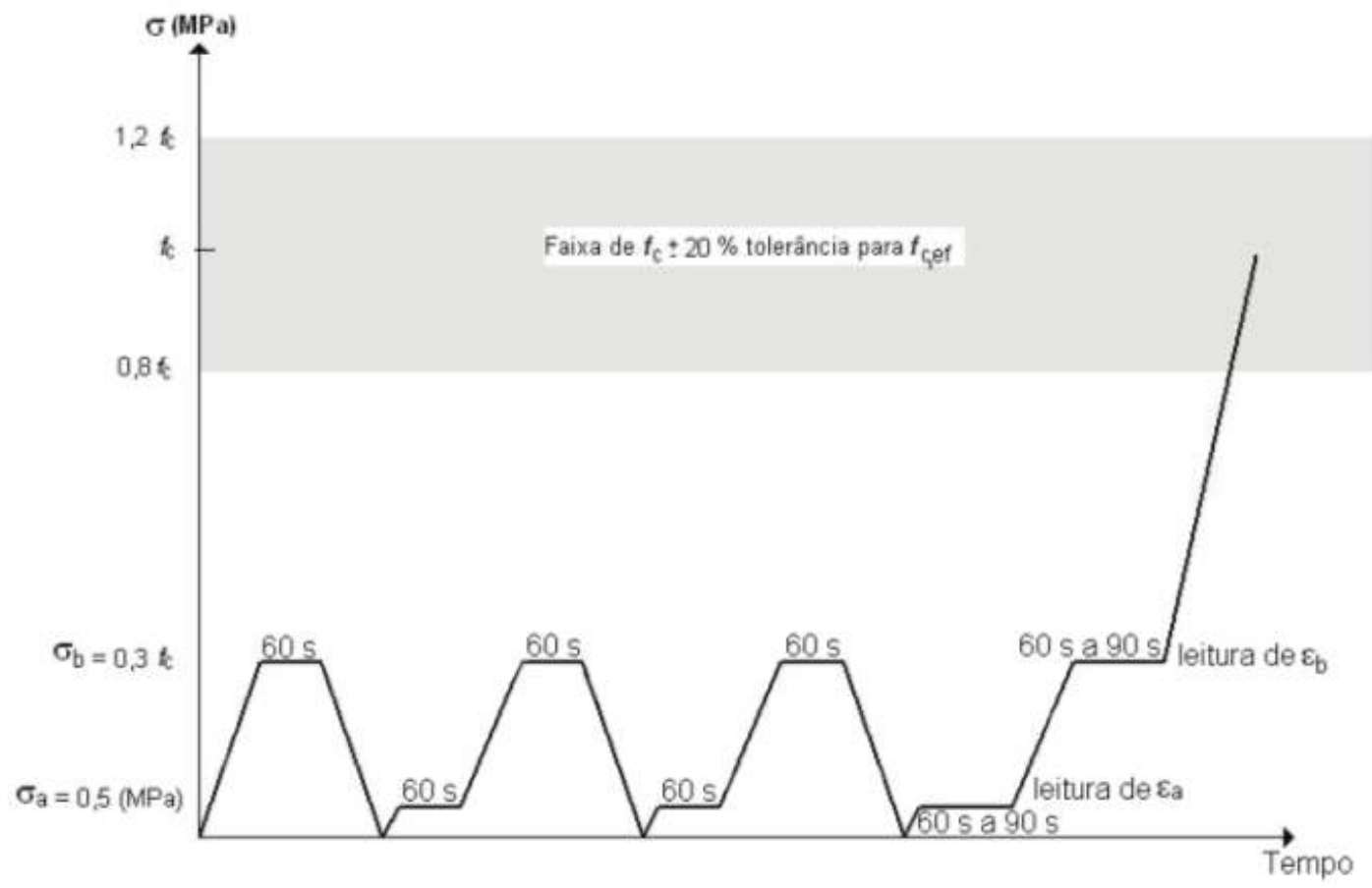

Figura 3.5 - Plano de carga para obtenção do módulo de deformação tangente inicial, Eci Metodologia A - Tensão $\sigma_{a}$ fixa - ABNT NBR 8522 (2008)

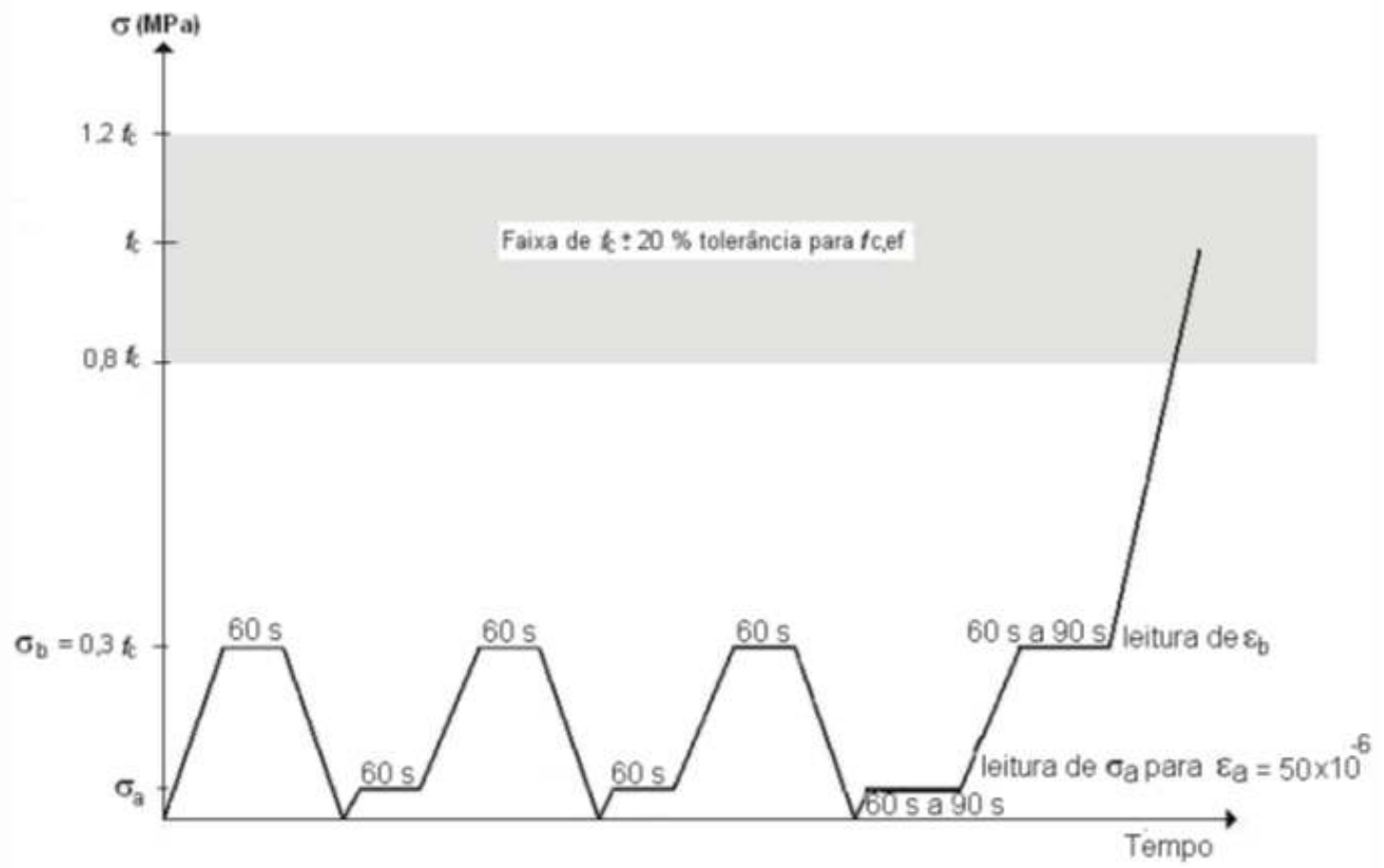

Figura 3.6 - Plano de carga para obtenção do módulo de deformação tangente inicial, $E_{c i}-$ Metodologia B - Deformação específica $\varepsilon_{a}$ fixa - ABNT NBR 8522 (2008) 


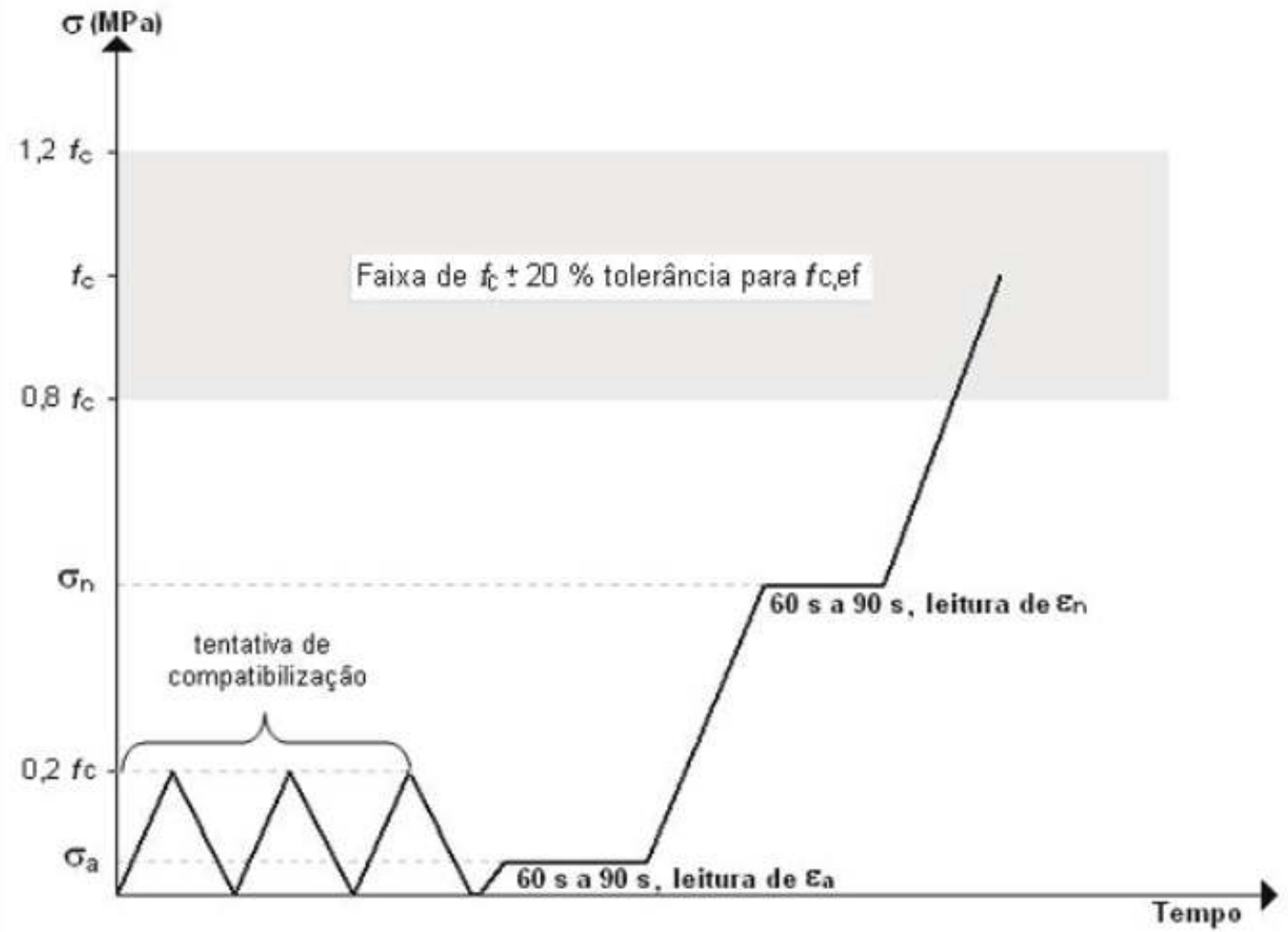

Figura 3.7 - Plano de carga para obtenção do módulo de deformação secante, $E_{c s}$, a uma tensão indicada $\sigma_{\mathrm{n}}$ - ABNT NBR 8522 (2008)

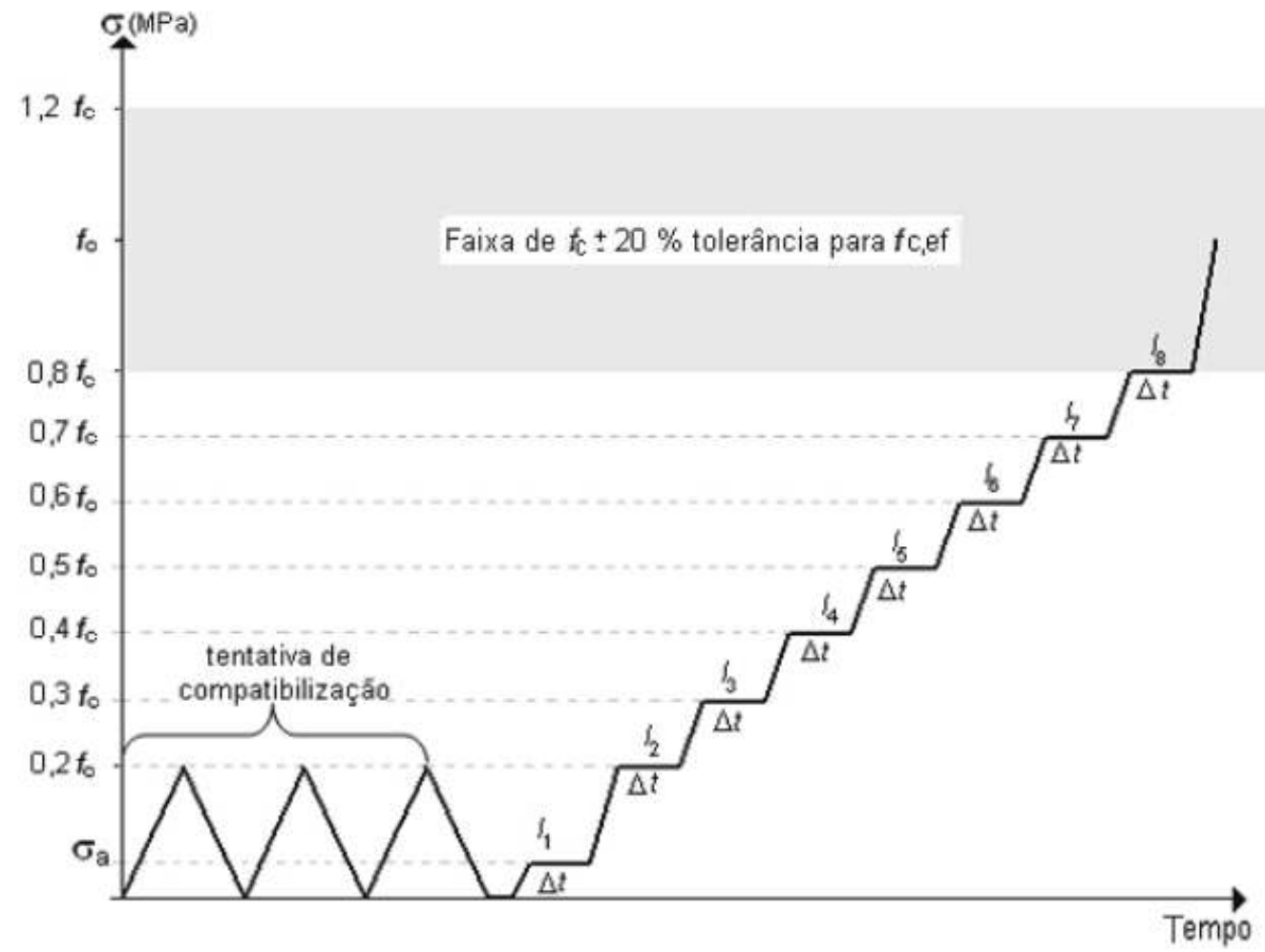

Figura 3.8 - Plano de carga para obtenção do módulo de deformação secante, $E_{c s}$, para o traçado do diagrama tensão-deformação ( $\sigma-\varepsilon)$ - ABNT NBR 8522 (2008) 


\subsection{Cálculos}

\subsection{Metodologia $A-T e n s a ̃ o ~ \sigma_{a}$ fixa}

O módulo de deformação, $E_{\mathrm{ci}}$, em GPa, é dado pela equação:

$$
E_{c i}=\frac{\Delta \sigma}{\Delta \varepsilon} 10^{-3}=\frac{\sigma_{b}-0,5}{\varepsilon_{b}-\varepsilon_{a}} 10^{-3}
$$

Onde:

$\sigma_{\mathrm{b}}$ é a tensão maior, em MPa $\left(\sigma_{\mathrm{b}}=0,3 f_{c}\right)$ ou outra tensão especificada em projeto, de até $40 \%$ de $f_{c}$;

0,5 é a tensão básica em MPa;

$\varepsilon_{\mathrm{b}}$ é a deformação específica média, sob a tensão maior;

$\varepsilon_{\mathrm{a}}$ é a deformação específica média, sob a tensão básica de $0,5 \mathrm{MPa}$;

\subsection{Metodologia B - Deformação específica Ea fixa}

O módulo de deformação, $E_{c i}$, em GPa, é dado pela equação:

$E_{c i}=\frac{\Delta \sigma}{\Delta \varepsilon} 10^{-3}=\frac{\sigma_{b}-\sigma_{a}}{\varepsilon_{b}-50 \times 10^{-6}} 10^{-3}$

Onde:

$\sigma_{\mathrm{b}}$ é a tensão maior, em $\mathrm{MPa}\left(\sigma_{\mathrm{b}}=0,3 f_{c}\right)$ ou outra tensão especificada em projeto, de até $40 \% f_{c}$;

$\sigma_{a}$ é a tensão básica correspondente à deformação específica $50 \times 10^{-6}$, em $\mathrm{MPa}$;

$\varepsilon_{\mathrm{b}}$ é a deformação específica média, sob a maior tensão; 


\subsubsection{Instrumentação utilizada}

A ABNT NBR 8522 (2008) não especifica um tipo de instrumento para medição da deformação, apenas cita que estes podem ser mecânicos, elétricos ou outros, e devem ter resolução de $\pm 1 \times 10^{-3} \mathrm{~mm}$ e erro relativo máximo inferior a $1 \%$.

Em seu estudo com diversos tipos de instrumentação, MONTIJA (2007) demonstrou que os menores resultados de dispersão do método de ensaio se deram sob a instrumentação clip gage. $O$ autor demonstrou que a influência dos procedimentos de ensaio nos resultados é minorada com o uso da instrumentação clip gage, pois há menor erro aleatório intrínseco à captação das deformações, principalmente no que diz respeito ao trabalho do operador, que não precisa realizar nenhum tratamento superficial nos corpos de prova (como no caso dos strain gages) ou posicionar e aparafusar o instrumento (relógios comparadores).

Como o presente estudo pretende determinar a variabilidade do material concreto, foi utilizada a instrumentação clip gage, em função da menor influência deste no resultado do ensaio.

\subsection{Clip gages}

Conforme ilustrado por MONTIJA (2007), os clip gages, são uma variação dos strain gages colados ou de superfície. Entretanto, neste caso os strain gages estão colados nas faces superior e inferior da lâmina metálica de ancoragem no corpo-deprova e a deformação deste, que corresponde ao deslocamento vertical da extremidade da lâmina em balanço, será inferida a partir da deformação dos strain gages.

A Figura 3.9, de ALMEIDA (2004), representa o princípio de funcionamento do sistema medidor clip gage.

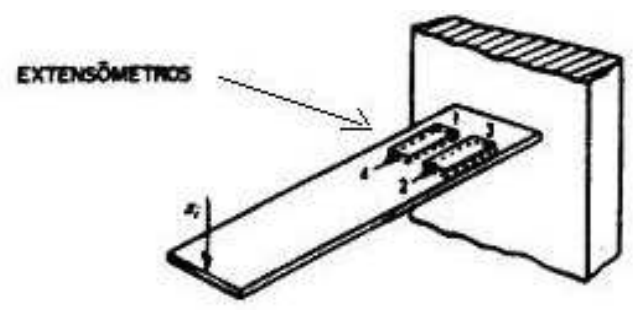

Figura 3.9 - Princípio de funcionamento dos clip gages - ALMEIDA (2004) 


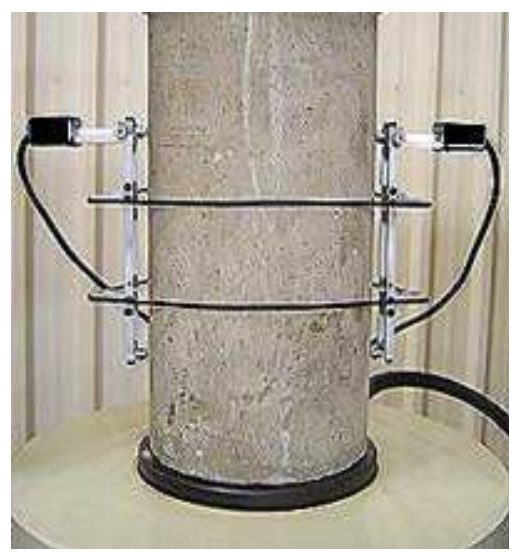

Figura 3.10 - Clip gages de contato em lâmina com ligação elástica por anéis de borracha 


\section{METODOLOGIA DA PESQUISA}

Este estudo pretende inserir-se no cenário de ampliação da discussão a respeito da análise da variabilidade total do material concreto no que se refere ao módulo de deformação, mais especificamente no detalhamento da variabilidade do módulo de deformação relativa às condições de produção do material.

O estudo foi realizado com o controle rotineiro do módulo de deformação, desenvolvido em laboratório. $O$ objetivo foi quantificar a variabilidade da propriedade em função das famílias de concreto normalmente produzidas pela central de concreto, que utiliza materiais de origem bem definida.

A primeira etapa da pesquisa foi realizada pelo período de nove meses, mantidas as condições de uniformidade dos concretos em cada família, diminuindose a possibilidade de interferência de variáveis intervenientes para maior confiabilidade estatística. Pretendeu-se com isto mapear os fatores ligados a variabilidade da determinação do módulo de deformação, compondo com a variabilidade do ensaio e a variabilidade total.

Para ampliar a análise, na segunda etapa foi avaliado o impacto da variabilidade do resultado no controle tecnológico em obra, onde foram realizados ensaios com concretos fornecidos para algumas obras da região da Grande São Paulo, para a resistência característica, $\mathrm{f}_{\mathrm{ck}}$, igual a $30 \mathrm{MPa}$.

Como objetivo complementar, a propriedade do módulo de deformação também será interpretada de maneira a ampliar a discussão sobre a possibilidade de aplicação do conceito semiprobabilístico normativo aos resultados de controle experimental do concreto. 


\subsection{Variabilidade da propriedade em função da variabilidade dos materiais}

Como já explicitado, a uniformidade do concreto é função da uniformidade apresentada pelos agregados, cimento e aditivos utilizados, esta variabilidade será verificada em uma central dosadora de concreto que utiliza materiais de origem definida e que devem ser mantidos dentro de certo desvio-padrão pelo fornecedor, a fim de que não se prejudique o processo produtivo.

Na pesquisa experimental foi abordada a variabilidade obtida no controle da propriedade módulo de deformação associada à variabilidade inerente ao material concreto, quantificando essa variabilidade em função das famílias de concreto normalmente produzidas pela central de concreto.

HELENE e TERZIAN (1993) ilustram que durante a produção do concreto, há a constante mudança da média, mantendo-se a resistência à compressão como variável gaussiana e estacionária por um determinado período. Esta mudança está diretamente ligada à variabilidade dos materiais. Esse esquema pode ser visto na Figura 4.1.

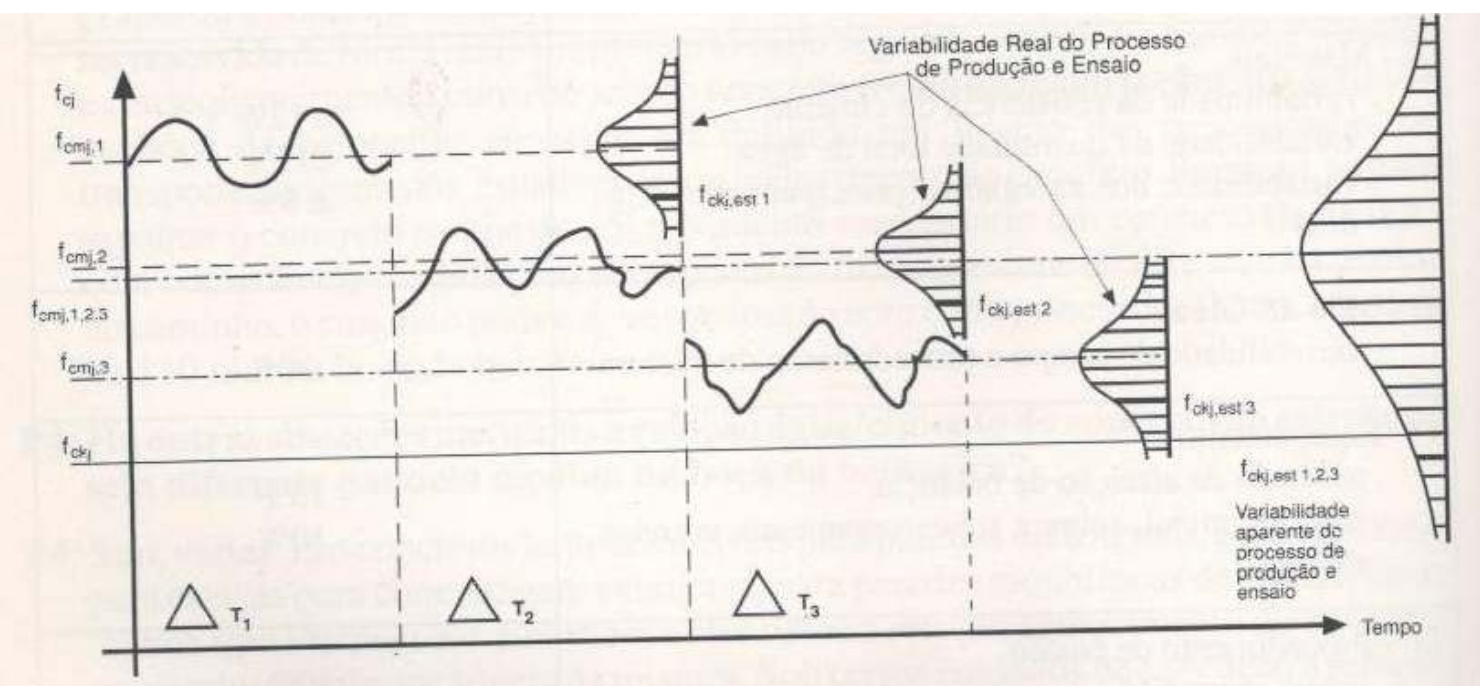

Figura 4.1 - Mudança de centragem média do processo de produção e ensaio do concreto em função do tempo, como decorrência da variação de alguns fatores que influem na resistência à compressão do concreto - HELENE e TERZIAN (1993)

Sabe-se que as alterações na granulometria ou mesmo na quantidade de agregados de uma ou outra betonada de um mesmo traço de concreto determinam 
alterações significativas na consistência do concreto fresco, bem como na quantidade de água requerida para a obtenção dessa consistência desejada.

Com essas considerações objetivou-se estudar a variabilidade do módulo de deformação do concreto ao longo do tempo para determinadas resistências características $\left(f_{\mathrm{ck}}\right)$ em função da variabilidade dos materiais constituintes do concreto. A Figura 4.1 apresenta essa variabilidade onde, observa-se para cada período, a variabilidade real da propriedade associada à variabilidade dos materiais constituintes do concreto.

Com base nos resultados obtidos, foi abordada a variabilidade real do processo de produção e ensaio retirados do controle estatístico da central de concreto.

\subsection{Resistência característica à compressão segundo a ABNT}

A resistência característica à compressão do concreto é definida pela ABNT NBR 12655 (2006) como o valor de resistência à compressão acima do qual se espera que estejam $95 \%$ dos resultados de ensaios de amostragem feitos conforme as normas ABNT NBR NM 33 (1998) e ABNT NBR 5738 (2008). Segundo ANG e TANG (1975), a distribuição de probabilidade do concreto pode ser estabelecida como variável Normal (distribuição de Gauss). Esta consideração recebe algumas críticas pelo fato de a distribuição Normal admitir valores negativos de resistência, o que fisicamente não é possível. Uma alternativa para isto seria, por exemplo, considerar a distribuição de probabilidade LogNormal, na qual os valores são definidos apenas para valores positivos. As normas brasileiras de concreto adotam a distribuição Normal de probabilidade ou distribuição de Gauss para descrever a resistência do concreto.

Neste contexto, surge $o$ conceito de $f_{c k}$, resistência característica à compressão do concreto. Este é o valor de resistência abaixo do qual existe a probabilidade de se ter apenas $5 \%$ dos resultados inferiores a ele. 


\subsubsection{Distribuição Normal}

Pesquisas apontam o século XVII como a época em que a distribuição de probabilidade normal foi estudada pela primeira vez. Nessa época foi observado que os padrões em erros de medida seguiam uma distribuição simétrica em forma de sino. Este modelo matemático foi apresentado pela primeira vez por DeMoivre em 1733; esta distribuição também era conhecida por Laplace já no ano de 1775. Entretanto, a referência histórica sobre a definição formal da distribuição normal tem sido atribuída a Gauss, cuja primeira publicação sobre o tema ocorreu no ano de 1809. Desde então, o termo Distribuição Gaussiana tem sido utilizado para determinar este tipo de distribuição de probabilidade (HINES et al., 2006).

Diz-se que uma variável aleatória possui uma distribuição de probabilidade normal, com média $\mu(-\infty<\mu<\infty)$ e variância $\sigma^{2}>0$ quando possui a seguinte função densidade:

$$
f(x)=\frac{1}{\sigma \cdot \sqrt{2 \pi}} e^{-(1 / 2)[(x-\mu) / \sigma]^{2}}
$$

Este modelo de distribuição de probabilidades é o mais utilizado para descrever o comportamento da resistência do concreto.

O valor de desvio padrão adotado pela norma brasileira é definido através da expressão a seguir.

$$
s=\sqrt{\frac{\sum_{i=1}^{n}\left(f_{i}-f_{c m}\right)^{2}}{n-1}}
$$

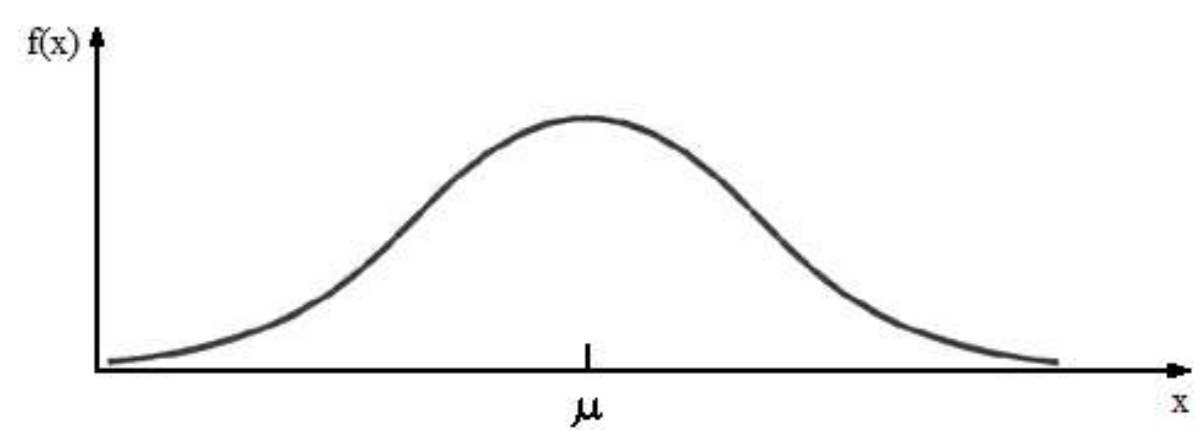

Figura 4.2 - Distribuição Normal de probabilidade da resistência do concreto 
Com a consideração de que possa ocorrer até $5 \%$ dos valores de $\mathrm{f}_{\mathrm{c}}$ abaixo de $\mathrm{f}_{\mathrm{ck}}$ e utilizando a distribuição Normal de probabilidade, chega-se a equação:

$$
f_{c k}=f_{c m}-1,65 . \sigma
$$

Onde:

$\mathrm{f}_{\mathrm{cm}}$ é a resistência média do concreto na idade considerada ( $\mathrm{MPa}$ );

$\mathrm{f}_{\mathrm{ck}}$ é a resistência característica à compressão (MPa);

$\sigma$ é o desvio padrão da dosagem.

Esta equação é utilizada pela NBR 12655 (ABNT, 2006) que estabelece a resistência de dosagem necessária para o traço $\left(f_{c j}\right)$ com um dado desvio padrão de dosagem apresentar $95 \%$ dos resultados acima do $f_{c k}$ estipulado em projeto:

$$
f_{c j}=f_{c k}+1,65 . \sigma
$$

Onde:

$\mathrm{f}_{\mathrm{cj}}$ é a resistência média do concreto à compressão, previsto para $j$ dias (MPa);

$\mathrm{f}_{\mathrm{ck}}$ é a resistência característica à compressão (MPa);

$\sigma$ é o desvio padrão da dosagem.

Sendo assim, a resistência de dosagem do concreto $f_{c j}$, deve ser a estabelecida pela Equação 4.4 na idade considerada.

\subsection{Conceito semiprobabilístico aplicado ao módulo de deformação}

Segundo MESEGUER (1976) apud HELENE (1980), desde que o processo de fabricação de um determinado produto se repita, atendidas certas condições essenciais, pode-se haver um controle estatístico.

Segundo HELENE (1993) a variabilidade das propriedades mecânicas dos materiais de construção obedece a processos aleatórios ou estocásticos. Assim, os métodos de segurança no projeto estrutural devem estar fundamentados em conceitos da teoria das probabilidades e não em métodos deterministas. 
Todo projeto estrutural deve ter por regra básica conseguir uma estrutura de mínimo custo que atenda com segurança às solicitações de uso. De acordo com HELENE (1986) um bom controle de tecnológico das construções em concreto terá por objetivo garantir um nível preestabelecido em projeto de qualidade daquela construção. O controle tecnológico inclui controles de qualidade de materiais e serviços realizados através de ensaios e inspeções.

HELENE (1980) resume que o controle de qualidade de um produto deve ser entendido como uma técnica que através de recursos matemáticos da estatística, tem por objetivo fornecer as informações essenciais para a manutenção do produto numa qualidade especificada, ao mínimo custo possível. Se aplicado à aceitação de um produto, terá por objetivo simplesmente fornecer a informação da conformidade ou não do produto a uma determinada qualidade.

MONTIJA (2007) cita que há no termo 'controle tecnológico' o conceito implícito de qualidade da produção tanto quanto dos materiais nela empregados. Atualmente, a cadeia de produção de estruturas em concreto armado está mais próxima da configuração de uma indústria seriada que de uma indústria de transformação, como foi no passado. Entretanto, este ainda é o caso das empresas de concreto dosado em central, cabendo, a esses fornecedores, garantia da qualidade de atendimento às propriedades solicitadas aos materiais que entregam às construtoras para que esta possa gerenciar o processo de construção realizando o controle tecnológico global.

HELENE (1980) salienta que todo projeto estrutural deve ter por objetivo a elaboração de uma estrutura de mínimo custo que atenda com segurança às solicitações de uso. Como a variabilidade das propriedades mecânicas dos materiais de construção obedece a processos aleatórios, ou seja, tem uma probabilidade de serem ou não atingidos, correspondem muito mais à realidade do que os métodos determinísticos. 
Segundo HELENE e TERZIAN (1993), a uniformidade do concreto decorre da uniformidade apresentada pelos seus materiais constituintes. Portanto, as operações de controle devem ser rigorosamente constantes, a fim de não prejudicar a avaliação da variabilidade real do processo de produção do concreto.

Para o módulo de deformação do concreto, assume-se que o valor médio obtido seja comparado diretamente com o valor especificado, não sendo considerado qualquer tratamento estatístico inerente aos ensaios laboratoriais.

MONTIJA (2007) descreve então a necessidade de avaliar a aplicabilidade dos conceitos semiprobabilísticos de normas técnicas de dosagem, controle e projeto de estruturas de concreto atualmente considerados para a resistência à compressão uniaxial, também para o módulo de deformação.

AÏTCIN (2000) descreve que a resistência à compressão especificada não é usada diretamente no cálculo de uma determinada dosagem. $O$ autor salienta que, em termos estatísticos, é totalmente inaceitável especificar um concreto dizendo que sua resistência à compressão deveria ser sempre maior do que a resistência de projeto. A especificação da resistência do concreto deve estabelecer que se aceita, num número limitado de casos, que a resistência à compressão possa ser mais baixa que a resistência especificada em projeto. Esse número limitado de casos nos quais a resistência à compressão seja inferior à resistência média qualifica o critério de aceitação, conforme ilustra a Figura 4.3.

A resistência do concreto não tem um único valor, devendo ser descrita como uma população de valores que pode ser considerada normal (distribuição de Gauss) e ser descrita por dois parâmetros: média e desvio-padrão. Dessa forma, como o módulo de deformação do concreto é função da resistência à compressão, que é uma grandeza que apresenta uma variável probabilística, não se pode atribuir à propriedade a característica de uma variável determinística. 


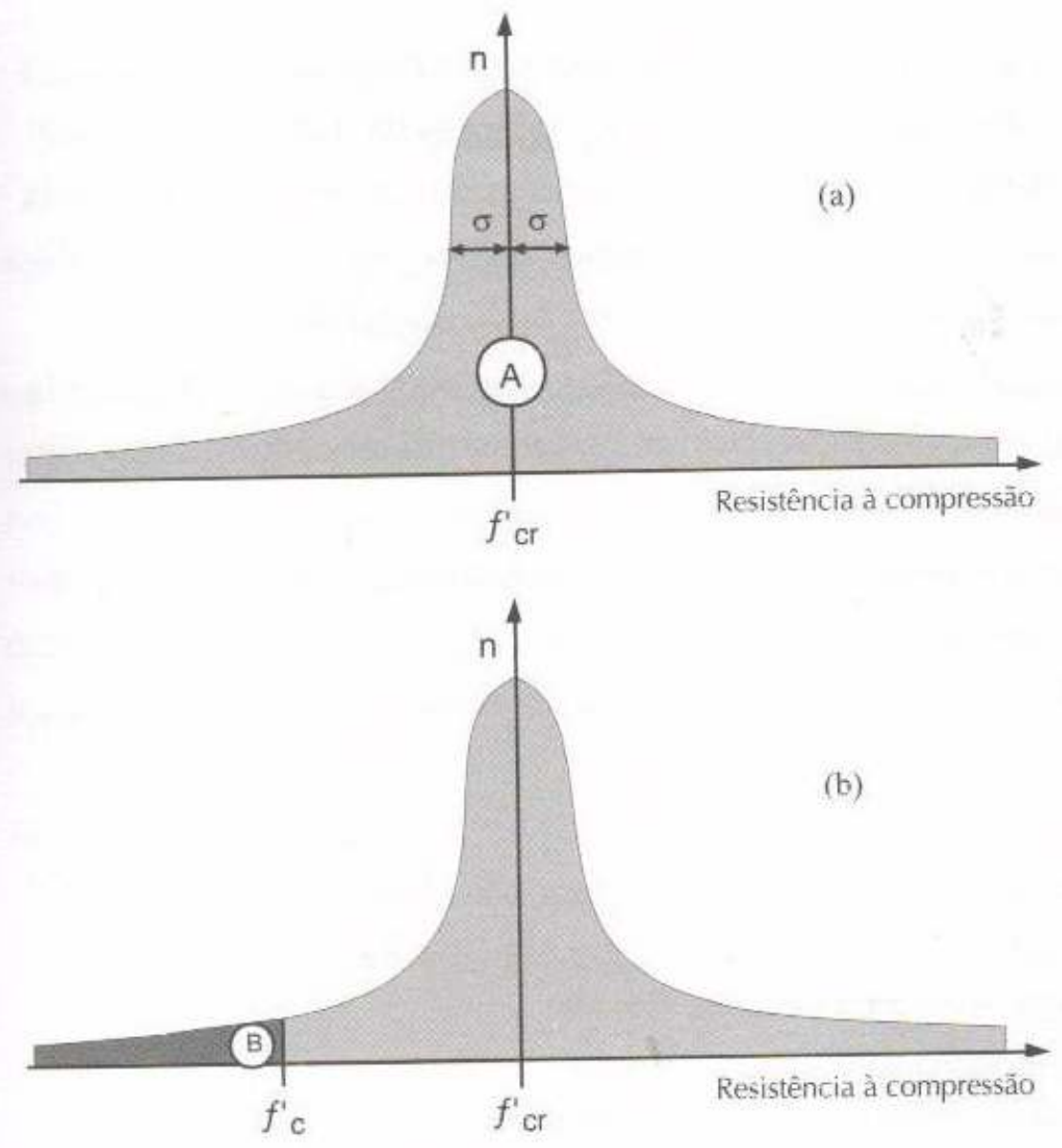

Figura 4.3 - Distribuição estatística dos resultados de resistência à compressão - AïTCIN (2000)

Assim, a discussão da aplicabilidade do conceito semiprobabilístico aos resultados de módulo de deformação foi realizada sobre o controle de qualidade realizado numa central de concreto, simulando-se o fornecimento de concreto para atendimento ao módulo de deformação especificado, atrelado a uma resistência característica $\left(f_{\mathrm{ck}}\right)$ fornecida.

Também foi avaliado o impacto da variabilidade do resultado no controle tecnológico em obra, onde foram verificados concretos de resistência característica, $f_{c k}$, igual a $30 \mathrm{MPa}$, fornecidos para obras distintas na região da Grande São Paulo (segunda etapa). 


\subsection{Programa experimental}

Para a realização da parte experimental foram utilizadas as instalações do Laboratório do Centro Tecnológico da Holcim (Brasil).

O programa experimental foi constituído de realização de dosagens de dois traços de concreto para produção de diferentes resistências características $\left(f_{c k}\right)$ iguais a 25 e $30 \mathrm{MPa}$, de consistência igual a $120 \pm 20 \mathrm{~mm}$, com materiais coletados três vezes por semana em uma central de concreto pelo período de nove meses. Para cada dosagem foram moldados 8 corpos de prova de dimensões $100 \times 200 \mathrm{~mm}$, sendo mantidos em câmara úmida por 28 dias. Após esse período receberam capeamento com pasta de enxofre para em seguida serem ensaiados de acordo com a ABNT NBR 8522 (2008). Os resultados para determinação prévia da resistência à compressão foram realizados em dois corpos de prova e os outros seis ensaiados para determinação do módulo de deformação do concreto.

Conforme dito anteriormente, os ensaios para determinação do módulo de deformação do concreto foram realizados sob a instrumentação clip gage, em função da baixa dispersão dos resultados. Foi utilizado o plano de carregamento secante, conforme estabelecidos pela ABNT NBR 8522 (2008).

A ABNT NBR 6118 (2007) considera que o módulo de deformação a ser especificado em projeto e a ser controlado nas obras deve ser o módulo de deformação tangente inicial. Entretanto, recomenda a utilização do módulo de deformação secante no cálculo de esforços solicitantes e verificação de estados limites de serviço dos elementos estruturais da edificação.

MONTIJA (2007) ressaltou que a determinação do módulo de deformação tangente inicial tem plano de carregamento com solicitação de $30 \%$ da resistência à compressão do concreto e provavelmente por questão cultural vinculada ao hábito do cálculo estrutural, na prática do meio técnico nacional prevalece a especificação e o controle do módulo de deformação secante, geralmente a $40 \%$ da resistência do concreto.

Assim, no presente estudo, foi realizado o plano de carregamento secante a uma tensão de $40 \%$ da carga de ruptura. 


\subsubsection{Materiais constituintes do concreto utilizados na pesquisa}

\subsubsection{Cimento}

$\mathrm{O}$ cimento utilizado na pesquisa foi o CP $\vee$ ARI RS fabricado pela Holcim Brasil comumente usado no mercado de São Paulo para concreto dosado em central. O cimento foi coletado três vezes por semana no período de nove meses para produção do concreto em laboratório. Importante salientar que esta caracterização é uma média atualizada com dados do controle tecnológico de produção da fábrica durante o período analisado.

A caracterização físico-mecânica do cimento utilizado consta da Tabela 4.1 e a caracterização química da Tabela 4.2.

Tabela 4.1 - Características físicas e mecânicas do cimento CP V ARI RS

\begin{tabular}{|c|c|c|c|}
\hline ENSAIO & NORMA & \multicolumn{2}{|c|}{ RESULTADOS } \\
\hline Finura - Resíduo na peneira $75 \mathrm{~mm} \mathrm{( \% )}$ & NBR 11579/1991 & \multicolumn{2}{|c|}{0,2} \\
\hline Massa específica $\left(\mathrm{g} / \mathrm{cm}^{3}\right)$ & NBR NM 23/2001 & \multicolumn{2}{|c|}{3,03} \\
\hline Área específica $\left(\mathrm{cm}^{2} / \mathrm{g}\right)$ & NBR NM 76/1998 & \multicolumn{2}{|c|}{4400} \\
\hline Água da pasta de consistência normal (\%) & NBR NM 43/2003 & \multicolumn{2}{|c|}{29,8} \\
\hline \multirow{3}{*}{\begin{tabular}{lc} 
Tempos de pega (h:min) & início \\
\cline { 2 - 2 }
\end{tabular}} & \multirow{2}{*}{ NM 65/2003 } & \multicolumn{2}{|c|}{ 03:15 } \\
\hline & & \multicolumn{2}{|c|}{$04: 30$} \\
\hline & \multirow{4}{*}{ NBR 7215/1997 } & 1 dia & 16,4 \\
\hline \multirow{3}{*}{ Resistência à Compressão (MPa) } & & 3 dias & 32,5 \\
\hline & & 7 dias & 41,2 \\
\hline & & 28 dias & 50,4 \\
\hline
\end{tabular}

Tabela 4.2 - Características químicas do cimento CP V ARI RS

\begin{tabular}{lccc}
\hline \multicolumn{1}{c}{ ENSAIOS } & NORMA & RESULTADOS & $\begin{array}{c}\text { Limites da } \\
\text { NBR 5737/1992 }\end{array}$ \\
\hline Perda ao fogo - PF & NBR NM 18/2004 & 3,64 & $\leq 4,5 \%$ \\
\hline Óxido de magnésio $-\mathrm{MgO}$ & NBR NM 11-2/2004 & 2,11 & $\leq 6,5 \%$ \\
\hline Anidrido sulfúrico - $\mathrm{SO}_{3}$ & NBR NM 16/2004 & 2,04 & $\leq 4,5 \%$ \\
\hline Anidrido carbônico $-\mathrm{CO}_{2}$ & NBR NM 20/2004 & 3,24 & $\leq 3,0 \%$ \\
\hline
\end{tabular}

\subsubsection{Agregados miúdos}

Foram utilizados dois tipos de agregados miúdos na elaboração dos concretos. Uma areia de origem natural quartzosa e outra de origem artificial granítica, na proporção de $25 \%$ e $75 \%$ respectivamente. Também no caso dos 
agregados miúdos, foram amostrados três vezes por semana, em função da periodicidade de fornecimento.

Os ensaios de caracterização são mostrados na Tabela 4.3. Foram realizados ensaios de caracterização semanais, para verificar alteração das características dos mesmos quanto à granulometria e ao material pulverulento. Esses resultados são apresentados no Capítulo 5.

Tabela 4.3 - Caracterização do agregado miúdo - Areia quartzosa

\begin{tabular}{ccc}
\hline Ensaio & Resultados & Norma \\
\hline Massa específica $\left(\mathrm{kg} / \mathrm{dm}^{3}\right)$ & 2,62 & NM 52 \\
\hline Massa unitária $\left(\mathrm{kg} / \mathrm{dm}^{3}\right)$ & 1,43 & NBR 7251 \\
\hline Dimensão máxima $(\mathrm{mm})$ & 0,6 & NM 248 \\
\hline Módulo de finura & 1,26 & NM 248 \\
\hline Material pulverulento $(\%)$ & 1,71 & NBR 7219 \\
\hline Teor de argila (\%) & 0 & NBR 7218
\end{tabular}

Tabela 4.4 - Caracterização do agregado miúdo - Areia artificial granítica

\begin{tabular}{ccc}
\hline Ensaio & Resultados & Norma \\
\hline Massa específica $\left(\mathrm{kg} / \mathrm{dm}^{3}\right)$ & 2,68 & NM 52 \\
\hline Massa unitária $\left(\mathrm{kg} / \mathrm{dm}^{3}\right)$ & 1,64 & NBR 7251 \\
\hline Dimensão máxima $(\mathrm{mm})$ & 4,8 & NM 248 \\
\hline Módulo de finura & 2,55 & NM 248 \\
\hline Material pulverulento $(\%)$ & 8,58 & NBR 7219 \\
\hline Teor de argila & - & NBR 7218
\end{tabular}

\subsubsection{Agregados graúdos}

$\mathrm{Na}$ elaboração dos concretos estudados, foram utilizados agregados graúdos na composição de brita 0 e brita 1 de origem granítica, na proporção de 30\% e 70\% respectivamente.

A caracterização inicial dos agregados graúdos encontra-se nas Tabelas 4.5 e 4.6. Tal qual para os agregados miúdos, foram realizados ensaios de caracterização semanais, para verificar alteração das características dos mesmos quanto à granulometria e ao material pulverulento. Esses resultados são apresentados no Capítulo 5. 
Tabela 4.5 - Caracterização do agregado graúdo - Brita 0

\begin{tabular}{lcc}
\hline \multicolumn{1}{c}{ Ensaio } & Resultados & Norma \\
\hline Massa específica $\left(\mathrm{kg} / \mathrm{dm}^{3}\right)$ & 2,70 & NM 52 \\
\hline Massa unitária $\left(\mathrm{kg} / \mathrm{dm}^{3}\right)$ & 1,44 & NBR 7251 \\
\hline Dimensão máxima $(\mathrm{mm})$ & 12,5 & NM 248 \\
\hline Módulo de finura & 5,99 & NM 248 \\
\hline Absorção $(\%)$ & 1,0 & NBR 9777 \\
\hline Material pulverulento $(\%)$ & 0,92 & NBR 7219 \\
\hline Teor de argila (\%) & - & NBR 7218 \\
\hline
\end{tabular}

Tabela 4.6 - Caracterização do agregado graúdo - Brita 1

\begin{tabular}{lcc}
\hline \multicolumn{1}{c}{ Ensaio } & Resultados & Norma \\
\hline Massa específica $\left(\mathrm{kg} / \mathrm{dm}^{3}\right)$ & 2,70 & NM 52 \\
\hline Massa unitária $\left(\mathrm{kg} / \mathrm{dm}^{3}\right)$ & 1,45 & NBR 7251 \\
\hline Dimensão máxima $(\mathrm{mm})$ & 25,0 & NM 248 \\
\hline Módulo de finura & 6,96 & NM 248 \\
\hline Absorção $(\%)$ & 1,1 & NBR 9777 \\
\hline Material pulverulento $(\%)$ & 0,34 & NBR 7219 \\
\hline Teor de argila (\%) & - & NBR 7218 \\
\hline
\end{tabular}




\subsubsection{Aditivo}

Foi utilizado aditivo à base de lignina sulfonada, MC Bauchemie FK 100 B, plastificante polifuncional de pega normal. As características fornecidas pelo fabricante são mostradas na tabela 4.7.

Tabela 4.7 - Características do aditivo

\begin{tabular}{cc}
\hline Característica & Resultados \\
\hline Aspecto & Líquido \\
\hline Densidade $\left(\mathrm{g} / \mathrm{cm}^{3}\right)$ & 1,085 a 1,125 \\
\hline $\mathrm{pH}$ & 7 a 9 \\
\hline Base química & Lignina sulfonada \\
\hline Sólidos $(\%)$ & 25,5 a 27,5 \\
\hline Cor & Castanho escuro \\
\hline
\end{tabular}

\subsubsection{5. Água}

A água utilizada foi fornecida pela concessionária local (SABESP), apresentando-se dentro dos limites normais de potabilidade.

\subsubsection{Dosagem do concreto}

\subsubsection{Primeira etapa}

Os concretos analisados foram especificados segundo demanda das centrais dosadoras de concreto na cidade de São Paulo. Assim, optou-se por realizar os ensaios em concretos com resistências características nominais, $\mathrm{f}_{\mathrm{ck}}$, de 25 e $30 \mathrm{MPa}$, e consistência de $120+20 \mathrm{~mm}$ que permitisse o bombeamento.

A denominação de cada dosagem é função da resistência característica (C25 e C30).

Os traços dos concretos encontram-se na Tabela 4.8. 
Tabela 4.8 - Traços de concreto

\begin{tabular}{cccccccccc}
\hline $\begin{array}{c}\text { fck } \\
(\mathbf{M P a})\end{array}$ & Identificação & $\begin{array}{c}\text { Relação } \\
\text { a/c }\end{array}$ & $\begin{array}{c}\text { Cimento } \\
\left(\mathbf{k g} / \mathbf{m}^{3}\right)\end{array}$ & $\begin{array}{c}\text { Água } \\
\left(\mathbf{l} / \mathbf{m}^{3}\right)\end{array}$ & $\begin{array}{c}\text { Argamassa } \\
\mathbf{s e c a}(\%)\end{array}$ & $\begin{array}{c}\text { Areia } \\
\text { de } \\
\text { quartzo } \\
\left(\mathbf{k g} / \mathbf{m}^{3}\right)\end{array}$ & $\begin{array}{c}\text { Areia } \\
\text { artificial } \\
\left(\mathbf{k g} / \mathbf{m}^{3}\right)\end{array}$ & $\begin{array}{c}\text { Brita 0 } \\
\left(\mathbf{k g} / \mathbf{m}^{3}\right)\end{array}$ & $\begin{array}{c}\text { Brita 1 } \\
\left(\mathbf{k g} / \mathbf{m}^{3}\right)\end{array}$ \\
\hline $\mathbf{2 5 , 0}$ & $\mathrm{C} 25$ & 0,694 & 265 & 184 & 52,0 & 217 & 664 & 307 & 713 \\
\hline $\mathbf{3 0 , 0}$ & $\mathrm{C} 30$ & 0,610 & 295 & 180 & 52,6 & 210 & 641 & 311 & 723 \\
\hline
\end{tabular}

\subsubsection{Segunda etapa}

Como forma de complementar o estudo realizado em laboratório, foram analisados concretos fornecidos a diferentes obras na região da Grande São Paulo. Do concreto fornecido a cada obra foram moldados 5 corpos de prova adicionais ao controle tecnológico normalmente empregado para a resistência à compressão, para que fossem realizados os ensaios para determinação do módulo de deformação secante, $E_{c s}$. Optou-se por realizar esta parte do estudo com o $f_{c k}$ nominal de $30 \mathrm{MPa}$, em função da demanda maior por este $\mathrm{f}_{\mathrm{ck}}$ nesta região. Os concretos foram moldados com os mesmos materiais da primeira etapa, uma vez que provêm da mesma central de concreto.

A seguir são apresentados os resultados dos ensaios de determinação do módulo estático de deformação dos concretos dosados no programa experimental e a análise realizada de acordo com a metodologia descrita. 


\section{APRESENTAÇÃO E ANÁLISE DOS RESULTADOS OBTIDOS}

O propósito do presente capítulo é apresentar e analisar os resultados dos ensaios das propriedades mecânicas dos diversos concretos fabricados tanto em laboratório (primeira etapa) quanto em obra (segunda etapa). Inicialmente, foram analisados os resultados de resistência à compressão e módulo de deformação secante dos concretos produzidos, apresentando os dados encontrados por meio de análises estatísticas. Em seguida é feita uma análise comparativa dos resultados obtidos em relação às prescrições normativas (NBR 6118/2007, ACl 318/2005, EUROCODE 2/2004 e CEB 1990) quanto a resistência à compressão e módulo de deformação, bem como às equações que relacionam estas duas propriedades. Finalmente, a discussão sobre a possibilidade de aplicação do conceito semiprobabilístico normativo aos resultados de controle experimental do concreto.

Como objetivo complementar, a propriedade do módulo de deformação também será interpretada de maneira a ampliar a discussão sobre a possibilidade de aplicação do conceito semiprobabilístico normativo aos resultados de controle experimental do concreto.

\subsection{Primeira etapa}

Aqui são apresentados os resultados dos ensaios laboratoriais para determinação do módulo de deformação dos concretos de resistências características $\left(f_{c k}\right)$ iguais a 25 e $30 \mathrm{MPa}$, obtidos no período estudado. Como o objetivo do presente trabalho foi verificar a variabilidade do módulo de deformação do concreto, os traços de concreto foram fixados de forma a apresentar a mesma trabalhabilidade e o mesmo desempenho no estado endurecido.

\subsubsection{Análise dos agregados}

Os resultados dos ensaios de caracterização dos agregados utilizados na pesquisa ao longo dos meses são apresentados nas Tabelas 5.1 a 5.4. As Figuras 5.1 e 5.2 ilustram a variação da granulometria dos agregados miúdos utilizados na pesquisa e a Figura 5.3 ilustra a composição dos agregados miúdos na proporção de $25 \%$ de areia natural de quartzo e $75 \%$ de areia artificial granítica. As Figuras 5.4 
e 5.5 mostram a variação da granulometria dos agregados graúdos de origem granítica utilizados elaboração dos concretos estudados, assim como na Figura 5.6 é mostrada a composição dos agregados graúdos, na proporção de $30 \%$ Brita 0 e $70 \%$ Brita 1. Optou-se por ilustrar a composição dos agregados, aproveitando-se o conceito de agregado total, tal qual exposto na ABNT NBR 7211 (2009).

Tabela 5.1 - Caracterização dos agregados - AREIA DE QUARTZO

\begin{tabular}{|c|c|c|c|c|c|c|c|c|c|c|}
\hline \multicolumn{2}{|c|}{ PENEIRAS } & \multicolumn{9}{|c|}{$\%$ PASSANTE } \\
\hline $\mathbf{N}^{\circ}$ & $\begin{array}{l}\text { ABERTURA } \\
(\mathrm{mm})\end{array}$ & MÊS 1 & MÊS 2 & MÊS 3 & MÊS 4 & MÊS 5 & MÊS 6 & MÊS 7 & MÊS 8 & MÊS 9 \\
\hline 3 & 76 & 100,0 & 100,0 & 100,0 & 100,0 & 100,0 & 100,0 & 100,0 & 100,0 & 100,0 \\
\hline $2 / 1 / 2$ & (64) & 100,0 & 100,0 & 100,0 & 100,0 & 100,0 & 100,0 & 100,0 & 100,0 & 100,0 \\
\hline 2 & (50) & 100,0 & 100,0 & 100,0 & 100,0 & 100,0 & 100,0 & 100,0 & 100,0 & 100,0 \\
\hline $11 / 2$ & 38 & 100,0 & 100,0 & 100,0 & 100,0 & 100,0 & 100,0 & 100,0 & 100,0 & 100,0 \\
\hline $11 / 4$ & (32) & 100,0 & 100,0 & 100,0 & 100,0 & 100,0 & 100,0 & 100,0 & 100,0 & 100,0 \\
\hline 1 & (25) & 100,0 & 100,0 & 100,0 & 100,0 & 100,0 & 100,0 & 100,0 & 100,0 & 100,0 \\
\hline $3 / 4$ & 19 & 100,0 & 100,0 & 100,0 & 100,0 & 100,0 & 100,0 & 100,0 & 100,0 & 100,0 \\
\hline $1 / 2$ & $(12,5)$ & 100,0 & 100,0 & 100,0 & 100,0 & 100,0 & 100,0 & 100,0 & 100,0 & 100,0 \\
\hline $3 / 8$ & 9,5 & 100,0 & 100,0 & 100,0 & 100,0 & 100,0 & 100,0 & 100,0 & 100,0 & 100,0 \\
\hline $1 / 4$ & $(6,3)$ & 100,0 & 100,0 & 100,0 & 100,0 & 100,0 & 100,0 & 100,0 & 100,0 & 100,0 \\
\hline 4 & 4,8 & 100,0 & 100,0 & 100,0 & 100,0 & 100,0 & 100,0 & 100,0 & 100,0 & 100,0 \\
\hline 8 & 2,4 & 100,0 & 100,0 & 100,0 & 100,0 & 100,0 & 100,0 & 100,0 & 100,0 & 100,0 \\
\hline 16 & 1,2 & 99,6 & 99,5 & 99,7 & 99,8 & 100,0 & 99,8 & 99,0 & 99,0 & 99,7 \\
\hline 30 & 0,6 & 95,0 & 95,3 & 93,7 & 94,3 & 98,0 & 92,7 & 94,4 & 94,4 & 92,6 \\
\hline 50 & 0,3 & 63,7 & 65,5 & 57,7 & 53,1 & 75,3 & 58,1 & 71,5 & 71,5 & 67,7 \\
\hline 100 & 0,15 & 15,5 & 22,1 & 15,2 & 12,9 & 17,3 & 16,9 & 22,0 & 22,0 & 17,4 \\
\hline 200 & $(0,075)$ & 1,7 & 3,8 & 1,7 & 1,8 & 1,5 & 2,5 & 2,4 & 2,4 & 2,1 \\
\hline \multicolumn{2}{|c|}{$\begin{array}{c}\text { MÓDULO DE FINURA } \\
\text { NBR } 7217\end{array}$} & 1,26 & 1,18 & 1,34 & 1,40 & 1,09 & 1,33 & 1,13 & 1,13 & 1,22 \\
\hline \multicolumn{2}{|c|}{$\begin{array}{c}\text { DIMENSÃO MÁXIMA } \\
\text { NBR } 7217 \\
\end{array}$} & 0,6 & 0,6 & 1,2 & 1,2 & 0,6 & 1,2 & 1,2 & 1,2 & 1,2 \\
\hline \multicolumn{2}{|c|}{$\begin{array}{l}\text { MASSA ESPECíFICA } \\
\text { NBR } 9776\end{array}$} & 2,62 & 2,64 & 2,61 & 2,63 & 2,63 & 2,63 & 2,64 & 2,65 & 2,64 \\
\hline \multicolumn{2}{|c|}{$\begin{array}{l}\text { MASSA UNITÁRIA SECA } \\
\text { NBR } 7251\end{array}$} & 1,430 & 1,377 & 1,487 & 1,450 & 1,437 & 1,434 & 1,48 & 1,44 & 1,48 \\
\hline \multicolumn{2}{|c|}{$\begin{array}{c}\text { MATERIAL PULVERULENTO } \\
\text { NBR } 7211\end{array}$} & 1,7 & 1,9 & 3,8 & 1,7 & 1,8 & 1,5 & 1,9 & 2,4 & 2,0 \\
\hline
\end{tabular}




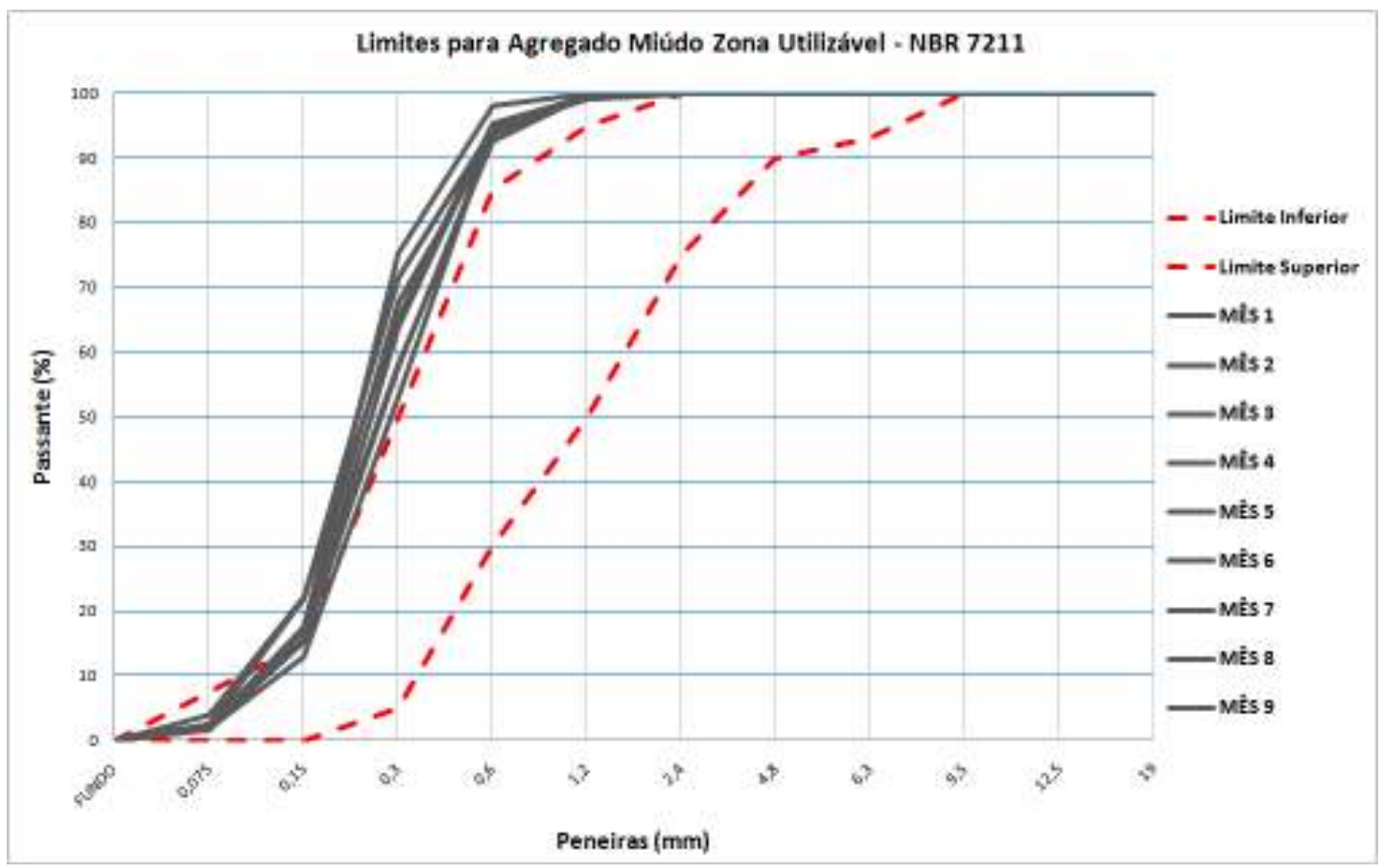

Figura 5.1 - Curvas granulométricas - Areia de quartzo

Tabela 5.2 - Caracterização dos agregados - AREIA ARTIFICIAL GRANÍTICA

\begin{tabular}{|c|c|c|c|c|c|c|c|c|c|c|}
\hline \multicolumn{2}{|c|}{ PENEIRAS } & \multicolumn{9}{|c|}{$\%$ PASSANTE } \\
\hline $\mathbf{N}^{\circ}$ & $\begin{array}{l}\text { ABERTURA } \\
(\mathrm{mm})\end{array}$ & MÊS 1 & MÊS 2 & MÊS 3 & MÊS 4 & MÊS 5 & MÊS 6 & MÊS 7 & MÊS 8 & MÊS 9 \\
\hline 3 & 76 & 100,0 & 100,0 & 100,0 & 100,0 & 100,0 & 100,0 & 100,0 & 100,0 & 100,0 \\
\hline $2 / 1 / 2$ & (64) & 100,0 & 100,0 & 100,0 & 100,0 & 100,0 & 100,0 & 100,0 & 100,0 & 100,0 \\
\hline 2 & (50) & 100,0 & 100,0 & 100,0 & 100,0 & 100,0 & 100,0 & 100,0 & 100,0 & 100,0 \\
\hline $11 / 2$ & 38 & 100,0 & 100,0 & 100,0 & 100,0 & 100,0 & 100,0 & 100,0 & 100,0 & 100,0 \\
\hline $11 / 4$ & (32) & 100,0 & 100,0 & 100,0 & 100,0 & 100,0 & 100,0 & 100,0 & 100,0 & 100,0 \\
\hline 1 & $(25)$ & 100,0 & 100,0 & 100,0 & 100,0 & 100,0 & 100,0 & 100,0 & 100,0 & 100,0 \\
\hline $3 / 4$ & 19 & 100,0 & 100,0 & 100,0 & 100,0 & 100,0 & 100,0 & 100,0 & 100,0 & 100,0 \\
\hline $1 / 2$ & $(12,5)$ & 100,0 & 100,0 & 100,0 & 100,0 & 100,0 & 100,0 & 100,0 & 100,0 & 100,0 \\
\hline $3 / 8$ & 9,5 & 100,0 & 100,0 & 100,0 & 100,0 & 100,0 & 100,0 & 100,0 & 100,0 & 100,0 \\
\hline $1 / 4$ & $(6,3)$ & 100,0 & 100,0 & 100,0 & 100,0 & 100,0 & 100,0 & 100,0 & 100,0 & 100,0 \\
\hline 4 & 4,8 & 97,3 & 98,2 & 97,9 & 96,4 & 97,6 & 96,8 & 96,8 & 97,3 & 97,3 \\
\hline 8 & 2,4 & 75,5 & 77,6 & 75,8 & 73,2 & 76,7 & 77,0 & 77,0 & 75,5 & 75,5 \\
\hline 16 & 1,2 & 55,5 & 56,3 & 56,4 & 54,1 & 58,2 & 59,7 & 59,7 & 55,5 & 55,5 \\
\hline 30 & 0,6 & 43,2 & 43,7 & 44,0 & 41,6 & 45,3 & 47,5 & 47,5 & 43,2 & 43,2 \\
\hline 50 & 0,3 & 34,5 & 34,3 & 34,9 & 32,7 & 35,7 & 36,5 & 36,5 & 34,5 & 34,5 \\
\hline 100 & 0,15 & 26,1 & 26,0 & 26,2 & 24,5 & 26,5 & 27,2 & 27,2 & 26,1 & 26,1 \\
\hline 200 & $(0,075)$ & 16,3 & 16,9 & 16,1 & 15,5 & 16,3 & 16,8 & 16,8 & 16,3 & 16,3 \\
\hline \multicolumn{2}{|c|}{$\begin{array}{c}\text { MÓDULO DE FINURA } \\
\text { NBR } 7217\end{array}$} & 2,68 & 2,64 & 2,65 & 2,77 & 2,60 & 2,55 & 2,55 & 2,68 & 2,68 \\
\hline \multicolumn{2}{|c|}{$\begin{array}{c}\text { DIMENSÃO MÁXIMA } \\
\text { NBR } 7217\end{array}$} & 4,8 & 4,8 & 4,8 & 4,8 & 4,8 & 4,8 & 4,8 & 4,8 & 4,8 \\
\hline \multicolumn{2}{|c|}{$\begin{array}{c}\text { MASSA ESPECÍFICA } \\
\text { NBR } 9776\end{array}$} & 2,680 & 2,655 & 2,680 & 2,650 & 2,673 & 2,684 & 2,680 & 2,668 & 2,656 \\
\hline \multicolumn{2}{|c|}{$\begin{array}{c}\text { MASSA UNITÁRIA SECA } \\
\text { NBR } 7251\end{array}$} & 1,537 & 1,610 & 1,650 & 1,622 & 1,573 & 1,640 & 1,537 & 1,549 & 1,619 \\
\hline \multicolumn{2}{|c|}{$\begin{array}{l}\text { MATERIAL PULVERULENTO } \\
\text { NBR } 7211\end{array}$} & 16,3 & 16,9 & 16,2 & 15,5 & 16,3 & 16,8 & 16,3 & 14,5 & 16,9 \\
\hline
\end{tabular}




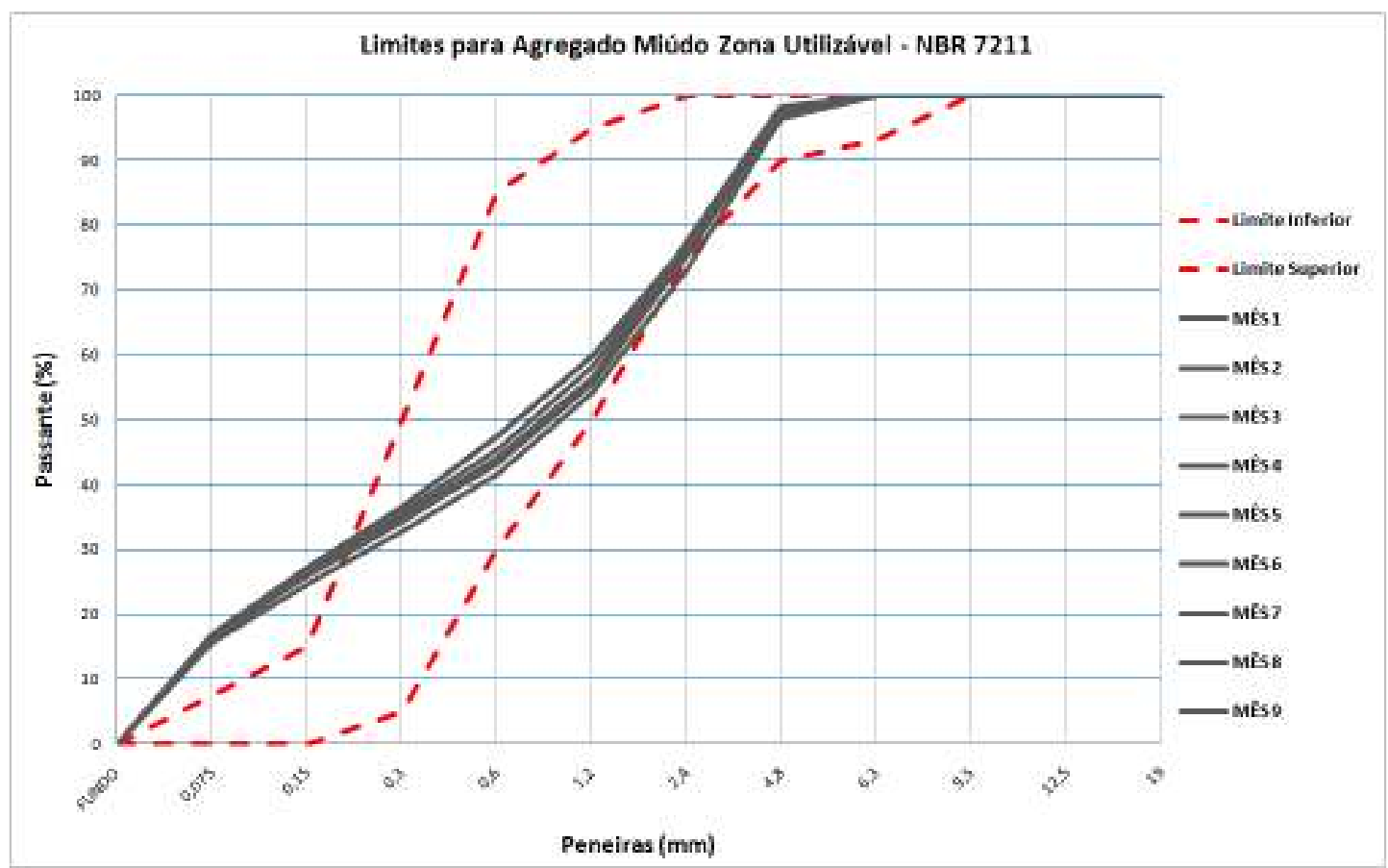

Figura 5.2 - Curvas granulométricas - Areia artificial granítica

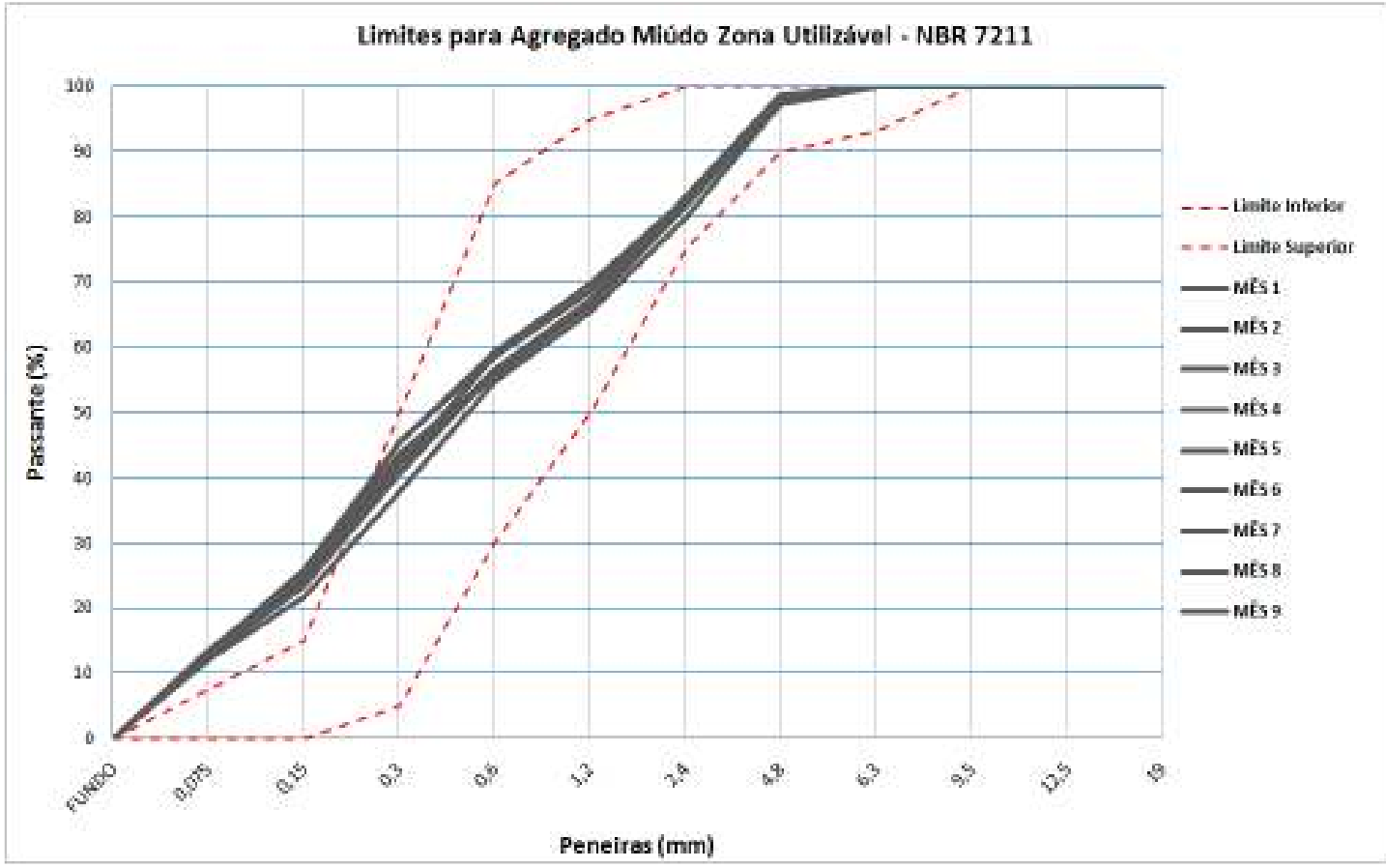

Figura 5.3 - Curvas granulométricas - Agregado miúdo composto 
Tabela 5.3 - Caracterização dos agregados - BRITA 0 GRANÍTICA

\begin{tabular}{|c|c|c|c|c|c|c|c|c|c|c|}
\hline \multicolumn{2}{|c|}{ PENEIRAS } & \multicolumn{9}{|c|}{$\%$ PASSANTE } \\
\hline $\mathbf{N}^{\circ}$ & $\begin{array}{l}\text { ABERTURA } \\
(\mathbf{m m})\end{array}$ & MÊS 1 & MÊS 2 & MÊS 3 & MÊS 4 & MÊS 5 & MÊS 6 & MÊS 7 & MÊS 8 & MÊS 9 \\
\hline 3 & 76 & 100,0 & 100,0 & 100,0 & 100,0 & 100,0 & 100,0 & 100,0 & 100,0 & 100,0 \\
\hline $2 / 1 / 2$ & (64) & 100,0 & 100,0 & 100,0 & 100,0 & 100,0 & 100,0 & 100,0 & 100,0 & 100,0 \\
\hline 2 & (50) & 100,0 & 100,0 & 100,0 & 100,0 & 100,0 & 100,0 & 100,0 & 100,0 & 100,0 \\
\hline $11 / 2$ & 38 & 100,0 & 100,0 & 100,0 & 100,0 & 100,0 & 100,0 & 100,0 & 100,0 & 100,0 \\
\hline $11 / 4$ & (32) & 100,0 & 100,0 & 100,0 & 100,0 & 100,0 & 100,0 & 100,0 & 100,0 & 100,0 \\
\hline 1 & (25) & 100,0 & 100,0 & 100,0 & 100,0 & 100,0 & 100,0 & 100,0 & 100,0 & 100,0 \\
\hline $3 / 4$ & 19 & 100,0 & 100,0 & 100,0 & 100,0 & 100,0 & 100,0 & 100,0 & 100,0 & 100,0 \\
\hline $1 / 2$ & $(12,5)$ & 97,7 & 98,9 & 98,5 & 99,3 & 100,0 & 98,5 & 99,3 & 93,5 & 95,1 \\
\hline $3 / 8$ & 9,5 & 77,6 & 80,7 & 72,5 & 80,2 & 98,5 & 72,5 & 86,7 & 58,9 & 60,3 \\
\hline $1 / 4$ & $(6,3)$ & 28,9 & 32,1 & 21,1 & 29,3 & 48,4 & 21,1 & 33,7 & 14,5 & 16,1 \\
\hline 4 & 4,8 & 9,8 & 10,2 & 6,4 & 10,1 & 18,3 & 6,4 & 11,5 & 4,4 & 5,6 \\
\hline 8 & 2,4 & 2,5 & 1,5 & 1,2 & 1,6 & 2,8 & 1,2 & 0,9 & 2,0 & 3,2 \\
\hline 16 & 1,2 & 1,8 & 0,8 & 1,1 & 1,2 & 1,2 & 1,1 & 0,6 & 2,0 & 3,0 \\
\hline 30 & 0,6 & 1,5 & 0,8 & 1,1 & 1,2 & 0,7 & 1,1 & 0,6 & 2,0 & 3,0 \\
\hline 50 & 0,3 & 1,4 & 0,7 & 1,1 & 1,2 & 0,5 & 1,1 & 0,6 & 2,0 & 3,0 \\
\hline 100 & 0,15 & 1,3 & 0,7 & 1,1 & 1,2 & 0,4 & 1,0 & 0,6 & 2,0 & 3,0 \\
\hline 200 & $(0,075)$ & 1,0 & 0,6 & 0,9 & 0,9 & 0,3 & 0,9 & 0,4 & 1,3 & 1,8 \\
\hline \multicolumn{2}{|c|}{$\begin{array}{l}\text { MÓDULO DE FINURA } \\
\text { NBR } 7217\end{array}$} & 6,04 & 6,04 & 6,16 & 6,03 & 5,78 & 6,16 & 5,61 & 5,99 & 5,38 \\
\hline \multicolumn{2}{|c|}{$\begin{array}{l}\text { DIMENSÃO MÁXIMA } \\
\text { NBR } 7217 \\
\end{array}$} & 12,5 & 12,5 & 12,5 & 12,5 & 9,5 & 12,5 & 9,5 & 12,5 & 12,5 \\
\hline \multicolumn{2}{|c|}{$\begin{array}{l}\text { MASSA ESPECíFICA } \\
\text { NBR } 9776\end{array}$} & 2,68 & 2,69 & 2,69 & 2,70 & 2,69 & 2,69 & 2,70 & 2,69 & 2,68 \\
\hline \multicolumn{2}{|c|}{$\begin{array}{l}\text { MASSA UNITÁRIA SECA } \\
\text { NBR } 7251\end{array}$} & 1,46 & 1,44 & 1,42 & 1,42 & 1,37 & 1,41 & 1,44 & 1,44 & 1,45 \\
\hline \multicolumn{2}{|c|}{$\begin{array}{l}\text { MATERIAL PULVERULENTO } \\
\text { NBR } 7211\end{array}$} & 1,00 & 0,60 & 0,90 & 0,92 & 0,26 & 0,50 & 0,38 & 1,27 & 1,79 \\
\hline
\end{tabular}

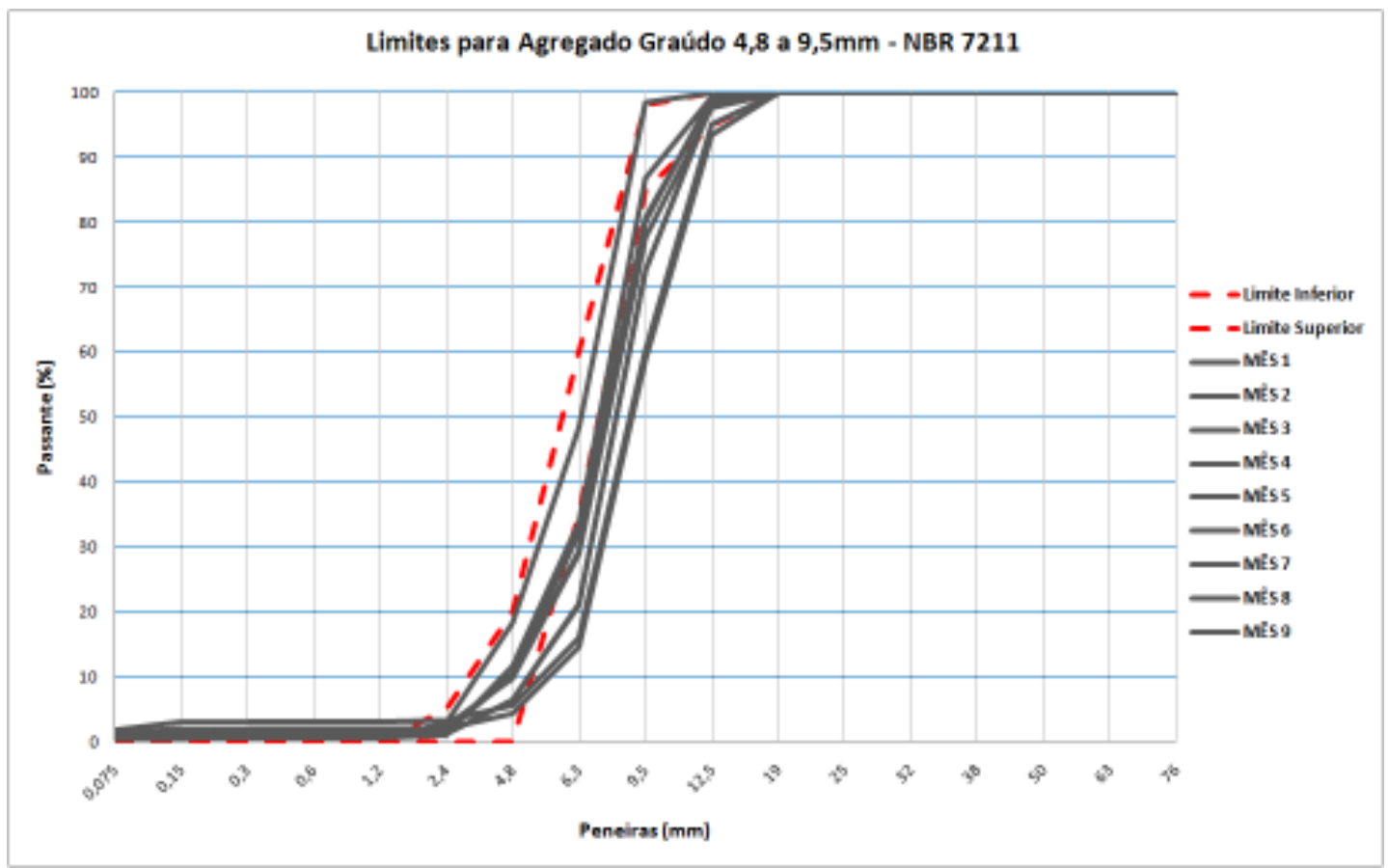

Figura 5.4 - Curvas granulométricas - Brita 0 
Tabela 5.4 - Caracterização dos agregados - BRITA 1 GRANÍTICA

\begin{tabular}{|c|c|c|c|c|c|c|c|c|c|c|}
\hline \multicolumn{2}{|c|}{ PENEIRAS } & \multicolumn{9}{|c|}{$\%$ PASSANTE } \\
\hline $\mathbf{N}^{\circ}$ & $\begin{array}{l}\text { ABERTURA } \\
(\mathbf{m m})\end{array}$ & MÊS 1 & MÊS 2 & MÊS 3 & MÊS 4 & MÊS 5 & MÊS 6 & MÊS 7 & MÊS 8 & MÊS 9 \\
\hline 3 & 76 & 100,0 & 100,0 & 100,0 & 100,0 & 100,0 & 100,0 & 100,0 & 100,0 & 100,0 \\
\hline $2 / 1 / 2$ & (64) & 100,0 & 100,0 & 100,0 & 100,0 & 100,0 & 100,0 & 100,0 & 100,0 & 100,0 \\
\hline 2 & (50) & 100,0 & 100,0 & 100,0 & 100,0 & 100,0 & 100,0 & 100,0 & 100,0 & 100,0 \\
\hline $11 / 2$ & 38 & 100,0 & 100,0 & 100,0 & 100,0 & 100,0 & 100,0 & 100,0 & 100,0 & 100,0 \\
\hline $11 / 4$ & (32) & 100,0 & 100,0 & 100,0 & 100,0 & 100,0 & 100,0 & 100,0 & 100,0 & 100,0 \\
\hline 1 & (25) & 100,0 & 100,0 & 100,0 & 100,0 & 100,0 & 100,0 & 100,0 & 100,0 & 100,0 \\
\hline $3 / 4$ & 19 & 85,6 & 95,8 & 91,3 & 95,8 & 94,5 & 91,8 & 97,4 & 92,6 & 95,0 \\
\hline $1 / 2$ & $(12,5)$ & 11,5 & 40,5 & 14,1 & 29,1 & 31,0 & 18,6 & 50,1 & 32,2 & 40,1 \\
\hline $3 / 8$ & 9,5 & 2,5 & 9,4 & 2,1 & 6,6 & 8,0 & 3,5 & 15,5 & 8,7 & 12,2 \\
\hline $1 / 4$ & $(6,3)$ & 0,6 & 0,9 & 0,3 & 0,5 & 0,6 & 0,6 & 1,6 & 0,9 & 1,5 \\
\hline 4 & 4,8 & 0,4 & 0,4 & 0,2 & 0,2 & 0,3 & 0,4 & 0,4 & 0,4 & 0,6 \\
\hline 8 & 2,4 & 0,4 & 0,4 & 0,2 & 0,2 & 0,3 & 0,4 & 0,4 & 0,4 & 0,6 \\
\hline 16 & 1,2 & 0,4 & 0,4 & 0,2 & 0,2 & 0,3 & 0,4 & 0,4 & 0,4 & 0,6 \\
\hline 30 & 0,6 & 0,4 & 0,4 & 0,2 & 0,2 & 0,3 & 0,4 & 0,4 & 0,4 & 0,6 \\
\hline 50 & 0,3 & 0,4 & 0,4 & 0,2 & 0,2 & 0,3 & 0,4 & 0,4 & 0,4 & 0,6 \\
\hline 100 & 0,15 & 0,4 & 0,4 & 0,2 & 0,2 & 0,3 & 0,4 & 0,4 & 0,4 & 0,6 \\
\hline 200 & $(0,075)$ & 0,3 & 0,2 & 0,2 & 0,1 & 0,3 & 0,3 & 0,4 & 0,5 & 0,6 \\
\hline \multicolumn{2}{|c|}{$\begin{array}{l}\text { MÓDULO DE FINURA } \\
\text { NBR } 7217\end{array}$} & 6,95 & 6,88 & 6,97 & 6,92 & 6,90 & 6,94 & 6,82 & 6,89 & 6,84 \\
\hline \multicolumn{2}{|c|}{$\begin{array}{l}\text { DIMENSÃO MÁXIMA } \\
\text { NBR } 7217\end{array}$} & 25,0 & 19,0 & 25,0 & 19,0 & 25,0 & 25,0 & 19,0 & 25,0 & 19,0 \\
\hline \multicolumn{2}{|c|}{$\begin{array}{c}\text { MASSA ESPECíFICA } \\
\text { NBR } 9776\end{array}$} & 2,67 & 2,69 & 2,69 & 2,70 & 2,71 & 2,71 & 2,68 & 2,69 & 2,71 \\
\hline \multicolumn{2}{|c|}{$\begin{array}{c}\text { MASSA UNITÁRIA SECA } \\
\text { NBR } 7251 \\
\end{array}$} & 1,43 & 1,41 & 1,44 & 1,45 & 1,43 & 1,41 & 1,45 & 1,44 & 1,45 \\
\hline \multicolumn{2}{|c|}{$\begin{array}{l}\text { MATERIAL PULVERULENTO } \\
\text { NBR } 7211\end{array}$} & 0,33 & 0,20 & 0,17 & 0,14 & 0,30 & 0,34 & 0,41 & 0,17 & 0,53 \\
\hline
\end{tabular}

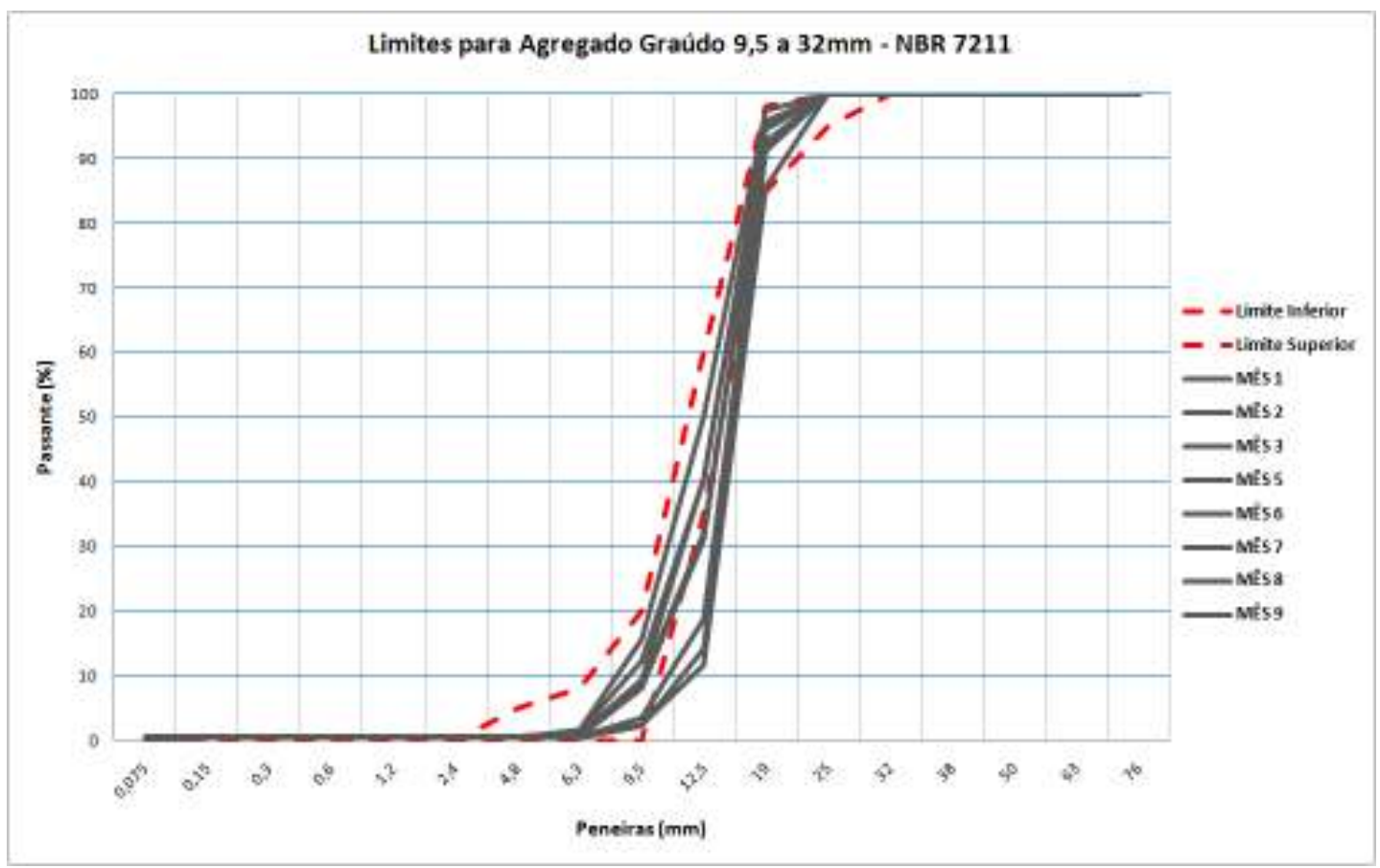

Figura 5.5 - Curvas granulométricas - Brita 1 


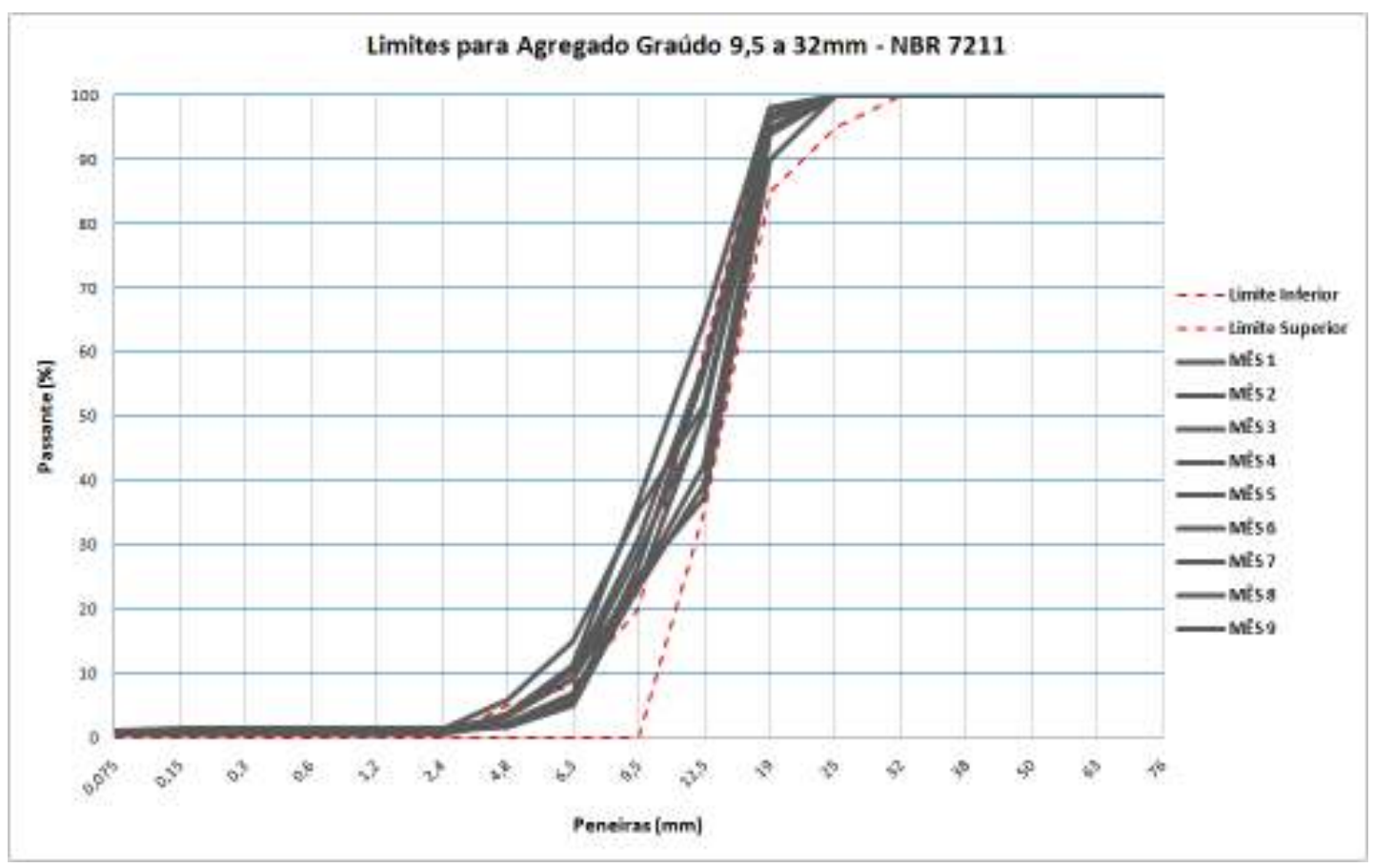

Figura 5.6 - Curvas granulométricas - Agregado graúdo composto

Com base nos resultados dos ensaios obtidos, pode-se observar que os agregados utilizados nos concretos utilizados na pesquisa ao longo dos meses não apresentaram variações significativas, pois foram obtidos de fornecedores credenciados e com o compromisso de manter as características aprovadas no momento do contrato de fornecimento. Isso contribui fundamentalmente para a menor variação do concreto durante o processo de produção,

\subsubsection{Avaliação da resistência à compressão dos concretos estudados}

Nas Tabelas 5.5 e 5.7 apresentam-se os resumos das análises estatísticas dos resultados de resistência à compressão obtidos para os $f_{\text {cks }}$ estudados $-f_{\text {cks }} 25 \mathrm{e}$ $30 \mathrm{MPa}$.

Para o estudo foram realizadas análises baseadas nos ensaios de resistência aos 28 dias de idade, envolvendo, para o $\mathrm{f}_{\mathrm{ck}} 25 \mathrm{MPa}, 274$ corpos de prova, e para o $\mathrm{f}_{\mathrm{ck}} 30 \mathrm{MPa}, 210$ corpos de prova. Foram considerados, neste caso, os valores de rompimento dos dois corpos de prova ensaiados em cada idade, sem desconsiderar 
o valor menor, conforme instruções da ABNT. Os resultados detalhados estão apresentados no Apêndice A, Tabelas A-1.a-c e A-2.a-b.

As Figuras 5.7 e 5.10 mostram a variação da resistência à compressão para os $\mathrm{f}_{\mathrm{cks}} 25 \mathrm{MPa}$ e $30 \mathrm{MPa}$, respectivamente, ao longo do período estudado.

Os dados analisados são dispostos na forma de uma tabela denominada distribuição de freqüências ou tabela de freqüências. Nessa tabela constam os intervalos de classes em que os dados foram subdivididos e as freqüências com que os dados apareceram dentro de cada um dos intervalos. As freqüências referentes a esses dados são apresentadas nas Tabelas 5.6 e 5.8 .

Através da tabela de freqüências puderam ser construídos os histogramas relativos a esses dados, expostos nas Figuras 5.8 e 5.11, que contêm as análises da distribuição de probabilidade Normal, em atendimento a NBR 12655 (ABNT, 2006). Como análise complementar, são apresentadas as Figuras 5.9 e 5.12 que ilustram a aderência à distribuição Normal dos resultados de resistência à compressão para os concretos estudados.

Tabela 5.5 - Resumo da análise estatística - $\mathrm{f}_{\mathrm{ck}} 25 \mathrm{MPa}$

\begin{tabular}{ll}
\hline \multicolumn{1}{c}{ Variável } & Valor obtido \\
\hline Número de amostras & 138 \\
\hline $\mathrm{f}_{\mathrm{ck}}$, est (NBR 12655) & 27,7 \\
\hline $\mathrm{f}_{\mathrm{c}}$ médio $(\mathrm{MPa})$ & 32,1 \\
\hline Desvio-padrão $\mathrm{f}_{\mathrm{c}}(\mathrm{MPa})$ & 2,63 \\
\hline Coeficiente de variação $\mathrm{f}_{\mathrm{c}}(\%)$ & 8,2 \\
\hline
\end{tabular}

A Figura 5.7 mostra a variação da resistência à compressão para o $\mathrm{f}_{\mathrm{ck}} 25 \mathrm{MPa}$ ao longo do período estudado. 


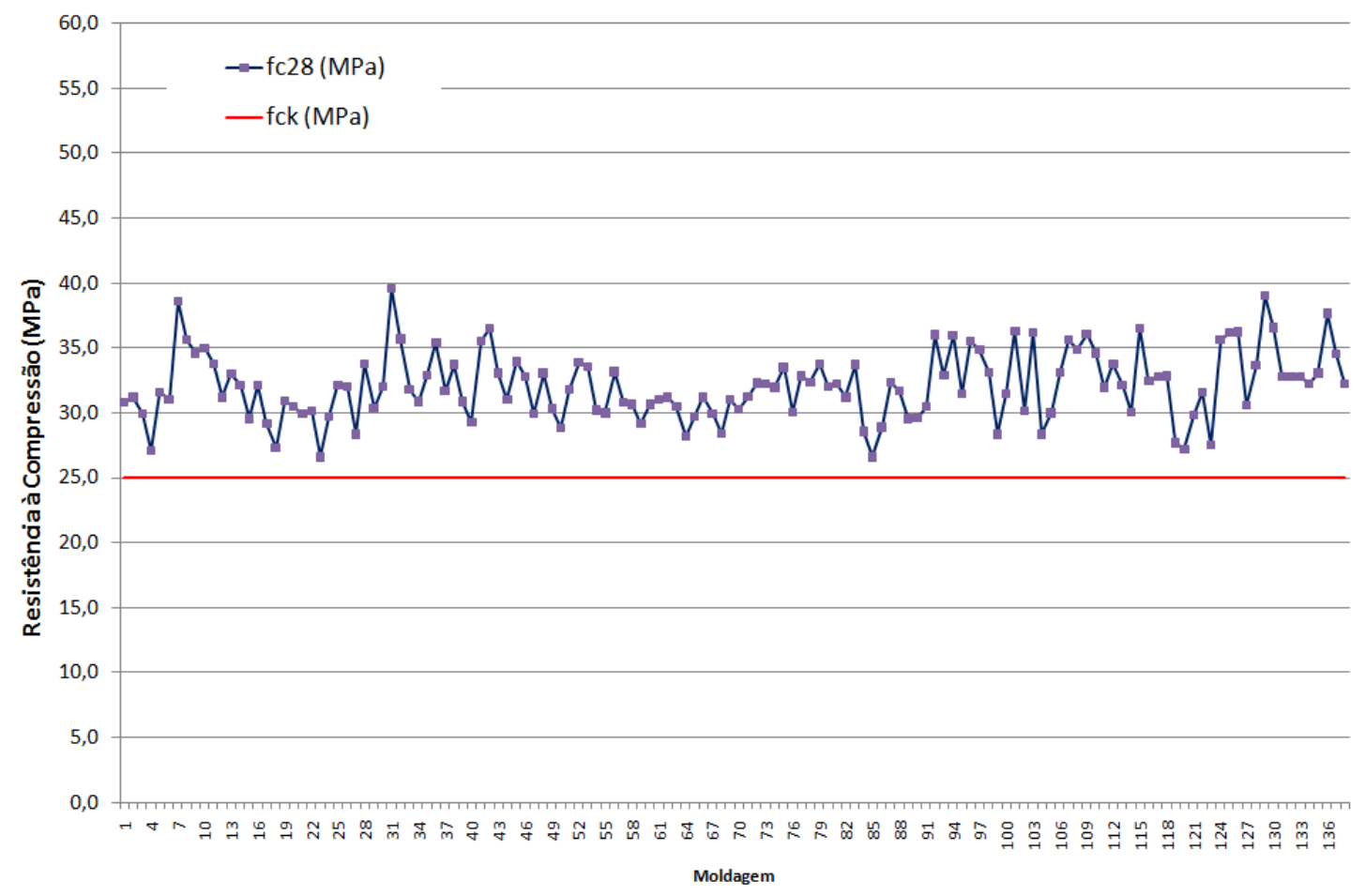

Figura 5.7 - Variação da Resistência à Compressão - $f_{c k} 25 \mathrm{MPa}$

Tabela 5.6 - Distribuição de frequências $-f_{c k} 25 \mathrm{MPa}$

\begin{tabular}{ccc}
\hline Bloco & Freqüência & \% cumulativo \\
\hline 31,3 & 27 & $1,45 \%$ \\
\hline 32,5 & 25 & $5,07 \%$ \\
\hline 33,7 & 19 & $10,87 \%$ \\
\hline 30,1 & 17 & $23,19 \%$ \\
\hline 36,1 & 12 & $42,75 \%$ \\
\hline 34,9 & 11 & $60,87 \%$ \\
\hline 29,0 & 8 & $74,64 \%$ \\
\hline 37,2 & 8 & $82,61 \%$ \\
\hline 27,8 & 5 & $91,30 \%$ \\
\hline 26,6 & 2 & $97,10 \%$ \\
\hline 38,4 & 1 & $97,83 \%$ \\
\hline Mais & 3 & $100,00 \%$ \\
\hline
\end{tabular}




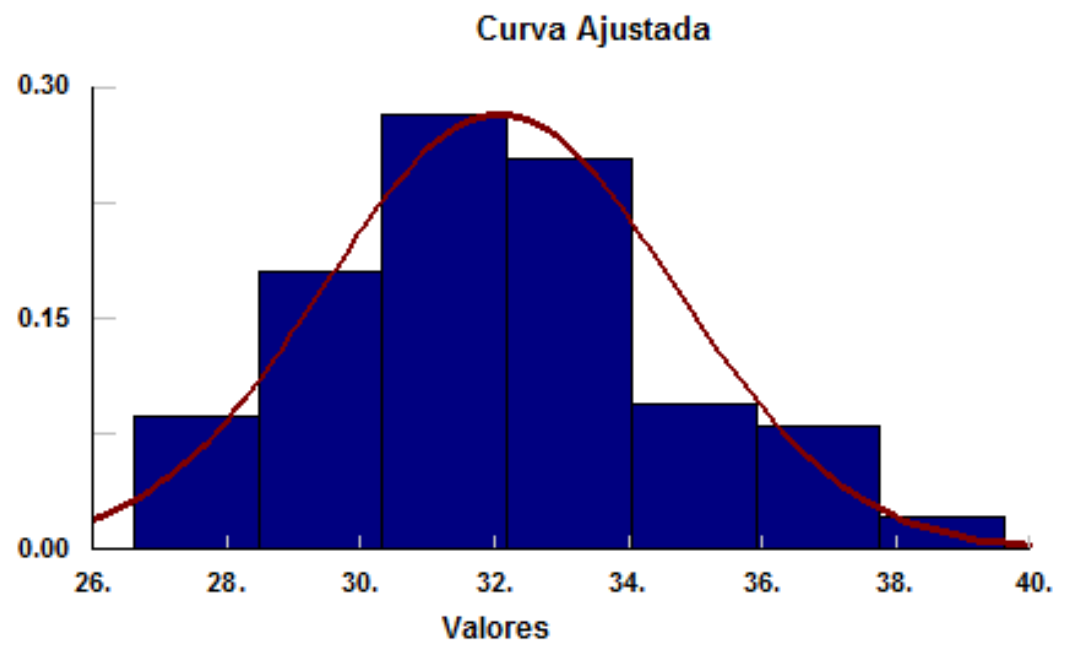

- Dados de entrada normal

Figura 5.8 - Histograma de frequência para os resultados de resistência à compressão $-f_{c k} 25 \mathrm{MPa}$

A Figura 5.9 ilustra a aderência dos resultados de resistência à compressão para o $\mathrm{f}_{\mathrm{ck}} 25 \mathrm{MPa}$, à distribuição Normal.

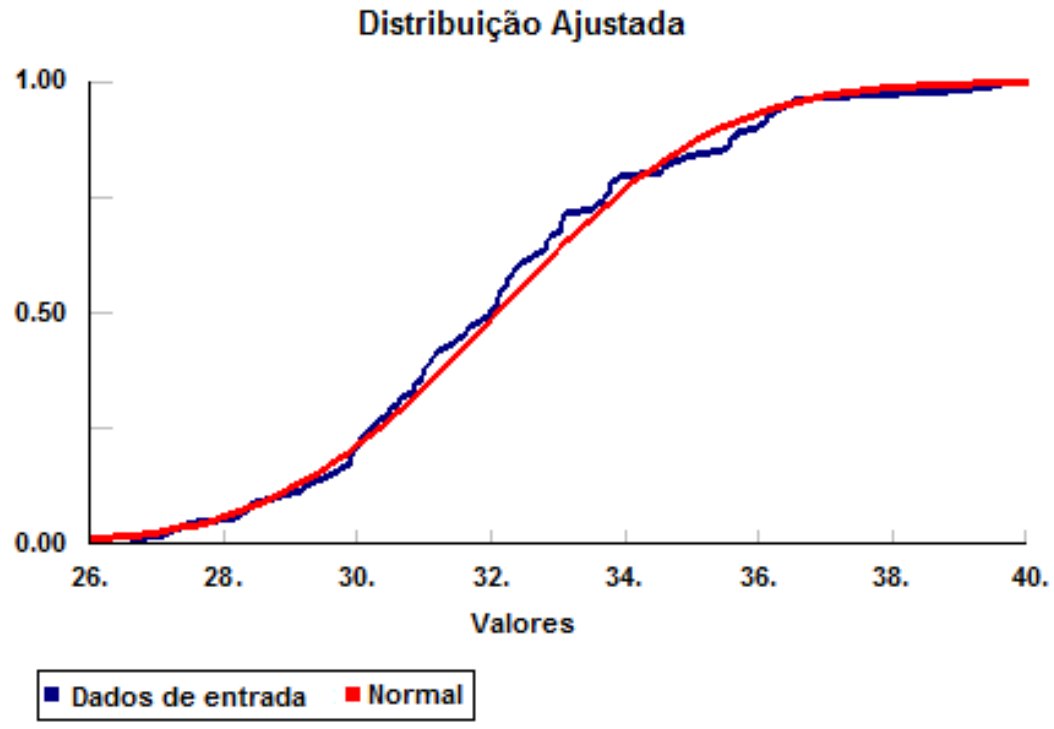

Figura 5.9 - Aderência dos resultados de resistência à compressão - curva Normal de distribuição $\mathrm{f}_{\mathrm{ck}} 25 \mathrm{MPa}$ 
Tabela 5.7 - Resumo da análise estatística - $\mathrm{f}_{\mathrm{ck}} 30 \mathrm{MPa}$

\begin{tabular}{lc}
\hline \multicolumn{1}{c}{ Variável } & Valor obtido \\
\hline Número de amostras & 105 \\
\hline $\mathrm{f}_{\mathrm{ck}}$, est (NBR 12655) & 34,1 \\
\hline $\mathrm{f}_{\mathrm{c}}$ médio $(\mathrm{MPa})$ & 38,8 \\
\hline Desvio-padrão $\mathrm{f}_{\mathrm{c}}(\mathrm{MPa})$ & 2,87 \\
\hline Coeficiente de variação $\mathrm{f}_{\mathrm{c}}(\%)$ & 7,4 \\
\hline
\end{tabular}

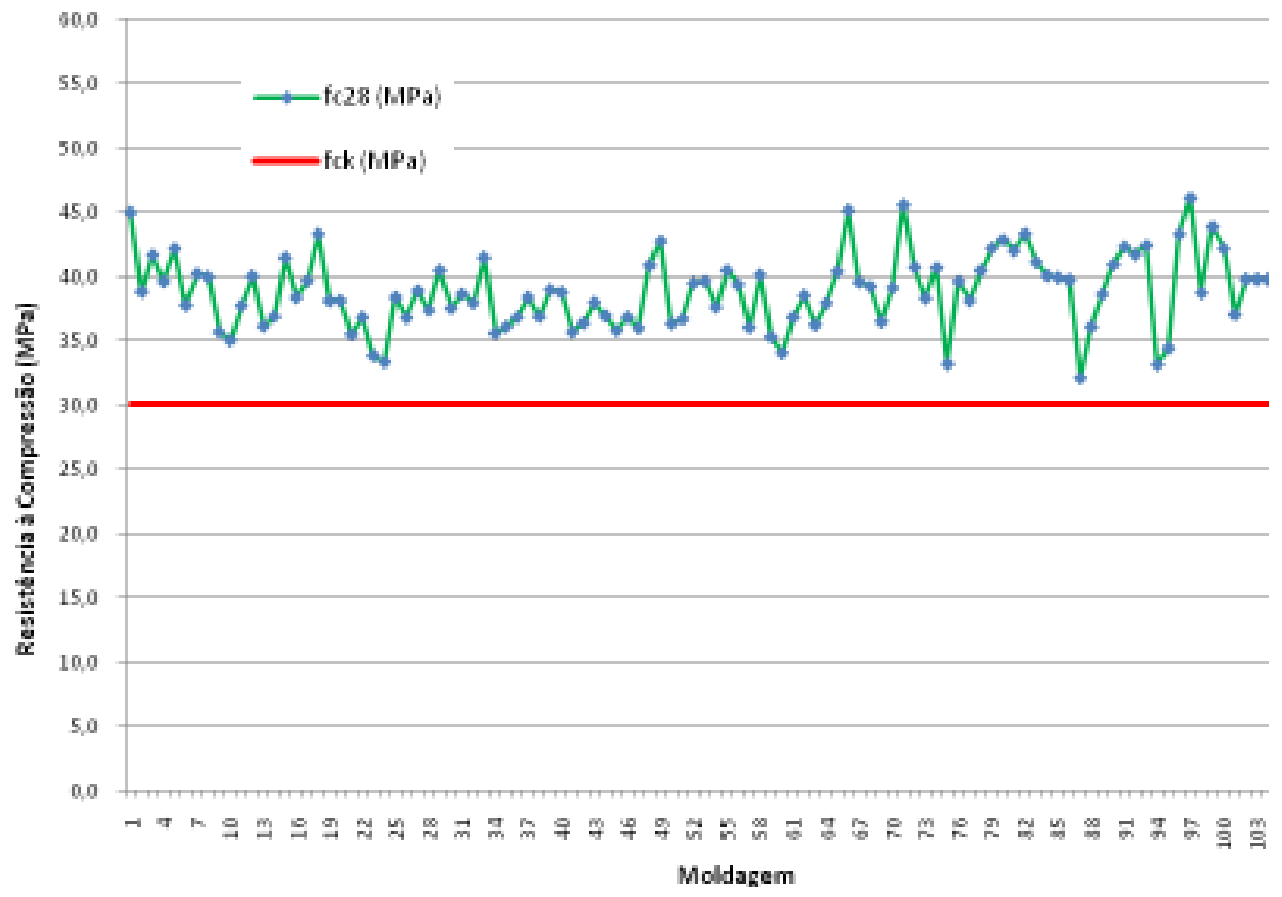

Figura 5.10 - Variação da Resistência à Compressão - $f_{c k} 30 \mathrm{MPa}$

Tabela 5.8 - Distribuição de frequências $-f_{c k} 30 \mathrm{MPa}$

\begin{tabular}{ccc}
\hline Bloco & Freqüência & $\%$ cumulativo \\
\hline 32,1 & 1 & $0,95 \%$ \\
\hline 33,5 & 3 & $3,81 \%$ \\
\hline 34,9 & 3 & $6,67 \%$ \\
\hline 36,3 & 13 & $19,05 \%$ \\
\hline 37,7 & 16 & $34,29 \%$ \\
\hline 39,1 & 20 & $53,33 \%$ \\
\hline 40,5 & 23 & $75,24 \%$ \\
\hline 41,9 & 9 & $83,81 \%$ \\
\hline 43,3 & 9 & $92,38 \%$ \\
\hline 44,7 & 4 & $96,19 \%$ \\
\hline Mais & 4 & $100,00 \%$ \\
\hline
\end{tabular}




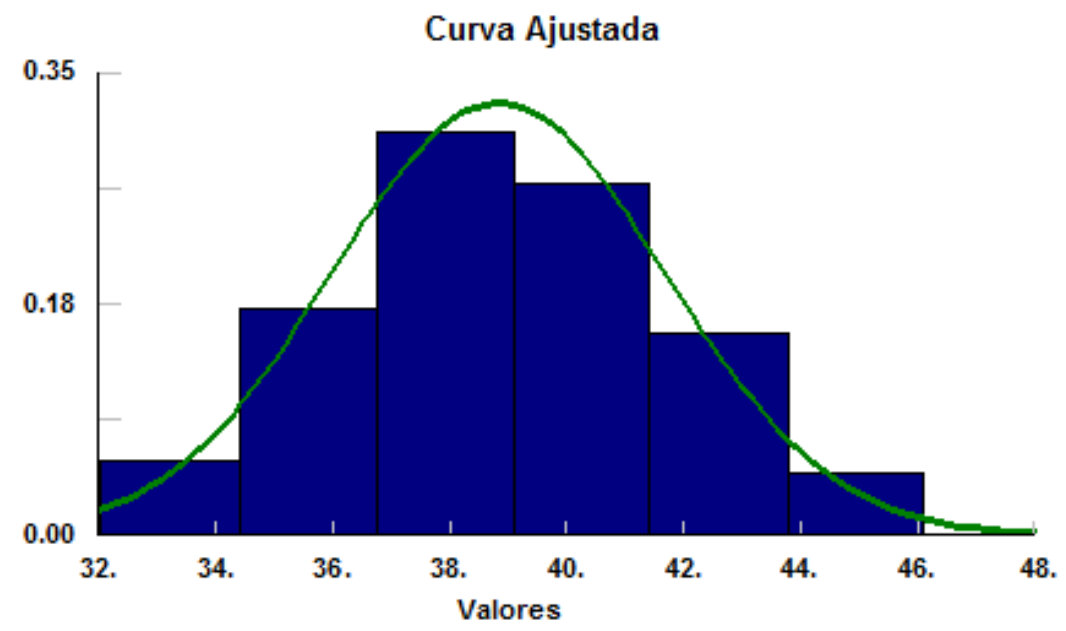

- Dados de entrada normal

Figura 5.11 - Histograma de frequência para os resultados de resistência à compressão $\mathrm{f}_{\mathrm{ck}} 30 \mathrm{MPa}$

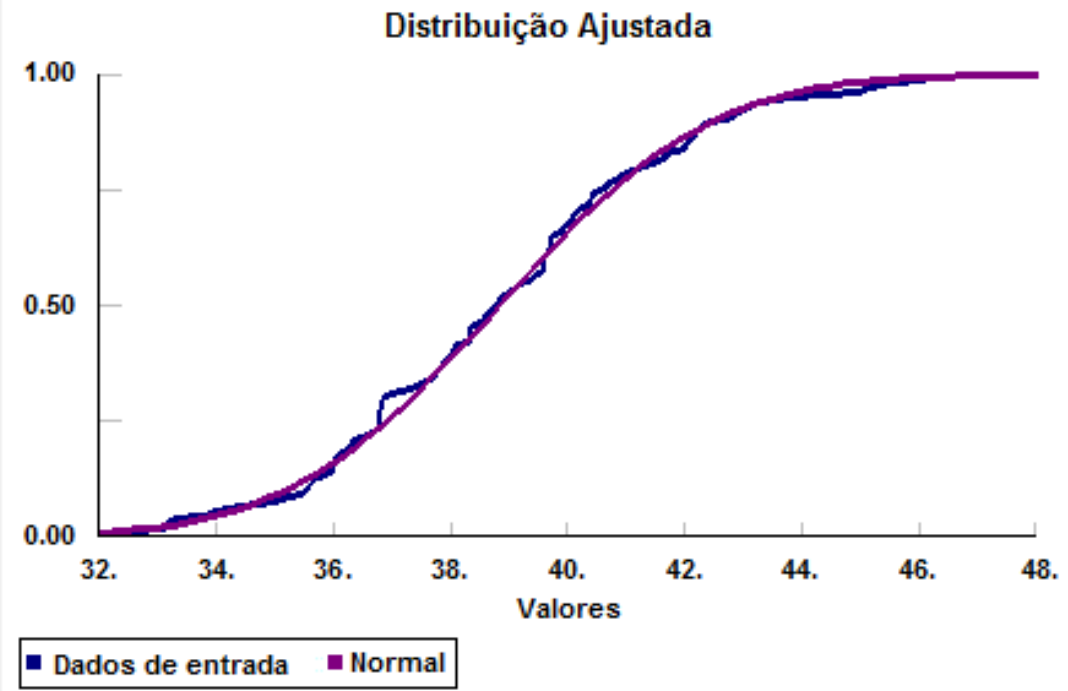

Figura 5.12 - Aderência dos resultados de resistência à compressão - curva Normal de distribuição $\mathrm{f}_{\mathrm{ck}} 30 \mathrm{MPa}$

Percebe-se, através da análise dos resultados expostos nas Tabelas 5.6 e 5.9 referentes aos $f_{c k s} 25$ e $30 \mathrm{MPa}$, respectivamente, que $\circ f_{c k, e s t i m a d o}$ de cada população, de acordo com a ABNT NBR 12655 (2066), apresentaram valores superiores ao $f_{c k}$ esperado para cada família, mostrando que o controle rigoroso dos 
materiais constituintes do concreto influencia diretamente no atendimento das especificações normativas para o controle tecnológico do concreto.

\subsubsection{Avaliação do módulo de deformação dos concretos estudados}

Inicialmente pretendia-se verificar se os resultados obtidos para o módulo de deformação representavam uma distribuição Normal (também denominada distribuição Gaussiana). Costa Neto (1977) define que um fenômeno é normal quando os valores da variável que o exprime encontram abrigo sob a curva normal (curva de sinos).

Assim, foi realizada análise estatística com os resultados obtidos por meio do teste de Kolmogorov-Smirnov (teste K-S). Utilizou-se o teste de Kolmogorov Smirnow por ser aplicável a um maior número de dados (LAW \& KELTON, 1991).

Posteriormente, são apresentados os resultados dos ensaios de módulo de deformação, $E_{c s}$, obtidos para os $f_{c k s} 25$ e $30 \mathrm{MPa}$ estudados. Também foram realizadas as análises estatísticas com os resultados obtidos e sua demonstração gráfica.

\subsubsection{Análises de distribuição Normal dos resultados}

Variáveis aleatórias podem assumir inúmeros padrões de freqüência. A partir de modelagem estatística é possível representar esses padrões e prever probabilisticamente o comportamento de determinado evento em função da distribuição dos dados amostrais.

Quando os dados em análise aproximam-se de uma distribuição Normal (distribuição Gaussiana), as técnicas de inferência estatísticas são, em sua maioria, mais facilmente aplicadas. Através de testes não paramétricos como KolmogorovSmirnov e Anderson-Darling, entre outros, é possível verificar se a distribuição de um conjunto de dados, em estudo, adere ao modelo de distribuição normal de forma satisfatória.

O teste Kolmogorov-Smirnov (KS) avalia o grau de concordância entre a distribuição de um conjunto de valores amostrais e determinada distribuição teórica específica, portanto adotando-se como hipótese nula que a distribuição teórica $(F(x))$ 
seja equivalente a distribuição observada $(\mathrm{Fn}(\mathrm{x}))$, é razoável esperar que para cada valor de $\mathrm{x}$, o resultado em ambas as distribuições esteja próximo, ou seja, que as diferenças entre $F n(x)$ e $F(x)$ sejam pequenas. Portanto o teste K-S adota a maior diferença em módulo, denominada desvio máximo, para verificar a aderência entre os modelos.

Assim:

$$
\begin{array}{ll}
D=\max \left(D^{+}, D^{-}\right) & \\
D^{+}=\max \left(\frac{i}{n}-F(x)\right) & i=1, \ldots, n \\
D^{-}=\max \left(F(x)-\frac{(i-1)}{n}\right) & i=1, \ldots, n
\end{array}
$$

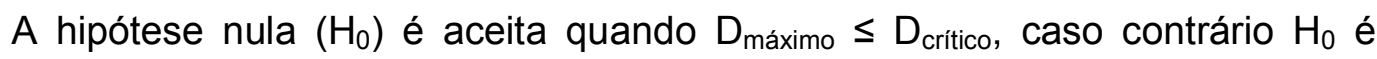
rejeitada e assume-se que as distribuições não são equivalentes $\left(\mathrm{H}_{1}\right)$. $\mathrm{O}$ valor de

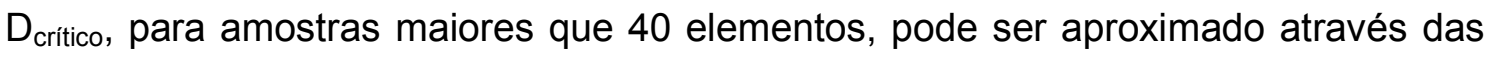
equações constantes da Tabela 5.9.

Tabela 5.9 - Equações para determinação do $D_{\text {critico }}$

\begin{tabular}{c|c|c|c|c}
\hline \multicolumn{5}{c}{$\boldsymbol{\alpha}$} \\
\hline $\mathbf{0 . 2 0}$ & $\mathbf{0 . 1 0}$ & $\mathbf{0 . 0 5}$ & $\mathbf{0 . 0 2}$ & $\mathbf{0 . 0 1}$ \\
\hline$\frac{1.07}{\sqrt{n}}$ & $\frac{1.22}{\sqrt{n}}$ & $\frac{1.36}{\sqrt{n}}$ & $\frac{1.52}{\sqrt{n}}$ & $\frac{1.63}{\sqrt{n}}$ \\
\hline
\end{tabular}

No presente estudo os resultados do Módulo de deformação secante, $E_{c s}$, para os concretos estudados foram comparados a uma distribuição Normal, através do teste K-S, adotando grau de significância de $\alpha=5 \%$. O sumário dos resultados para o Teste K-S são apresentados nas Tabelas 5.10 e 5.11 e detalhados no Apêndice A, Tabelas A-3.a-c a A-4.a-b. 
Tabela 5.10 - Resumo - teste de ajustamento de Kolmogorov-Smirnov $-f_{c k} 25 \mathrm{MPa}$

\begin{tabular}{ccccc}
\hline $\begin{array}{c}\text { Tamanho da } \\
\text { amostra }(\mathbf{n})\end{array}$ & Média $(\boldsymbol{\mu})$ & $\begin{array}{c}\text { Desvio Padrão } \\
(\boldsymbol{\sigma})\end{array}$ & $\mathbf{D}_{\text {critico }}(\boldsymbol{\alpha}=\mathbf{5 \%})$ & $\mathrm{D=máx}\left(\mathrm{D}^{+}, \mathrm{D}_{-}\right)$ \\
\hline 138 & 25,8 & 1,36 & 0,11577 & 0,04569 \\
\hline
\end{tabular}

Tabela 5.11 - Resumo - teste de ajustamento de Kolmogorov-Smirnov $-f_{c k} 30 \mathrm{MPa}$

\begin{tabular}{ccccc}
\hline $\begin{array}{c}\text { Tamanho da } \\
\text { amostra }(n)\end{array}$ & Média $(\mu)$ & $\begin{array}{c}\text { Desvio Padrão } \\
(\sigma)\end{array}$ & $D_{\text {critico }}(\alpha=5 \%)$ & $D=$ máx $\left(D^{\ddagger}, D_{-}\right)$ \\
\hline 105 & 27,19 & 0,888801 & 0,13272 & 0,08653 \\
\hline
\end{tabular}

De acordo com os resultados obtidos, para ambos os $f_{\text {cks }}$ estudados, o valor $D=\operatorname{máx}\left(D^{\dagger}, D_{-}\right)$foi inferior a $D_{\text {crítico }}(\alpha=5 \%)$, mostrando que o modelo foi considerado satisfatório segundo o teste de aderência estatística adotado para a distribuição Normal.

Nas Tabelas 5.12.a-b e 5.13.a-b a seguir são apresentados os resultados dos ensaios de módulo de deformação, $E_{c S}$, da primeira etapa obtidos para os $f_{c k s}$ estudados. Esses resultados estão detalhados no Apêndice A, Tabelas A-5.a-e a A6.a-d.

Nas Tabelas 5.14 e 5.16 apresentam-se os resumos das análises estatísticas dos resultados.

Para a realização das análises estatísticas dos resultados obtidos para o módulo de deformação secante, $\mathrm{E}_{\mathrm{cs}}$, foi utilizado o software de ajuste estatístico StatFit versão 2.0 . 
Tabela 5.12.a Módulo de deformação $E_{c s}$ e Resistência à Compressão $f_{c}-f_{c k} 25 \mathrm{MPa}$

\begin{tabular}{|c|c|c|c|c|c|}
\hline Amostra & $\begin{array}{c}\mathrm{E}_{\mathrm{cs}} \text {, médio } \\
\text { (GPa) }\end{array}$ & $\begin{array}{c}\text { Resistência à } \\
\text { Compressão } \\
\text { após ensaio } \\
\text { (MPa) }\end{array}$ & Amostra & $\begin{array}{c}E_{c s} \text {, médio } \\
\text { (GPa) }\end{array}$ & $\begin{array}{c}\text { Resistência à } \\
\text { Compressão } \\
\text { após ensaio } \\
(\mathrm{MPa})\end{array}$ \\
\hline 1 & 24,53 & 31,70 & 36 & 25,93 & 35,93 \\
\hline 2 & 22,32 & 30,47 & 37 & 23,61 & 31,35 \\
\hline 3 & 22,19 & 30,05 & 38 & 26,32 & 34,47 \\
\hline 4 & 23,42 & 30,50 & 39 & 25,81 & 34,27 \\
\hline 5 & 22,29 & 31,10 & 40 & 25,73 & 30,10 \\
\hline 6 & 24,16 & 31,00 & 41 & 25,45 & 34,97 \\
\hline 7 & 25,10 & 37,20 & 42 & 25,38 & 28,70 \\
\hline 8 & 26,05 & 36,63 & 43 & 25,07 & 34,70 \\
\hline 9 & 26,05 & 34,57 & 44 & 25,75 & 29,90 \\
\hline 10 & 28,04 & 35,43 & 45 & 23,78 & 35,07 \\
\hline 11 & 24,50 & 34,13 & 46 & 25,04 & 37,07 \\
\hline 12 & 23,39 & 33,30 & 47 & 25,08 & 30,83 \\
\hline 13 & 25,96 & 36,50 & 48 & 24,76 & 33,37 \\
\hline 14 & 23,72 & 33,10 & 49 & 26,06 & 30,70 \\
\hline 15 & 25,65 & 30,33 & 50 & 23,71 & 26,55 \\
\hline 16 & 26,11 & 33,10 & 51 & 25,77 & 31,97 \\
\hline 17 & 24,97 & 29,40 & 52 & 24,16 & 33,50 \\
\hline 18 & 24,40 & 27,87 & 53 & 25,19 & 32,80 \\
\hline 19 & 25,45 & 30,80 & 54 & 24,37 & 30,83 \\
\hline 20 & 24,95 & 28,87 & 55 & 27,56 & 33,23 \\
\hline 21 & 24,99 & 29,93 & 56 & 25,32 & 33,90 \\
\hline 22 & 23,08 & 29,73 & 57 & 25,94 & 34,10 \\
\hline 23 & 24,56 & 27,73 & 58 & 24,74 & 30,50 \\
\hline 24 & 26,97 & 29,83 & 59 & 21,87 & 28,95 \\
\hline 25 & 24,65 & 31,87 & 60 & 26,53 & 31,97 \\
\hline 26 & 26,55 & 33,57 & 61 & 23,95 & 32,50 \\
\hline 27 & 24,84 & 29,07 & 62 & 25,16 & 31,97 \\
\hline 28 & 25,14 & 30,20 & 63 & 26,99 & 34,07 \\
\hline 29 & 24,88 & 29,33 & 64 & 23,11 & 29,57 \\
\hline 30 & 25,55 & 38,70 & 65 & 24,80 & 29,03 \\
\hline 31 & 24,82 & 37,67 & 66 & 25,90 & 34,87 \\
\hline 32 & 25,64 & 36,77 & 67 & 25,44 & 30,57 \\
\hline 33 & 25,36 & 31,23 & 68 & 25,20 & 30,37 \\
\hline 34 & 24,45 & 30,27 & 69 & 25,29 & 37,05 \\
\hline 35 & 23,54 & 33,47 & 70 & 25,51 & 34,33 \\
\hline
\end{tabular}


Tabela 5.12.b Módulo de deformação $E_{c s}$ e Resistência à Compressão $f_{c}-f_{c k} 25 \mathrm{MPa}$

\begin{tabular}{|c|c|c|c|c|c|}
\hline Amostra & $\begin{array}{c}E_{\mathrm{cs}}, \text { médio } \\
(\mathrm{GPa})\end{array}$ & $\begin{array}{c}\text { Resistência à } \\
\text { Compressão } \\
\text { após ensaio } \\
\text { (MPa) }\end{array}$ & Amostra & $\begin{array}{c}E_{c s}, \text { médio } \\
(G P a)\end{array}$ & $\begin{array}{c}\text { Resistência à } \\
\text { Compressão } \\
\text { após ensaio } \\
(\mathrm{MPa})\end{array}$ \\
\hline 71 & 25,43 & 31,73 & 105 & 26,39 & 30,57 \\
\hline 72 & 26,60 & 30,50 & 106 & 26,86 & 33,40 \\
\hline 73 & 26,63 & 31,16 & 107 & 26,86 & 34,87 \\
\hline 74 & 26,39 & 31,46 & 108 & 26,47 & 34,07 \\
\hline 75 & 26,64 & 32,51 & 109 & 26,50 & 32,90 \\
\hline 76 & 27,50 & 30,26 & 110 & 24,79 & 35,93 \\
\hline 77 & 27,28 & 31,68 & 111 & 25,96 & 33,70 \\
\hline 78 & 27,18 & 31,70 & 112 & 26,46 & 34,37 \\
\hline 79 & 27,95 & 28,26 & 113 & 26,15 & 31,73 \\
\hline 80 & 25,50 & 31,65 & 114 & 25,31 & 30,73 \\
\hline 81 & 27,31 & 31,72 & 115 & 25,96 & 35,09 \\
\hline 82 & 27,74 & 31,72 & 116 & 26,50 & 34,48 \\
\hline 83 & 27,77 & 31,80 & 117 & 25,80 & 32,39 \\
\hline 84 & 27,04 & 27,68 & 118 & 24,75 & 33,07 \\
\hline 85 & 26,45 & 29,03 & 119 & 25,44 & 28,90 \\
\hline 86 & 27,03 & 28,66 & 120 & 24,54 & 26,97 \\
\hline 87 & 26,42 & 30,19 & 121 & 25,60 & 31,04 \\
\hline 88 & 28,03 & 30,77 & 122 & 25,70 & 30,28 \\
\hline 89 & 25,89 & 30,57 & 123 & 26,54 & 27,47 \\
\hline 90 & 27,37 & 29,39 & 124 & 25,65 & 34,22 \\
\hline 91 & 27,21 & 29,41 & 125 & 25,59 & 35,88 \\
\hline 92 & 28,39 & 35,05 & 126 & 25,58 & 34,19 \\
\hline 93 & 27,42 & 32,77 & 127 & 28,75 & 32,13 \\
\hline 94 & 28,26 & 34,43 & 128 & 28,89 & 32,27 \\
\hline 95 & 27,01 & 31,19 & 129 & 27,75 & 36,51 \\
\hline 96 & 27,47 & 32,06 & 130 & 26,17 & 33,46 \\
\hline 97 & 26,35 & 31,02 & 131 & 27,59 & 34,08 \\
\hline 98 & 26,73 & 32,33 & 132 & 26,15 & 32,52 \\
\hline 99 & 27,20 & 30,89 & 133 & 26,24 & 32,41 \\
\hline 100 & 25,95 & 31,35 & 134 & 26,73 & 31,48 \\
\hline 101 & 26,01 & 35,53 & 135 & 25,01 & 32,77 \\
\hline 102 & 26,42 & 31,23 & 136 & 26,73 & 35,91 \\
\hline 103 & 24,21 & 34,40 & 137 & 26,52 & 35,76 \\
\hline 104 & 25,71 & 28,80 & 138 & 27,72 & 32,65 \\
\hline
\end{tabular}


Tabela 5.13.a Módulo de deformação $E_{c s}$ e Resistência à Compressão $f_{c}-f_{c k} 30 \mathrm{MPa}$

\begin{tabular}{|c|c|c|c|c|c|}
\hline Amostra & $\begin{array}{c}E_{c s} \text {, médio } \\
\text { (GPa) }\end{array}$ & $\begin{array}{c}\text { Resistência à } \\
\text { Compressão } \\
\text { após ensaio } \\
\text { (MPa) }\end{array}$ & Amostra & $\begin{array}{c}\mathrm{E}_{\mathrm{cs}} \text {, médio } \\
\text { (GPa) }\end{array}$ & $\begin{array}{c}\text { Resistência à } \\
\text { Compressão } \\
\text { após ensaio } \\
\text { (MPa) }\end{array}$ \\
\hline 1 & 27,33 & 45,0 & 28 & 25,95 & 37,4 \\
\hline 2 & 26,18 & 38,5 & 29 & 28,13 & 39,8 \\
\hline 3 & 27,62 & 42,0 & 30 & 28,44 & 37,2 \\
\hline 4 & 26,55 & 40,3 & 31 & 25,82 & 38,2 \\
\hline 5 & 28,10 & 41,7 & 32 & 26,09 & 37,1 \\
\hline 6 & 27,11 & 38,1 & 33 & 26,77 & 43,5 \\
\hline 7 & 26,37 & 40,7 & 34 & 26,12 & 37,2 \\
\hline 8 & 25,97 & 40,3 & 35 & 26,39 & 36,1 \\
\hline 9 & 27,73 & 35,8 & 36 & 26,11 & 38,9 \\
\hline 10 & 26,05 & 35,6 & 37 & 26,63 & 41,3 \\
\hline 11 & 26,06 & 37,1 & 38 & 25,56 & 39,0 \\
\hline 12 & 26,10 & 38,3 & 39 & 26,13 & 37,7 \\
\hline 13 & 26,27 & 37,3 & 40 & 27,27 & 39,5 \\
\hline 14 & 26,43 & 35,9 & 41 & 27,44 & 36,5 \\
\hline 15 & 25,81 & 40,0 & 42 & 27,24 & 37,1 \\
\hline 16 & 27,50 & 38,6 & 43 & 28,76 & 37,5 \\
\hline 17 & 26,73 & 41,0 & 44 & 26,43 & 37,6 \\
\hline 18 & 26,56 & 42,4 & 45 & 27,12 & 36,4 \\
\hline 19 & 26,22 & 39,3 & 46 & 27,64 & 37,0 \\
\hline 20 & 26,21 & 37,7 & 47 & 27,05 & 36,1 \\
\hline 21 & 26,91 & 36,4 & 48 & 28,38 & 40,1 \\
\hline 22 & 26,03 & 35,4 & 49 & 28,05 & 37,5 \\
\hline 23 & 26,80 & 34,1 & 50 & 28,02 & 36,2 \\
\hline 24 & 26,30 & 34,9 & 51 & 28,14 & 38,9 \\
\hline 25 & 28,17 & 39,4 & 52 & 27,59 & 38,4 \\
\hline 26 & 26,34 & 37,1 & 53 & 28,16 & 38,1 \\
\hline 27 & 26,97 & 37,6 & 54 & 27,56 & 36,8 \\
\hline
\end{tabular}


Tabela 5.13.b Módulo de deformação $E_{c s}$ e Resistência à Compressão $f_{c}-f_{c k} 30 \mathrm{MPa}$

\begin{tabular}{|c|c|c|c|c|c|}
\hline Amostra & $\begin{array}{c}\mathrm{E}_{\mathrm{cs}}, \text { médio } \\
(\mathrm{GPa})\end{array}$ & $\begin{array}{c}\text { Resistência à } \\
\text { Compressão } \\
\text { após ensaio } \\
\text { (MPa) }\end{array}$ & Amostra & $\begin{array}{c}E_{\mathrm{cs}} \text {, médio } \\
(\mathrm{GPa})\end{array}$ & $\begin{array}{c}\text { Resistência à } \\
\text { Compressão } \\
\text { após ensaio } \\
\text { (MPa) }\end{array}$ \\
\hline 55 & 26,87 & 39,4 & 81 & 27,18 & 43,5 \\
\hline 56 & 27,74 & 38,0 & 82 & 28,04 & 42,6 \\
\hline 57 & 27,42 & 37,4 & 83 & 28,20 & 41,7 \\
\hline 58 & 27,25 & 38,2 & 84 & 25,53 & 39,7 \\
\hline 59 & 27,85 & 34,9 & 85 & 27,24 & 40,1 \\
\hline 60 & 27,61 & 36,6 & 86 & 25,93 & 38,0 \\
\hline 61 & 27,99 & 34,6 & 87 & 26,31 & 33,4 \\
\hline 62 & 28,09 & 35,2 & 88 & 26,32 & 35,7 \\
\hline 63 & 27,11 & 37,1 & 89 & 26,28 & 38,1 \\
\hline 64 & 28,10 & 36,5 & 90 & 27,39 & 39,6 \\
\hline 65 & 27,20 & 38,2 & 91 & 28,88 & 41,9 \\
\hline 66 & 28,46 & 42,5 & 92 & 26,63 & 42,1 \\
\hline 67 & 27,45 & 37,4 & 93 & 27,16 & 43,8 \\
\hline 68 & 27,63 & 39,6 & 94 & 27,96 & 34,0 \\
\hline 69 & 27,68 & 37,7 & 95 & 28,26 & 33,8 \\
\hline 70 & 27,08 & 39,2 & 96 & 28,87 & 43,7 \\
\hline 71 & 27,25 & 34,2 & 97 & 29,41 & 46,6 \\
\hline 72 & 28,14 & 39,4 & 98 & 28,18 & 43,0 \\
\hline 73 & 26,44 & 38,0 & 99 & 27,64 & 35,9 \\
\hline 74 & 26,62 & 40,8 & 100 & 27,22 & 42,5 \\
\hline 75 & 26,86 & 33,3 & 101 & 27,62 & 36,2 \\
\hline 76 & 28,15 & 39,6 & 102 & 27,85 & 38,7 \\
\hline 77 & 26,74 & 38,0 & 103 & 26,66 & 39,3 \\
\hline 78 & 29,71 & 41,3 & 104 & 26,44 & 37,4 \\
\hline 79 & 27,89 & 36,5 & 105 & 28,47 & 40,2 \\
\hline 80 & 26,99 & 40,4 & & & \\
\hline
\end{tabular}


Tabela 5.14 Resumo da análise estatística do $\mathrm{E}_{\mathrm{cs}}-\mathrm{f}_{\mathrm{ck}} 25 \mathrm{MPa}$

\begin{tabular}{lc}
\hline \multicolumn{1}{c}{ Variável } & Valor obtido \\
\hline Número de amostras & 138 \\
\hline $\mathrm{E}_{\mathrm{cs}}$ previsto segundo NBR $6118(\mathrm{GPa})$ & 23,80 \\
\hline $\mathrm{E}_{\mathrm{cs}}$ médio $(\mathrm{GPa})$ & 25,76 \\
\hline Desvio-padrão $\mathrm{E}_{\mathrm{cs}}, \sigma(\mathrm{GPa})$ & 1,36 \\
\hline Coeficiente de variação $\mathrm{E}_{\mathrm{cs}}, \mathrm{cv}(\%)$ & 5,3 \\
\hline Mediana & 25,79 \\
\hline Moda & 26,05 \\
\hline
\end{tabular}

Tabela 5.15 - Distribuição de frequências $-f_{c k} 25 \mathrm{MPa}$

\begin{tabular}{ccc}
\hline Bloco & Freqüência & $\%$ cumulativo \\
\hline 21,87 & 1 & $0,72 \%$ \\
\hline 22,50 & 3 & $2,90 \%$ \\
\hline 23,14 & 2 & $4,35 \%$ \\
\hline 23,78 & 7 & $9,42 \%$ \\
\hline 24,42 & 6 & $13,77 \%$ \\
\hline 25,06 & 19 & $27,54 \%$ \\
\hline 25,70 & 27 & $47,10 \%$ \\
\hline 26,34 & 24 & $64,49 \%$ \\
\hline 26,97 & 23 & $81,16 \%$ \\
\hline 27,61 & 15 & $92,03 \%$ \\
\hline 28,25 & 7 & $97,10 \%$ \\
\hline Mais & 4 & $100,00 \%$ \\
\hline
\end{tabular}

Tabela 5.16 - Resumo da análise estatística do $E_{c s}-f_{c k} 30 \mathrm{MPa}$

\begin{tabular}{lc}
\hline \multicolumn{1}{c}{ Variável } & Valor obtido \\
\hline Número de amostras & 105 \\
\hline $\mathrm{E}_{\mathrm{cs}}$ previsto segundo NBR $6118(\mathrm{GPa})$ & 26,07 \\
\hline $\mathrm{E}_{\mathrm{cs}}$ médio $(\mathrm{GPa})$ & 27,19 \\
\hline Desvio-padrão $\mathrm{E}_{\mathrm{cs}}, \sigma(\mathrm{GPa})$ & 0,89 \\
\hline Coeficiente de variação $\mathrm{E}_{\mathrm{cs}}(\%)$ & 3,27 \\
\hline Mediana & 27,2 \\
\hline Moda & 27,11 \\
\hline
\end{tabular}


Tabela 5.17 - Distribuição de frequências $-f_{c k} 30 \mathrm{MPa}$

\begin{tabular}{ccc}
\hline Bloco & Freqüência & $\%$ cumulativo \\
\hline 25,53 & 1 & $0,95 \%$ \\
\hline 25,95 & 4 & $4,76 \%$ \\
\hline 26,37 & 19 & $22,86 \%$ \\
\hline 26,78 & 15 & $37,14 \%$ \\
\hline 27,20 & 13 & $49,52 \%$ \\
\hline 27,62 & 17 & $65,71 \%$ \\
\hline 28,04 & 13 & $78,10 \%$ \\
\hline 28,45 & 16 & $93,33 \%$ \\
\hline 28,87 & 4 & $97,14 \%$ \\
\hline 29,29 & 1 & $98,10 \%$ \\
\hline Mais & 2 & $100,00 \%$ \\
\hline
\end{tabular}

As Figuras 5.13 e 5.15 apresentam os histogramas relacionados aos resultados experimentais do módulo de deformação secante, $E_{c s}$, para os $f_{c k s} 25 \mathrm{MPa}$ e 30MPa, respectivamente. Nas Figuras 5.14 e 5.16 são mostradas as curvas de aderência à distribuição Normal dos resultados obtidos para o módulo de deformação secante, $\mathrm{E}_{\mathrm{cs}}$.

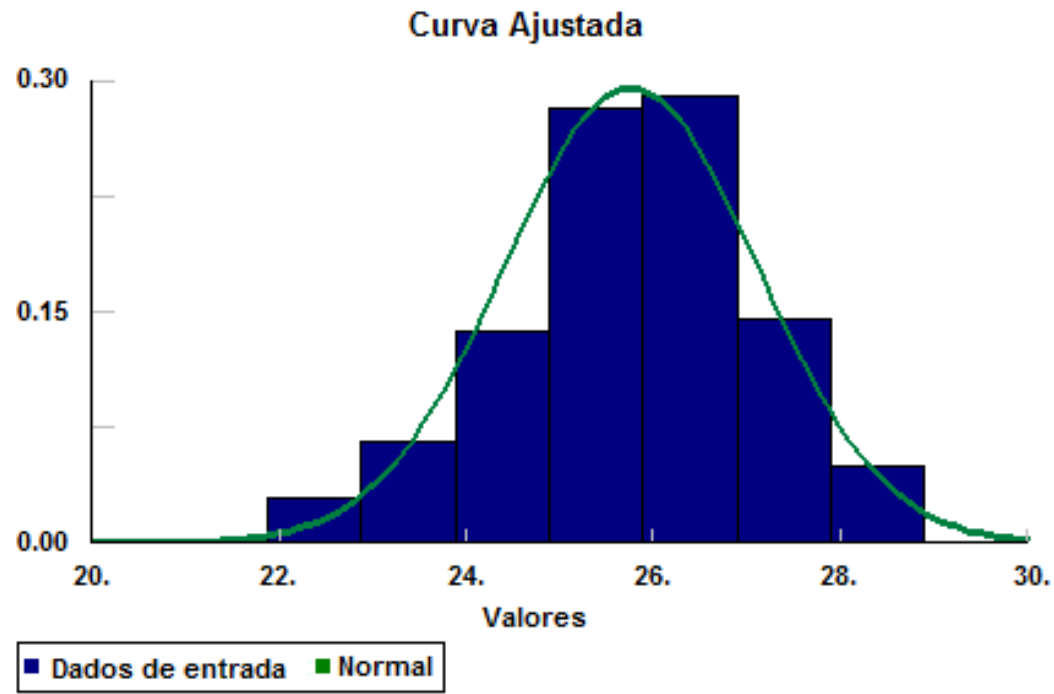

Figura 5.13- Histograma de frequência para os resultados do módulo de deformação, $E_{c s}-f_{c k} 25 \mathrm{MPa}$ 


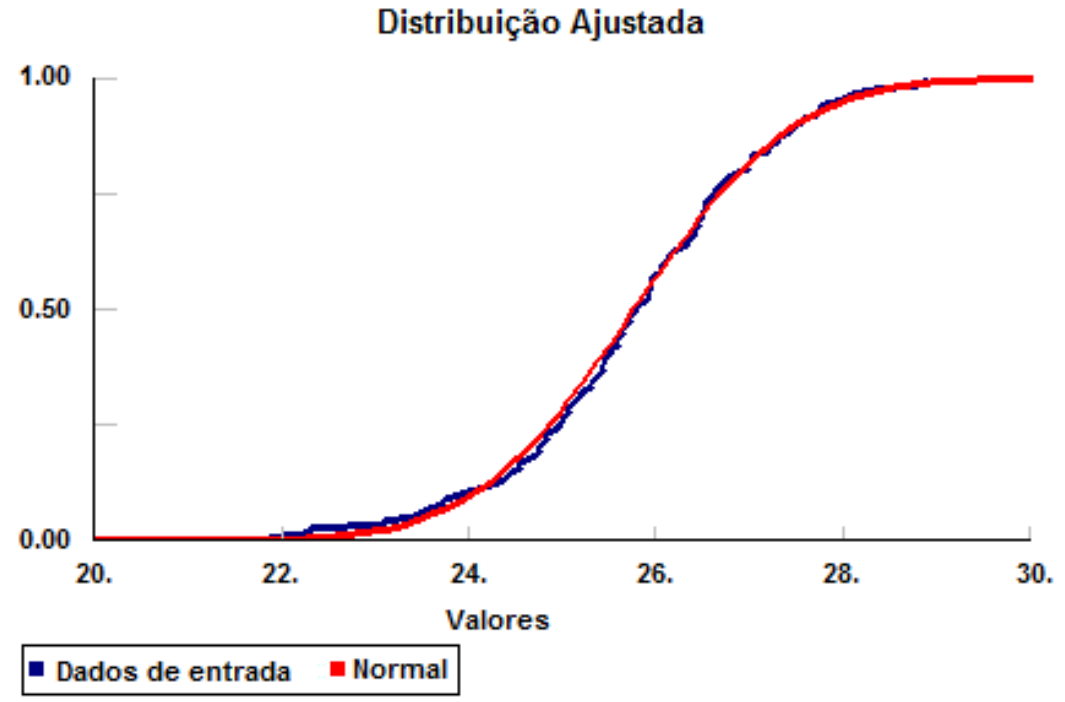

Figura 5.14 - Aderência dos resultados de módulo de deformação secante, $\mathrm{E}_{\mathrm{cs}}$ Curva Normal de distribuição $-f_{c k} 25 \mathrm{MPa}$

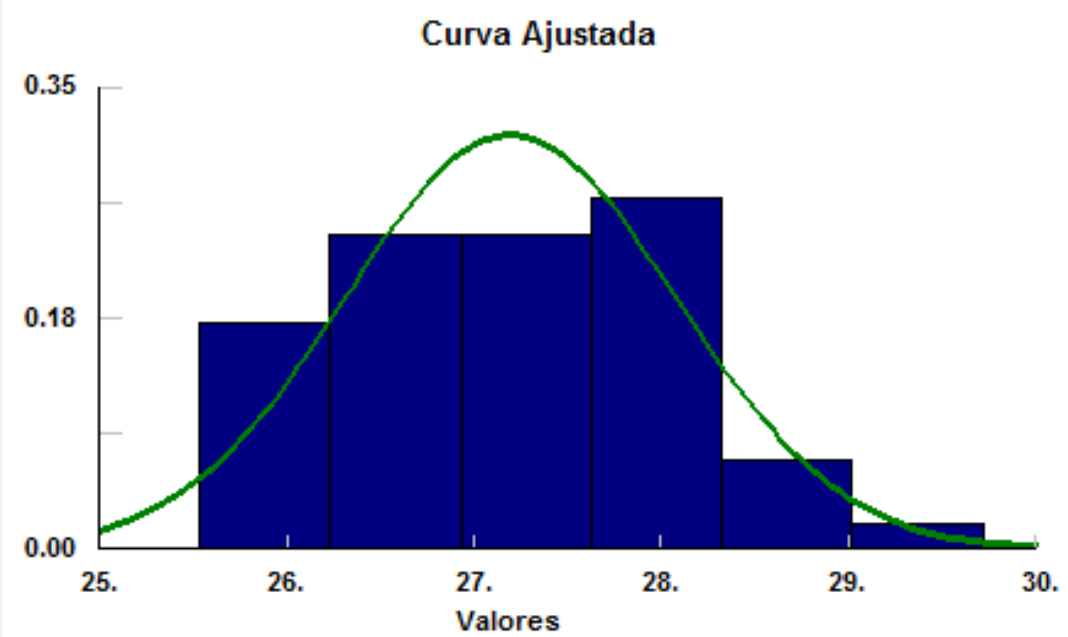

- Dados de entrada normal

Figura 5.15 - Histograma de frequência para os resultados do módulo de deformação, $E_{c s}-f_{c k}$ $30 \mathrm{MPa}$ 


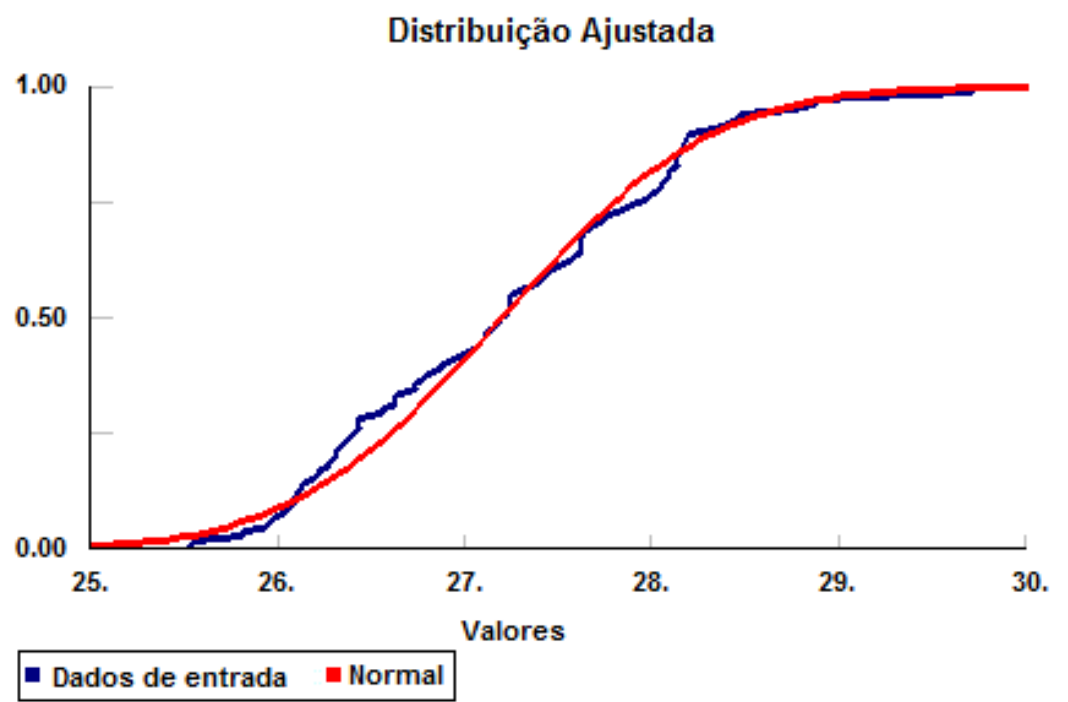

Figura 5.16 - Aderência dos resultados de módulo de deformação secante, $E_{c s}$ Curva Normal de distribuição $-f_{c k} 30 \mathrm{MPa}$

Pelos resultados obtidos pode-se afirmar que as distribuições de freqüência do módulo de deformação das duas famílias de concreto analisadas seguem a distribuição normal. Além disso, em ambos os casos os valores médios superaram os valores previstos pela modelo de estimativa previsto na norma ABNT NBR 6118 . No entanto, estes resultados não contam com a variabilidade resultante dos fatores intervenientes que podem afetar o resultado obtido em obra. Assim, pode-se levantar a dúvida sobre a representatividade da amostra obtida no laboratório para explicar o comportamento em campo do concreto. Por essa razão, foi feita a análise complementar da segunda etapa descrita no próximo item.

\subsection{Segunda etapa}

O objetivo desta etapa foi verificar se há equivalência entre a amostragem obtida em campo e a amostragem laboratorial mais ampla realizada na primeira etapa deste trabalho.

Nesta etapa são apresentados os resultados dos ensaios laboratoriais para determinação do módulo de deformação do concreto de $\mathrm{f}_{\mathrm{ck}} 30 \mathrm{MPa}$, provenientes de aplicações em campo, em obras da região da Grande São Paulo. Em função do curto tempo para coleta e realização dos ensaios, a amostragem em campo foi feita 
para 6 obras distintas. Por se tratar de uma pequena amostra foi proposta análise através da aplicação do teste $t$ de Student.

Quando se trabalha com amostras pequenas, da qual não se conhece a média e o desvio da população, mas supõe-se que obedeça a uma distribuição Normal, é comum a utilização da distribuição probabilística $t$ de Student para teste e análises.

Esta distribuição de probabilidade teórica é simétrica, e com forma de sino, semelhante à distribuição normal, contudo com caudas mais largas, o que pode gerar valores mais extremos.

O parâmetro que define sua forma é o número de graus de liberdade. Quanto maior o número de graus de liberdade mais próxima a distribuição $t$ de Student se torna da distribuição normal.

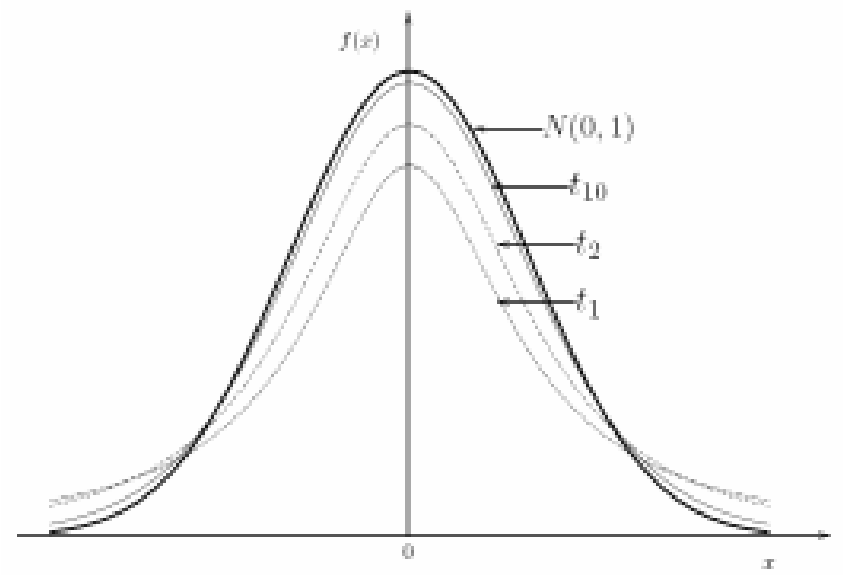

Figura 5.17 - Distribuição $t$ de Student

Para o teste $t$ definimos como hipótese nula $\left(\mathrm{H}_{0}\right)$ que as médias dos resultados em campo como em laboratório são equivalentes. Ou seja, que não há diferença significativa entre ambas as amostras. O contrário é a hipótese alternativa $\left(\mathrm{H}_{1}\right)$.

O Teste t para média de uma amostra é dado por:

$t=\frac{\bar{x}-\mu_{0}}{s / \sqrt{n}}$ 
Onde:

$\bar{x}$ : Média da amostra

$\mu_{0}$ : Valor fixo usado para comparação

s: Desvio padrão amostral

$\mathrm{n}$ : Tamanho da amostra

No presente estudo, foi feita uma comparação para a média de duas amostras, as quais possuem tamanhos diferentes e, por se tratarem de processos distintos (amostra proveniente do campo e amostra proveniente do laboratório), assumindo que as variâncias são diferentes. Para estas condições a estatística $t$ é calculada conforme a fórmula:

$$
t=\frac{\bar{x}_{1}-\bar{x}_{2}}{\sqrt{\frac{s_{1}^{2}}{n_{1}}+\frac{s_{2}^{2}}{n_{2}}}}
$$

E o grau de liberdade é obtido pela equação de Welch-Satterthwaite:

$$
\frac{\left(s_{1}^{2} / n_{1}+s_{2}^{2} / n_{2}\right)^{2}}{\frac{\left(s_{1}^{2} / n_{1}\right)^{2}}{\left(n_{1}-1\right)}+\frac{\left(s_{2}^{2} / n_{2}\right)^{2}}{\left(n_{2}-1\right)}}
$$

Os resultados dos ensaios de módulo de deformação secante, $E_{c s}$, obtidos para o $\mathrm{f}_{\mathrm{ck}} 30 \mathrm{MPa}$ moldado em campo são apresentados na Tabela 5.18 e detalhados no Apêndice B, Tab. B-1.

Tabela 5.18 Módulo de deformação $E_{c, s}$ - teste em campo

\begin{tabular}{ccc}
\hline Amostra & $\begin{array}{c}\mathbf{E}_{\mathrm{cs}}, \text { médio } \\
(\mathbf{G P a})\end{array}$ & $\begin{array}{c}\text { Resistência à } \\
\text { Compressão após } \\
\text { ensaio (MPa) }\end{array}$ \\
\hline $\mathbf{1}$ & 26,68 & 39,1 \\
\hline $\mathbf{2}$ & 28,33 & 37,3 \\
\hline $\mathbf{3}$ & 28,30 & 40,1 \\
\hline $\mathbf{4}$ & 30,01 & 34,2 \\
\hline $\mathbf{5}$ & 25,93 & 31,9 \\
\hline $\mathbf{6}$ & 26,19 & 31,6 \\
\hline
\end{tabular}


Tabela 5.19 Teste $t$ : duas amostras presumindo variâncias diferentes

\begin{tabular}{ccc}
\hline & Laboratório & Campo \\
\hline Média & 27,20223 & 27,5725 \\
\hline Variância & 0,799591 & 2,493317 \\
\hline Observações & 103 & 6 \\
\hline $\begin{array}{c}\text { Hipótese da diferença de } \\
\text { média }\end{array}$ & 0 & \\
\hline gl & 5 & \\
\hline Stat $t$ & $-\mathbf{0 , 5 6 9 0 9}$ & \\
\hline $\mathrm{P}(\mathrm{T}<=\mathrm{t})$ uni-caudal & 0,296952 & \\
\hline $\mathrm{t}$ crítico uni-caudal & 2,015048 & \\
\hline $\mathrm{P}(\mathrm{T}<=\mathrm{t})$ bi-caudal & 0,593904 & \\
\hline $\mathrm{t}$ crítico bi-caudal & $\mathbf{2 , 5 7 0 5 8 2}$ &
\end{tabular}

Conforme mostrado na Tabela 5.19, o módulo da estatística $t$ calculado pelo teste foi de 0,56909 que é menor que o $t$ crítico bi-caudal (2,570580), para um grau de significância igual a $5 \%$. Portanto podemos aceitar $\mathrm{H}_{0}$ como hipótese verdadeira, ou seja, a média das amostras em campo é equivalente a média das amostras realizadas em laboratório. No entanto, há observou-se que a variabilidade em campo é maior que a obtida no laboratório, ou seja, pode ser comparadas as médias e a amostra obtida no laboratório é representativa da média de campo. O mesmo não pode ser afirmado para a variabilidade.

\subsection{Conceito semi-probabilístico aplicado ao módulo de deformação}

Os histogramas apresentados nas Figuras 5.12 e 5.14 apresentam a distribuição de freqüências encontradas para os valores obtidos para o módulo de deformação secante, $\mathrm{E}_{\mathrm{cs}}$. De acordo com os dados apresentados na Tabela 5.15 para $\circ \mathrm{f}_{\mathrm{ck}} 25 \mathrm{MPa}$ o módulo de deformação secante apresentou valor mínimo de 21,87 GPa e máximo de 28,25 GPa, com um desvio-padrão de 1,36 GPa. Na Tabela 5.17 são apresentados os valores do módulo de deformação secante obtidos para o $\mathrm{f}_{\mathrm{ck}} 30 \mathrm{MPa}$, que variou de $25,53 \mathrm{GPa}$ a $29,29 \mathrm{GPa}$, apresentando um desvio-padrão de 0,89 GPa. Essa variação é menor do que aquela apresentada por MONTIJA (2007) quando realizou análise dos resultados constantes dos relatórios técnicos de Inácio, Andrade e Bittencourt (2005) e Inácio, Andrade e Bittencourt (2006) referentes a ensaios interlaboratoriais de alcance nacional de 2004 e 2005, 
respectivamente e também muito menor do que a variação apresentada por BORIN et all (2010) quando realizou análise de diversos concretos da região da Grande São Paulo. Este resultado é logicamente o esperado, dado que no caso do estudo experimental desta dissertação, pretende-se avaliar a parcela de variabilidade das condições de produção, enquanto que no estudo apresentado por BORIN et al. (2010) pretendia-se apresentar a variabilidade encontrada numa região inteira, por exemplo.

Assim, fica evidenciada que a variabilidade aqui obtida corresponde à parcela de contribuição na variação da propriedade que advêm da amostragem realizada por um único laboratório, com materiais de origem definida e controlados, e mão-de-obra especializada. Essa variação apresentada para ambos os $f_{c k s}$ analisados está atrelada a uma série de fatores ligados à variação dos materiais que constituem o concreto, bem como à produção e ensaio do material para determinação da propriedade. Assim, fica demonstrado que o módulo de deformação, tal qual o valor da resistência à compressão característica possui uma distribuição Normal não sendo, portanto, uma variável determinística.

Ao utilizar-se o modelo de previsão proposto pela ABNT NBR 6118 (2007) de acordo com a Tabela 2.1 obtém-se o valor de módulo estático de deformação secante de 23,08 e 26,07 GPa, respectivamente para os valores de resistência característica de 25 e $30 \mathrm{MPa}$. Apesar de ambos de os valores experimentais médios terem sido superiores aos previstos pela norma, deve-se apontar que ao se especificar um valor de módulo de deformação a partir do modelo previsto por esta norma há uma probabilidade de o mesmo não ser atendido dado que o valor do módulo de deformação do concreto segue uma distribuição normal de densidade de probabilidade. Isto ocorre da mesma forma como acontece para a resistência característica, onde a probabilidade máxima de um valor experimental estar abaixo do valor especificado é normalmente fixada em 5\%. A partir da análise dos histogramas é possível verificar qual a probabilidade de um valor de módulo estático de deformação secante estar abaixo do previsto pela norma. Com base nos resultados obtidos para o módulo de deformação secante podemos calcular a probabilidade dos resultados estarem abaixo do valor especificado pela ABNT NBR 6118 (2007). 
Assim, temos a probabilidade para que uma variável aleatória x com distribuição normal genérica $X \sim N\left(\mu, \sigma^{2}\right)$ e a variável $Z$ dada por:

$$
\mathrm{Z}=\frac{\mathrm{X}-\mu}{\sigma}
$$

Como $Z$ tem distribuição normal padrão, isto é, $Z \sim N(0,1)$. Isso significa que, a partir de valores tabelados da distribuição normal padrão, é possível o cálculo para quaisquer valores dos parâmetros $\mu$ e $\sigma^{2}$.

A Tabela 5.20 apresenta os valores de probabilidade dos resultados obtidos para o módulo de deformação secante, $E_{c s}$, estarem abaixo do valor especificado pela ABNT NBR 6118 (2007).

Tabela 5.20 - Probabilidade de não atendimento ao especificado pela ABNT NBR 6118 (2007)

\begin{tabular}{ccc}
\hline fck & $\mathbf{z}$ & Probabilidade (\%) \\
\hline 25 & $-1,44$ & 7,49 \\
\hline 30 & $-1,26$ & 10,38 \\
\hline
\end{tabular}

Assim, para os resultados obtidos no presente estudo tem-se que, para o $f_{c k}$ $25 \mathrm{MPa}$, existe a probabilidade de $7,5 \%$ dos resultados estarem abaixo do especificado pela norma e para o $\mathrm{f}_{\mathrm{ck}} 30 \mathrm{MPa}$, esse valor é de $10,4 \%$.

Dessa forma, ao se especificar o valor mínimo de módulo de deformação baseado na equação empírica de acordo com a ABNT NBR 6118 (2007), pode-se incorrer no não atendimento da propriedade, o que é muito frequente e pode ser observado nos resultados obtidos para os $f_{c k s}$ analisados onde para o $f_{c k} 25 \mathrm{MPa}$ existe a probabilidade de $7,5 \%$ dos resultados estarem abaixo do especificado pela norma e para o $\mathrm{f}_{\mathrm{ck}} 30 \mathrm{MPa}$, esse valor é de 10,4\%. MONTIJA (2007) descreve então a necessidade de avaliar a aplicabilidade dos conceitos semiprobabilísticos para o controle do módulo de deformação como já está implementado para a resistência à compressão nas normas técnicas brasileiras de dosagem, controle e projeto de estruturas de concreto. 
A Figura 5.18 ilustra o fato de que o módulo de deformação é uma grandeza com variação estatística, o que faz com que a sua consideração como variável determinística gera um elevado risco de não atendimento ao especificado. Valendo aqui o raciocínio exposto por MONTIJA (2007), ao se considerar um intervalo de confiança de $90 \%$ e um desvio padrão total para o módulo de $3,0 \mathrm{GPa}$, relativo ao desvio de produção e ensaio, tal qual é feito para a resistência à compressão, o controle tecnológico em obra do concreto fornecido por uma central dosadora poderia obter resultados variando de 22,2 a 29,9 GPa. Caso a distribuição estatística dos resultados dos ensaios obtidos na obra tiver a média coincidente com a mediana, haveria a probabilidade de $45 \%$ de não atendimento da propriedade, com $100 \%$ de confiança.

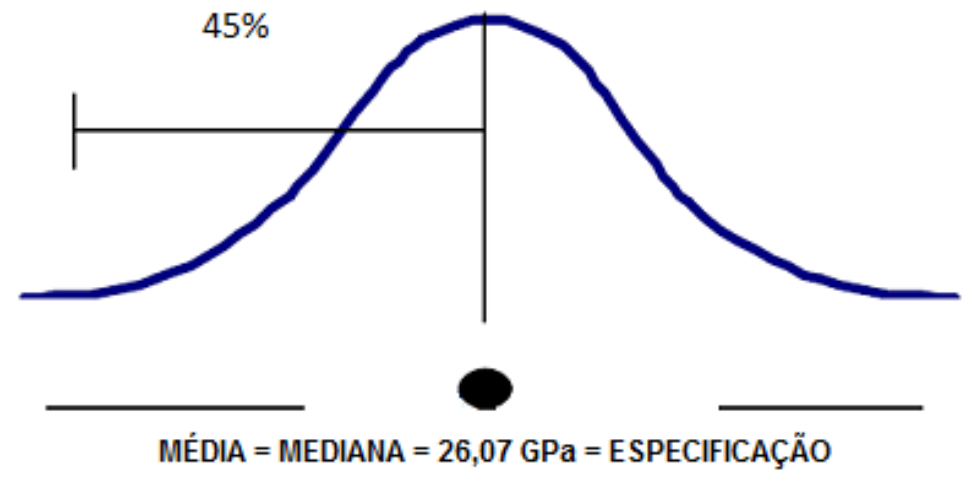

Figura 5.18 - Risco de não atendimento à especificação do módulo de deformação - Adaptado de MONTIJA (2007)

Dessa forma, os fornecedores de concreto têm aumentado a resistência média do concreto para que a probabilidade de rejeição da propriedade módulo de deformação seja menor, conforme demonstraram os resultados de BORIN et al. (2010). Isso incorre em aumento no consumo de cimento, para aumento da rigidez do compósito e, consequentemente, aumento dos custos finais do produto concreto, prática que não garante o atendimento da propriedade.

Conforme exposto por MONTIJA (2007), em função da responsabilidade estrutural o controle do módulo de deformação poderia ser menos rigoroso que o controle realizado para a resistência à compressão de acordo com a ABNT NBR 12655 (2008). Para isso, ao invés de se exigir um intervalo de confiança de $90 \%$, o 
que garante o atendimento à especificação de $95 \%$, poderia ser exigido um intervalo de confiança menor, como o de $80 \%$, o que garantiria que $90 \%$ dos resultados atenderiam à especificação ou mesmo o de $68 \%$, que garantiria $84 \%$ de atendimento à especificação. Segundo o autor ressalta, esta alternativa seria viável também pela menor quantidade de ensaios a serem realizados, comparativamente à resistência à compressão sem que, com isso, estivesse sendo desobedecido o conceito semiprobabilístico normativo. 


\section{CONCLUSÕES}

O presente trabalho demonstra a parcela de contribuição na variação do módulo de deformação do concreto proveniente de ensaios realizados com materiais controlados e de origem definida, bem como mão-de-obra especializada é bem reduzida. Isto ficou demonstrado pelos baixos valores obtidos para o desvio padrão do módulo de deformação experimental obtidos para resistências características de $25 \mathrm{MPa}$ e $30 \mathrm{MPa}$, que corresponderam a 1,36 MPa e 0,89 MPa, respectivamente. Essa variação se dá por haver uma variação, ainda que pequena, dos materiais constituintes do concreto, assim como aquela advinda da produção do concreto e também do ensaio propriamente dito. Demonstra-se, portanto, que o módulo de deformação do concreto, tal como a resistência à compressão, possui uma distribuição de resultados sendo, portanto, uma variável probabilística.

A principal consideração a ser colocada no presente trabalho é o fato de que, sendo o módulo de deformação do concreto função da resistência à compressão, que obedece a uma distribuição probabilística, não se pode atribuir à propriedade uma característica determinística, incorrendo no risco de não atendimento em grande parte dos casos. Nesta dissertação, viu-se que existe sempre uma probabilidade de não atendimento ao especificado em projeto, quando se utiliza o modelo empírico, conforme proposto pela ABNT NBR 6118 (2007). Isso é muito frequente, podendo ser observado nos resultados obtidos no presente trabalho, que apontou uma probabilidade de $7,5 \%$ dos resultados estarem abaixo do especificado pela norma para of $\mathrm{f}_{\mathrm{ck}} 25 \mathrm{MPa}$ e de $10,4 \%$ para of $\mathrm{f}_{\mathrm{ck}} 30 \mathrm{MPa}$.

Com isto, percebe-se uma tendência natural do mercado de elevar a resistência média do concreto com o objetivo de atender ao especificado para o módulo de deformação, prática que causa aumento de custo do concreto, sem que com isso esteja garantido o atendimento da propriedade.

Concluiu-se também que os resultados de controle de produção na Central de Concreto são comparáveis aos resultados de campo em termos de valores médios, mas não em termos de desvio padrão. Isto ocorre pelo fato do concreto estar sujeito a maior número de variáveis intervenientes nas condições de fornecimento em campo. Mesmo assim, pode-se dizer que os resultados obtidos no laboratório são passíveis de serem utilizados para o controle de produção do concreto com a finalidade de atendimento aos requisitos de módulo de deformação. É importante 
ressaltar que, pelo fato de haver maior variabilidade nas condições de produção em escala para a obra, há também uma maior probabilidade de rejeição do concreto em razão da exigência do módulo de deformação.

Conclui-se, portanto, que há a necessidade de estabelecimento de tolerâncias para a especificação do módulo de deformação, dado que é uma variável com distribuição de probabilidade normal e, consequentemente, possui uma probabilidade de rejeição mesmo tendo o valor médio superior ao especificado por norma. No entanto, a amostra analisada para avaliar o módulo de deformação é sempre muito pequena em relação àquela utilizada para se julgar o valor da resistência característica, o qual já embute a verificação de sua variabilidade em seus estimadores previstos em norma. Assim, pode-se dizer que há grande probabilidade de rejeição de concretos conformes durante o controle de recebimento do material na obra.

Desta forma, no futuro devem ser discutidas as possibilidades de mudança de enfoque no controle do módulo, como o controle por valor característico, como ocorre para a resistência. Neste caso, sugere-se não manter o estimador atual da norma e sim obter outro que atribua valores inferiores ao módulo de deformação de modo que a probabilidade de rejeição seja aceitável. Também se pode determinar uma faixa de variação aceitável do valor em torno da média. Pode-se dizer que esta é uma alternativa mais interessante, dado que a responsabilidade estrutural do parâmetro módulo de deformação é menor do que o da resistência à compressão.

Fica evidente também que a valorização do controle corriqueiro do módulo de deformação com a execução dos ensaios em laboratórios credenciados fornecendo, assim, subsídios importantes para maior controle de engenharia das estruturas de concreto. 


\section{PROPOSTA DE ESTUDOS FUTUROS}

Como proposta de futuros estudos, deve-se apontar para a necessidade de se quantificar o real impacto da variabilidade do módulo de deformação do concreto na deformabilidade das estruturas. Com isto, poderão ser estabelecidos parâmetros adequados para as tolerâncias que estes valores devem apresentar no controle de campo.

Outra importante pesquisa que necessita ser realizada é a possibilidade de desenvolvimento de novos ensaios não destrutivos para a determinação do módulo de deformação. Neste sentido, a utilização do pulso ultrassônico pode ser bem promissora e, dessa maneira, seria possível obter um número maior de resultados em campo e aumentar significativamente a representatividade do ensaio diminuindo a probabilidade de aceitação de concretos não conformes e rejeição de concretos conformes.

Outra pesquisa interessante é a definição de faixas esperadas de módulo de deformação por região, dado que esta propriedade é muito dependente das características dos agregados e, com isto, tem um caráter eminentemente regional. Assim, se diminuiria a probabilidade de rejeição do concreto em termos de módulo de deformação para regiões específicas e não se cometeria o equívoco de superestimar o valor de módulo de deformação do concreto quando da utilização de um estimador único para todo o Brasil, como acontece hoje quando se segue o recomendado pela norma NBR 6118. 


\section{REFERÊNCIAS BIBLIOGRÁFICAS}

AïTCIN, P.C. Concreto de alto desempenho. São Paulo: Pini, 2000.

AÏTCIN, P.C.; MEHTA, P.K. Effect of coarse-aggregate characteristics on mechanical properties of high-strength concrete. ACl Materials Journal, p.103107, Março/Abril,1990.

ALMEIDA, P.A.O. Transdutores para medida de deslocamentos lineares. Notas de aula. Escola Politécnica, Universidade de São Paulo. São Paulo, 2004.

AMERICAN SOCIETY FOR TESTING AND MATERIALS (ASTM). Standard test method for compressive strength of cylindrical concrete specimens - C-39. Filadélfia (EUA), 2003.

Standard test method for static modulus of elasticity and poisson's ratio in concrete in compression - C-469. Filadélfia (EUA), 2002.

ANDRADE, W.P. (Ed.). Concretos massa, estrutural, projetado e compactado com rolo - Ensaios e propriedades. São Paulo: Pini, 1997.

ANDRIOLO, F.R.; SGARBOZA, B.C. Inspeção e controle de qualidade do concreto. São Paulo: Newswork, 1993.

ASSOCIAÇÃO BRASILEIRA DE NORMAS TÉCNICAS (ABNT). Amostragem de concreto fresco - NBR NM 33. Rio de Janeiro, 1998.

. Concreto - Procedimento para moldagem e cura de corpos-de-prova NBR 5738. Rio de Janeiro, 2003.

. Concreto - Ensaios de compressão de corpos-de-prova cilíndricos - NBR 5739. Rio de Janeiro, 2007.

Projeto de estruturas de concreto - Procedimento - NBR 6118. Rio de Janeiro, 2007.

. Concreto - Concreto - Determinação do módulo estático de elasticidade à compressão - NBR 8522. Rio de Janeiro, 2008.

. Concreto de cimento Portland - Preparo, controle e recebimento Procedimento - NBR 12655. Rio de Janeiro, 2006.

BORIN, L.A., FONSECA, L.P.T., DE MARCHI, R.D., SILVA, R.M.S., FIGUEIREDO, A.D. Risco de rejeição de concretos devido à não conformidade com os 
parâmetros normalizados para o módulo de elasticidade, $52^{\circ}$ Congresso Brasileiro de Concreto, IBRACON, Fortaleza, Outubro, 2010.

COMITE EURO-INTERNACIONAL du BETON. CEB - FIP Model Code 1990. Bulletin d' Information, may 1993

CARRASQUILlO, R. L., NILSON, A. H., SLATE, F.O., 1981, Properties of High Strength Concrete Subject to Short-Term Loads, ACl Journal, V. 78, May/June., p. 171-178.

CALLISTER, W.D., Jr. Ciência e engenharia de materiais: uma introdução. $5^{a}$ edição - LTC - Rio de Janeiro, 2002.

COSTA NETO, P.L.O. Estatística. 2a edição - Edgard Blücher - São Paulo, 2002.

CUNHA, C.H.M. Deformabilidade das estruturas de concreto: impacto da variabilidade do módulo de elasticidade secante e da resistência à tração, decorrente das modificações dos materiais, cimentos e agregados. Dissertação (Mestrado) - Escola Politécnica, Universidade de São Paulo. São Paulo, 2000.

DE MARCHI, R.D., FONSECA, L.P.T., BORIN, L.A., SILVA, R.M.S., FIGUEIREDO, A.D. Avaliação de parâmetros de dosagem para atendimento do módulo de deformação do concreto produzido em central dosadora. , $52^{\circ}$ Congresso Brasileiro de Concreto, IBRACON, Fortaleza, Outubro, 2010.

EVANGELISTA, Ana C. J., Avaliação da Resistência do Concreto Usando Diferentes Ensaios Não Destrutivos, Tese de Doutorado, COPPE, Universidade Federal do Rio de Janeiro, Rio de Janeiro, 2002.

FIGUEIREDO, A.D. Princípios de ciência dos materiais. Notas de aula. Escola Politécnica, Universidade de São Paulo. São Paulo, 2008.

FREITAS, L. B.; JÚDICE, F, M. S.; CARNEIRO, L. A. V.; EVANGELISTA, A. C. J.; SHEHATA, L. C. D., Avaliação do Módulo de Elasticidade de Concretos de Alto Desempenho com Diferentes Idades, $43^{\circ}$ Congresso Brasileiro de Concreto, IBRACON, Foz do Iguaçu, Agosto, 2001.

HELENE, P.R.L. Controle de qualidade do concreto. Dissertação (Mestrado) Escola Politécnica, Universidade de São Paulo. São Paulo, 1981. 
HELENE, P.R.L. Contribuição ao estabelecimento de parâmetros de dosagem e controle dos concretos de cimento Portland. Tese (Doutorado) - Escola Politécnica, Universidade de São Paulo. São Paulo, 1987.

HELENE, P.R.L. Estudo da variação do módulo de elasticidade do concreto com a composição e características do concreto fresco e endurecido. Escola Politécnica da Universidade de São Paulo, Interessado: Associação Brasileira de Cimento Portland (ABCP). São Paulo, 1998 (Relatório Técnico no 10.122).

HELENE, P.R.L.; MONTEIRO, P.J.M. Design concrete mixtures for strength, elastic modulus and fracture energy, Materials and Structures, Vol. 26, No. 162, p.443-452, Outubro, 1993.

HELENE, P.R.L. Dosagem de concreto de cimento Portland. Notas de Aula. Escola Politécnica, Universidade de São Paulo. São Paulo, 2008.

HELENE, Paulo R.L. \& TERZIAN, Paulo R. Manual de Dosagem e Controle do Concreto, Ed. PINI/SENAI, São Paulo, 1993.

LIMA, E.P. Influência do volume de pasta na zona de transição pasta/agregado com relação às propriedades mecânicas e de durabilidade do concreto. Dissertação (Mestrado) - Escola Politécnica, Universidade de São Paulo. São Paulo, 2000.

MEHTA, P.K. \& MONTEIRO, P.J.M. Concreto: Estrutura, Propriedades e Materiais, Ed. PINI, São Paulo, 2008.

MONTIJA, Fernando C. Aspectos da variabilidade experimental do ensaio de módulo de deformação do concreto. Dissertação (Mestrado) - Escola Politécnica, Universidade de São Paulo. São Paulo, 2007.

MURDOCK, Leonard J. \& BROOK, K. M. Concrete Materials and Practice. London, Arnold,1991.

NEVILLE, A.M. Propriedades do Concreto, Ed. PINI, São Paulo, 1997.

PAULON, V.A. Estudo da microestrutura da zona de transição entre a pasta de cimento e o agregado. Tese (Doutorado) - Escola Politécnica, Universidade de São Paulo. São Paulo, 1991. 
PAULON, V.A., In ISAIA, G.C. (Ed.). Concreto: ensino, pesquisa e realizações. vol. 1, cap. 19, IBRACON - São Paulo, 2005.

PEREIRA NETO, P.M. Efeito do agregado graúdo em algumas propriedades do concreto de alta resistência com microssílica. Dissertação (Mestrado) - Escola Politécnica, Universidade de São Paulo. São Paulo, 1994.

POWERS, Treval C. The Properties of Fresh Concrete. New York, J. Willey,1968.

SBRIGHI NETO, C., In ISAIA, G.C. (Ed.). Concreto: ensino, pesquisa e realizações. vol. 1, cap. 11, IBRACON - São Paulo, 2005.

SHEHATA, L.D., In ISAIA, G.C. (Ed.). Concreto: ensino, pesquisa e realizações. vol. 1, cap. 21, IBRACON - São Paulo, 2005.

SHEHATA, Lídia C.D. \& MARTINS, Paulo C.R. Classificação e Propriedades do Concreto e do Aço. III Simpósio EPUSP sobre Estruturas de Concreto, Adendo, Dez. 1998.

SPIEGEL, Murray Ralph. Estatística, Ed. McGraw-Hill, Brasília, 1974.

TANGO, C. E. S., In ISAIA, G.C. (Ed.). Concreto: ensino, pesquisa e realizações. vol. 1, cap. 17, IBRACON - São Paulo, 2005.

TIMOSHENKO, S.P.; GOODIER, J.N. Teoria da elasticidade. 3a edição Guanabara Dois - Rio de Janeiro, 1980.

VAN VLACK, L.H. Princípios de ciência dos materiais. Edgard Blücher - Brasília, 1973.

VASCONCELOS, A.C.; GIAMMUSSO, S.E. O misterioso módulo de elasticidade, Anais do $40^{\circ}$ Congresso Brasileiro do Concreto, 1998. 


\section{APÊNDICE A - Resultados dos ensaios realizados - Primeira etapa}

Tabela A-1.a - Resultados dos ensaios de resistência à compressão $-f_{c k} 25 \mathrm{MPa}$

\begin{tabular}{|c|c|c|c|c|c|c|c|c|c|c|c|}
\hline Moldagem & Amostra & $\begin{array}{c}\mathbf{f}_{\mathrm{c} 28} \\
(\mathrm{MPa})\end{array}$ & $\begin{array}{l}\text { Média } \\
(\mathrm{MPa})\end{array}$ & $\begin{array}{c}\sigma \\
(\mathrm{MPa})\end{array}$ & $\begin{array}{l}\mathrm{CV} \\
(\%)\end{array}$ & Moldagem & Amostra & $\begin{array}{c}\mathbf{f}_{\mathrm{c} 28} \\
(\mathrm{MPa})\end{array}$ & $\begin{array}{l}\text { Média } \\
(\mathrm{MPa})\end{array}$ & $\begin{array}{c}\sigma \\
(\mathrm{MPa})\end{array}$ & $\begin{array}{l}\mathrm{CV} \\
(\%)\end{array}$ \\
\hline \multirow{2}{*}{1} & 1 & 30,2 & \multirow{2}{*}{30,8} & \multirow{2}{*}{0,85} & \multirow{2}{*}{2,75} & \multirow{2}{*}{24} & 1 & 30,5 & \multirow{2}{*}{29,7} & \multirow{2}{*}{1,13} & \multirow{2}{*}{3,81} \\
\hline & 2 & 31,4 & & & & & 2 & 28,9 & & & \\
\hline \multirow{2}{*}{2} & 1 & 31,4 & \multirow{2}{*}{31,2} & \multirow{2}{*}{0,28} & \multirow{2}{*}{0,91} & \multirow{2}{*}{25} & 1 & 33,4 & \multirow{2}{*}{32,2} & \multirow{2}{*}{1,77} & \multirow{2}{*}{5,50} \\
\hline & 2 & 31,0 & & & & & 2 & 30,9 & & & \\
\hline \multirow{2}{*}{3} & 1 & 30,7 & \multirow{2}{*}{29,9} & \multirow{2}{*}{1,13} & \multirow{2}{*}{3,78} & 26 & 1 & 31,3 & 221 & 106 & 321 \\
\hline & 2 & 29,1 & & & & $\angle 0$ & 2 & 32,8 & $3<, 1$ & 1,00 & 3,31 \\
\hline 4 & 1 & 28,7 & 271 & 226 & 835 & 27 & 1 & 29,3 & 284 & 134 & 474 \\
\hline 4 & 2 & 25,5 & $2 T, 1$ & $2, \angle O$ & 0,05 & 21 & 2 & 27,4 & 20,4 & 1,04 & 4,14 \\
\hline 5 & 1 & 31,3 & 316 & 0,12 & 134 & 28 & 1 & 33,7 & 338 & 707 & 021 \\
\hline 5 & 2 & 31,9 & 31,6 & U,4L & 1,34 & 28 & 2 & 33,8 & 33,8 & 0,07 & $0, \angle 1$ \\
\hline 6 & 1 & 29,9 & 310 & 156 & 502 & 29 & 1 & 30,1 & 304 & 035 & 116 \\
\hline 0 & 2 & 32,1 & (31,0 & 1,56 & 5,02 & 29 & 2 & 30,6 & 30,4 & 0,35 & 1,16 \\
\hline 7 & 1 & 37,9 & 386 & 099 & 256 & 30 & 1 & 32,1 & 320 & 014 & 044 \\
\hline$t$ & 2 & 39,3 & 30,0 & 0,59 & 2,00 & 50 & 2 & 31,9 & 32,0 & 0,14 & 0,44 \\
\hline 8 & 1 & 36,0 & 356 & 0.57 & 150 & 21 & 1 & 39,7 & 396 & 011 & ת? \\
\hline 8 & 2 & 35,2 & 35,6 & $0,5 /$ & 1,59 & 31 & 2 & 39,5 & 39,6 & 0,14 & 0,36 \\
\hline 9 & 1 & 34,6 & 346 & & م00 & 32 & 1 & 34,4 & & & \\
\hline$y$ & 2 & 34,6 & 34,6 & 0,00 & 0,00 & 32 & 2 & 37,0 & 35,7 & 1,84 & 5,15 \\
\hline 10 & 1 & 34,4 & 350 & 078 & 223 & 33 & 1 & 31,0 & 318 & 113 & 356 \\
\hline 10 & 2 & 35,5 & 35,0 & 0,10 & $2, \angle 3$ & 30 & 2 & 32,6 & 31,8 & 1,13 & 3,56 \\
\hline 11 & 1 & 33,1 & 338 & 099 & 293 & 34 & 1 & 30,8 & 309 & 007 & 023 \\
\hline 11 & 2 & 34,5 & 30,0 & 0,99 & 2,93 & 34 & 2 & 30,9 & 30,9 & 0,01 & $0, \angle 0$ \\
\hline 12 & 1 & 30,8 & 312 & 57 & 181 & 35 & 1 & 32,5 & 329 & 057 & 172 \\
\hline 12 & 2 & 31,6 & 31,2 & 0,51 & 1,81 & 35 & 2 & 33,3 & $3<, 9$ & 0,57 & 1,72 \\
\hline 13 & 1 & 31,1 & 330 & 269 & 814 & 36 & 1 & 36,8 & 354 & 198 & 559 \\
\hline 13 & 2 & 34,9 & 33,0 & 2,69 & 8,14 & 30 & 2 & 34,0 & 35,4 & 1,98 & 5,59 \\
\hline 14 & 1 & 31,1 & 322 & 148 & 462 & 37 & 1 & 32,3 & 317 & ?9? & 200 \\
\hline 14 & 2 & 33,2 & J2, & 1,40 & 4,02 & (1 & 2 & 31,0 & 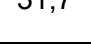 & 0,92 & 2,90 \\
\hline 15 & 1 & 29,6 & 206 & 0707 & 021 & & 1 & 34,8 & & & \\
\hline 15 & 2 & 29,5 & 29,6 & 0,07 & $0, Z 4$ & 38 & 2 & 32,6 & 33,7 & 1,56 & 4,62 \\
\hline 16 & 1 & 32,0 & 321 & 014 & 0.44 & 39 & 1 & 28,7 & 309 & 304 & 986 \\
\hline 10 & 2 & 32,2 & $0<, 1$ & 0,14 & 0,44 & 39 & 2 & 33,0 & 0,9 & 0,04 & 9,00 \\
\hline 17 & 1 & 29,4 & 20 ? & 35 & 121 & 10 & 1 & 29,7 & 203 & 061 & 218 \\
\hline 11 & 2 & 28,9 & 29,2 & 0,30 & $1, \angle 1$ & 40 & 2 & 28,8 & 29,3 & 0,04 & 2,10 \\
\hline 18 & 1 & 27,4 & 273 & 014 & 0.52 & 41 & 1 & 35,0 & 356 & 078 & 219 \\
\hline 10 & 2 & 27,2 & $2 T, v$ & 0,14 & $0, v 2$ & 41 & 2 & 36,1 & 00,0 & 0,10 & 2,15 \\
\hline 19 & 1 & 31,0 & 310 & $0 \cap 7$ & 023 & 12 & 1 & 35,7 & 365 & 113 & 310 \\
\hline 19 & 2 & 30,9 & 31,0 & 0,07 & $0, \angle 3$ & 42 & 2 & 37,3 & 36,5 & 1,13 & 3,10 \\
\hline 20 & 1 & 31,4 & 305 & 134 & 411 & 43 & 1 & 33,5 & 331 & 064 & 103 \\
\hline$\angle 0$ & 2 & 29,5 & 30,5 & 1,34 & 4,41 & 43 & 2 & 32,6 & 33,1 & 0,64 & 1,93 \\
\hline 21 & 1 & 30,0 & 300 & 007 & 024 & 44 & 1 & 31,0 & 310 & مחת & חת ח \\
\hline 21 & 2 & 29,9 & 30,0 & 0,07 & $0, \angle 4$ & 44 & 2 & 31,0 & טו, & 0,00 & 0,00 \\
\hline 22 & 1 & 30,8 & 302 & 0.92 & 305 & 45 & 1 & 33,2 & 340 & 106 & 312 \\
\hline & 2 & 29,5 & 30,2 & 0,92 & 3,05 & 45 & 2 & 34,7 & 34,0 & 1,06 & 3,12 \\
\hline 23 & 1 & 26,3 & 266 & 042 & 159 & 46 & 1 & 32,2 & 328 & 085 & 259 \\
\hline$\angle 3$ & 2 & 26,9 & $\angle 0,0$ & $0,4 Z$ & 1,09 & 40 & 2 & 33,4 & 32,0 & 0,05 & 2,59 \\
\hline
\end{tabular}


Tabela A-1.b - Resultados dos ensaios de resistência à compressão - $f_{c k} 25 \mathrm{MPa}$

\begin{tabular}{|c|c|c|c|c|c|c|c|c|c|c|c|}
\hline Moldagem & Amostra & $\begin{array}{c}\mathbf{f}_{\mathrm{c} 28} \\
(\mathrm{MPa})\end{array}$ & $\begin{array}{l}\text { Média } \\
(\mathrm{MPa})\end{array}$ & $\begin{array}{c}\sigma \\
(\mathrm{MPa})\end{array}$ & $\begin{array}{l}\text { CV } \\
(\%)\end{array}$ & Moldagem & Amostra & $\begin{array}{c}\mathbf{f}_{\mathrm{c} 28} \\
(\mathrm{MPa})\end{array}$ & $\begin{array}{l}\text { Média } \\
(\mathrm{MPa})\end{array}$ & $\begin{array}{c}\sigma \\
(\mathrm{MPa})\end{array}$ & $\begin{array}{l}\text { CV } \\
(\%)\end{array}$ \\
\hline \multirow{2}{*}{47} & 1 & 30,0 & \multirow{2}{*}{30,0} & \multirow{2}{*}{0,07} & \multirow{2}{*}{0,24} & \multirow{2}{*}{70} & 1 & 31,1 & \multirow{2}{*}{30,3} & \multirow{2}{*}{1,20} & \multirow{2}{*}{3,97} \\
\hline & 2 & 29,9 & & & & & 2 & 29,4 & & & \\
\hline \multirow{2}{*}{48} & 1 & 33,0 & \multirow{2}{*}{33,1} & \multirow{2}{*}{0,07} & \multirow{2}{*}{0,21} & \multirow{2}{*}{71} & 1 & 31,1 & \multirow{2}{*}{31,3} & \multirow{2}{*}{0,21} & \multirow{2}{*}{0,68} \\
\hline & 2 & 33,1 & & & & & 2 & 31,4 & & & \\
\hline \multirow{2}{*}{49} & 1 & 30,3 & \multirow{2}{*}{30,3} & \multirow{2}{*}{0,00} & \multirow{2}{*}{0,00} & 72 & 1 & 32,4 & 323 & 011 & 011 \\
\hline & 2 & 30,3 & & & & 12 & 2 & 32,2 & 32,3 & 0,14 & 0,44 \\
\hline 50 & 1 & 28,8 & 280 & $\cap \cap 7$ & 025 & 73 & 1 & 32,2 & 322 & מחم & מחת \\
\hline 50 & 2 & 28,9 & $\angle 0,9$ & 0,01 & $0, \angle 5$ & 13 & 2 & 32,2 & 32,2 & 0,00 & 0,00 \\
\hline 51 & 1 & 31,6 & 318 & 028 & 089 & 74 & 1 & 32,1 & 320 & 01 & 066 \\
\hline 51 & 2 & 32,0 & 31,8 & 0,28 & 0,89 & 14 & 2 & 31,8 & 32,0 & 0,21 & 0,60 \\
\hline ५? & 1 & 33,5 & 230 & 057 & 167 & 75 & 1 & 33,6 & 235 & 014 & (1) \\
\hline 52 & 2 & 34,3 & 33,9 & 0,51 & 1,01 & 15 & 2 & 33,4 & 33,5 & 0,14 & 0,42 \\
\hline 53 & 1 & 33,6 & 336 & 7مि & 021 & 76 & 1 & 30,2 & 301 & 021 & 071 \\
\hline 30 & 2 & 33,5 & 30,0 & 0,01 & 0,21 & 10 & 2 & 29,9 & 00,1 & 0,21 & $0, \pi 1$ \\
\hline 54 & 1 & 31,8 & 302 & 226 & 749 & 77 & 1 & 31,7 & 329 & 163 & 405 \\
\hline 34 & 2 & 28,6 & 0,2 & $2, \angle 0$ & $1,4 \mathrm{~J}$ & 11 & 2 & 34,0 & $\mathrm{~J}, \mathrm{~J}$ & 1,00 & 4,50 \\
\hline 55 & 1 & 29,7 & 300 & 042 & 141 & 78 & 1 & 32,1 & & 035 & 109 \\
\hline 50 & 2 & 30,3 & 30,0 & 0,42 & 1,41 & 18 & 2 & 32,6 & 32,4 & 0,35 & 1,09 \\
\hline & 1 & 33,7 & 322 & 078 & 235 & 70 & 1 & 33,7 & 338 & 014 & 042 \\
\hline 50 & 2 & 32,6 & 30,2 & 0,10 & 2,35 & 19 & 2 & 33,9 & 33,0 & 0,14 & 0,42 \\
\hline 57 & 1 & 30,7 & 308 & 014 & 046 & 80 & 1 & 31,4 & 321 & 092 & 287 \\
\hline 31 & 2 & 30,9 & 3,0 & 0,14 & 0,40 & OU & 2 & 32,7 & 32,1 & 0,92 & 2,01 \\
\hline 58 & 1 & 29,9 & 307 & 106 & 346 & 81 & 1 & 32,8 & 322 & 085 & 264 \\
\hline 58 & 2 & 31,4 & 30,1 & 1,00 & 3,46 & 81 & 2 & 31,6 & $3<, 2$ & 0,85 & 2,64 \\
\hline 59 & 1 & 30,0 & 292 & 116 & 397 & 82 & 1 & 32,6 & 312 & 198 & 635 \\
\hline 59 & 2 & 28,4 & 29,2 & 1,10 & 3,91 & 82 & 2 & 29,8 & 31,2 & 1,98 & 0,35 \\
\hline 60 & 1 & 30,7 & 307 & 7ח & 023 & 83 & 1 & 33,1 & 337 & 085 & 252 \\
\hline 00 & 2 & 30,6 & $30, r$ & 0,01 & $0, \angle J$ & 00 & 2 & 34,3 & $30, r$ & 0,00 & 2,02 \\
\hline 61 & 1 & 31,2 & 310 & 028 & 091 & 84 & 1 & 29,5 & 286 & 134 & 471 \\
\hline & 2 & 30,8 & & & & & 2 & 27,6 & & & \\
\hline 62 & 1 & 31,7 & 312 & 071 & 227 & 85 & 1 & 26,8 & 266 & (28 & 106 \\
\hline 62 & 2 & 30,7 & 31,2 & $0, / 1$ & 2,27 & 85 & 2 & 26,4 & 26,6 & 0,28 & 1,06 \\
\hline 63 & 1 & 30,3 & 305 & 028 & 093 & 86 & 1 & 29,7 & 289 & 113 & 301 \\
\hline 03 & 2 & 30,7 & 3,0 & $0, \angle 0$ & 0,93 & 00 & 2 & 28,1 & $\angle 0,9$ & 1,13 & 3,91 \\
\hline 64 & 1 & 28,9 & 282 & 106 & 377 & 87 & 1 & 33,0 & 324 & 092 & 284 \\
\hline 04 & 2 & 27,4 & $\angle O, \angle$ & 1,00 & $0, \pi t$ & or & 2 & 31,7 & $0<, 4$ & 0,92 & 2,04 \\
\hline 65 & 1 & 29,8 & 298 & 70 0 & 021 & 88 & 1 & 30,8 & 317 & 120 & 380 \\
\hline 05 & 2 & 29,7 & 29,0 & 0,07 & 0,24 & 00 & 2 & 32,5 & ה & $1, \angle U$ & 3,00 \\
\hline 66 & 1 & 31,2 & 312 & ח & מחم & 89 & 1 & 29,3 & 296 & 035 & 120 \\
\hline 60 & 2 & 31,2 & 31,2 & 0,00 & 0,00 & 89 & 2 & 29,8 & 29,6 & 0,35 & $\mathrm{~T}, \angle \mathrm{U}$ \\
\hline 67 & 1 & 29,8 & 290 & 014 & 0.47 & 90 & 1 & 30,3 & 296 & 099 & 334 \\
\hline $6 /$ & 2 & 30,0 & 29,9 & 0,14 & 0,47 & 90 & 2 & 28,9 & 29,0 & 0,99 & 3,34 \\
\hline 68 & 1 & 28,9 & 284 & 071 & 249 & 91 & 1 & 30,2 & 305 & 042 & 139 \\
\hline & 2 & 27,9 & & & & प्रा & 2 & 30,8 & & & כ, \\
\hline 69 & 1 & 30,2 & 310 & 113 & 365 & 92 & 1 & 36,7 & 360 & O 99 & 275 \\
\hline 69 & 2 & 31,8 & 31,0 & 1,13 & 3,65 & 92 & 2 & 35,3 & 36,0 & 0,99 & 2,15 \\
\hline
\end{tabular}


Tabela A-1..c - Resultados dos ensaios de resistência à compressão $-f_{c k} 25 \mathrm{MPa}$

\begin{tabular}{|c|c|c|c|c|c|c|c|c|c|c|c|}
\hline Moldagem & Amostra & $\begin{array}{c}\mathbf{f}_{\mathrm{c} 28} \\
(\mathrm{MPa})\end{array}$ & $\begin{array}{l}\text { Média } \\
(\mathrm{MPa})\end{array}$ & $\begin{array}{c}\sigma \\
(\mathrm{MPa})\end{array}$ & $\begin{array}{l}\text { CV } \\
(\%)\end{array}$ & Moldagem & Amostra & $\begin{array}{c}\mathbf{f}_{\mathrm{c} 28} \\
(\mathrm{MPa})\end{array}$ & $\begin{array}{l}\text { Média } \\
\text { (MPa) }\end{array}$ & $\begin{array}{c}\sigma \\
(\mathrm{MPa})\end{array}$ & $\begin{array}{l}\mathrm{CV} \\
(\%)\end{array}$ \\
\hline \multirow{2}{*}{93} & 1 & 32,7 & \multirow{2}{*}{32,9} & \multirow{2}{*}{0,28} & \multirow{2}{*}{0,86} & \multirow{2}{*}{116} & 1 & 32,9 & \multirow{2}{*}{32,5} & \multirow{2}{*}{0,64} & \multirow{2}{*}{1,96} \\
\hline & 2 & 33,1 & & & & & 2 & 32,0 & & & \\
\hline \multirow{2}{*}{94} & 1 & 33,7 & \multirow{2}{*}{36,0} & \multirow{2}{*}{3,18} & \multirow{2}{*}{8,85} & \multirow{2}{*}{117} & 1 & 32,6 & \multirow{2}{*}{32,8} & \multirow{2}{*}{0,28} & \multirow{2}{*}{0,86} \\
\hline & 2 & 38,2 & & & & & 2 & 33,0 & & & \\
\hline \multirow{2}{*}{95} & 1 & 31,3 & \multirow{2}{*}{31,5} & \multirow{2}{*}{0,21} & \multirow{2}{*}{0,67} & 118 & 1 & 33,0 & 320 & 021 & 065 \\
\hline & 2 & 31,6 & & & & 178 & 2 & 32,7 & $32, y$ & 0,21 & 0,65 \\
\hline 06 & 1 & 35,5 & 255 & POP & 促 & 110 & 1 & 27,7 & 277 & חת ח & חת ח \\
\hline 90 & 2 & 35,5 & 30,5 & 0,00 & 0,00 & 119 & 2 & 27,7 & $27, T$ & 0,00 & 0,00 \\
\hline 07 & 1 & 34,9 & 340 & ח ח & מחم & 120 & 1 & 26,8 & 272 & 057 & 208 \\
\hline प्रा & 2 & 34,9 & $34, y$ & 0,00 & 0,00 & $1 \angle 0$ & 2 & 27,6 & $2 T, \angle$ & 0,01 & 2,00 \\
\hline 09 & 1 & 33,1 & 231 & PO० & מחת & 121 & 1 & 30,2 & & 010 & 100 \\
\hline 90 & 2 & 33,1 & 30,1 & 0,00 & 0,00 & 121 & 2 & 29,5 & 29,9 & 0,49 & 1,00 \\
\hline 99 & 1 & 27,2 & 28.4 & 163 & 574 & 122 & 1 & 31,6 & 316 & 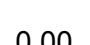 & חم 0 \\
\hline 99 & 2 & 29,5 & 28,4 & 1,63 & 5,14 & $12 \angle$ & 2 & 31,6 & 31,6 & 0,00 & 0,00 \\
\hline 100 & 1 & 31,2 & 315 & 035 & 112 & 123 & 1 & 27,5 & 275 & ח & חم 0 \\
\hline 100 & 2 & 31,7 & & 0,35 & 1,12 & 120 & 2 & 27,5 & $2 t, 0$ & 0,00 & 0,00 \\
\hline 101 & 1 & 36,4 & 362 & 014 & 0 & 121 & 1 & 35,3 & 256 & 012 & 110 \\
\hline 101 & 2 & 36,2 & 30,3 & 0,14 & 0,39 & $1 \angle 4$ & 2 & 35,9 & 35,6 & 0,42 & 1,19 \\
\hline 102 & 1 & 30,0 & 302 & 021 & O 70 & 125 & 1 & 35,9 & $36 ?$ & 035 & ه \\
\hline 102 & 2 & 30,3 & 30,2 & 0,21 & 0,10 & 125 & 2 & 36,4 & 36,2 & 0,35 & 0,98 \\
\hline 102 & 1 & 36,2 & $36 ?$ & 7م 0 & ח? 0 & 126 & 1 & 36,5 & $36 ?$ & 025 & ه 0 Q \\
\hline 100 & 2 & 36,1 & 30,2 & 0,01 & $0, \angle U$ & 120 & 2 & 36,0 & 30,0 & 0,05 & 0,90 \\
\hline 104 & 1 & 28,5 & 284 & 021 & 075 & 127 & 1 & 30,8 & 306 & 028 & 29 0 \\
\hline 104 & 2 & 28,2 & $\angle 0,4$ & $0, \angle 1$ & 0,13 & 126 & 2 & 30,4 & 3,0 & $0, \angle 0$ & $0, \overline{3}$ \\
\hline 105 & 1 & 30,0 & 300 & חמת ח & 促 & 120 & 1 & 33,8 & 327 & 021 & 063 \\
\hline 105 & 2 & 30,0 & 30,0 & 0,00 & 0,00 & $1 \angle 8$ & 2 & 33,5 & 30,1 & $0, \angle 1$ & 0,03 \\
\hline 106 & 1 & 33,1 & 331 & ח & 促 & 129 & 1 & 38,7 & 391 & 049 & 127 \\
\hline 106 & 2 & 33,1 & 33,1 & 0,00 & 0,00 & 129 & 2 & 39,4 & 39,1 & 0,49 & 1,21 \\
\hline 107 & 1 & 35,7 & 357 & 7חم & ח? 0 & 130 & 1 & 36,4 & 366 & 021 & 058 \\
\hline 101 & 2 & 35,6 & 30,1 & 0,01 & $0, \angle 0$ & 100 & 2 & 36,7 & 30,0 & $0, \angle 1$ & 0,50 \\
\hline 100 & 1 & 34,9 & 240 & คด & 0 & 121 & 1 & 35,3 & ת ח & 0 & 1070 \\
\hline 108 & 2 & 34,9 & 34,9 & 0,00 & 0,00 & 131 & 2 & 30,3 & 32,8 & 3,54 & $10, / 8$ \\
\hline 109 & 1 & 35,7 & 361 & 057 & 157 & 132 & 1 & 33,1 & 328 & 042 & 120 \\
\hline 109 & 2 & 36,5 & 30,1 & 0,51 & 1,51 & 132 & 2 & 32,5 & $3<, 8$ & 0,42 & 1,29 \\
\hline 110 & 1 & 33,5 & 246 & 156 & 150 & 122 & 1 & 33,1 & 220 & 012 & 120 \\
\hline 170 & 2 & 35,7 & 34,6 & 1,56 & 4,50 & 133 & 2 & 32,5 & $3<, 8$ & 0,42 & 1,29 \\
\hline 111 & 1 & 32,1 & 320 & 021 & 066 & 134 & 1 & 31,9 & 323 & 049 & 153 \\
\hline TII & 2 & 31,8 & $\mathrm{~J} 2, \mathrm{U}$ & 0,21 & 0,00 & 134 & 2 & 32,6 & $3<, 3$ & 0,49 & 1,53 \\
\hline 112 & 1 & 33,7 & 328 & 011 & P1? & 125 & 1 & 33,7 & 231 & $0 ?$ & 278 \\
\hline 112 & 2 & 33,9 & 33,8 & 0,14 & 0,42 & 135 & 2 & 32,4 & 33,1 & 0,92 & 2,78 \\
\hline 113 & 1 & 32,6 & 321 & 071 & 220 & 136 & 1 & 39,3 & 377 & 233 & 620 \\
\hline 113 & 2 & 31,6 & 32,1 & $0, \pi 1$ & $2, \angle 0$ & 136 & 2 & 36,0 & 31,1 & 2,33 & $0, \angle 0$ \\
\hline 111 & 1 & 30,1 & 1 & 7مिم & 021 & 137 & 1 & 35,2 & 345 & ค 99 & 287 \\
\hline 114 & 2 & 30,0 & 00,1 & 0,07 & 0,24 & 102 & 2 & 33,8 & 34,5 & 0,99 & 2,01 \\
\hline & 1 & 37,3 & & & & & 1 & 33,3 & & & \\
\hline 115 & 2 & 35,7 & 36,5 & 1,13 & 3,10 & 138 & 2 & 31,2 & 32,3 & 1,48 & 4,60 \\
\hline
\end{tabular}


Tabela A-2.a - Resultados dos ensaios de resistência à compressão $-f_{c k} 30 \mathrm{MPa}$

\begin{tabular}{|c|c|c|c|c|c|c|c|c|c|c|c|}
\hline Moldagem & Amostra & $\begin{array}{c}\mathbf{f}_{\mathrm{c} 28} \\
(\mathrm{MPa})\end{array}$ & $\begin{array}{l}\text { Média } \\
(\mathrm{MPa})\end{array}$ & $\begin{array}{c}\sigma \\
(\mathrm{MPa})\end{array}$ & $\begin{array}{l}\text { CV } \\
(\%)\end{array}$ & Moldagem & Amostra & $\begin{array}{c}\mathbf{f}_{\mathrm{c} 28} \\
(\mathrm{MPa})\end{array}$ & $\begin{array}{l}\text { Média } \\
(\mathrm{MPa})\end{array}$ & $\begin{array}{c}\sigma \\
(\mathrm{MPa})\end{array}$ & $\begin{array}{l}\text { CV } \\
(\%)\end{array}$ \\
\hline \multirow{2}{*}{1} & 1 & 45,3 & \multirow{2}{*}{45,0} & \multirow{2}{*}{0,42} & \multirow{2}{*}{0,94} & \multirow{2}{*}{19} & 1 & 37,8 & \multirow{2}{*}{38,1} & \multirow{2}{*}{0,42} & \multirow{2}{*}{1,11} \\
\hline & 2 & 44,7 & & & & & 2 & 38,4 & & & \\
\hline \multirow{2}{*}{2} & 1 & 39,0 & \multirow{2}{*}{38,8} & \multirow{2}{*}{0,28} & \multirow{2}{*}{0,73} & \multirow{2}{*}{20} & 1 & 38,0 & \multirow{2}{*}{38,1} & \multirow{2}{*}{0,14} & \multirow{2}{*}{0,37} \\
\hline & 2 & 38,6 & & & & & 2 & 38,2 & & & \\
\hline \multirow{2}{*}{3} & 1 & 42,0 & \multirow{2}{*}{41,7} & \multirow{2}{*}{0,49} & \multirow{2}{*}{1,19} & \multirow{2}{*}{21} & 1 & 35,4 & \multirow{2}{*}{35,5} & \multirow{2}{*}{0,07} & \multirow{2}{*}{0,20} \\
\hline & 2 & 41,3 & & & & & 2 & 35,5 & & & \\
\hline \multirow{2}{*}{4} & 1 & 41,3 & $30 \mathrm{c}$ & 210 & 607 & ? & 1 & 36,9 & 260 & 011 & 20 \\
\hline & 2 & 37,9 & (3), & 2,40 & 0,01 & 24 & 2 & 36,7 & 0,0 & 0,14 & 0,00 \\
\hline 5 & 1 & 42,1 & $12 ?$ & 07 & 017 & 22 & 1 & 34,2 & 220 & 057 & 167 \\
\hline 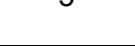 & 2 & 42,2 & $4<, 2$ & 0,01 & 0,17 & 20 & 2 & 33,4 & 33,8 & 0,01 & 1,01 \\
\hline 6 & 1 & 37,5 & 270 & 025 & 0 & 21 & 1 & 32,8 & ?2 ? & 071 & 212 \\
\hline 0 & 2 & 38,0 & 3,0 & 0,35 & 0,94 & 24 & 2 & 33,8 & 0,0 & $0, \pi 1$ & 2,12 \\
\hline 7 & 1 & 39,9 & $10 ?$ & 0.12 & 106 & 25 & 1 & 38,7 & 201 & 010 & 120 \\
\hline$r$ & 2 & 40,5 & 40,4 & 0,72 & 1,00 & 20 & 2 & 38,0 & 0,4 & 0,70 & 1,20 \\
\hline 8 & 1 & 40,2 & 100 & 025 & ( 89 & 26 & 1 & 35,8 & 368 & 121 & 366 \\
\hline 0 & 2 & 39,7 & 40,0 & 0,00 & 0,00 & 20 & 2 & 37,7 & 3,0 & 1,04 & 0,00 \\
\hline 0 & 1 & 36,9 & 257 & 177 & 106 & 27 & 1 & 39,0 & 200 & ? 21 & 05 \\
\hline 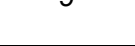 & 2 & 34,4 & r & TI & 4,00 & $2 t$ & 2 & 38,7 & 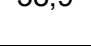 & 0,41 & U, \\
\hline 10 & 1 & 34,0 & 350 & 141 & 104 & 28 & 1 & 36,7 & 374 & ?9? & 216 \\
\hline & 2 & 36,0 & & & & 20 & 2 & 38,0 & דו & $0, \sqrt{2}$ & 2,40 \\
\hline 11 & 1 & 38,3 & 277 & 085 & 205 & 20 & 1 & 40,7 & 105 & 025 & 07 \\
\hline 列 & 2 & 37,1 & ST, & 0,00 & $2, \angle J$ & 29 & 2 & 40,2 & 40,5 & 0,35 & 0,81 \\
\hline 10 & 1 & 40,9 & 100 & 107 & 210 & & 1 & 38,8 & 275 & 10 & 100 \\
\hline 12 & 2 & 39,1 & 40,0 & $1, \angle I$ & 3,10 & 30 & 2 & 36,2 & 37,5 & 1,84 & 4,90 \\
\hline 12 & 1 & 35,7 & 361 & 057 & 157 & 21 & 1 & 38,3 & 206 & 012 & 110 \\
\hline & 2 & 36,5 & 30,1 & 0,01 & 1,01 & 31 & 2 & 38,9 & 38,6 & 0,42 & 1,10 \\
\hline 11 & 1 & 37,9 & 360 & 148 & 102 & 22 & 1 & 37,9 & 270 & مחת & ח 0 ח \\
\hline 14 & 2 & 35,8 & 3,5 & 1,40 & 4,00 & 32 & 2 & 37,9 & Ji, & 0,00 & 0,00 \\
\hline 15 & 1 & 40,7 & 115 & 106 & 256 & 23 & 1 & 41,9 & 5 & 1 & \\
\hline 10 & 2 & 42,2 & 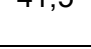 & 1,00 & 2,00 & 30 & 2 & 41,0 & 4,0 & 0,04 & 1,04 \\
\hline 16 & 1 & 38,5 & 201 & 021 & 055 & 21 & 1 & 33,6 & 6 & 6 & 76 \\
\hline 10 & 2 & 38,2 & 30,4 & $0, \angle 1$ & 0,00 & 34 & 2 & 37,5 & 3,0 & 2,10 & $T, 10$ \\
\hline 17 & 1 & 39,5 & 397 & 021 & 051 & 35 & 1 & 34,6 & 61 & 05 & 569 \\
\hline 11 & 2 & 39,8 & $39, r$ & 0,21 & 0,34 & 30 & 2 & 37,5 & 30,1 & 2,00 & 0,09 \\
\hline 18 & 1 & 43,7 & 122 & 57 & 121 & 36 & 1 & 36,5 & 68 & 12 & 115 \\
\hline 10 & 2 & 42,9 & 43,3 & 0,01 & 1,31 & 30 & 2 & 37,1 & 30,8 & 0,42 & 1,15 \\
\hline
\end{tabular}


Tabela A-2.b - Resultados dos ensaios de resistência à compressão $-f_{c k} 30 \mathrm{MPa}$

\begin{tabular}{|c|c|c|c|c|c|c|c|c|c|c|c|}
\hline Moldagem & Amostra & $\begin{array}{c}\mathbf{f}_{\mathrm{c} 28} \\
(\mathrm{MPa}) \\
\end{array}$ & $\begin{array}{l}\text { Média } \\
(\mathrm{MPa}) \\
\end{array}$ & $\begin{array}{c}\sigma \\
(\mathrm{MPa}) \\
\end{array}$ & $\begin{array}{l}\text { CV } \\
(\%) \\
\end{array}$ & Moldagem & Amostra & $\begin{array}{c}f_{\mathrm{c} 28} \\
(\mathrm{MPa}) \\
\end{array}$ & $\begin{array}{l}\text { Média } \\
(\mathrm{MPa}) \\
\end{array}$ & $\begin{array}{c}\sigma \\
(\mathrm{MPa}) \\
\end{array}$ & $\begin{array}{l}\mathrm{CV} \\
(\%) \\
\end{array}$ \\
\hline \multirow{2}{*}{37} & 1 & 38,5 & \multirow{2}{*}{38,4} & \multirow{2}{*}{0,21} & \multirow{2}{*}{0,55} & \multirow{2}{*}{55} & 1 & 40,2 & \multirow{2}{*}{40,5} & \multirow{2}{*}{0,35} & \multirow{2}{*}{0,87} \\
\hline & 2 & 38,2 & & & & & 2 & 40,7 & & & \\
\hline \multirow{2}{*}{38} & 1 & 37,4 & \multirow{2}{*}{36,9} & \multirow{2}{*}{0,78} & \multirow{2}{*}{2,11} & \multirow{2}{*}{56} & 1 & 39,5 & \multirow{2}{*}{39,4} & \multirow{2}{*}{0,21} & \multirow{2}{*}{0,54} \\
\hline & 2 & 36,3 & & & & & 2 & 39,2 & & & \\
\hline \multirow{2}{*}{39} & 1 & 39,2 & \multirow{2}{*}{39,0} & \multirow{2}{*}{0,35} & \multirow{2}{*}{0,91} & \multirow{2}{*}{57} & 1 & 36,9 & \multirow{2}{*}{36,0} & \multirow{2}{*}{1,27} & \multirow{2}{*}{3,54} \\
\hline & 2 & 38,7 & & & & & 2 & 35,1 & & & \\
\hline \multirow{2}{*}{40} & 1 & 38,3 & & & & 50 & 1 & 40,6 & & & \\
\hline & 2 & 39,2 & & & & 30 & 2 & 39,6 & 40,1 & 0,11 & \\
\hline & 1 & 35,3 & & & & 50 & 1 & 33,7 & & & \\
\hline & 2 & 36,0 & $3, r$ & $0,4 \mathrm{~J}$ & 1,05 & 35 & 2 & 36,8 & 30,3 & 2,19 & $0, \angle 2$ \\
\hline 10 & 1 & 36,4 & (20 & r & 0.10 & 60 & 1 & 33,7 & 240 & 010 & 128 \\
\hline & 2 & 36,3 & & 0,01 & 0,15 & 00 & 2 & 34,3 & 34,0 & 0,42 & $1, \angle 3$ \\
\hline & 1 & 38,8 & & & & & 1 & 36,8 & & & \\
\hline & 2 & 37,1 & & $1, \angle U$ & 0,11 & or & 2 & 36,8 & 30,0 & 0,00 & 0,00 \\
\hline & 1 & 35,1 & & & & & 1 & 38,8 & & & \\
\hline & 2 & 38,7 & & & & & 2 & 38,2 & & & \\
\hline & 1 & 36,0 & & & & & 1 & 35,9 & & & \\
\hline $4 J$ & 2 & 35,5 & J,0 & 0,30 & 0,50 & 00 & 2 & 36,5 & 30,2 & 0,42 & $1, I I$ \\
\hline 10 & 1 & 36,8 & & & & & 1 & 37,1 & & & \\
\hline 40 & 2 & 36,8 & 30,0 & $0, v 0$ & 0,00 & 04 & 2 & 38,7 & J & (1, & $2, \sqrt{3}$ \\
\hline 17 & 1 & 35,8 & & 0 & & $\rho^{2}$ & 1 & 41,1 & 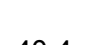 & ar & \\
\hline $4 !$ & 2 & 36,1 & 30,0 & $0, \angle 1$ & 0,09 & 05 & 2 & 39,6 & 40,4 & 1,U6 & 2,63 \\
\hline 10 & 1 & 40,7 & 100 & 001 & 0 & ge & 1 & 44,1 & 150 & 110 & תחת \\
\hline 48 & 2 & 41,0 & 40,9 & $0, \angle 1$ & 0,52 & 60 & 2 & 46,2 & 45,2 & 1,48 & 3,29 \\
\hline 10 & 1 & 42,8 & 10 & ד0 & 0.17 & 07 & 1 & 39,7 & P० & $0 ?$ & $0-51$ \\
\hline 49 & 2 & 42,7 & $42, \delta$ & 0,07 & 0,17 & br & 2 & 39,4 & 39,6 & 0,21 & 0,54 \\
\hline 50 & 1 & 36,4 & תחת & 011 & 000 & $\mathrm{~s}^{2}$ & 1 & 39,3 & & & \\
\hline 50 & 2 & 36,2 & 36,3 & 0,14 & 0,39 & 68 & 2 & 39,1 & 39,2 & 0,14 & 0,36 \\
\hline & 1 & 37,2 & & & & & 1 & 35,0 & & & \\
\hline 51 & 2 & 36,1 & 36,7 & 0,78 & 2,12 & 69 & 2 & 37,9 & 36,5 & 2,05 & 5,63 \\
\hline & 1 & 39,2 & & & & & 1 & 39,2 & & & \\
\hline 52 & 2 & 39,7 & 39,5 & 0,35 & 0,90 & 70 & 2 & 39,0 & 39,1 & 0,14 & 0,36 \\
\hline Г2 & 1 & 40,0 & 306 & 057 & 112 & 71 & 1 & 45,6 & 150 & 7ח0 & 016 \\
\hline 53 & 2 & 39,2 & 39,6 & $0,5 /$ & 1,43 & 71 & 2 & 45,5 & 45,6 & 0,07 & 0,16 \\
\hline 5 & 1 & 36,4 & 276 & 170 & 51 & 7 & 1 & 40,7 & 107 & (200 & ( \\
\hline 54 & 2 & 38,8 & 37,6 & 1,10 & 4,51 & 12 & 2 & 40,7 & 40,7 & 0,00 & 0,00 \\
\hline
\end{tabular}


Tabela A-2.c - Resultados dos ensaios de resistência à compressão $-f_{c k} 30 \mathrm{MPa}$

\begin{tabular}{|c|c|c|c|c|c|c|c|c|c|c|c|}
\hline Moldagem & Amostra & $\begin{array}{c}f_{\mathrm{c} 28} \\
(\mathrm{MPa})\end{array}$ & $\begin{array}{l}\text { Média } \\
(\mathrm{MPa})\end{array}$ & $\begin{array}{c}\sigma \\
(\mathrm{MPa})\end{array}$ & $\begin{array}{l}\text { CV } \\
(\%)\end{array}$ & Moldagem & Amostra & $\begin{array}{c}\mathrm{f}_{\mathrm{c} 28} \\
(\mathrm{MPa})\end{array}$ & $\begin{array}{l}\text { Média } \\
(\mathrm{MPa})\end{array}$ & $\begin{array}{c}\sigma \\
(\mathrm{MPa})\end{array}$ & $\begin{array}{l}\text { CV } \\
(\%)\end{array}$ \\
\hline \multirow{2}{*}{73} & 1 & 38,2 & \multirow{2}{*}{38,3} & \multirow{2}{*}{0,14} & \multirow{2}{*}{0,37} & \multirow{2}{*}{90} & 1 & 40,5 & \multirow{2}{*}{40,9} & \multirow{2}{*}{0,57} & \multirow{2}{*}{1,38} \\
\hline & 2 & 38,4 & & & & & 2 & 41,3 & & & \\
\hline \multirow{2}{*}{74} & 1 & 40,7 & \multirow{2}{*}{40,7} & \multirow{2}{*}{0,07} & \multirow{2}{*}{0,17} & \multirow{2}{*}{91} & 1 & 40,9 & \multirow{2}{*}{42,3} & \multirow{2}{*}{1,98} & \multirow{2}{*}{4,68} \\
\hline & 2 & 40,6 & & & & & 2 & 43,7 & & & \\
\hline \multirow{2}{*}{75} & 1 & 33,1 & \multirow{2}{*}{33,2} & \multirow{2}{*}{0,07} & \multirow{2}{*}{0,21} & \multirow{2}{*}{92} & 1 & 40,9 & \multirow{2}{*}{41,7} & \multirow{2}{*}{1,13} & \multirow{2}{*}{2,71} \\
\hline & 2 & 33,2 & & & & & 2 & 42,5 & & & \\
\hline \multirow{2}{*}{76} & 1 & 39,5 & \multirow{2}{*}{39,6} & 014 & 036 & 93 & 1 & 41,6 & 424 & 113 & 267 \\
\hline & 2 & 39,7 & & 0,14 & 0,00 & 90 & 2 & 43,2 & $4<, 4$ & 1,10 & 2,01 \\
\hline 77 & 1 & 38,2 & 201 & 014 & 027 & 01 & 1 & 33,9 & 221 & 112 & 312 \\
\hline 71 & 2 & 38,0 & 38,1 & 0,14 & 0,31 & 94 & 2 & 32,3 & 33,1 & 1,13 & 3,42 \\
\hline 78 & 1 & 40,7 & 405 & 035 & 087 & 95 & 1 & 34,6 & 344 & 028 & 082 \\
\hline 10 & 2 & 40,2 & 40,5 & 0,30 & 0,01 & 95 & 2 & 34,2 & 34,4 & $0, \angle 0$ & 0,02 \\
\hline 70 & 1 & 42,5 & $12 ?$ & 012 & 101 & 06 & 1 & 42,1 & 133 & 170 & 392 \\
\hline 19 & 2 & 41,9 & $4<, \angle$ & $0,4 Z$ & 1,01 & 90 & 2 & 44,5 & 40,3 & 1,10 & 0,92 \\
\hline م0 & 1 & 43,4 & 120 & 7 70 & 100 & 07 & 1 & 46,6 & & & \\
\hline 80 & 2 & 42,3 & 42,9 & $0, / 8$ & 1,82 & 97 & 2 & 45,6 & 46,1 & 0,71 & 1,53 \\
\hline 81 & 1 & 40,5 & 420 & 212 & 505 & 98 & 1 & 39,2 & 387 & 71 & 183 \\
\hline 81 & 2 & 43,5 & 42,0 & 2,12 & 5,05 & 98 & 2 & 38,2 & 38,1 & $0, \pi 1$ & 1,83 \\
\hline ר? & 1 & 43,3 & 122 & POP & מחת & 99 & 1 & 45,2 & 439 & 101 & 435 \\
\hline 02 & 2 & 43,3 & 40,0 & 0,00 & 0,00 & 99 & 2 & 42,5 & $43, y$ & 1,91 & 4,35 \\
\hline 83 & 1 & 40,9 & 411 & 028 & 069 & 100 & 1 & 42,4 & $42 ?$ & 035 & 084 \\
\hline OJ & 2 & 41,3 & 41,1 & $0, \angle 0$ & 0,09 & 100 & 2 & 41,9 & $4<,<$ & 0,00 & 0,04 \\
\hline 81 & 1 & 40,4 & 1 & 019 & 121 & 101 & 1 & 39,0 & 270 & 282 & 761 \\
\hline 84 & 2 & 39,7 & 40,1 & 0,49 & 1,Z4 & 101 & 2 & 35,0 & $3 /, 0$ & 2,83 & 7,64 \\
\hline 85 & 1 & 40,4 & 399 & 071 & 177 & 102 & 1 & 40,4 & 398 & ० १? & 231 \\
\hline 05 & 2 & 39,4 & 39,9 & 0,11 & $1, \pi 1$ & 102 & 2 & 39,1 & 39,0 & 0,92 & 2,01 \\
\hline 86 & 1 & 40,1 & 307 & 057 & 112 & 102 & 1 & 41,3 & 300 & 210 & 551 \\
\hline 80 & 2 & 39,3 & 39,1 & 0,01 & 1,42 & 103 & 2 & 38,2 & 39,8 & 2,19 & 5,51 \\
\hline 87 & 1 & 30,6 & 321 & 205 & 640 & 104 & 1 & 39,3 & 398 & 064 & 160 \\
\hline & 2 & 33,5 & 32,1 & 2,05 & 0,40 & 104 & 2 & 40,2 & 39,8 & 0,04 & 1,00 \\
\hline 88 & 1 & 33,9 & 361 & 301 & 813 & 105 & 1 & 41,2 & 121 & 120 & 286 \\
\hline 88 & 2 & 38,2 & 36,1 & 3,04 & 8,43 & 105 & 2 & 42,9 & 42,1 & 1,20 & 2,86 \\
\hline 80 & 1 & 36,9 & 206 & 290 & $6 ? 2$ & & & & & & \\
\hline 09 & 2 & 40,3 & 30,0 & 2,40 & $0, \angle J$ & & & & & & \\
\hline
\end{tabular}


Tabela A-3.a - Resultados do teste de ajustamento de Kolmogorov-Smirnov $-f_{c k} 25 \mathrm{MPa}$

\begin{tabular}{|c|c|c|c|c|c|c|}
\hline $\begin{array}{c}\mathrm{E} \\
(\mathrm{GPa})\end{array}$ & Frequência & $\begin{array}{l}\text { Frequencia } \\
\text { Acumulada }\end{array}$ & $\begin{array}{c}\mathrm{Fn}(\mathbf{x}) \\
\text { [empirica] }\end{array}$ & $\begin{array}{c}F(\mathbf{x}) \\
{[\text { [Teórica] }}\end{array}$ & $D^{\prime}=\operatorname{máx}|F n[x(i)]-F[x(i)]|$ & $D_{-}=\operatorname{máx} \mid F[x(i)]-F n[x(i-1)]$ \\
\hline 21,87 & 1 & 1 & 0,00725 & 0,00208 & 0,00516 & 0,00208 \\
\hline 22,19 & 1 & 2 & 0,01449 & 0,00432 & 0,01018 & 0,00293 \\
\hline 22,29 & 1 & 3 & 0,02174 & 0,00535 & 0,01639 & 0,00915 \\
\hline 22,32 & 1 & 4 & 0,02899 & 0,00569 & 0,02329 & 0,01605 \\
\hline 23,08 & 1 & 5 & 0,03623 & 0,02421 & 0,01202 & 0,00477 \\
\hline 23,11 & 1 & 6 & 0,04348 & 0,02579 & 0,01769 & 0,01044 \\
\hline 23,39 & 1 & 7 & 0,05072 & 0,04067 & 0,01005 & 0,00281 \\
\hline 23,42 & 1 & 8 & 0,05797 & 0,04241 & 0,01556 & 0,00831 \\
\hline 23,54 & 1 & 9 & 0,06522 & 0,05128 & 0,01394 & 0,00669 \\
\hline 23,61 & 1 & 10 & 0,07246 & 0,05722 & 0,01525 & 0,00800 \\
\hline 23,71 & 1 & 11 & 0,07971 & 0,06538 & 0,01433 & 0,00708 \\
\hline 23,72 & 1 & 12 & 0,08696 & 0,06632 & 0,02063 & 0,01339 \\
\hline 23,78 & 1 & 13 & 0,09420 & 0,07271 & 0,02149 & 0,01425 \\
\hline 23,95 & 1 & 14 & 0,10145 & 0,09163 & 0,00981 & 0,00257 \\
\hline 24,16 & 1 & 15 & 0,10870 & 0,11927 & 0,01058 & 0,01782 \\
\hline 24,16 & 1 & 16 & 0,11594 & 0,11976 & 0,00382 & 0,01107 \\
\hline 24,21 & 1 & 17 & 0,12319 & 0,12727 & 0,00408 & 0,01133 \\
\hline 24,37 & 1 & 18 & 0,13043 & 0,15348 & 0,02305 & 0,03030 \\
\hline 24,40 & 1 & 19 & 0,13768 & 0,15877 & 0,02109 & 0,02834 \\
\hline 24,45 & 1 & 20 & 0,14493 & 0,16785 & 0,02292 & 0,03016 \\
\hline 24,50 & 1 & 21 & 0,15217 & 0,17661 & 0,02444 & 0,03168 \\
\hline 24,53 & 1 & 22 & 0,15942 & 0,18369 & 0,02427 & 0,03152 \\
\hline 24,54 & 1 & 23 & 0,16667 & 0,18402 & 0,01735 & 0,02460 \\
\hline 24,56 & 1 & 24 & 0,17391 & 0,18962 & 0,01571 & 0,02295 \\
\hline 24,65 & 1 & 25 & 0,18116 & 0,20669 & 0,02553 & 0,03278 \\
\hline 24,74 & 1 & 26 & 0,18841 & 0,22685 & 0,03845 & 0,04569 \\
\hline 24,75 & 1 & 27 & 0,19565 & 0,22982 & 0,03417 & 0,04142 \\
\hline 24,76 & 1 & 28 & 0,20290 & 0,23131 & 0,02841 & 0,03566 \\
\hline 24,79 & 1 & 29 & 0,21014 & 0,23885 & 0,02871 & 0,03596 \\
\hline 24,80 & 1 & 30 & 0,21739 & 0,24038 & 0,02299 & 0,03023 \\
\hline 24,82 & 1 & 31 & 0,22464 & 0,24421 & 0,01957 & 0,02682 \\
\hline 24,84 & 1 & 32 & 0,23188 & 0,25041 & 0,01853 & 0,02578 \\
\hline 24,88 & 1 & 33 & 0,23913 & 0,25828 & 0,01915 & 0,02640 \\
\hline 24,95 & 1 & 34 & 0,24638 & 0,27685 & 0,03048 & 0,03772 \\
\hline 24,97 & 1 & 35 & 0,25362 & 0,28097 & 0,02735 & 0,03460 \\
\hline 24,99 & 1 & 36 & 0,26087 & 0,28513 & 0,02426 & 0,03150 \\
\hline 25,01 & 1 & 37 & 0,26812 & 0,29099 & 0,02287 & 0,03012 \\
\hline 25,04 & 1 & 38 & 0,27536 & 0,29860 & 0,02324 & 0,03049 \\
\hline 25,07 & 1 & 39 & 0,28261 & 0,30717 & 0,02456 & 0,03181 \\
\hline 25,08 & 1 & 40 & 0,28986 & 0,30976 & 0,01991 & 0,02715 \\
\hline 25,10 & 1 & 41 & 0,29710 & 0,31497 & 0,01787 & 0,02512 \\
\hline 25,14 & 1 & 42 & 0,30435 & 0,32330 & 0,01895 & 0,02620 \\
\hline 25,16 & 1 & 43 & 0,31159 & 0,33082 & 0,01923 & 0,02648 \\
\hline 25,19 & 1 & 44 & 0,31884 & 0,33887 & 0,02003 & 0,02727 \\
\hline 25,20 & 1 & 45 & 0,32609 & 0,33976 & 0,01368 & 0,02092 \\
\hline
\end{tabular}


Tabela A-3.b - Resultados do teste de ajustamento de Kolmogorov-Smirnov $-f_{c k} 25 \mathrm{MPa}$

\begin{tabular}{|c|c|c|c|c|c|c|}
\hline$\underset{(\mathrm{GPa})}{\mathrm{E}}$ & Frequência & $\begin{array}{l}\text { Frequencia } \\
\text { Acumulada }\end{array}$ & $\begin{array}{c}\mathrm{Fn}(\mathbf{x}) \\
\text { [empirica] }\end{array}$ & $\begin{array}{c}F(\mathbf{x}) \\
{[\text { [Teórica] }}\end{array}$ & $D^{\prime}=\operatorname{máx}|F n[x(i)]-F[x(i)]|$ & $D_{-}=\operatorname{má} x \mid F[x(i)]-F n[x(i-1)]$ \\
\hline 25,29 & 1 & 46 & 0,33333 & 0,36389 & 0,03056 & 0,03780 \\
\hline 25,31 & 1 & 47 & 0,34058 & 0,36989 & 0,02931 & 0,03656 \\
\hline 25,32 & 1 & 48 & 0,34783 & 0,37268 & 0,02485 & 0,03210 \\
\hline 25,36 & 1 & 49 & 0,35507 & 0,38481 & 0,02974 & 0,03698 \\
\hline 25,38 & 1 & 50 & 0,36232 & 0,39045 & 0,02813 & 0,03537 \\
\hline 25,43 & 1 & 51 & 0,36957 & 0,40369 & 0,03413 & 0,04137 \\
\hline 25,44 & 2 & 53 & 0,38406 & 0,40845 & 0,02439 & 0,03888 \\
\hline 25,45 & 1 & 54 & 0,39130 & 0,40940 & 0,01810 & 0,02534 \\
\hline 25,45 & 1 & 55 & 0,39855 & 0,41036 & 0,01180 & 0,01905 \\
\hline 25,50 & 1 & 56 & 0,40580 & 0,42376 & 0,01796 & 0,02521 \\
\hline 25,51 & 1 & 57 & 0,41304 & 0,42761 & 0,01457 & 0,02181 \\
\hline 25,55 & 1 & 58 & 0,42029 & 0,44016 & 0,01987 & 0,02711 \\
\hline 25,58 & 1 & 59 & 0,42754 & 0,44646 & 0,01892 & 0,02617 \\
\hline 25,59 & 1 & 60 & 0,43478 & 0,45180 & 0,01701 & 0,02426 \\
\hline 25,60 & 1 & 61 & 0,44203 & 0,45277 & 0,01074 & 0,01799 \\
\hline 25,64 & 1 & 62 & 0,44928 & 0,46640 & 0,01713 & 0,02437 \\
\hline 25,65 & 2 & 64 & 0,46377 & 0,46835 & 0,00458 & 0,01908 \\
\hline 25,70 & 1 & 65 & 0,47101 & 0,48203 & 0,01101 & 0,01826 \\
\hline 25,71 & 1 & 66 & 0,47826 & 0,48692 & 0,00866 & 0,01590 \\
\hline 25,73 & 1 & 67 & 0,48551 & 0,49083 & 0,00533 & 0,01257 \\
\hline 25,75 & 1 & 68 & 0,49275 & 0,49671 & 0,00395 & 0,01120 \\
\hline 25,77 & 1 & 69 & 0,50000 & 0,50356 & 0,00356 & 0,01080 \\
\hline 25,80 & 1 & 70 & 0,50725 & 0,51236 & 0,00512 & 0,01236 \\
\hline 25,81 & 1 & 71 & 0,51449 & 0,51628 & 0,00178 & 0,00903 \\
\hline 25,89 & 1 & 72 & 0,52174 & 0,53873 & 0,01700 & 0,02424 \\
\hline 25,90 & 1 & 73 & 0,52899 & 0,54068 & 0,01170 & 0,01894 \\
\hline 25,93 & 1 & 74 & 0,53623 & 0,54944 & 0,01320 & 0,02045 \\
\hline 25,94 & 1 & 75 & 0,54348 & 0,55186 & 0,00839 & 0,01563 \\
\hline 25,95 & 1 & 76 & 0,55072 & 0,55623 & 0,00550 & 0,01275 \\
\hline 25,96 & 1 & 77 & 0,55797 & 0,55817 & 0,00019 & 0,00744 \\
\hline 25,96 & 2 & 79 & 0,57246 & 0,55913 & 0,01333 & 0,00116 \\
\hline 26,01 & 1 & 80 & 0,57971 & 0,57361 & 0,00610 & 0,00115 \\
\hline 26,05 & 2 & 82 & 0,59420 & 0,58417 & 0,01004 & 0,00446 \\
\hline 26,06 & 1 & 83 & 0,60145 & 0,58704 & 0,01441 & 0,00717 \\
\hline 26,11 & 1 & 84 & 0,60870 & 0,60225 & 0,00644 & 0,00080 \\
\hline 26,15 & 1 & 85 & 0,61594 & 0,61263 & 0,00331 & 0,00393 \\
\hline 26,15 & 1 & 86 & 0,62319 & 0,61451 & 0,00868 & 0,00144 \\
\hline 26,17 & 1 & 87 & 0,63043 & 0,61919 & 0,01125 & 0,00400 \\
\hline 26,24 & 1 & 88 & 0,63768 & 0,63866 & 0,00098 & 0,00822 \\
\hline 26,32 & 1 & 89 & 0,64493 & 0,65958 & 0,01465 & 0,02190 \\
\hline 26,35 & 1 & 90 & 0,65217 & 0,66942 & 0,01724 & 0,02449 \\
\hline 26,39 & 1 & 91 & 0,65942 & 0,67914 & 0,01972 & 0,02696 \\
\hline 26,39 & 1 & 92 & 0,66667 & 0,68002 & 0,01335 & 0,02060 \\
\hline 26,42 & 1 & 93 & 0,67391 & 0,68613 & 0,01222 & 0,01947 \\
\hline 26,42 & 1 & 94 & 0,68116 & 0,68700 & 0,00584 & 0,01309 \\
\hline
\end{tabular}


Tabela A-3.c - Resultados do teste de ajustamento de Kolmogorov-Smirnov $-\mathrm{f}_{\mathrm{ck}} 25 \mathrm{MPa}$

\begin{tabular}{|c|c|c|c|c|c|c|}
\hline$\underset{(\mathrm{GPa})}{\mathrm{E}}$ & Frequência & $\begin{array}{l}\text { Frequencia } \\
\text { Acumulada }\end{array}$ & $\begin{array}{c}\mathrm{Fn}(\mathrm{x}) \\
\text { [empirica] }\end{array}$ & $\begin{array}{c}F(\mathbf{x}) \\
{[\text { [Teórica] }}\end{array}$ & $D^{\prime}=\operatorname{máx}|F n[x(i)]-F[x(i)]|$ & $D_{-}=\operatorname{máx} \mid F[x(i)]-F n[x(i-1)]$ \\
\hline 26,45 & 1 & 95 & 0,68841 & 0,69392 & 0,00552 & 0,01276 \\
\hline 26,46 & 1 & 96 & 0,69565 & 0,69821 & 0,00256 & 0,00981 \\
\hline 26,47 & 1 & 97 & 0,70290 & 0,69992 & 0,00298 & 0,00427 \\
\hline 26,50 & 1 & 98 & 0,71014 & 0,70671 & 0,00343 & 0,00381 \\
\hline 26,50 & 1 & 99 & 0,71739 & 0,70756 & 0,00984 & 0,00259 \\
\hline 26,52 & 1 & 100 & 0,72464 & 0,71259 & 0,01204 & 0,00480 \\
\hline 26,53 & 1 & 101 & 0,73188 & 0,71510 & 0,01679 & 0,00954 \\
\hline 26,54 & 1 & 102 & 0,73913 & 0,71759 & 0,02154 & 0,01429 \\
\hline 26,55 & 1 & 103 & 0,74638 & 0,71925 & 0,02713 & 0,01988 \\
\hline 26,60 & 1 & 104 & 0,75362 & 0,73152 & 0,02210 & 0,01486 \\
\hline 26,63 & 1 & 105 & 0,76087 & 0,73835 & 0,02252 & 0,01527 \\
\hline 26,64 & 1 & 106 & 0,76812 & 0,74272 & 0,02539 & 0,01815 \\
\hline 26,73 & 1 & 107 & 0,77536 & 0,76173 & 0,01363 & 0,00639 \\
\hline 26,73 & 1 & 108 & 0,78261 & 0,76211 & 0,02050 & 0,01325 \\
\hline 26,73 & 1 & 109 & 0,78986 & 0,76362 & 0,02623 & 0,01898 \\
\hline 26,86 & 1 & 110 & 0,79710 & 0,79068 & 0,00642 & 0,00083 \\
\hline 26,86 & 1 & 111 & 0,80435 & 0,79209 & 0,01226 & 0,00501 \\
\hline 26,97 & 1 & 112 & 0,81159 & 0,81320 & 0,00161 & 0,00886 \\
\hline 26,99 & 1 & 113 & 0,81884 & 0,81778 & 0,00106 & 0,00619 \\
\hline 27,01 & 1 & 114 & 0,82609 & 0,82101 & 0,00508 & 0,00217 \\
\hline 27,03 & 1 & 115 & 0,83333 & 0,82451 & 0,00882 & 0,00157 \\
\hline 27,04 & 1 & 116 & 0,84058 & 0,82798 & 0,01260 & 0,00536 \\
\hline 27,18 & 1 & 117 & 0,84783 & 0,85184 & 0,00401 & 0,01126 \\
\hline 27,20 & 1 & 118 & 0,85507 & 0,85494 & 0,00014 & 0,00711 \\
\hline 27,21 & 1 & 119 & 0,86232 & 0,85688 & 0,00543 & 0,00181 \\
\hline 27,28 & 1 & 120 & 0,86957 & 0,86794 & 0,00162 & 0,00563 \\
\hline 27,31 & 1 & 121 & 0,87681 & 0,87388 & 0,00293 & 0,00432 \\
\hline 27,37 & 1 & 122 & 0,88406 & 0,88183 & 0,00223 & 0,00502 \\
\hline 27,42 & 1 & 123 & 0,89130 & 0,88942 & 0,00188 & 0,00536 \\
\hline 27,47 & 1 & 124 & 0,89855 & 0,89577 & 0,00278 & 0,00446 \\
\hline 27,50 & 1 & 125 & 0,90580 & 0,89971 & 0,00609 & 0,00116 \\
\hline 27,56 & 1 & 126 & 0,91304 & 0,90766 & 0,00538 & 0,00187 \\
\hline 27,59 & 1 & 127 & 0,92029 & 0,91166 & 0,00863 & 0,00138 \\
\hline 27,72 & 1 & 128 & 0,92754 & 0,92601 & 0,00152 & 0,00572 \\
\hline 27,74 & 1 & 129 & 0,93478 & 0,92772 & 0,00706 & 0,00018 \\
\hline 27,75 & 1 & 130 & 0,94203 & 0,92873 & 0,01330 & 0,00606 \\
\hline 27,77 & 1 & 131 & 0,94928 & 0,93038 & 0,01889 & 0,01165 \\
\hline 27,95 & 1 & 132 & 0,95652 & 0,94669 & 0,00983 & 0,00258 \\
\hline 28,03 & 1 & 133 & 0,96377 & 0,95278 & 0,01098 & 0,00374 \\
\hline 28,04 & 1 & 134 & 0,97101 & 0,95350 & 0,01751 & 0,01026 \\
\hline 28,26 & 1 & 135 & 0,97826 & 0,96725 & 0,01102 & 0,00377 \\
\hline 28,39 & 1 & 136 & 0,98551 & 0,97351 & 0,01200 & 0,00476 \\
\hline 28,75 & 1 & 137 & 0,99275 & 0,98618 & 0,00657 & 0,00068 \\
\hline 28,89 & 1 & 138 & 1,00000 & 0,98943 & 0,01057 & 0,00332 \\
\hline
\end{tabular}


Tabela A-4.a - Resultados do teste de ajustamento de Kolmogorov-Smirnov $-f_{c k} 30 \mathrm{MPa}$

\begin{tabular}{|c|c|c|c|c|c|c|}
\hline $\begin{array}{c}E \\
(\mathrm{GPa}) \\
\end{array}$ & Frequência & $\begin{array}{l}\text { Frequência } \\
\text { Acumulada } \\
\end{array}$ & $\begin{array}{c}\mathrm{Fn}(\mathbf{x}) \\
\text { [empirica] }\end{array}$ & $\begin{array}{c}F(\mathbf{x}) \\
\text { [Teórica] }\end{array}$ & $D^{*}=\operatorname{máx}|F n[x(i)]-F[x(i)]|$ & $D_{-}=\operatorname{máx} \mid F[x(i)]-F n[x(i-1)]$ \\
\hline 25,53 & 1 & 1 & 0,00952 & 0,03059 & 0,02107 & 0,03059 \\
\hline 25,56 & 1 & 2 & 0,01905 & 0,03259 & 0,01354 & 0,02307 \\
\hline 25,81 & 1 & 3 & 0,02857 & 0,05972 & 0,03115 & 0,04067 \\
\hline 25,82 & 1 & 4 & 0,03810 & 0,06152 & 0,02343 & 0,03295 \\
\hline 25,93 & 1 & 5 & 0,04762 & 0,07696 & 0,02934 & 0,03886 \\
\hline 25,95 & 1 & 6 & 0,05714 & 0,08082 & 0,02367 & 0,03320 \\
\hline 25,97 & 1 & 7 & 0,06667 & 0,08482 & 0,01816 & 0,02768 \\
\hline 26,03 & 1 & 8 & 0,07619 & 0,09517 & 0,01898 & 0,02850 \\
\hline 26,05 & 1 & 9 & 0,08571 & 0,09838 & 0,01267 & 0,02219 \\
\hline 26,06 & 1 & 10 & 0,09524 & 0,10034 & 0,00511 & 0,01463 \\
\hline 26,09 & 1 & 11 & 0,10476 & 0,10710 & 0,00234 & 0,01186 \\
\hline 26,10 & 1 & 12 & 0,11429 & 0,10990 & 0,00439 & 0,00513 \\
\hline 26,11 & 1 & 13 & 0,12381 & 0,11131 & 0,01250 & 0,00297 \\
\hline 26,12 & 1 & 14 & 0,13333 & 0,11418 & 0,01915 & 0,00963 \\
\hline 26,13 & 1 & 15 & 0,14286 & 0,11637 & 0,02649 & 0,01696 \\
\hline 26,18 & 1 & 16 & 0,15238 & 0,12677 & 0,02562 & 0,01609 \\
\hline 26,21 & 1 & 17 & 0,16190 & 0,13332 & 0,02858 & 0,01906 \\
\hline 26,22 & 1 & 18 & 0,17143 & 0,13576 & 0,03567 & 0,02615 \\
\hline 26,27 & 1 & 19 & 0,18095 & 0,14927 & 0,03168 & 0,02216 \\
\hline 26,28 & 1 & 20 & 0,19048 & 0,15190 & 0,03858 & 0,02905 \\
\hline 26,30 & 1 & 21 & 0,20000 & 0,15725 & 0,04275 & 0,03322 \\
\hline 26,31 & 1 & 22 & 0,20952 & 0,16089 & 0,04864 & 0,03911 \\
\hline 26,32 & 1 & 23 & 0,21905 & 0,16365 & 0,05540 & 0,04587 \\
\hline 26,34 & 1 & 24 & 0,22857 & 0,16832 & 0,06025 & 0,05072 \\
\hline 26,37 & 1 & 25 & 0,23810 & 0,17695 & 0,06115 & 0,05162 \\
\hline 26,39 & 1 & 26 & 0,24762 & 0,18285 & 0,06477 & 0,05524 \\
\hline 26,43 & 2 & 28 & 0,26667 & 0,19502 & 0,07165 & 0,05260 \\
\hline 26,44 & 1 & 29 & 0,27619 & 0,19814 & 0,07805 & 0,06853 \\
\hline 26,44 & 1 & 30 & 0,28571 & 0,19918 & 0,08653 & 0,07701 \\
\hline 26,55 & 1 & 31 & 0,29524 & 0,23408 & 0,06116 & 0,05164 \\
\hline 26,56 & 1 & 32 & 0,30476 & 0,23783 & 0,06693 & 0,05740 \\
\hline 26,62 & 1 & 33 & 0,31429 & 0,25921 & 0,05507 & 0,04555 \\
\hline 26,63 & 1 & 34 & 0,32381 & 0,26165 & 0,06216 & 0,05264 \\
\hline 26,63 & 1 & 35 & 0,33333 & 0,26287 & 0,07046 & 0,06094 \\
\hline 26,66 & 1 & 36 & 0,34286 & 0,27275 & 0,07011 & 0,06059 \\
\hline 26,73 & 1 & 37 & 0,35238 & 0,29953 & 0,05286 & 0,04333 \\
\hline 26,74 & 1 & 38 & 0,36190 & 0,30476 & 0,05715 & 0,04762 \\
\hline 26,77 & 1 & 39 & 0,37143 & 0,31534 & 0,05609 & 0,04656 \\
\hline 26,80 & 1 & 40 & 0,38095 & 0,32879 & 0,05216 & 0,04264 \\
\hline 26,86 & 1 & 41 & 0,39048 & 0,35216 & 0,03832 & 0,02879 \\
\hline 26,87 & 1 & 42 & 0,40000 & 0,35774 & 0,04226 & 0,03273 \\
\hline 26,91 & 1 & 43 & 0,40952 & 0,37468 & 0,03485 & 0,02532 \\
\hline 26,97 & 1 & 44 & 0,41905 & 0,40052 & 0,01852 & 0,00900 \\
\hline 26,99 & 1 & 45 & 0,42857 & 0,40779 & 0,02078 & 0,01126 \\
\hline 27,05 & 1 & 46 & 0,43810 & 0,43566 & 0,00243 & 0,00709 \\
\hline 27,08 & 1 & 47 & 0,44762 & 0,44676 & 0,00086 & 0,00866 \\
\hline 27,11 & 2 & 49 & 0,46667 & 0,46088 & 0,00579 & 0,01326 \\
\hline 27,12 & 1 & 50 & 0,47619 & 0,46460 & 0,01159 & 0,00207 \\
\hline 27,16 & 1 & 51 & 0,48571 & 0,48625 & 0,00054 & 0,01006 \\
\hline 27,18 & 1 & 52 & 0,49524 & 0,49373 & 0,00151 & 0,00802 \\
\hline 27,20 & 1 & 53 & 0,50476 & 0,50420 & 0,00056 & 0,00897 \\
\hline
\end{tabular}


Tabela A-4.b - Resultados do teste de ajustamento de Kolmogorov-Smirnov $-f_{c k} 30 M P a$

\begin{tabular}{|c|c|c|c|c|c|c|}
\hline $\begin{array}{c}\mathrm{E} \\
(\mathrm{GPa})\end{array}$ & Frequência & $\begin{array}{l}\text { Frequência } \\
\text { Acumulada }\end{array}$ & $\begin{array}{c}\mathrm{Fn}(\mathbf{x}) \\
\text { [empírica] }\end{array}$ & $\begin{array}{c}\mathrm{F}(\mathbf{x}) \\
\text { [Teórica] }\end{array}$ & $D^{\prime}=\operatorname{máx}|F n[x(i)]-F[x(i)]|$ & $D_{-}=\operatorname{máx} \mid F[x(i)]-F n[x(i-1)]$ \\
\hline 27,22 & 1 & 54 & 0,51429 & 0,51318 & 0,00111 & 0,00842 \\
\hline 27,24 & 1 & 55 & 0,52381 & 0,51841 & 0,00540 & 0,00413 \\
\hline 27,24 & 1 & 56 & 0,53333 & 0,52215 & 0,01119 & 0,00166 \\
\hline 27,25 & 1 & 57 & 0,54286 & 0,52513 & 0,01772 & 0,00820 \\
\hline 27,25 & 1 & 58 & 0,55238 & 0,52663 & 0,02575 & 0,01623 \\
\hline 27,27 & 1 & 59 & 0,56190 & 0,53558 & 0,02633 & 0,01680 \\
\hline 27,33 & 1 & 60 & 0,57143 & 0,56124 & 0,01019 & 0,00066 \\
\hline 27,39 & 1 & 61 & 0,58095 & 0,58582 & 0,00487 & 0,01439 \\
\hline 27,42 & 1 & 62 & 0,59048 & 0,59892 & 0,00845 & 0,01797 \\
\hline 27,44 & 1 & 63 & 0,60000 & 0,60904 & 0,00904 & 0,01856 \\
\hline 27,45 & 1 & 64 & 0,60952 & 0,61335 & 0,00383 & 0,01335 \\
\hline 27,50 & 1 & 65 & 0,61905 & 0,63470 & 0,01565 & 0,02517 \\
\hline 27,56 & 1 & 66 & 0,62857 & 0,65977 & 0,03120 & 0,04072 \\
\hline 27,59 & 1 & 67 & 0,63810 & 0,67340 & 0,03531 & 0,04483 \\
\hline 27,61 & 1 & 68 & 0,64762 & 0,67879 & 0,03118 & 0,04070 \\
\hline 27,62 & 1 & 69 & 0,65714 & 0,68245 & 0,02531 & 0,03483 \\
\hline 27,62 & 1 & 70 & 0,66667 & 0,68548 & 0,01882 & 0,02834 \\
\hline 27,63 & 1 & 71 & 0,67619 & 0,68947 & 0,01327 & 0,02280 \\
\hline 27,64 & 1 & 72 & 0,68571 & 0,69079 & 0,00507 & 0,01460 \\
\hline 27,64 & 1 & 73 & 0,69524 & 0,69211 & 0,00313 & 0,00639 \\
\hline 27,68 & 1 & 74 & 0,70476 & 0,70776 & 0,00299 & 0,01252 \\
\hline 27,73 & 1 & 75 & 0,71429 & 0,72802 & 0,01374 & 0,02326 \\
\hline 27,74 & 1 & 76 & 0,72381 & 0,72927 & 0,00546 & 0,01498 \\
\hline 27,85 & 1 & 77 & 0,73333 & 0,76978 & 0,03644 & 0,04597 \\
\hline 27,85 & 1 & 78 & 0,74286 & 0,77091 & 0,02806 & 0,03758 \\
\hline 27,89 & 1 & 79 & 0,75238 & 0,78156 & 0,02918 & 0,03871 \\
\hline 27,96 & 1 & 80 & 0,76190 & 0,80562 & 0,04372 & 0,05324 \\
\hline 27,99 & 1 & 81 & 0,77143 & 0,81327 & 0,04184 & 0,05136 \\
\hline 28,02 & 1 & 82 & 0,78095 & 0,82365 & 0,04270 & 0,05222 \\
\hline 28,04 & 1 & 83 & 0,79048 & 0,83037 & 0,03989 & 0,04942 \\
\hline 28,05 & 1 & 84 & 0,80000 & 0,83226 & 0,03226 & 0,04178 \\
\hline 28,09 & 1 & 85 & 0,80952 & 0,84195 & 0,03243 & 0,04195 \\
\hline 28,10 & 1 & 86 & 0,81905 & 0,84599 & 0,02694 & 0,03647 \\
\hline 28,10 & 1 & 87 & 0,82857 & 0,84688 & 0,01831 & 0,02783 \\
\hline 28,13 & 1 & 88 & 0,83810 & 0,85257 & 0,01447 & 0,02400 \\
\hline 28,14 & 1 & 89 & 0,84762 & 0,85515 & 0,00753 & 0,01705 \\
\hline 28,14 & 1 & 90 & 0,85714 & 0,85727 & 0,00013 & 0,00965 \\
\hline 28,15 & 1 & 91 & 0,86667 & 0,85896 & 0,00771 & 0,00181 \\
\hline 28,16 & 1 & 92 & 0,87619 & 0,86229 & 0,01391 & 0,00438 \\
\hline 28,17 & 1 & 93 & 0,88571 & 0,86311 & 0,02261 & 0,01308 \\
\hline 28,18 & 1 & 94 & 0,89524 & 0,86637 & 0,02887 & 0,01934 \\
\hline 28,20 & 1 & 95 & 0,90476 & 0,87195 & 0,03281 & 0,02329 \\
\hline 28,26 & 1 & 96 & 0,91429 & 0,88408 & 0,03020 & 0,02068 \\
\hline 28,38 & 1 & 97 & 0,92381 & 0,90958 & 0,01423 & 0,00471 \\
\hline 28,44 & 1 & 98 & 0,93333 & 0,91953 & 0,01380 & 0,00428 \\
\hline 28,46 & 1 & 99 & 0,94286 & 0,92284 & 0,02002 & 0,01049 \\
\hline 28,47 & 1 & 100 & 0,95238 & 0,92499 & 0,02740 & 0,01787 \\
\hline 28,76 & 1 & 101 & 0,96190 & 0,96096 & 0,00094 & 0,00858 \\
\hline 28,87 & 1 & 102 & 0,97143 & 0,97033 & 0,00109 & 0,00843 \\
\hline 28,88 & 1 & 103 & 0,98095 & 0,97108 & 0,00987 & 0,00034 \\
\hline 29,41 & 1 & 104 & 0,99048 & 0,99367 & 0,00320 & 0,01272 \\
\hline 29,71 & 1 & 105 & 1,00000 & 0,99765 & 0,00235 & 0,00717 \\
\hline
\end{tabular}


Tabela A-5.a - Resultados dos ensaios de módulo de deformação secante, $\mathrm{E}_{\mathrm{cs}}$ - fck 25MPa

\begin{tabular}{|c|c|c|c|c|c|c|c|c|c|c|c|}
\hline \multicolumn{2}{|c|}{ Amostra } & 1 & 2 & 3 & 4 & 5 & 6 & 7 & 8 & 9 & 10 \\
\hline \multicolumn{2}{|c|}{$\mathrm{f}_{\mathrm{c}, \text { médio }}(\mathrm{MPa})$} & 30,8 & 31,2 & 29,9 & 27,1 & 31,6 & 31,0 & 38,6 & 35,6 & 34,6 & 35,0 \\
\hline \multicolumn{2}{|l|}{$40 \%$ fc } & 12,32 & 12,48 & 11,96 & 10,84 & 12,64 & 12,40 & 15,44 & 14,24 & 13,84 & 13,98 \\
\hline \multirow{3}{*}{$\begin{array}{l}\text { Def. esp. inicial } \\
\varepsilon_{\mathrm{i}}(\mathrm{mm} / \mathrm{mm})\end{array}$} & $\varepsilon_{i, 1}$ & 0,00005 & 0,00000 & 0,00005 & 0,00005 & 0,00000 & 0,00000 & 0,00000 & 0,00005 & 0,00000 & 0,00005 \\
\hline & $\varepsilon_{i, 2}$ & 0,00000 & 0,00000 & 0,00000 & 0,00000 & 0,00005 & 0,00005 & 0,00000 & 0,00000 & 0,00005 & 0,00000 \\
\hline & $\varepsilon_{i, 3}$ & 0,00000 & 0,00000 & 0,00005 & 0,00000 & 0,00005 & 0,00005 & 0,00000 & 0,00000 & 0,00000 & 0,00005 \\
\hline \multirow{3}{*}{$\begin{array}{l}\text { Def. esp. final } \\
\varepsilon_{f}(\mathrm{~mm} / \mathrm{mm})\end{array}$} & $\varepsilon_{\mathrm{f}, 1}$ & 0,00044 & 0,00042 & 0,00044 & 0,00039 & 0,00040 & 0,00040 & 0,00042 & 0,00043 & 0,00040 & 0,00044 \\
\hline & $\varepsilon_{\mathrm{f}, 2}$ & 0,00038 & 0,00041 & 0,00039 & 0,00036 & 0,00046 & 0,00045 & 0,00043 & 0,00040 & 0,00047 & 0,00040 \\
\hline & $\varepsilon_{\mathrm{f}, 3}$ & 0,00039 & 0,00040 & 0,00045 & 0,00036 & 0,00046 & 0,00045 & 0,00040 & 0,00039 & 0,00038 & 0,00044 \\
\hline \multirow{3}{*}{$\begin{array}{l}\text { Deformação } \\
\text { específica } \\
\varepsilon(\mathrm{mm} / \mathrm{mm})\end{array}$} & $\varepsilon_{1}$ & 0,00039 & 0,00042 & 0,00039 & 0,00034 & 0,00040 & 0,00040 & 0,00042 & 0,00038 & 0,00040 & 0,00039 \\
\hline & $\varepsilon_{2}$ & 0,00038 & 0,00041 & 0,00039 & 0,00036 & 0,00041 & 0,00040 & 0,00043 & 0,00040 & 0,00042 & 0,00040 \\
\hline & $\varepsilon_{3}$ & 0,00039 & 0,00040 & 0,00040 & 0,00036 & 0,00041 & 0,00040 & 0,00040 & 0,00039 & 0,00038 & 0,00039 \\
\hline \multirow{3}{*}{$\mathrm{E}_{\mathrm{cs}}(\mathrm{GPa})$} & $E_{1}$ & 24,89 & 22,12 & 22,50 & 23,67 & 22,99 & 24,79 & 23,88 & 25,92 & 26,41 & 28,04 \\
\hline & $\mathrm{E}_{2}$ & 24,18 & 22,42 & 25,02 & 23,67 & 21,80 & 23,66 & 25,38 & 26,30 & 24,92 & 28,04 \\
\hline & $E_{3}$ & 24,53 & 22,42 & 21,88 & 22,91 & 22,08 & 24,02 & 26,05 & 25,92 & 26,81 & 28,04 \\
\hline \multicolumn{2}{|c|}{$\mathrm{E}_{\mathrm{cs}, \text { médio }}(\mathrm{GPa})$} & 24,53 & 22,32 & 23,13 & 23,42 & 22,29 & 24,16 & 25,10 & 26,05 & 26,05 & 28,04 \\
\hline \multicolumn{2}{|c|}{ Amostra } & 11 & 12 & 13 & 14 & 15 & 16 & 17 & 18 & 19 & 20 \\
\hline \multicolumn{2}{|c|}{ fc,médio (MPa) } & 33,8 & 31,2 & 33,0 & 32,2 & 29,6 & 32,1 & 29,2 & 27,3 & 31,0 & 30,5 \\
\hline \multicolumn{2}{|l|}{$40 \%$ fc } & 13,52 & 12,48 & 13,20 & 12,86 & 11,82 & 12,84 & 11,66 & 10,92 & 12,38 & 12,18 \\
\hline \multirow{3}{*}{$\begin{array}{c}\text { Def. esp. inicial } \\
\varepsilon_{\mathrm{i}}(\mathrm{mm} / \mathrm{mm})\end{array}$} & $\varepsilon_{i, 1}$ & 0,00000 & 0,00005 & 0,00000 & 0,00000 & 0,00005 & 0,00000 & 0,00005 & 0,00000 & 0,00005 & 0,00005 \\
\hline & $\varepsilon_{i, 2}$ & 0,00000 & 0,00000 & 0,00000 & 0,00000 & 0,00000 & 0,00000 & 0,00000 & 0,00000 & 0,00005 & 0,00000 \\
\hline & $\varepsilon_{\mathrm{i}, 3}$ & 0,00005 & 0,00005 & 0,00000 & 0,00000 & 0,00000 & 0,00005 & 0,00005 & 0,00000 & 0,00000 & 0,00000 \\
\hline \multirow{3}{*}{$\begin{array}{l}\text { Def. esp. final } \\
\varepsilon_{\mathrm{f}}(\mathrm{mm} / \mathrm{mm})\end{array}$} & $\varepsilon_{\mathrm{f}, 1}$ & 0,00039 & 0,00038 & 0,00035 & 0,00040 & 0,00046 & 0,00039 & 0,00045 & 0,00039 & 0,00045 & 0,00047 \\
\hline & $\varepsilon_{\mathrm{f}, 2}$ & 0,00038 & 0,00036 & 0,00037 & 0,00038 & 0,00039 & 0,00039 & 0,00040 & 0,00039 & 0,00045 & 0,00043 \\
\hline & $\varepsilon_{\mathrm{f}, 3}$ & 0,00046 & 0,00044 & 0,00036 & 0,00043 & 0,00037 & 0,00044 & 0,00045 & 0,00039 & 0,00040 & 0,00042 \\
\hline \multirow{3}{*}{$\begin{array}{l}\text { Deformação } \\
\text { específica } \\
\varepsilon(\mathrm{mm} / \mathrm{mm})\end{array}$} & $\varepsilon_{1}$ & 0,00039 & 0,00033 & 0,00035 & 0,00040 & 0,00041 & 0,00039 & 0,00040 & 0,00039 & 0,00040 & 0,00042 \\
\hline & $\varepsilon_{2}$ & 0,00038 & 0,00036 & 0,00037 & 0,00038 & 0,00039 & 0,00039 & 0,00040 & 0,00039 & 0,00040 & 0,00043 \\
\hline & $\varepsilon_{3}$ & 0,00041 & 0,00039 & 0,00036 & 0,00043 & 0,00037 & 0,00039 & 0,00040 & 0,00039 & 0,00040 & 0,00042 \\
\hline \multirow{3}{*}{$\mathrm{E}_{\mathrm{cs}}(\mathrm{GPa})$} & $E_{1}$ & 24,82 & 26,01 & 26,09 & 23,38 & 25,22 & 26,25 & 24,97 & 24,26 & 25,45 & 24,67 \\
\hline & $E_{2}$ & 25,17 & 24,06 & 25,69 & 24,05 & 26,09 & 26,25 & 24,97 & 24,26 & 25,45 & 24,29 \\
\hline & $E_{3}$ & 23,50 & 22,72 & 26,09 & 21,62 & 25,64 & 25,83 & 24,97 & 24,68 & 25,45 & 25,90 \\
\hline \multicolumn{2}{|c|}{$\mathrm{E}_{\mathrm{cs}, \text { médio }}(\mathrm{GPa})$} & 24,50 & 24,26 & 25,96 & 23,02 & 25,65 & 26,11 & 24,97 & 24,40 & 25,45 & 24,95 \\
\hline \multicolumn{2}{|c|}{ Amostra } & 21 & 22 & 23 & 24 & 25 & 26 & 27 & 28 & 29 & 30 \\
\hline \multicolumn{2}{|c|}{ fc,médio (MPa) } & 30,0 & 30,2 & 26,6 & 29,7 & 32,2 & 32,1 & 28,4 & 33,8 & 30,4 & 32,0 \\
\hline \multicolumn{2}{|l|}{$40 \% \mathrm{fc}$} & 11,98 & 12,06 & 10,64 & 11,88 & 12,86 & 12,82 & 11,34 & 13,50 & 12,14 & 12,80 \\
\hline & $\varepsilon_{i, 1}$ & 0,00005 & 0,00000 & 0,00005 & 0,00005 & 0,00005 & 0,00005 & 0,00005 & 0,00000 & 0,00005 & 0,00000 \\
\hline $\begin{array}{l}\text { Def. esp. inicial } \\
\varepsilon_{\mathrm{i}}(\mathrm{mm} / \mathrm{mm})\end{array}$ & $\varepsilon_{\mathrm{i}, 2}$ & 0,00000 & 0,00000 & 0,00000 & 0,00005 & 0,00000 & 0,00005 & 0,00000 & 0,00000 & 0,00000 & 0,00000 \\
\hline & $\varepsilon_{i, 3}$ & 0,00005 & 0,00000 & 0,00005 & 0,00005 & 0,00005 & 0,00005 & 0,00000 & 0,00005 & 0,00000 & 0,00000 \\
\hline & $\varepsilon_{\mathrm{f}, 1}$ & 0,00045 & 0,00040 & 0,00044 & 0,00043 & 0,00044 & 0,00044 & 0,00043 & 0,00050 & 0,00045 & 0,00033 \\
\hline $\begin{array}{l}\text { Def. esp. final } \\
\varepsilon_{\mathrm{f}}(\mathrm{mm} / \mathrm{mm})\end{array}$ & $\varepsilon_{\mathrm{f}, 2}$ & 0,00039 & 0,00040 & 0,00038 & 0,00046 & 0,00042 & 0,00042 & 0,00040 & 0,00040 & 0,00040 & 0,00032 \\
\hline & $\varepsilon_{\mathrm{f}, 3}$ & 0,00045 & 0,00042 & 0,00044 & 0,00045 & 0,00045 & 0,00043 & 0,00039 & 0,00048 & 0,00044 & 0,00033 \\
\hline & $\varepsilon_{1}$ & 0,00040 & 0,00040 & 0,00039 & 0,00038 & 0,00039 & 0,00039 & 0,00038 & 0,00050 & 0,00040 & 0,00033 \\
\hline especifica & $\varepsilon_{2}$ & 0,00039 & 0,00040 & 0,00038 & 0,00041 & 0,00042 & 0,00037 & 0,00040 & 0,00040 & 0,00040 & 0,00032 \\
\hline & $\varepsilon_{3}$ & 0,00040 & 0,00042 & 0,00039 & 0,00040 & 0,00040 & 0,00038 & 0,00039 & 0,00043 & 0,00044 & 0,00033 \\
\hline & $\mathrm{E}_{1}$ & 23,93 & 23,04 & 24,54 & 26,17 & 25,13 & 25,83 & 24,29 & 25,86 & 24,61 & 25,55 \\
\hline $\mathrm{E}_{\mathrm{cs}}(\mathrm{GPa})$ & $\mathrm{E}_{2}$ & 25,09 & 23,04 & 23,70 & 27,11 & 24,05 & 27,13 & 25,12 & 24,41 & 25,41 & 25,88 \\
\hline & $E_{3}$ & 25,94 & 23,15 & 25,45 & 27,62 & 24,76 & 26,68 & 25,12 & 23,14 & 24,61 & 25,23 \\
\hline $\mathrm{E}_{\mathrm{cs}, \text { médio }}(\mathrm{GP}$ & & 24,99 & 23,08 & 24,56 & 26,97 & 24,65 & 26,55 & 24,84 & 24,47 & 24,88 & 25,55 \\
\hline
\end{tabular}


Tabela A-5.b - Resultados dos ensaios de módulo de deformação secante, $E_{c s}$ - fck 25MPa

\begin{tabular}{|c|c|c|c|c|c|c|c|c|c|c|c|}
\hline \multicolumn{2}{|c|}{ Amostra } & 31 & 32 & 33 & 34 & 35 & 36 & 37 & 38 & 39 & 40 \\
\hline \multicolumn{2}{|c|}{$\mathrm{f}_{\mathrm{c}, \text { médio }}(\mathrm{MPa})$} & 39,6 & 35,7 & 31,8 & 30,9 & 32,9 & 35,4 & 31,7 & 33,7 & 30,9 & 29,3 \\
\hline \multicolumn{2}{|l|}{$40 \%$ fc } & 15,84 & 14,28 & 12,72 & 12,34 & 13,16 & 14,16 & 12,66 & 13,48 & 12,34 & 11,70 \\
\hline \multirow{3}{*}{$\begin{array}{l}\text { Def. esp. inicial } \\
\varepsilon_{\mathrm{i}}(\mathrm{mm} / \mathrm{mm})\end{array}$} & $\varepsilon_{i, 1}$ & 0,00000 & 0,00000 & 0,00005 & 0,00000 & 0,00005 & 0,00000 & 0,00000 & 0,00005 & 0,00000 & 0,00000 \\
\hline & $\varepsilon_{i, 2}$ & 0,00000 & 0,00005 & 0,00000 & 0,00005 & 0,00005 & 0,00000 & 0,00000 & 0,00005 & 0,00000 & 0,00000 \\
\hline & $\varepsilon_{i, 3}$ & 0,00005 & 0,00000 & 0,00000 & 0,00005 & 0,00005 & 0,00000 & 0,00000 & 0,00005 & 0,00000 & 0,00000 \\
\hline \multirow{3}{*}{$\begin{array}{l}\text { Def. esp. final } \\
\varepsilon_{f}(\mathrm{~mm} / \mathrm{mm})\end{array}$} & $\varepsilon_{\mathrm{f}, 1}$ & 0,00042 & 0,00039 & 0,00045 & 0,00042 & 0,00044 & 0,00039 & 0,00040 & 0,00045 & 0,00037 & 0,00039 \\
\hline & $\varepsilon_{\mathrm{f}, 2}$ & 0,00042 & 0,00043 & 0,00041 & 0,00046 & 0,00046 & 0,00039 & 0,00040 & 0,00044 & 0,00036 & 0,00039 \\
\hline & $\varepsilon_{\mathrm{f}, 3}$ & 0,00047 & 0,00040 & 0,00041 & 0,00044 & 0,00043 & 0,00040 & 0,00041 & 0,00044 & 0,00036 & 0,00039 \\
\hline \multirow{3}{*}{$\begin{array}{l}\text { Deformação } \\
\text { específica } \\
\varepsilon(\mathrm{mm} / \mathrm{mm})\end{array}$} & $\varepsilon_{1}$ & 0,00042 & 0,00039 & 0,00040 & 0,00042 & 0,00039 & 0,00039 & 0,00040 & 0,00040 & 0,00037 & 0,00039 \\
\hline & $\varepsilon_{2}$ & 0,00042 & 0,00038 & 0,00041 & 0,00041 & 0,00041 & 0,00039 & 0,00040 & 0,00039 & 0,00036 & 0,00039 \\
\hline & $\varepsilon_{3}$ & 0,00042 & 0,00040 & 0,00041 & 0,00039 & 0,00038 & 0,00040 & 0,00041 & 0,00039 & 0,00036 & 0,00039 \\
\hline \multirow{3}{*}{$\mathrm{E}_{\mathrm{cs}}(\mathrm{GPa})$} & $E_{1}$ & 24,71 & 25,76 & 24,84 & 24,20 & 23,51 & 26,56 & 23,05 & 26,59 & 26,67 & 25,29 \\
\hline & $\mathrm{E}_{2}$ & 24,42 & 25,76 & 25,62 & 24,95 & 24,51 & 25,42 & 24,41 & 26,18 & 25,79 & 26,17 \\
\hline & $E_{3}$ & 25,32 & 25,41 & 25,62 & 24,20 & 22,60 & 25,80 & 23,38 & 26,18 & 24,98 & 25,72 \\
\hline \multicolumn{2}{|c|}{$\mathrm{E}_{\mathrm{cs}, \text { médio }}(\mathrm{GPa})$} & 24,82 & 25,64 & 25,36 & 24,45 & 23,54 & 25,93 & 23,61 & 26,32 & 25,81 & 25,73 \\
\hline \multicolumn{2}{|c|}{ Amostra } & 41 & 42 & 43 & 44 & 45 & 46 & 47 & 48 & 49 & 50 \\
\hline \multicolumn{2}{|c|}{ fc,médio (MPa) } & 35,6 & 36,5 & 33,1 & 31,0 & 34,0 & 32,8 & 30,0 & 33,1 & 30,3 & 28,9 \\
\hline \multicolumn{2}{|l|}{$40 \%$ fc } & 14,22 & 14,60 & 13,22 & 12,40 & 13,58 & 13,12 & 11,98 & 13,22 & 12,12 & 11,54 \\
\hline \multirow{3}{*}{$\begin{array}{c}\text { Def. esp. inicial } \\
\varepsilon_{\mathrm{i}}(\mathrm{mm} / \mathrm{mm})\end{array}$} & $\varepsilon_{i, 1}$ & 0,00005 & 0,00000 & 0,00005 & 0,00000 & 0,00005 & 0,00000 & 0,00000 & 0,00005 & 0,00000 & 0,00000 \\
\hline & $\varepsilon_{\mathrm{i}, 2}$ & 0,00005 & 0,00005 & 0,00005 & 0,00000 & 0,00005 & 0,00005 & 0,00005 & 0,00005 & 0,00005 & 0,00000 \\
\hline & $\varepsilon_{\mathrm{i}, 3}$ & 0,00000 & 0,00000 & 0,00005 & 0,00000 & 0,00005 & 0,00005 & 0,00000 & 0,00000 & 0,00000 & 0,00005 \\
\hline \multirow{3}{*}{$\begin{array}{l}\text { Def. esp. final } \\
\varepsilon_{\mathrm{f}}(\mathrm{mm} / \mathrm{mm})\end{array}$} & $\varepsilon_{\mathrm{f}, 1}$ & 0,00045 & 0,00042 & 0,00045 & 0,00041 & 0,00044 & 0,00036 & 0,00039 & 0,00043 & 0,00038 & 0,00044 \\
\hline & $\varepsilon_{\mathrm{f}, 2}$ & 0,00047 & 0,00062 & 0,00042 & 0,00041 & 0,00043 & 0,00041 & 0,00045 & 0,00045 & 0,00045 & 0,00040 \\
\hline & $\varepsilon_{\mathrm{f}, 3}$ & 0,00041 & 0,00057 & 0,00042 & 0,00042 & 0,00044 & 0,00039 & 0,00038 & 0,00041 & 0,00041 & 0,00048 \\
\hline \multirow{3}{*}{$\begin{array}{l}\text { Deformação } \\
\text { específica } \\
\varepsilon(\mathrm{mm} / \mathrm{mm})\end{array}$} & $\varepsilon_{1}$ & 0,00040 & 0,00042 & 0,00040 & 0,00041 & 0,00039 & 0,00036 & 0,00039 & 0,00038 & 0,00038 & 0,00044 \\
\hline & $\varepsilon_{2}$ & 0,00042 & 0,00057 & 0,00037 & 0,00041 & 0,00038 & 0,00036 & 0,00040 & 0,00040 & 0,00040 & 0,00040 \\
\hline & $\varepsilon_{3}$ & 0,00041 & 0,00057 & 0,00037 & 0,00042 & 0,00039 & 0,00034 & 0,00038 & 0,00041 & 0,00041 & 0,00043 \\
\hline \multirow{3}{*}{$\mathrm{E}_{\mathrm{cs}}(\mathrm{GPa})$} & $E_{1}$ & 26,28 & 25,38 & 26,29 & 26,29 & 23,25 & 24,82 & 25,29 & 25,00 & 25,76 & 23,52 \\
\hline & $\mathrm{E}_{2}$ & 25,21 & 25,38 & 24,64 & 26,29 & 23,56 & 25,48 & 24,88 & 24,64 & 25,76 & 25,53 \\
\hline & $E_{3}$ & 24,85 & 25,38 & 24,29 & 24,66 & 24,53 & 24,82 & 25,08 & 24,64 & 26,65 & 23,89 \\
\hline \multicolumn{2}{|c|}{$\mathrm{E}_{\mathrm{cs}, \text { médio }}(\mathrm{GPa})$} & 25,45 & 25,38 & 25,07 & 25,75 & 23,78 & 25,04 & 25,08 & 24,76 & 26,06 & 24,31 \\
\hline \multicolumn{2}{|c|}{ Amostra } & 51 & 52 & 53 & 54 & 55 & 56 & 57 & 58 & 59 & 60 \\
\hline \multicolumn{2}{|c|}{ fc,médio (MPa) } & 31,8 & 33,9 & 33,6 & 30,2 & 30,0 & 33,2 & 30,8 & 30,7 & 29,2 & 30,7 \\
\hline \multicolumn{2}{|l|}{$40 \% \mathrm{fc}$} & 12,72 & 13,56 & 13,42 & 12,08 & 12,00 & 13,26 & 12,32 & 12,26 & 11,67 & 12,26 \\
\hline & $\varepsilon_{i, 1}$ & 0,00005 & 0,00000 & 0,00005 & 0,00005 & 0,00005 & 0,00000 & 0,00005 & 0,00005 & 0,00005 & 0,00000 \\
\hline $\begin{array}{l}\text { Def. esp. inicial } \\
\varepsilon_{\mathrm{i}}(\mathrm{mm} / \mathrm{mm})\end{array}$ & $\varepsilon_{\mathrm{i}, 2}$ & 0,00000 & 0,00005 & 0,00000 & 0,00000 & 0,00005 & 0,00000 & 0,00005 & 0,00005 & 0,00000 & 0,00000 \\
\hline & $\varepsilon_{i, 3}$ & 0,00005 & 0,00000 & 0,00000 & 0,00000 & 0,00000 & 0,00000 & 0,00000 & 0,00000 & 0,00000 & 0,00000 \\
\hline & $\varepsilon_{\mathrm{f}, 1}$ & 0,00046 & 0,00040 & 0,00047 & 0,00044 & 0,00041 & 0,00039 & 0,00042 & 0,00044 & 0,00046 & 0,00037 \\
\hline $\begin{array}{l}\text { Def. esp. final } \\
\varepsilon_{\mathrm{f}}(\mathrm{mm} / \mathrm{mm})\end{array}$ & $\varepsilon_{\mathrm{f}, 2}$ & 0,00040 & 0,00045 & 0,00039 & 0,00039 & 0,00043 & 0,00039 & 0,00045 & 0,00044 & 0,00040 & 0,00040 \\
\hline & $\varepsilon_{\mathrm{f}, 3}$ & 0,00044 & 0,00041 & 0,00042 & 0,00039 & 0,00035 & 0,00039 & 0,00036 & 0,00041 & 0,00040 & 0,00038 \\
\hline & $\varepsilon_{1}$ & 0,00041 & 0,00040 & 0,00042 & 0,00039 & 0,00036 & 0,00039 & 0,00037 & 0,00039 & 0,00041 & 0,00037 \\
\hline especifica & $\varepsilon_{2}$ & 0,00040 & 0,00040 & 0,00039 & 0,00039 & 0,00038 & 0,00039 & 0,00040 & 0,00039 & 0,00040 & 0,00040 \\
\hline & $\varepsilon_{3}$ & 0,00039 & 0,00041 & 0,00042 & 0,00039 & 0,00035 & 0,00039 & 0,00036 & 0,00041 & 0,00040 & 0,00038 \\
\hline & $E_{1}$ & 25,23 & 23,81 & 26,43 & 25,26 & 18,94 & 25,07 & 25,72 & 25,22 & 21,70 & 25,93 \\
\hline $\mathrm{E}_{\mathrm{cs}}(\mathrm{GPa})$ & $\mathrm{E}_{2}$ & 26,46 & 25,17 & 24,25 & 24,47 & 28,34 & 25,44 & 23,79 & 27,04 & 22,03 & 26,83 \\
\hline & $E_{3}$ & 25,62 & 23,50 & 24,90 & 23,38 & 26,78 & 25,44 & 26,15 & 24,26 & 23,73 & 26,83 \\
\hline $\mathrm{E}_{\mathrm{cs}, \text { médio }}(\mathrm{GP}$ & & 25,77 & 24,16 & 25,19 & 24,37 & 24,69 & 25,32 & 25,22 & 25,51 & 22,49 & 26,53 \\
\hline
\end{tabular}


Tabela A-5.c - Resultados dos ensaios de módulo de deformação secante, $\mathrm{E}_{\mathrm{cs}}$ - fck $25 \mathrm{MPa}$

\begin{tabular}{|c|c|c|c|c|c|c|c|c|c|c|c|}
\hline \multicolumn{2}{|c|}{ Amostra } & 61 & 62 & 63 & 64 & 65 & 66 & 67 & 68 & 69 & 70 \\
\hline \multicolumn{2}{|c|}{$\mathrm{f}_{\mathrm{c}, \text { médio }}(\mathrm{MPa})$} & 31,0 & 31,2 & 30,5 & 28,2 & 29,8 & 31,2 & 29,9 & 28,4 & 31,0 & 30,3 \\
\hline \multicolumn{2}{|l|}{$40 \%$ fc } & 12,40 & 12,48 & 12,20 & 11,26 & 11,90 & 12,48 & 11,96 & 11,36 & 12,40 & 12,10 \\
\hline \multirow{3}{*}{$\begin{array}{c}\text { Def. esp. inicial } \\
\varepsilon_{\mathrm{i}}(\mathrm{mm} / \mathrm{mm})\end{array}$} & $\varepsilon_{\mathrm{i}, 1}$ & 0,00005 & 0,00000 & 0,00005 & 0,00000 & 0,00005 & 0,00005 & 0,00005 & 0,00005 & 0,00000 & 0,00000 \\
\hline & $\varepsilon_{\mathrm{i}, 2}$ & 0,00000 & 0,00005 & 0,00005 & 0,00000 & 0,00000 & 0,00000 & 0,00005 & 0,00005 & 0,00000 & 0,00000 \\
\hline & $\varepsilon_{\mathrm{i}, 3}$ & 0,00000 & 0,00005 & 0,00005 & 0,00000 & 0,00005 & 0,00005 & 0,00000 & 0,00000 & 0,00005 & 0,00000 \\
\hline \multirow{3}{*}{$\begin{array}{l}\text { Def. esp. final } \\
\varepsilon_{\mathrm{f}}(\mathrm{mm} / \mathrm{mm})\end{array}$} & $\varepsilon_{\mathrm{f}, 1}$ & 0,00044 & 0,00039 & 0,00040 & 0,00037 & 0,00047 & 0,00041 & 0,00043 & 0,00042 & 0,00037 & 0,00039 \\
\hline & $\varepsilon_{\mathrm{f}, 2}$ & 0,00038 & 0,00044 & 0,00041 & 0,00039 & 0,00039 & 0,00035 & 0,00046 & 0,00044 & 0,00032 & 0,00032 \\
\hline & $\varepsilon_{\mathrm{f}, 3}$ & 0,00038 & 0,00043 & 0,00042 & 0,00038 & 0,00047 & 0,00041 & 0,00039 & 0,00037 & 0,00041 & 0,00035 \\
\hline \multirow{3}{*}{$\begin{array}{l}\text { Deformação } \\
\text { específica } \\
\varepsilon(\mathrm{mm} / \mathrm{mm})\end{array}$} & $\varepsilon_{1}$ & 0,00039 & 0,00039 & 0,00035 & 0,00037 & 0,00042 & 0,00036 & 0,00038 & 0,00037 & 0,00037 & 0,00039 \\
\hline & $\varepsilon_{2}$ & 0,00038 & 0,00039 & 0,00036 & 0,00039 & 0,00039 & 0,00035 & 0,00041 & 0,00039 & 0,00032 & 0,00032 \\
\hline & $\varepsilon_{3}$ & 0,00038 & 0,00038 & 0,00037 & 0,00038 & 0,00042 & 0,00036 & 0,00039 & 0,00037 & 0,00036 & 0,00035 \\
\hline \multirow{3}{*}{$\mathrm{E}_{\mathrm{cs}}(\mathrm{GPa})$} & $\mathrm{E}_{1}$ & 24,54 & 25,16 & 27,31 & 23,35 & 24,92 & 24,79 & 25,44 & 25,49 & 27,77 & 25,51 \\
\hline & $\mathrm{E}_{2}$ & 24,17 & 25,56 & 26,83 & 23,35 & 24,14 & 26,01 & 25,02 & 25,05 & 24,83 & 25,51 \\
\hline & $\mathrm{E}_{3}$ & 23,14 & 24,77 & 26,83 & 22,64 & 25,34 & 26,89 & 25,87 & 25,05 & 25,74 & 25,51 \\
\hline \multicolumn{2}{|c|}{$\mathrm{E}_{\mathrm{cs}, \text { médio }}(\mathrm{GPa})$} & 23,95 & 25,16 & 26,99 & 23,11 & 24,80 & 25,90 & 25,44 & 25,20 & 26,11 & 25,51 \\
\hline \multicolumn{2}{|c|}{ Amostra } & 71 & 72 & 73 & 74 & 75 & 76 & 77 & 78 & 79 & 80 \\
\hline \multicolumn{2}{|c|}{ fc,médio $(\mathrm{MPa})$} & 31,3 & 32,3 & 32,2 & 32,0 & 33,5 & 30,1 & 32,9 & 32,4 & 33,8 & 32,1 \\
\hline \multicolumn{2}{|l|}{$40 \%$ fc } & 12,50 & 12,92 & 12,88 & 12,78 & 13,40 & 12,02 & 13,14 & 12,94 & 13,52 & 12,82 \\
\hline \multirow{3}{*}{$\begin{array}{c}\text { Def. esp. inicial } \\
\varepsilon_{\mathrm{i}}(\mathrm{mm} / \mathrm{mm})\end{array}$} & $\varepsilon_{\mathrm{i}, 1}$ & 0,00005 & 0,00005 & 0,00000 & 0,00005 & 0,00005 & 0,00005 & 0,00005 & 0,00005 & 0,00005 & 0,00000 \\
\hline & $\varepsilon_{\mathrm{i}, 2}$ & 0,00000 & 0,00000 & 0,00000 & 0,00000 & 0,00000 & 0,00005 & 0,00000 & 0,00000 & 0,00005 & 0,00000 \\
\hline & $\varepsilon_{\mathrm{i}, 3}$ & 0,00005 & 0,00005 & 0,00000 & 0,00005 & 0,00005 & 0,00005 & 0,00005 & 0,00005 & 0,00005 & 0,00005 \\
\hline \multirow{3}{*}{$\begin{array}{l}\text { Def. esp. final } \\
\varepsilon_{f}(\mathrm{~mm} / \mathrm{mm})\end{array}$} & $\varepsilon_{\mathrm{f}, 1}$ & 0,00044 & 0,00045 & 0,00041 & 0,00045 & 0,00046 & 0,00046 & 0,00048 & 0,00045 & 0,00049 & 0,00041 \\
\hline & $\varepsilon_{\mathrm{f}, 2}$ & 0,00040 & 0,00045 & 0,00042 & 0,00041 & 0,00041 & 0,00045 & 0,00042 & 0,00041 & 0,00057 & 0,00042 \\
\hline & $\varepsilon_{\mathrm{f}, 3}$ & 0,00044 & 0,00047 & 0,00042 & 0,00046 & 0,00047 & 0,00044 & 0,00045 & 0,00047 & 0,00046 & 0,00044 \\
\hline \multirow{3}{*}{$\begin{array}{l}\text { Deformação } \\
\text { específica } \\
\varepsilon(\mathrm{mm} / \mathrm{mm})\end{array}$} & $\varepsilon_{1}$ & 0,00039 & 0,00040 & 0,00041 & 0,00040 & 0,00041 & 0,00041 & 0,00043 & 0,00040 & 0,00044 & 0,00041 \\
\hline & $\varepsilon_{2}$ & 0,00040 & 0,00045 & 0,00042 & 0,00041 & 0,00041 & 0,00040 & 0,00042 & 0,00041 & 0,00052 & 0,00042 \\
\hline & $\varepsilon_{3}$ & 0,00039 & 0,00042 & 0,00042 & 0,00041 & 0,00042 & 0,00039 & 0,00040 & 0,00042 & 0,00041 & 0,00039 \\
\hline \multirow{3}{*}{$\mathrm{E}_{\mathrm{cs}}(\mathrm{GPa})$} & $\mathrm{E}_{1}$ & 25,56 & 25,59 & 26,67 & 27,05 & 27,16 & 27,73 & 22,80 & 26,48 & 27,45 & 26,01 \\
\hline & $\mathrm{E}_{2}$ & 25,56 & 27,10 & 26,58 & 25,59 & 25,48 & 27,62 & 26,79 & 27,56 & 28,45 & 25,50 \\
\hline & $\mathrm{E}_{3}$ & 25,16 & 27,10 & 24,13 & 26,54 & 27,29 & 27,14 & 27,76 & 27,49 & 25,48 & 24,98 \\
\hline \multicolumn{2}{|c|}{$\mathrm{E}_{\mathrm{cs}, \text { médio }}(\mathrm{GPa})$} & 25,43 & 26,60 & 25,79 & 26,39 & 26,64 & 27,50 & 25,78 & 27,18 & 27,13 & 25,50 \\
\hline \multicolumn{2}{|c|}{ Amostra } & 81 & 82 & 83 & 84 & 85 & 86 & 87 & 88 & 89 & 90 \\
\hline \multicolumn{2}{|c|}{ fc,médio (MPa) } & 32,2 & 31,2 & 33,7 & 28,6 & 26,6 & 28,9 & 32,4 & 31,7 & 29,6 & 29,6 \\
\hline \multicolumn{2}{|l|}{$40 \% \mathrm{fc}$} & 12,88 & 12,48 & 13,48 & 11,42 & 10,64 & 11,56 & 12,94 & 12,66 & 11,82 & 11,84 \\
\hline & $\varepsilon_{\mathrm{i}, 1}$ & 0,00000 & 0,00005 & 0,00000 & 0,00005 & 0,00005 & 0,00005 & 0,00005 & 0,00005 & 0,00005 & 0,00005 \\
\hline $\begin{array}{l}\text { Def. esp. inicial } \\
\mathcal{E}_{\mathrm{i}}(\mathrm{mm} / \mathrm{mm})\end{array}$ & $\varepsilon_{i, 2}$ & 0,00000 & 0,00005 & 0,00005 & 0,00005 & 0,00000 & 0,00005 & 0,00000 & 0,00000 & 0,00000 & 0,00005 \\
\hline & $\varepsilon_{i, 3}$ & 0,00005 & 0,00005 & 0,00005 & 0,00005 & 0,00000 & 0,00005 & 0,00005 & 0,00005 & 0,00000 & 0,00005 \\
\hline & $\varepsilon_{\mathrm{f}, 1}$ & 0,00042 & 0,00045 & 0,00044 & 0,00048 & 0,00044 & 0,00046 & 0,00048 & 0,00045 & 0,00044 & 0,00046 \\
\hline $\begin{array}{l}\text { Def. esp. final } \\
\varepsilon_{f}(\mathrm{~mm} / \mathrm{mm})\end{array}$ & $\varepsilon_{\mathrm{f}, 2}$ & 0,00040 & 0,00044 & 0,00047 & 0,00045 & 0,00038 & 0,00045 & 0,00046 & 0,00042 & 0,00040 & 0,00046 \\
\hline & $\varepsilon_{\mathrm{f}, 3}$ & 0,00044 & 0,00045 & 0,00046 & 0,00046 & 0,00034 & 0,00046 & 0,00045 & 0,00044 & 0,00037 & 0,00044 \\
\hline & $\varepsilon_{1}$ & 0,00042 & 0,00040 & 0,00044 & 0,00043 & 0,00039 & 0,00041 & 0,00043 & 0,00040 & 0,00039 & 0,00041 \\
\hline específica & $\varepsilon_{2}$ & 0,00040 & 0,00039 & 0,00042 & 0,00040 & 0,00038 & 0,00040 & 0,00046 & 0,00042 & 0,00040 & 0,00041 \\
\hline & $\varepsilon_{3}$ & 0,00039 & 0,00040 & 0,00041 & 0,00041 & 0,00034 & 0,00041 & 0,00040 & 0,00039 & 0,00037 & 0,00039 \\
\hline & $E_{1}$ & 27,52 & 27,46 & 28,21 & 27,44 & 26,16 & 26,84 & 26,98 & 27,67 & 27,90 & 27,30 \\
\hline $\mathrm{E}_{\mathrm{cs}}(\mathrm{GPa})$ & $\mathrm{E}_{2}$ & 28,08 & 28,02 & 28,50 & 26,99 & 26,30 & 27,21 & 27,07 & 28,39 & 26,21 & 27,17 \\
\hline & $E_{3}$ & 26,34 & 24,79 & 26,59 & 26,70 & 26,88 & 24,28 & 25,20 & 25,48 & 25,57 & 27,63 \\
\hline $\mathrm{E}_{\mathrm{cs}, \text { médio }}(\mathrm{GP}$ & & 27,31 & 26,76 & 27,77 & 27,04 & 26,45 & 26,11 & 26,42 & 27,18 & 26,56 & 27,37 \\
\hline
\end{tabular}


Tabela A-5.d - Resultados dos ensaios de módulo de deformação secante, $E_{\mathrm{cs}}-f_{\mathrm{ck}} 25 \mathrm{MPa}$

\begin{tabular}{|c|c|c|c|c|c|c|c|c|c|c|c|}
\hline \multicolumn{2}{|c|}{ Amostra } & 91 & 92 & 93 & 94 & 95 & 96 & 97 & 98 & 99 & 100 \\
\hline \multicolumn{2}{|c|}{$\mathrm{f}_{\mathrm{c}, \text { médio }}(\mathrm{MPa})$} & 30,5 & 36,0 & 32,9 & 36,0 & 31,5 & 35,5 & 34,9 & 33,1 & 28,4 & 31,5 \\
\hline \multicolumn{2}{|l|}{$40 \%$ fc } & 12,20 & 14,40 & 13,16 & 14,38 & 12,58 & 14,20 & 13,96 & 13,24 & 11,34 & 12,58 \\
\hline \multirow{3}{*}{$\begin{array}{l}\text { Def. esp. inicial } \\
\varepsilon_{\mathrm{i}}(\mathrm{mm} / \mathrm{mm})\end{array}$} & $\varepsilon_{i, 1}$ & 0,00000 & 0,00005 & 0,00005 & 0,00000 & 0,00005 & 0,00000 & 0,00000 & 0,00005 & 0,00000 & 0,00005 \\
\hline & $\varepsilon_{i, 2}$ & 0,00005 & 0,00000 & 0,00000 & 0,00000 & 0,00000 & 0,00005 & 0,00000 & 0,00000 & 0,00005 & 0,00000 \\
\hline & $\varepsilon_{i, 3}$ & 0,00005 & 0,00005 & 0,00005 & 0,00000 & 0,00005 & 0,00000 & 0,00005 & 0,00005 & 0,00000 & 0,00000 \\
\hline \multirow{3}{*}{$\begin{array}{l}\text { Def. esp. final } \\
\varepsilon_{f}(\mathrm{~mm} / \mathrm{mm})\end{array}$} & $\varepsilon_{\mathrm{f}, 1}$ & 0,00040 & 0,00048 & 0,00045 & 0,00041 & 0,00046 & 0,00043 & 0,00044 & 0,00046 & 0,00039 & 0,00044 \\
\hline & $\varepsilon_{\mathrm{f}, 2}$ & 0,00047 & 0,00040 & 0,00040 & 0,00042 & 0,00041 & 0,00054 & 0,00045 & 0,00041 & 0,00040 & 0,00041 \\
\hline & $\varepsilon_{\mathrm{f}, 3}$ & 0,00049 & 0,00046 & 0,00045 & 0,00042 & 0,00044 & 0,00041 & 0,00051 & 0,00045 & 0,00038 & 0,00040 \\
\hline \multirow{3}{*}{$\begin{array}{l}\text { Deformação } \\
\text { específica } \\
\varepsilon(\mathrm{mm} / \mathrm{mm})\end{array}$} & $\varepsilon_{1}$ & 0,00040 & 0,00043 & 0,00040 & 0,00041 & 0,00041 & 0,00043 & 0,00044 & 0,00041 & 0,00039 & 0,00039 \\
\hline & $\varepsilon_{2}$ & 0,00042 & 0,00040 & 0,00040 & 0,00042 & 0,00041 & 0,00049 & 0,00045 & 0,00041 & 0,00035 & 0,00041 \\
\hline & $\varepsilon_{3}$ & 0,00044 & 0,00041 & 0,00040 & 0,00042 & 0,00039 & 0,00041 & 0,00046 & 0,00040 & 0,00038 & 0,00040 \\
\hline \multirow{3}{*}{$\mathrm{E}_{\mathrm{cs}}(\mathrm{GPa})$} & $E_{1}$ & 27,78 & 28,51 & 28,42 & 28,66 & 27,36 & 27,34 & 25,49 & 26,93 & 23,93 & 25,50 \\
\hline & $\mathrm{E}_{2}$ & 26,69 & 28,56 & 27,20 & 27,01 & 26,80 & 26,81 & 27,07 & 26,93 & 27,54 & 25,85 \\
\hline & $E_{3}$ & 27,15 & 28,09 & 26,64 & 29,11 & 26,86 & 28,25 & 26,50 & 26,32 & 26,85 & 26,50 \\
\hline \multicolumn{2}{|c|}{$\mathrm{E}_{\mathrm{cs}, \text { médio }}(\mathrm{GPa})$} & 27,21 & 28,39 & 27,42 & 28,26 & 27,01 & 27,47 & 26,35 & 26,73 & 26,11 & 25,95 \\
\hline \multicolumn{2}{|c|}{ Amostra } & 101 & 102 & 103 & 104 & 105 & 106 & 107 & 108 & 109 & 110 \\
\hline \multicolumn{2}{|c|}{ fc,médio (MPa) } & 36,3 & 30,2 & 36,2 & 28,4 & 30,0 & 33,1 & 35,7 & 34,9 & 36,1 & 34,6 \\
\hline \multicolumn{2}{|l|}{$40 \%$ fc } & 14,52 & 12,06 & 14,46 & 11,34 & 12,00 & 13,24 & 14,26 & 13,96 & 14,44 & 13,84 \\
\hline \multirow{3}{*}{$\begin{array}{c}\text { Def. esp. inicial } \\
\varepsilon_{\mathrm{i}}(\mathrm{mm} / \mathrm{mm})\end{array}$} & $\varepsilon_{i, 1}$ & 0,00005 & 0,00005 & 0,00000 & 0,00005 & 0,00005 & 0,00005 & 0,00000 & 0,00005 & 0,00000 & 0,00005 \\
\hline & $\varepsilon_{\mathrm{i}, 2}$ & 0,00000 & 0,00005 & 0,00000 & 0,00005 & 0,00005 & 0,00000 & 0,00000 & 0,00000 & 0,00005 & 0,00005 \\
\hline & $\varepsilon_{\mathrm{i}, 3}$ & 0,00000 & 0,00000 & 0,00000 & 0,00000 & 0,00000 & 0,00000 & 0,00000 & 0,00000 & 0,00005 & 0,00005 \\
\hline \multirow{3}{*}{$\begin{array}{l}\text { Def. esp. final } \\
\varepsilon_{\mathrm{f}}(\mathrm{mm} / \mathrm{mm})\end{array}$} & $\varepsilon_{\mathrm{f}, 1}$ & 0,00045 & 0,00043 & 0,00041 & 0,00044 & 0,00044 & 0,00045 & 0,00040 & 0,00046 & 0,00045 & 0,00044 \\
\hline & $\varepsilon_{\mathrm{f}, 2}$ & 0,00041 & 0,00044 & 0,00043 & 0,00045 & 0,00044 & 0,00040 & 0,00041 & 0,00041 & 0,00049 & 0,00044 \\
\hline & $\varepsilon_{\mathrm{f}, 3}$ & 0,00041 & 0,00038 & 0,00042 & 0,00039 & 0,00040 & 0,00039 & 0,00042 & 0,00041 & 0,00048 & 0,00043 \\
\hline \multirow{3}{*}{$\begin{array}{l}\text { Deformação } \\
\text { específica } \\
\varepsilon(\mathrm{mm} / \mathrm{mm})\end{array}$} & $\varepsilon_{1}$ & 0,00040 & 0,00038 & 0,00041 & 0,00039 & 0,00039 & 0,00040 & 0,00040 & 0,00041 & 0,00045 & 0,00039 \\
\hline & $\varepsilon_{2}$ & 0,00041 & 0,00039 & 0,00043 & 0,00040 & 0,00039 & 0,00040 & 0,00041 & 0,00041 & 0,00044 & 0,00039 \\
\hline & $\varepsilon_{3}$ & 0,00041 & 0,00038 & 0,00042 & 0,00039 & 0,00040 & 0,00039 & 0,00042 & 0,00041 & 0,00043 & 0,00038 \\
\hline \multirow{3}{*}{$\mathrm{E}_{\mathrm{cs}}(\mathrm{GPa})$} & $E_{1}$ & 26,01 & 26,57 & 24,52 & 25,71 & 26,39 & 27,00 & 26,31 & 26,60 & 25,87 & 25,25 \\
\hline & $\mathrm{E}_{2}$ & 26,01 & 26,57 & 24,21 & 25,71 & 26,39 & 27,00 & 27,13 & 26,21 & 26,62 & 24,23 \\
\hline & $E_{3}$ & 26,01 & 26,12 & 23,90 & 25,72 & 26,39 & 26,57 & 27,15 & 26,60 & 27,01 & 24,90 \\
\hline \multicolumn{2}{|c|}{$\mathrm{E}_{\mathrm{cs}, \text { médio }}(\mathrm{GPa})$} & 26,01 & 26,42 & 24,21 & 25,71 & 26,39 & 26,86 & 26,86 & 26,47 & 26,50 & 24,79 \\
\hline \multicolumn{2}{|c|}{ Amostra } & 111 & 112 & 113 & 114 & 115 & 116 & 117 & 118 & 119 & 120 \\
\hline \multicolumn{2}{|c|}{ fc,médio (MPa) } & 32,0 & 33,8 & 32,1 & 30,1 & 36,5 & 32,5 & 32,8 & 32,9 & 27,7 & 27,2 \\
\hline \multicolumn{2}{|l|}{$40 \% \mathrm{fc}$} & 12,78 & 13,52 & 12,84 & 12,02 & 14,60 & 12,98 & 13,12 & 13,14 & 11,08 & 10,88 \\
\hline & $\varepsilon_{i, 1}$ & 0,00005 & 0,00005 & 0,00000 & 0,00005 & 0,00005 & 0,00005 & 0,00000 & 0,00005 & 0,00005 & 0,00005 \\
\hline $\begin{array}{l}\text { Def. esp. inicial } \\
\varepsilon_{\mathrm{i}}(\mathrm{mm} / \mathrm{mm})\end{array}$ & $\varepsilon_{\mathrm{i}, 2}$ & 0,00000 & 0,00005 & 0,00000 & 0,00005 & 0,00005 & 0,00000 & 0,00000 & 0,00000 & 0,00000 & 0,00000 \\
\hline & $\varepsilon_{i, 3}$ & 0,00000 & 0,00000 & 0,00000 & 0,00000 & 0,00000 & 0,00000 & 0,00000 & 0,00000 & 0,00005 & 0,00000 \\
\hline & $\varepsilon_{\mathrm{f}, 1}$ & 0,00043 & 0,00044 & 0,00041 & 0,00044 & 0,00048 & 0,00041 & 0,00041 & 0,00045 & 0,00043 & 0,00035 \\
\hline $\begin{array}{l}\text { Def. esp. final } \\
\varepsilon_{\mathrm{f}}(\mathrm{mm} / \mathrm{mm})\end{array}$ & $\varepsilon_{\mathrm{f}, 2}$ & 0,00038 & 0,00043 & 0,00041 & 0,00043 & 0,00047 & 0,00039 & 0,00040 & 0,00040 & 0,00039 & 0,00040 \\
\hline & $\varepsilon_{\mathrm{f}, 3}$ & 0,00039 & 0,00042 & 0,00040 & 0,00040 & 0,00039 & 0,00038 & 0,00040 & 0,00039 & 0,00043 & 0,00041 \\
\hline & $\varepsilon_{1}$ & 0,00038 & 0,00039 & 0,00041 & 0,00039 & 0,00043 & 0,00036 & 0,00041 & 0,00040 & 0,00038 & 0,00030 \\
\hline especifica & $\varepsilon_{2}$ & 0,00038 & 0,00038 & 0,00041 & 0,00038 & 0,00042 & 0,00039 & 0,00040 & 0,00040 & 0,00039 & 0,00040 \\
\hline & $\varepsilon_{3}$ & 0,00039 & 0,00042 & 0,00040 & 0,00040 & 0,00039 & 0,00038 & 0,00040 & 0,00039 & 0,00038 & 0,00041 \\
\hline & $E_{1}$ & 25,34 & 25,79 & 25,86 & 26,57 & 26,05 & 26,41 & 26,03 & 24,77 & 25,41 & 26,71 \\
\hline $\mathrm{E}_{\mathrm{cs}}(\mathrm{GPa})$ & $\mathrm{E}_{2}$ & 26,58 & 27,01 & 25,45 & 25,26 & 25,86 & 26,57 & 25,77 & 24,74 & 25,70 & 24,58 \\
\hline & $E_{3}$ & 23,88 & 26,59 & 27,15 & 24,09 & 25,97 & 26,51 & 25,60 & 24,75 & 25,22 & 24,49 \\
\hline $\mathrm{E}_{\mathrm{cs}, \text { médio }}(\mathrm{GP}$ & & 25,27 & 26,46 & 26,15 & 25,31 & 25,96 & 26,50 & 25,80 & 24,75 & 25,44 & 25,26 \\
\hline
\end{tabular}


Tabela A-5.e - Resultados dos ensaios de módulo de deformação secante, $E_{c s}-f_{c k} 25 \mathrm{MPa}$

\begin{tabular}{|c|c|c|c|c|c|c|c|c|c|c|c|}
\hline \multicolumn{2}{|c|}{ Amostra } & 121 & 122 & 123 & 124 & 125 & 126 & 127 & 128 & 129 & 130 \\
\hline \multicolumn{2}{|c|}{$\mathrm{f}_{\mathrm{c}, \text { médio }}(\mathrm{MPa})$} & 29,9 & 31,6 & 27,5 & 35,6 & 36,2 & 36,3 & 30,6 & 33,7 & 39,1 & 36,6 \\
\hline \multicolumn{2}{|l|}{$40 \%$ fc } & 11,94 & 12,64 & 11,00 & 14,24 & 14,46 & 14,50 & 12,24 & 13,46 & 15,62 & 14,62 \\
\hline \multirow{3}{*}{$\begin{array}{l}\text { Def. esp. inicial } \\
\varepsilon_{\mathrm{i}}(\mathrm{mm} / \mathrm{mm})\end{array}$} & $\varepsilon_{i, 1}$ & 0,00000 & 0,00005 & 0,00000 & 0,00005 & 0,00005 & 0,00000 & 0,00000 & 0,00005 & 0,00000 & 0,00005 \\
\hline & $\varepsilon_{\mathrm{i}, 2}$ & 0,00000 & 0,00005 & 0,00005 & 0,00000 & 0,00000 & 0,00000 & 0,00000 & 0,00000 & 0,00000 & 0,00000 \\
\hline & $\varepsilon_{\mathrm{i}, 3}$ & 0,00005 & 0,00000 & 0,00000 & 0,00005 & 0,00000 & 0,00000 & 0,00000 & 0,00000 & 0,00005 & 0,00005 \\
\hline \multirow{3}{*}{$\begin{array}{l}\text { Def. esp. final } \\
\mathcal{E}_{\mathrm{f}}(\mathrm{mm} / \mathrm{mm})\end{array}$} & $\varepsilon_{\mathrm{f}, 1}$ & 0,00038 & 0,00046 & 0,00040 & 0,00047 & 0,00046 & 0,00041 & 0,00038 & 0,00049 & 0,00043 & 0,00054 \\
\hline & $\varepsilon_{\mathrm{f}, 2}$ & 0,00038 & 0,00047 & 0,00043 & 0,00042 & 0,00040 & 0,00044 & 0,00038 & 0,00041 & 0,00043 & 0,00040 \\
\hline & $\varepsilon_{\mathrm{f}, 3}$ & 0,00044 & 0,00042 & 0,00042 & 0,00047 & 0,00040 & 0,00042 & 0,00040 & 0,00041 & 0,00047 & 0,00045 \\
\hline \multirow{3}{*}{$\begin{array}{l}\text { Deformação } \\
\text { específica } \\
\varepsilon(\mathrm{mm} / \mathrm{mm})\end{array}$} & $\varepsilon_{1}$ & 0,00038 & 0,00041 & 0,00040 & 0,00042 & 0,00041 & 0,00041 & 0,00038 & 0,00044 & 0,00043 & 0,00049 \\
\hline & $\varepsilon_{2}$ & 0,00038 & 0,00042 & 0,00038 & 0,00042 & 0,00040 & 0,00044 & 0,00038 & 0,00041 & 0,00043 & 0,00040 \\
\hline & $\varepsilon_{3}$ & 0,00039 & 0,00042 & 0,00042 & 0,00042 & 0,00040 & 0,00042 & 0,00040 & 0,00041 & 0,00042 & 0,00040 \\
\hline \multirow{3}{*}{$\mathrm{E}_{\mathrm{cs}}(\mathrm{GPa})$} & $E_{1}$ & 26,20 & 25,68 & 25,83 & 25,98 & 25,51 & 26,31 & 28,89 & 28,21 & 27,40 & 25,95 \\
\hline & $\mathrm{E}_{2}$ & 25,62 & 25,44 & 27,33 & 26,02 & 25,31 & 24,84 & 28,61 & 28,80 & 27,91 & 26,39 \\
\hline & $\mathrm{E}_{3}$ & 24,97 & 25,97 & 26,46 & 24,95 & 25,96 & 27,81 & 26,13 & 29,66 & 27,94 & 28,67 \\
\hline \multicolumn{2}{|c|}{$\mathrm{E}_{\mathrm{cs}, \text { médio }}(\mathrm{GPa})$} & 25,60 & 25,70 & 26,54 & 25,65 & 25,59 & 26,32 & 27,88 & 28,89 & 27,75 & 27,00 \\
\hline \multicolumn{2}{|c|}{ Amostra } & 131 & 132 & 133 & 134 & 135 & 136 & 137 & 138 & & \\
\hline \multicolumn{2}{|c|}{ fc,médio (MPa) } & 32,8 & 32,8 & 32,8 & 32,3 & 33,1 & 37,7 & 34,5 & 32,3 & & \\
\hline \multicolumn{2}{|l|}{$40 \%$ fc } & 13,12 & 13,12 & 13,12 & 12,90 & 13,22 & 15,06 & 13,80 & 12,90 & & \\
\hline \multirow{3}{*}{$\begin{array}{l}\text { Def. esp. inicial } \\
\varepsilon_{\mathrm{i}}(\mathrm{mm} / \mathrm{mm})\end{array}$} & $\varepsilon_{\mathrm{i}, 1}$ & 0,00000 & 0,00005 & 0,00005 & 0,00005 & 0,00000 & 0,00005 & 0,00005 & 0,00005 & & \\
\hline & $\varepsilon_{\mathrm{i}, 2}$ & 0,00000 & 0,00005 & 0,00000 & 0,00000 & 0,00000 & 0,00000 & 0,00000 & 0,00000 & & \\
\hline & $\varepsilon_{\mathrm{i}, 3}$ & 0,00000 & 0,00000 & 0,00000 & 0,00005 & 0,00000 & 0,00005 & 0,00005 & 0,00005 & & \\
\hline \multirow{3}{*}{$\begin{array}{l}\text { Def. esp. final } \\
\varepsilon_{f}(\mathrm{~mm} / \mathrm{mm})\end{array}$} & $\varepsilon_{\mathrm{f}, 1}$ & 0,00041 & 0,00047 & 0,00044 & 0,00046 & 0,00041 & 0,00050 & 0,00043 & 0,00043 & & \\
\hline & $\varepsilon_{\mathrm{f}, 2}$ & 0,00038 & 0,00044 & 0,00041 & 0,00041 & 0,00039 & 0,00040 & 0,00040 & 0,00043 & & \\
\hline & $\varepsilon_{\mathrm{f}, 3}$ & 0,00037 & 0,00040 & 0,00041 & 0,00046 & 0,00040 & 0,00046 & 0,00042 & 0,00043 & & \\
\hline \multirow{3}{*}{$\begin{array}{l}\text { Deformação } \\
\text { específica } \\
\varepsilon(\mathrm{mm} / \mathrm{mm})\end{array}$} & $\varepsilon_{1}$ & 0,00041 & 0,00042 & 0,00039 & 0,00041 & 0,00041 & 0,00045 & 0,00038 & 0,00038 & & \\
\hline & $\varepsilon_{2}$ & 0,00038 & 0,00039 & 0,00041 & 0,00041 & 0,00039 & 0,00040 & 0,00040 & 0,00043 & & \\
\hline & $\varepsilon_{3}$ & 0,00037 & 0,00040 & 0,00041 & 0,00041 & 0,00040 & 0,00041 & 0,00037 & 0,00038 & & \\
\hline \multirow{3}{*}{$\mathrm{E}_{\mathrm{cs}}(\mathrm{GPa})$} & $E_{1}$ & 26,23 & 25,88 & 26,47 & 26,22 & 25,33 & 26,39 & 26,18 & 27,30 & & \\
\hline & $\mathrm{E}_{2}$ & 28,19 & 26,33 & 26,22 & 29,24 & 24,82 & 26,74 & 26,99 & 28,27 & & \\
\hline & $E_{3}$ & 28,36 & 26,23 & 26,03 & 27,23 & 24,88 & 27,07 & 26,39 & 27,60 & & \\
\hline \multicolumn{2}{|c|}{$\mathrm{E}_{\mathrm{cs} \text {,médio }}(\mathrm{GPa})$} & 27,59 & 26,15 & 26,24 & 27,56 & 25,01 & 26,73 & 26,52 & 27,72 & & \\
\hline
\end{tabular}


Tabela A-6.a - Resultados dos ensaios de módulo de deformação secante, $E_{c s}-f_{c k} 30 \mathrm{MPa}$

\begin{tabular}{|c|c|c|c|c|c|c|c|c|c|c|c|}
\hline \multicolumn{2}{|l|}{ Amostra } & 1 & 2 & 3 & 4 & 5 & 6 & 7 & 8 & 9 & 10 \\
\hline \multicolumn{2}{|c|}{$\mathrm{f}_{\mathrm{c}, \text { médio }}(\mathrm{MPa})$} & 45,0 & 38,8 & 41,7 & 39,6 & 42,2 & 37,8 & 40,2 & 40,0 & 35,7 & 35,0 \\
\hline \multicolumn{2}{|l|}{$40 \%$ fc } & 18,00 & 15,52 & 16,66 & 15,84 & 16,86 & 15,10 & 16,08 & 15,98 & 14,26 & 14,00 \\
\hline \multirow{3}{*}{$\begin{array}{l}\text { Def. esp. inicial } \\
\varepsilon_{\mathrm{i}}(\mathrm{mm} / \mathrm{mm})\end{array}$} & $\varepsilon_{i, 1}$ & 0,00005 & 0,00000 & 0,00005 & 0,00000 & 0,00005 & 0,00005 & 0,00000 & 0,00005 & 0,00005 & 0,00005 \\
\hline & $\varepsilon_{i, 2}$ & 0,00000 & 0,00000 & 0,00000 & 0,00000 & 0,00005 & 0,00005 & 0,00000 & 0,00000 & 0,00000 & 0,00005 \\
\hline & $\varepsilon_{i, 3}$ & 0,00005 & 0,00005 & 0,00000 & 0,00000 & 0,00005 & 0,00005 & 0,00005 & 0,00005 & 0,00000 & 0,00005 \\
\hline \multirow{3}{*}{$\begin{array}{l}\text { Def. esp. final } \\
\varepsilon_{f}(\mathrm{~mm} / \mathrm{mm})\end{array}$} & $\varepsilon_{\mathrm{f}, 1}$ & 0,00069 & 0,00060 & 0,00065 & 0,00059 & 0,00065 & 0,00061 & 0,00061 & 0,00066 & 0,00057 & 0,00059 \\
\hline & $\varepsilon_{\mathrm{f}, 2}$ & 0,00066 & 0,00061 & 0,00060 & 0,00060 & 0,00065 & 0,00060 & 0,00061 & 0,00061 & 0,00051 & 0,00059 \\
\hline & $\varepsilon_{\mathrm{f}, 3}$ & 0,00073 & 0,00062 & 0,00061 & 0,00060 & 0,00065 & 0,00061 & 0,00067 & 0,00067 & 0,00052 & 0,00058 \\
\hline \multirow{3}{*}{$\begin{array}{l}\text { Deformação } \\
\text { específica } \\
\varepsilon(\mathrm{mm} / \mathrm{mm})\end{array}$} & $\varepsilon_{1}$ & 0,00064 & 0,00060 & 0,00060 & 0,00059 & 0,00060 & 0,00056 & 0,00061 & 0,00061 & 0,00052 & 0,00054 \\
\hline & $\varepsilon_{2}$ & 0,00066 & 0,00061 & 0,00060 & 0,00060 & 0,00060 & 0,00055 & 0,00061 & 0,00061 & 0,00051 & 0,00054 \\
\hline & $\varepsilon_{3}$ & 0,00068 & 0,00057 & 0,00061 & 0,00060 & 0,00060 & 0,00056 & 0,00062 & 0,00062 & 0,00052 & 0,00053 \\
\hline \multirow{3}{*}{$\mathrm{E}_{\mathrm{cs}}(\mathrm{GPa})$} & $E_{1}$ & 28,13 & 25,87 & 27,95 & 26,85 & 28,10 & 26,98 & 26,52 & 26,10 & 27,59 & 25,92 \\
\hline & $\mathrm{E}_{2}$ & 27,40 & 25,44 & 27,58 & 26,40 & 28,10 & 27,36 & 26,52 & 26,10 & 28,02 & 25,92 \\
\hline & $E_{3}$ & 26,47 & 27,23 & 27,31 & 26,40 & 28,10 & 26,98 & 26,07 & 25,72 & 27,59 & 26,30 \\
\hline \multicolumn{2}{|c|}{$\mathrm{E}_{\mathrm{cs}, \text { médio }}(\mathrm{GPa})$} & 27,33 & 26,18 & 27,62 & 26,55 & 28,10 & 27,11 & 26,37 & 25,97 & 27,73 & 26,05 \\
\hline \multicolumn{2}{|l|}{ Amostra } & 11 & 12 & 13 & 14 & 15 & 16 & 17 & 18 & 19 & 20 \\
\hline \multicolumn{2}{|c|}{ fc,médio (MPa) } & 37,7 & 40,0 & 36,1 & 36,9 & 41,5 & 38,4 & 39,7 & 43,3 & 38,1 & 38,1 \\
\hline \multicolumn{2}{|l|}{$40 \%$ fc } & 15,08 & 16,00 & 14,44 & 14,74 & 16,58 & 15,34 & 15,86 & 17,32 & 15,24 & 15,24 \\
\hline \multirow{3}{*}{$\begin{array}{c}\text { Def. esp. inicial } \\
\mathcal{E}_{\mathrm{i}}(\mathrm{mm} / \mathrm{mm})\end{array}$} & $\varepsilon_{i, 1}$ & 0,00000 & 0,00005 & 0,00000 & 0,00000 & 0,00005 & 0,00000 & 0,00005 & 0,00000 & 0,00005 & 0,00005 \\
\hline & $\varepsilon_{i, 2}$ & 0,00005 & 0,00005 & 0,00000 & 0,00000 & 0,00005 & 0,00000 & 0,00000 & 0,00005 & 0,00005 & 0,00000 \\
\hline & $\varepsilon_{\mathrm{i}, 3}$ & 0,00005 & 0,00005 & 0,00000 & 0,00000 & 0,00000 & 0,00000 & 0,00005 & 0,00000 & 0,00005 & 0,00005 \\
\hline \multirow{3}{*}{$\begin{array}{l}\text { Def. esp. final } \\
\varepsilon_{\mathrm{f}}(\mathrm{mm} / \mathrm{mm})\end{array}$} & $\varepsilon_{\mathrm{f}, 1}$ & 0,00058 & 0,00065 & 0,00057 & 0,00055 & 0,00067 & 0,00056 & 0,00063 & 0,00065 & 0,00064 & 0,00063 \\
\hline & $\varepsilon_{\mathrm{f}, 2}$ & 0,00063 & 0,00067 & 0,00054 & 0,00054 & 0,00072 & 0,00055 & 0,00062 & 0,00072 & 0,00064 & 0,00058 \\
\hline & $\varepsilon_{\mathrm{f}, 3}$ & 0,00063 & 0,00067 & 0,00054 & 0,00058 & 0,00055 & 0,00056 & 0,00064 & 0,00064 & 0,00061 & 0,00064 \\
\hline \multirow{3}{*}{$\begin{array}{l}\text { Deformação } \\
\text { específica } \\
\varepsilon(\mathrm{mm} / \mathrm{mm})\end{array}$} & $\varepsilon_{1}$ & 0,00058 & 0,00060 & 0,00057 & 0,00055 & 0,00062 & 0,00056 & 0,00058 & 0,00065 & 0,00059 & 0,00058 \\
\hline & $\varepsilon_{2}$ & 0,00058 & 0,00062 & 0,00054 & 0,00054 & 0,00067 & 0,00055 & 0,00062 & 0,00067 & 0,00059 & 0,00058 \\
\hline & $\varepsilon_{3}$ & 0,00058 & 0,00062 & 0,00054 & 0,00058 & 0,00055 & 0,00056 & 0,00059 & 0,00064 & 0,00056 & 0,00059 \\
\hline \multirow{3}{*}{$\mathrm{E}_{\mathrm{cs}}(\mathrm{GPa})$} & $E_{1}$ & 26,18 & 26,55 & 25,53 & 26,78 & 26,74 & 27,37 & 27,43 & 26,76 & 25,62 & 26,44 \\
\hline & $\mathrm{E}_{2}$ & 26,16 & 25,88 & 26,64 & 27,17 & 24,88 & 27,76 & 25,69 & 25,83 & 25,97 & 26,44 \\
\hline & $E_{3}$ & 25,83 & 25,88 & 26,64 & 25,34 & 30,24 & 27,37 & 27,06 & 27,09 & 27,06 & 25,74 \\
\hline \multicolumn{2}{|c|}{$\mathrm{E}_{\mathrm{cs}, \text { médio }}(\mathrm{GPa})$} & 26,06 & 26,10 & 26,27 & 26,43 & 27,29 & 27,50 & 26,73 & 26,56 & 26,22 & 26,21 \\
\hline \multicolumn{2}{|l|}{ Amostra } & 21 & 22 & 23 & 24 & 25 & 26 & 27 & 28 & 29 & 30 \\
\hline \multicolumn{2}{|c|}{ fc,médio (MPa) } & 35,5 & 36,8 & 33,8 & 33,3 & 38,4 & 36,8 & 38,9 & 37,4 & 40,5 & 37,5 \\
\hline \multicolumn{2}{|l|}{$40 \% \mathrm{fc}$} & 14,18 & 14,72 & 13,52 & 13,32 & 15,34 & 14,70 & 15,54 & 14,94 & 16,18 & 15,00 \\
\hline & $\varepsilon_{\mathrm{i}, 1}$ & 0,00005 & 0,00000 & 0,00005 & 0,00005 & 0,00005 & 0,00005 & 0,00005 & 0,00005 & 0,00005 & 0,00000 \\
\hline $\begin{array}{c}\text { Def. esp. inicial } \\
\varepsilon_{\mathrm{i}}(\mathrm{mm} / \mathrm{mm})\end{array}$ & $\varepsilon_{\mathrm{i}, 2}$ & 0,00000 & 0,00005 & 0,00005 & 0,00005 & 0,00000 & 0,00005 & 0,00005 & 0,00000 & 0,00000 & 0,00000 \\
\hline & $\varepsilon_{i, 3}$ & 0,00005 & 0,00000 & 0,00005 & 0,00005 & 0,00005 & 0,00005 & 0,00005 & 0,00005 & 0,00005 & 0,00005 \\
\hline & $\varepsilon_{\mathrm{f}, 1}$ & 0,00058 & 0,00058 & 0,00056 & 0,00056 & 0,00060 & 0,00060 & 0,00062 & 0,00063 & 0,00068 & 0,00054 \\
\hline $\begin{array}{l}\text { Def. esp. final } \\
\mathcal{E}_{f}(\mathrm{~mm} / \mathrm{mm})\end{array}$ & $\varepsilon_{\mathrm{f}, 2}$ & 0,00053 & 0,00061 & 0,00055 & 0,00056 & 0,00054 & 0,00062 & 0,00063 & 0,00058 & 0,00057 & 0,00050 \\
\hline & $\varepsilon_{\mathrm{f}, 3}$ & 0,00058 & 0,00056 & 0,00056 & 0,00055 & 0,00059 & 0,00061 & 0,00062 & 0,00062 & 0,00063 & 0,00059 \\
\hline & $\varepsilon_{1}$ & 0,00053 & 0,00058 & 0,00051 & 0,00051 & 0,00055 & 0,00055 & 0,00057 & 0,00058 & 0,00063 & 0,00054 \\
\hline específica & $\varepsilon_{2}$ & 0,00053 & 0,00056 & 0,00050 & 0,00051 & 0,00054 & 0,00057 & 0,00058 & 0,00058 & 0,00057 & 0,00050 \\
\hline & $\varepsilon_{3}$ & 0,00053 & 0,00056 & 0,00051 & 0,00050 & 0,00054 & 0,00056 & 0,00057 & 0,00057 & 0,00058 & 0,00054 \\
\hline & $E_{1}$ & 26,91 & 25,41 & 26,66 & 25,89 & 27,76 & 26,71 & 27,10 & 25,95 & 25,83 & 27,98 \\
\hline $\mathrm{E}_{\mathrm{cs}}(\mathrm{GPa})$ & $\mathrm{E}_{2}$ & 26,91 & 26,50 & 27,08 & 26,30 & 28,58 & 25,97 & 26,71 & 25,83 & 28,32 & 29,77 \\
\hline & $E_{3}$ & 26,91 & 26,18 & 26,66 & 26,71 & 28,16 & 26,34 & 27,10 & 26,07 & 27,93 & 27,57 \\
\hline $\mathrm{E}_{\mathrm{cs}, \text { médio }}(\mathrm{GP}$ & & 26,91 & 26,03 & 26,80 & 26,30 & 28,17 & 26,34 & 26,97 & 25,95 & 27,36 & 28,44 \\
\hline
\end{tabular}


Tabela A-6.b - Resultados dos ensaios de módulo de deformação secante, $E_{c s}$ - fck 30MPa

\begin{tabular}{|c|c|c|c|c|c|c|c|c|c|c|c|}
\hline \multicolumn{2}{|l|}{ Amostra } & 31 & 32 & 33 & 34 & 35 & 36 & 37 & 38 & 39 & 40 \\
\hline \multicolumn{2}{|c|}{$\mathrm{f}_{\mathrm{c}, \text { médio }}(\mathrm{MPa})$} & 38,6 & 37,9 & 41,5 & 35,6 & 36,1 & 36,8 & 38,4 & 36,9 & 39,0 & 38,8 \\
\hline \multicolumn{2}{|l|}{$40 \%$ fc } & 15,44 & 15,16 & 16,58 & 14,22 & 14,42 & 14,72 & 15,34 & 14,74 & 15,58 & 15,50 \\
\hline \multirow{3}{*}{$\begin{array}{l}\text { Def. esp. inicial } \\
\varepsilon_{\mathrm{i}}(\mathrm{mm} / \mathrm{mm})\end{array}$} & $\varepsilon_{i, 1}$ & 0,00000 & 0,00000 & 0,00005 & 0,00000 & 0,00005 & 0,00000 & 0,00000 & 0,00005 & 0,00000 & 0,00000 \\
\hline & $\varepsilon_{i, 2}$ & 0,00000 & 0,00005 & 0,00000 & 0,00005 & 0,00005 & 0,00000 & 0,00000 & 0,00005 & 0,00000 & 0,00000 \\
\hline & $\varepsilon_{i, 3}$ & 0,00005 & 0,00000 & 0,00000 & 0,00005 & 0,00005 & 0,00000 & 0,00000 & 0,00005 & 0,00000 & 0,00000 \\
\hline \multirow{3}{*}{$\begin{array}{l}\text { Def. esp. final } \\
\varepsilon_{f}(\mathrm{~mm} / \mathrm{mm})\end{array}$} & $\varepsilon_{\mathrm{f}, 1}$ & 0,00060 & 0,00057 & 0,00065 & 0,00054 & 0,00061 & 0,00055 & 0,00058 & 0,00063 & 0,00058 & 0,00056 \\
\hline & $\varepsilon_{\mathrm{f}, 2}$ & 0,00060 & 0,00064 & 0,00063 & 0,00060 & 0,00059 & 0,00058 & 0,00056 & 0,00062 & 0,00061 & 0,00055 \\
\hline & $\varepsilon_{\mathrm{f}, 3}$ & 0,00064 & 0,00058 & 0,00064 & 0,00059 & 0,00059 & 0,00056 & 0,00058 & 0,00057 & 0,00060 & 0,00059 \\
\hline \multirow{3}{*}{$\begin{array}{l}\text { Deformação } \\
\text { específica } \\
\varepsilon(\mathrm{mm} / \mathrm{mm})\end{array}$} & $\varepsilon_{1}$ & 0,00060 & 0,00057 & 0,00060 & 0,00054 & 0,00056 & 0,00055 & 0,00058 & 0,00058 & 0,00058 & 0,00056 \\
\hline & $\varepsilon_{2}$ & 0,00060 & 0,00059 & 0,00063 & 0,00055 & 0,00054 & 0,00058 & 0,00056 & 0,00057 & 0,00061 & 0,00055 \\
\hline & $\varepsilon_{3}$ & 0,00059 & 0,00058 & 0,00064 & 0,00054 & 0,00054 & 0,00056 & 0,00058 & 0,00052 & 0,00060 & 0,00059 \\
\hline \multirow{3}{*}{$\mathrm{E}_{\mathrm{cs}}(\mathrm{GPa})$} & $E_{1}$ & 25,71 & 26,68 & 27,80 & 26,52 & 25,89 & 26,71 & 26,26 & 25,38 & 26,71 & 27,63 \\
\hline & $\mathrm{E}_{2}$ & 25,71 & 25,62 & 26,41 & 25,73 & 26,64 & 25,28 & 27,37 & 25,73 & 25,68 & 28,03 \\
\hline & $E_{3}$ & 26,05 & 25,97 & 26,09 & 26,12 & 26,64 & 26,34 & 26,26 & 28,08 & 26,01 & 26,16 \\
\hline \multicolumn{2}{|c|}{$\mathrm{E}_{\mathrm{cs}, \text { médio }}(\mathrm{GPa})$} & 25,82 & 26,09 & 26,77 & 26,12 & 26,39 & 26,11 & 26,63 & 26,40 & 26,13 & 27,27 \\
\hline \multicolumn{2}{|l|}{ Amostra } & 41 & 42 & 43 & 44 & 45 & 46 & 47 & 48 & 49 & 50 \\
\hline \multicolumn{2}{|c|}{ fc,médio (MPa) } & 35,7 & 36,4 & 38,0 & 36,9 & 35,8 & 36,8 & 36,0 & 40,9 & 42,8 & 36,3 \\
\hline \multicolumn{2}{|l|}{$40 \%$ fc } & 14,26 & 14,54 & 15,18 & 14,76 & 14,30 & 14,72 & 14,38 & 16,34 & 17,10 & 14,52 \\
\hline \multirow{3}{*}{$\begin{array}{c}\text { Def. esp. inicial } \\
\mathcal{E}_{\mathrm{i}}(\mathrm{mm} / \mathrm{mm})\end{array}$} & $\varepsilon_{i, 1}$ & 0,00005 & 0,00000 & 0,00005 & 0,00000 & 0,00005 & 0,00000 & 0,00000 & 0,00005 & 0,00005 & 0,00000 \\
\hline & $\varepsilon_{\mathrm{i}, 2}$ & 0,00005 & 0,00005 & 0,00005 & 0,00000 & 0,00005 & 0,00005 & 0,00005 & 0,00005 & 0,00005 & 0,00000 \\
\hline & $\varepsilon_{\mathrm{i}, 3}$ & 0,00000 & 0,00000 & 0,00005 & 0,00000 & 0,00005 & 0,00005 & 0,00000 & 0,00000 & 0,00000 & 0,00005 \\
\hline \multirow{3}{*}{$\begin{array}{l}\text { Def. esp. final } \\
\varepsilon_{\mathrm{f}}(\mathrm{mm} / \mathrm{mm})\end{array}$} & $\varepsilon_{\mathrm{f}, 1}$ & 0,00056 & 0,00054 & 0,00058 & 0,00054 & 0,00062 & 0,00054 & 0,00054 & 0,00064 & 0,00071 & 0,00051 \\
\hline & $\varepsilon_{\mathrm{f}, 2}$ & 0,00058 & 0,00054 & 0,00058 & 0,00057 & 0,00057 & 0,00057 & 0,00056 & 0,00063 & 0,00068 & 0,00052 \\
\hline & $\varepsilon_{\mathrm{f}, 3}$ & 0,00052 & 0,00053 & 0,00069 & 0,00057 & 0,00059 & 0,00059 & 0,00054 & 0,00056 & 0,00059 & 0,00057 \\
\hline \multirow{3}{*}{$\begin{array}{l}\text { Deformação } \\
\text { específica } \\
\varepsilon(\mathrm{mm} / \mathrm{mm})\end{array}$} & $\varepsilon_{1}$ & 0,00051 & 0,00054 & 0,00053 & 0,00054 & 0,00057 & 0,00054 & 0,00054 & 0,00059 & 0,00066 & 0,00051 \\
\hline & $\varepsilon_{2}$ & 0,00053 & 0,00049 & 0,00053 & 0,00057 & 0,00052 & 0,00052 & 0,00051 & 0,00058 & 0,00063 & 0,00052 \\
\hline & $\varepsilon_{3}$ & 0,00052 & 0,00053 & 0,00064 & 0,00057 & 0,00054 & 0,00054 & 0,00054 & 0,00056 & 0,00059 & 0,00052 \\
\hline \multirow{3}{*}{$\mathrm{E}_{\mathrm{cs}}(\mathrm{GPa})$} & $E_{1}$ & 28,00 & 26,83 & 28,76 & 27,57 & 24,89 & 27,46 & 26,57 & 27,81 & 25,87 & 28,24 \\
\hline & $\mathrm{E}_{2}$ & 26,75 & 29,43 & 28,76 & 25,68 & 27,52 & 28,04 & 28,07 & 28,36 & 27,24 & 27,91 \\
\hline & $E_{3}$ & 27,57 & 27,64 & 23,82 & 26,04 & 26,71 & 27,41 & 26,51 & 28,98 & 28,86 & 27,91 \\
\hline \multicolumn{2}{|c|}{$\mathrm{E}_{\mathrm{cs}, \text { médio }}(\mathrm{GPa})$} & 27,44 & 27,97 & 27,11 & 26,43 & 26,37 & 27,64 & 27,05 & 28,38 & 27,32 & 28,02 \\
\hline \multicolumn{2}{|l|}{ Amostra } & 51 & 52 & 53 & 54 & 55 & 56 & 57 & 58 & 59 & 60 \\
\hline \multicolumn{2}{|c|}{ fc,médio (MPa) } & 36,7 & 39,5 & 39,6 & 37,6 & 40,5 & 39,4 & 36,0 & 40,1 & 35,3 & 34,0 \\
\hline \multicolumn{2}{|l|}{$40 \% \mathrm{fc}$} & 14,66 & 15,78 & 15,84 & 15,04 & 16,18 & 15,74 & 14,40 & 16,04 & 14,10 & 13,60 \\
\hline & $\varepsilon_{i, 1}$ & 0,00005 & 0,00005 & 0,00005 & 0,00005 & 0,00005 & 0,00000 & 0,00005 & 0,00005 & 0,00005 & 0,00005 \\
\hline $\begin{array}{l}\text { Def. esp. inicial } \\
\varepsilon_{\mathrm{i}}(\mathrm{mm} / \mathrm{mm})\end{array}$ & $\varepsilon_{\mathrm{i}, 2}$ & 0,00005 & 0,00005 & 0,00000 & 0,00000 & 0,00005 & 0,00000 & 0,00005 & 0,00005 & 0,00000 & 0,00000 \\
\hline & $\varepsilon_{i, 3}$ & 0,00005 & 0,00005 & 0,00000 & 0,00000 & 0,00005 & 0,00000 & 0,00005 & 0,00005 & 0,00000 & 0,00000 \\
\hline & $\varepsilon_{\mathrm{f}, 1}$ & 0,00058 & 0,00064 & 0,00063 & 0,00058 & 0,00066 & 0,00054 & 0,00056 & 0,00057 & 0,00055 & 0,00053 \\
\hline $\begin{array}{l}\text { Def. esp. final } \\
\varepsilon_{\mathrm{f}}(\mathrm{mm} / \mathrm{mm})\end{array}$ & $\varepsilon_{\mathrm{f}, 2}$ & 0,00057 & 0,00062 & 0,00056 & 0,00054 & 0,00066 & 0,00058 & 0,00057 & 0,00063 & 0,00052 & 0,00048 \\
\hline & $\varepsilon_{\mathrm{f}, 3}$ & 0,00057 & 0,00060 & 0,00055 & 0,00057 & 0,00064 & 0,00058 & 0,00059 & 0,00065 & 0,00055 & 0,00051 \\
\hline & $\varepsilon_{1}$ & 0,00053 & 0,00059 & 0,00058 & 0,00053 & 0,00061 & 0,00054 & 0,00051 & 0,00052 & 0,00050 & 0,00048 \\
\hline especifica & $\varepsilon_{2}$ & 0,00052 & 0,00057 & 0,00056 & 0,00054 & 0,00061 & 0,00058 & 0,00052 & 0,00058 & 0,00052 & 0,00048 \\
\hline & $\varepsilon_{3}$ & 0,00052 & 0,00055 & 0,00055 & 0,00057 & 0,00059 & 0,00058 & 0,00054 & 0,00060 & 0,00055 & 0,00051 \\
\hline & $E_{1}$ & 27,85 & 26,59 & 27,35 & 28,59 & 26,51 & 28,89 & 28,01 & 31,12 & 28,42 & 28,06 \\
\hline $\mathrm{E}_{\mathrm{cs}}(\mathrm{GPa})$ & $\mathrm{E}_{2}$ & 28,13 & 27,57 & 28,19 & 27,61 & 26,55 & 27,29 & 27,67 & 27,55 & 27,28 & 28,11 \\
\hline & $E_{3}$ & 28,45 & 28,62 & 28,95 & 26,48 & 27,55 & 27,03 & 26,57 & 26,95 & 25,71 & 26,65 \\
\hline $\mathrm{E}_{\mathrm{cs}, \text { médio }}(\mathrm{GP}$ & & 28,14 & 27,59 & 28,16 & 27,56 & 26,87 & 27,74 & 27,42 & 28,54 & 27,14 & 27,61 \\
\hline
\end{tabular}


Tabela A-6.c - Resultados dos ensaios de módulo de deformação secante, $E_{c s}-f_{c k} 30 \mathrm{MPa}$

\begin{tabular}{|c|c|c|c|c|c|c|c|c|c|c|c|}
\hline \multicolumn{2}{|l|}{ Amostra } & 61 & 62 & 63 & 64 & 65 & 66 & 67 & 68 & 69 & 70 \\
\hline \multicolumn{2}{|c|}{$\mathrm{f}_{\mathrm{c}, \text { médio }}(\mathrm{MPa})$} & 36,8 & 38,5 & 36,2 & 37,9 & 40,4 & 45,2 & 39,6 & 39,2 & 36,5 & 39,1 \\
\hline \multicolumn{2}{|l|}{$40 \%$ fc } & 14,72 & 15,40 & 14,48 & 15,16 & 16,14 & 18,06 & 15,82 & 15,68 & 14,58 & 15,64 \\
\hline \multirow{3}{*}{$\begin{array}{l}\text { Def. esp. inicial } \\
\varepsilon_{\mathrm{i}}(\mathrm{mm} / \mathrm{mm})\end{array}$} & $\varepsilon_{i, 1}$ & 0,00005 & 0,00000 & 0,00005 & 0,00000 & 0,00005 & 0,00005 & 0,00005 & 0,00005 & 0,00000 & 0,00000 \\
\hline & $\varepsilon_{i, 2}$ & 0,00000 & 0,00000 & 0,00005 & 0,00000 & 0,00000 & 0,00000 & 0,00005 & 0,00005 & 0,00000 & 0,00000 \\
\hline & $\varepsilon_{i, 3}$ & 0,00000 & 0,00005 & 0,00005 & 0,00000 & 0,00005 & 0,00005 & 0,00000 & 0,00000 & 0,00005 & 0,00000 \\
\hline \multirow{3}{*}{$\begin{array}{l}\text { Def. esp. final } \\
\varepsilon_{f}(\mathrm{~mm} / \mathrm{mm})\end{array}$} & $\varepsilon_{\mathrm{f}, 1}$ & 0,00058 & 0,00056 & 0,00058 & 0,00054 & 0,00065 & 0,00071 & 0,00061 & 0,00061 & 0,00051 & 0,00056 \\
\hline & $\varepsilon_{\mathrm{f}, 2}$ & 0,00052 & 0,00054 & 0,00056 & 0,00054 & 0,00060 & 0,00063 & 0,00065 & 0,00062 & 0,00053 & 0,00060 \\
\hline & $\varepsilon_{\mathrm{f}, 3}$ & 0,00057 & 0,00065 & 0,00061 & 0,00054 & 0,00063 & 0,00067 & 0,00057 & 0,00057 & 0,00059 & 0,00064 \\
\hline \multirow{3}{*}{$\begin{array}{l}\text { Deformação } \\
\text { específica } \\
\varepsilon(\mathrm{mm} / \mathrm{mm})\end{array}$} & $\varepsilon_{1}$ & 0,00053 & 0,00056 & 0,00053 & 0,00054 & 0,00060 & 0,00066 & 0,00056 & 0,00056 & 0,00051 & 0,00056 \\
\hline & $\varepsilon_{2}$ & 0,00052 & 0,00054 & 0,00051 & 0,00054 & 0,00060 & 0,00063 & 0,00060 & 0,00057 & 0,00053 & 0,00060 \\
\hline & $\varepsilon_{3}$ & 0,00057 & 0,00060 & 0,00056 & 0,00054 & 0,00058 & 0,00062 & 0,00057 & 0,00057 & 0,00054 & 0,00064 \\
\hline \multirow{3}{*}{$\mathrm{E}_{\mathrm{cs}}(\mathrm{GPa})$} & $E_{1}$ & 27,79 & 27,43 & 27,13 & 28,00 & 27,10 & 27,34 & 28,12 & 27,83 & 28,53 & 28,08 \\
\hline & $\mathrm{E}_{2}$ & 28,18 & 28,74 & 28,24 & 28,31 & 26,76 & 28,86 & 26,45 & 27,34 & 27,28 & 26,07 \\
\hline & $E_{3}$ & 25,62 & 25,65 & 25,95 & 28,00 & 27,75 & 29,18 & 27,78 & 27,73 & 27,23 & 24,59 \\
\hline \multicolumn{2}{|c|}{$\mathrm{E}_{\mathrm{cs}, \text { médio }}(\mathrm{GPa})$} & 27,20 & 27,27 & 27,11 & 28,10 & 27,20 & 28,46 & 27,45 & 27,63 & 27,68 & 26,25 \\
\hline \multicolumn{2}{|l|}{ Amostra } & 71 & 72 & 73 & 74 & 75 & 76 & 77 & 78 & 79 & 80 \\
\hline \multicolumn{2}{|c|}{ fc,médio (MPa) } & 45,6 & 40,7 & 38,3 & 40,7 & 33,2 & 39,6 & 38,1 & 40,5 & 42,2 & 42,9 \\
\hline \multicolumn{2}{|l|}{$40 \%$ fc } & 18,22 & 16,28 & 15,32 & 16,26 & 13,26 & 15,84 & 15,24 & 16,18 & 16,88 & 17,14 \\
\hline \multirow{3}{*}{$\begin{array}{c}\text { Def. esp. inicial } \\
\mathcal{E}_{\mathrm{i}}(\mathrm{mm} / \mathrm{mm})\end{array}$} & $\varepsilon_{i, 1}$ & 0,00005 & 0,00005 & 0,00000 & 0,00005 & 0,00005 & 0,00005 & 0,00005 & 0,00005 & 0,00005 & 0,00000 \\
\hline & $\varepsilon_{\mathrm{i}, 2}$ & 0,00000 & 0,00000 & 0,00000 & 0,00000 & 0,00000 & 0,00005 & 0,00000 & 0,00000 & 0,00005 & 0,00000 \\
\hline & $\varepsilon_{\mathrm{i}, 3}$ & 0,00005 & 0,00005 & 0,00000 & 0,00005 & 0,00005 & 0,00005 & 0,00005 & 0,00005 & 0,00005 & 0,00005 \\
\hline \multirow{3}{*}{$\begin{array}{l}\text { Def. esp. final } \\
\varepsilon_{\mathrm{f}}(\mathrm{mm} / \mathrm{mm})\end{array}$} & $\varepsilon_{\mathrm{f}, 1}$ & 0,00072 & 0,00059 & 0,00058 & 0,00066 & 0,00054 & 0,00061 & 0,00063 & 0,00059 & 0,00068 & 0,00064 \\
\hline & $\varepsilon_{\mathrm{f}, 2}$ & 0,00068 & 0,00057 & 0,00058 & 0,00061 & 0,00049 & 0,00061 & 0,00057 & 0,00054 & 0,00063 & 0,00065 \\
\hline & $\varepsilon_{\mathrm{f}, 3}$ & 0,00070 & 0,00064 & 0,00058 & 0,00066 & 0,00055 & 0,00061 & 0,00062 & 0,00059 & 0,00058 & 0,00066 \\
\hline \multirow{3}{*}{$\begin{array}{l}\text { Deformação } \\
\text { específica } \\
\varepsilon(\mathrm{mm} / \mathrm{mm})\end{array}$} & $\varepsilon_{1}$ & 0,00067 & 0,00054 & 0,00058 & 0,00061 & 0,00049 & 0,00056 & 0,00058 & 0,00054 & 0,00063 & 0,00064 \\
\hline & $\varepsilon_{2}$ & 0,00068 & 0,00057 & 0,00058 & 0,00061 & 0,00049 & 0,00056 & 0,00057 & 0,00054 & 0,00058 & 0,00065 \\
\hline & $\varepsilon_{3}$ & 0,00065 & 0,00059 & 0,00058 & 0,00061 & 0,00050 & 0,00056 & 0,00057 & 0,00054 & 0,00053 & 0,00061 \\
\hline \multirow{3}{*}{$\mathrm{E}_{\mathrm{cs}}(\mathrm{GPa})$} & $E_{1}$ & 27,28 & 30,41 & 26,56 & 26,62 & 27,00 & 28,15 & 26,50 & 29,71 & 26,79 & 26,86 \\
\hline & $\mathrm{E}_{2}$ & 26,62 & 28,54 & 26,20 & 26,62 & 27,00 & 28,15 & 26,86 & 29,71 & 28,98 & 26,21 \\
\hline & $E_{3}$ & 27,86 & 27,73 & 26,57 & 26,62 & 26,57 & 28,15 & 26,86 & 29,70 & 32,13 & 27,89 \\
\hline \multicolumn{2}{|c|}{$\mathrm{E}_{\mathrm{cs}, \text { médio }}(\mathrm{GPa})$} & 27,25 & 28,89 & 26,44 & 26,62 & 26,86 & 28,15 & 26,74 & 29,71 & 29,30 & 26,99 \\
\hline \multicolumn{2}{|l|}{ Amostra } & 81 & 82 & 83 & 84 & 85 & 86 & 87 & 88 & 89 & 90 \\
\hline \multicolumn{2}{|c|}{ fc,médio (MPa) } & 42,0 & 43,3 & 41,1 & 40,1 & 39,9 & 39,7 & 32,1 & 36,1 & 38,6 & 40,9 \\
\hline \multicolumn{2}{|l|}{$40 \% \mathrm{fc}$} & 16,80 & 17,32 & 16,44 & 16,02 & 15,96 & 15,88 & 12,82 & 14,42 & 15,44 & 16,36 \\
\hline & $\varepsilon_{i, 1}$ & 0,00000 & 0,00005 & 0,00000 & 0,00005 & 0,00005 & 0,00005 & 0,00005 & 0,00005 & 0,00005 & 0,00005 \\
\hline $\begin{array}{l}\text { Def. esp. inicial } \\
\varepsilon_{\mathrm{i}}(\mathrm{mm} / \mathrm{mm})\end{array}$ & $\varepsilon_{\mathrm{i}, 2}$ & 0,00000 & 0,00005 & 0,00005 & 0,00005 & 0,00000 & 0,00005 & 0,00000 & 0,00000 & 0,00000 & 0,00005 \\
\hline & $\varepsilon_{i, 3}$ & 0,00005 & 0,00005 & 0,00005 & 0,00005 & 0,00000 & 0,00005 & 0,00005 & 0,00005 & 0,00000 & 0,00005 \\
\hline & $\varepsilon_{\mathrm{f}, 1}$ & 0,00063 & 0,00069 & 0,00056 & 0,00069 & 0,00064 & 0,00065 & 0,00052 & 0,00058 & 0,00066 & 0,00066 \\
\hline $\begin{array}{l}\text { Def. esp. final } \\
\varepsilon_{\mathrm{f}}(\mathrm{mm} / \mathrm{mm})\end{array}$ & $\varepsilon_{\mathrm{f}, 2}$ & 0,00062 & 0,00064 & 0,00065 & 0,00067 & 0,00059 & 0,00066 & 0,00049 & 0,00055 & 0,00056 & 0,00064 \\
\hline & $\varepsilon_{\mathrm{f}, 3}$ & 0,00066 & 0,00067 & 0,00064 & 0,00063 & 0,00059 & 0,00067 & 0,00055 & 0,00060 & 0,00060 & 0,00064 \\
\hline & $\varepsilon_{1}$ & 0,00063 & 0,00064 & 0,00056 & 0,00064 & 0,00059 & 0,00060 & 0,00047 & 0,00053 & 0,00061 & 0,00061 \\
\hline especifica & $\varepsilon_{2}$ & 0,00062 & 0,00059 & 0,00060 & 0,00062 & 0,00059 & 0,00061 & 0,00049 & 0,00055 & 0,00056 & 0,00059 \\
\hline & $\varepsilon_{3}$ & 0,00061 & 0,00062 & 0,00059 & 0,00058 & 0,00059 & 0,00062 & 0,00050 & 0,00055 & 0,00060 & 0,00059 \\
\hline & $E_{1}$ & 26,83 & 27,10 & 29,33 & 25,21 & 27,26 & 26,50 & 27,02 & 26,98 & 25,47 & 27,01 \\
\hline $\mathrm{E}_{\mathrm{cs}}(\mathrm{GPa})$ & $\mathrm{E}_{2}$ & 27,18 & 29,26 & 27,61 & 25,85 & 27,28 & 25,85 & 26,09 & 25,99 & 27,44 & 27,57 \\
\hline & $E_{3}$ & 27,53 & 27,77 & 27,67 & 27,78 & 27,19 & 25,43 & 25,83 & 26,00 & 25,93 & 27,58 \\
\hline $\mathrm{E}_{\mathrm{cs}, \text { médio }}(\mathrm{GP}$ & & 27,18 & 28,04 & 28,20 & 26,28 & 27,24 & 25,93 & 26,31 & 26,32 & 26,28 & 27,39 \\
\hline
\end{tabular}


Tabela A-6.d - Resultados dos ensaios de módulo de deformação secante, $E_{\mathrm{cs}}-f_{\mathrm{ck}} 30 \mathrm{MPa}$

\begin{tabular}{|c|c|c|c|c|c|c|c|c|c|c|c|}
\hline \multicolumn{2}{|l|}{ Amostra } & 91 & 92 & 93 & 94 & 95 & 96 & 97 & 98 & 99 & 100 \\
\hline \multicolumn{2}{|c|}{$\mathrm{f}_{\mathrm{c}, \text { médio }}(\mathrm{MPa})$} & 42,3 & 41,7 & 42,4 & 33,1 & 34,4 & 43,3 & 46,1 & 38,7 & 43,9 & 42,2 \\
\hline \multicolumn{2}{|l|}{$40 \%$ fc } & 16,92 & 16,68 & 16,96 & 13,24 & 13,76 & 17,32 & 18,44 & 15,48 & 17,54 & 16,86 \\
\hline \multirow{3}{*}{$\begin{array}{l}\text { Def. esp. inicial } \\
\varepsilon_{\mathrm{i}}(\mathrm{mm} / \mathrm{mm})\end{array}$} & $\varepsilon_{\mathrm{i}, 1}$ & 0,00000 & 0,00005 & 0,00005 & 0,00000 & 0,00005 & 0,00005 & 0,00005 & 0,00000 & 0,00005 & 0,00005 \\
\hline & $\varepsilon_{\mathrm{i}, 2}$ & 0,00005 & 0,00000 & 0,00000 & 0,00000 & 0,00000 & 0,00005 & 0,00000 & 0,00005 & 0,00000 & 0,00005 \\
\hline & $\varepsilon_{\mathrm{i}, 3}$ & 0,00005 & 0,00005 & 0,00005 & 0,00000 & 0,00005 & 0,00005 & 0,00005 & 0,00005 & 0,00005 & 0,00005 \\
\hline \multirow{3}{*}{$\begin{array}{l}\text { Def. esp. final } \\
\varepsilon_{f}(\mathrm{~mm} / \mathrm{mm})\end{array}$} & $\varepsilon_{\mathrm{f}, 1}$ & 0,00059 & 0,00066 & 0,00068 & 0,00046 & 0,00054 & 0,00065 & 0,00067 & 0,00056 & 0,00076 & 0,00066 \\
\hline & $\varepsilon_{\mathrm{t}, 2}$ & 0,00061 & 0,00063 & 0,00065 & 0,00047 & 0,00047 & 0,00064 & 0,00064 & 0,00060 & 0,00065 & 0,00069 \\
\hline & $\varepsilon_{\mathrm{f}, 3}$ & 0,00066 & 0,00069 & 0,00065 & 0,00048 & 0,00055 & 0,00066 & 0,00067 & 0,00059 & 0,00067 & 0,00066 \\
\hline \multirow{3}{*}{$\begin{array}{l}\text { Deformação } \\
\text { específica } \\
\varepsilon(\mathrm{mm} / \mathrm{mm})\end{array}$} & $\varepsilon_{1}$ & 0,00059 & 0,00061 & 0,00063 & 0,00046 & 0,00049 & 0,00060 & 0,00062 & 0,00056 & 0,00071 & 0,00061 \\
\hline & $\varepsilon_{2}$ & 0,00056 & 0,00063 & 0,00065 & 0,00047 & 0,00047 & 0,00059 & 0,00064 & 0,00055 & 0,00065 & 0,00064 \\
\hline & $\varepsilon_{3}$ & 0,00061 & 0,00064 & 0,00060 & 0,00048 & 0,00050 & 0,00061 & 0,00062 & 0,00054 & 0,00062 & 0,00061 \\
\hline \multirow{3}{*}{$\mathrm{E}_{\mathrm{cs}}(\mathrm{GPa})$} & $E_{1}$ & 28,57 & 27,28 & 26,95 & 28,55 & 28,12 & 29,06 & 29,83 & 27,86 & 24,59 & 27,72 \\
\hline & $\mathrm{E}_{2}$ & 30,18 & 26,66 & 26,26 & 27,89 & 29,03 & 29,27 & 28,89 & 28,12 & 26,86 & 26,42 \\
\hline & $E_{3}$ & 27,89 & 25,94 & 28,28 & 27,44 & 27,62 & 28,28 & 29,51 & 28,56 & 28,42 & 27,53 \\
\hline \multicolumn{2}{|c|}{$\mathrm{E}_{\mathrm{cs}, \text { médio }}(\mathrm{GPa})$} & 28,88 & 26,63 & 27,16 & 27,96 & 28,26 & 28,87 & 29,41 & 28,18 & 26,62 & 27,22 \\
\hline \multicolumn{2}{|l|}{ Amostra } & 101 & 102 & 103 & 104 & 105 & & & & & \\
\hline \multicolumn{2}{|c|}{ fc,médio (MPa) } & 37,0 & 39,8 & 39,8 & 39,8 & 42,1 & & & & & \\
\hline \multicolumn{2}{|l|}{$40 \%$ fc } & 14,80 & 15,90 & 15,90 & 15,90 & 16,82 & & & & & \\
\hline \multirow{3}{*}{$\begin{array}{l}\text { Def. esp. inicial } \\
\varepsilon_{\mathrm{i}}(\mathrm{mm} / \mathrm{mm})\end{array}$} & $\varepsilon_{\mathrm{i}, 1}$ & 0,00000 & 0,00000 & 0,00005 & 0,00000 & 0,00005 & & & & & \\
\hline & $\varepsilon_{\mathrm{i}, 2}$ & 0,00000 & 0,00005 & 0,00005 & 0,00005 & 0,00005 & & & & & \\
\hline & $\varepsilon_{\mathrm{i}, 3}$ & 0,00005 & 0,00005 & 0,00000 & 0,00005 & 0,00000 & & & & & \\
\hline \multirow{3}{*}{$\begin{array}{l}\text { Def. esp. final } \\
\varepsilon_{f}(\mathrm{~mm} / \mathrm{mm})\end{array}$} & $\varepsilon_{\mathrm{f}, 1}$ & 0,00054 & 0,00056 & 0,00066 & 0,00061 & 0,00065 & & & & & \\
\hline & $\varepsilon_{\mathrm{f}, 2}$ & 0,00055 & 0,00063 & 0,00065 & 0,00065 & 0,00063 & & & & & \\
\hline & $\varepsilon_{\mathrm{f}, 3}$ & 0,00057 & 0,00063 & 0,00058 & 0,00065 & 0,00059 & & & & & \\
\hline \multirow{3}{*}{$\begin{array}{l}\text { Deformação } \\
\text { específica } \\
\varepsilon(\mathrm{mm} / \mathrm{mm})\end{array}$} & $\varepsilon_{1}$ & 0,00054 & 0,00056 & 0,00061 & 0,00061 & 0,00060 & & & & & \\
\hline & $\varepsilon_{2}$ & 0,00055 & 0,00058 & 0,00060 & 0,00060 & 0,00058 & & & & & \\
\hline & $\varepsilon_{3}$ & 0,00052 & 0,00058 & 0,00058 & 0,00060 & 0,00059 & & & & & \\
\hline \multirow{3}{*}{$\mathrm{E}_{\mathrm{cs}}(\mathrm{GPa})$} & $E_{1}$ & 27,59 & 28,55 & 26,15 & 26,28 & 28,00 & & & & & \\
\hline & $E_{2}$ & 26,86 & 27,40 & 26,59 & 26,49 & 28,80 & & & & & \\
\hline & $E_{3}$ & 28,42 & 27,61 & 27,23 & 26,55 & 28,62 & & & & & \\
\hline \multicolumn{2}{|c|}{$\mathrm{E}_{\mathrm{cs}, \text { médio }}(\mathrm{GPa})$} & 27,62 & 27,85 & 26,66 & 26,44 & 28,47 & & & & & \\
\hline
\end{tabular}




\section{APÊNDICE B - Resultados dos ensaios realizados - Segunda etapa}

Tabela B-1 - Resultados dos ensaios de resistência à compressão (amostra campo) - $\mathrm{f}_{\mathrm{ck}} 30 \mathrm{MPa}$

\begin{tabular}{|c|c|c|c|c|c|}
\hline Moldagem & Amostra & $\begin{array}{c}f_{\mathrm{c} 28} \\
(\mathrm{MPa})\end{array}$ & $\begin{array}{l}\text { Média } \\
\text { (MPa) }\end{array}$ & $\begin{array}{c}\sigma \\
(\mathrm{MPa})\end{array}$ & $\begin{array}{l}\text { CV } \\
(\%)\end{array}$ \\
\hline \multirow{2}{*}{1} & 1 & 38,2 & \multirow{2}{*}{39,0} & \multirow[t]{2}{*}{1,20} & \multirow[t]{2}{*}{3,1} \\
\hline & 2 & 39,9 & & & \\
\hline \multirow{2}{*}{2} & 1 & 35,8 & \multirow{2}{*}{35,5} & \multirow[t]{2}{*}{0,45} & \multirow[t]{2}{*}{1,3} \\
\hline & 2 & 35,1 & & & \\
\hline \multirow{2}{*}{3} & 1 & 39,2 & \multirow{2}{*}{38,2} & \multirow[t]{2}{*}{1,39} & \multirow[t]{2}{*}{3,6} \\
\hline & 2 & 37,2 & & & \\
\hline \multirow{2}{*}{4} & 1 & 34,9 & \multirow{2}{*}{35,6} & \multirow[t]{2}{*}{1,00} & \multirow[t]{2}{*}{2,8} \\
\hline & 2 & 36,3 & & & \\
\hline \multirow{2}{*}{5} & 1 & 31,0 & \multirow{2}{*}{32,1} & \multirow[t]{2}{*}{1,56} & \multirow[t]{2}{*}{4,9} \\
\hline & 2 & 33,2 & & & \\
\hline \multirow{2}{*}{6} & 1 & 31,0 & \multirow{2}{*}{31,3} & \multirow{2}{*}{0,35} & \multirow{2}{*}{1,1} \\
\hline & 2 & 31,5 & & & \\
\hline
\end{tabular}

Tabela B-2 - Resultados dos ensaios de módulo de deformação secante, $E_{c s}$ (am. campo) $-f_{c k}$ $30 \mathrm{MPa}$

\begin{tabular}{|c|c|c|c|c|c|c|c|}
\hline \multicolumn{2}{|l|}{ Amostra } & 1 & 2 & 3 & 4 & 5 & 6 \\
\hline \multicolumn{2}{|c|}{$\mathrm{f}_{\mathrm{c}, \text { médio }}(\mathrm{MPa})$} & 39,0 & 35,5 & 38,2 & 35,6 & 32,1 & 31,3 \\
\hline \multicolumn{2}{|l|}{$40 \%$ fc } & 15,62 & 14,18 & 15,29 & 14,24 & 12,85 & 12,50 \\
\hline \multirow{2}{*}{$\begin{array}{l}\text { Def. esp. inicial } \\
\varepsilon_{\mathrm{i}}(\mathrm{mm} / \mathrm{mm})\end{array}$} & $\varepsilon_{i, 1}$ & 0,00000 & 0,00005 & 0,00005 & 0,00000 & 0,00005 & 0,00005 \\
\hline & $\varepsilon_{\mathrm{i}, 2}$ & 0,00000 & 0,00000 & 0,00000 & 0,00000 & 0,00000 & - \\
\hline \multirow{2}{*}{$\begin{array}{l}\text { Def. esp. final } \\
\varepsilon_{\mathrm{f}}(\mathrm{mm} / \mathrm{mm})\end{array}$} & $\varepsilon_{f, 1}$ & 0,00058 & 0,00054 & 0,00061 & 0,00053 & 0,00053 & 0,00053 \\
\hline & $\varepsilon_{\mathrm{t}, 2}$ & 0,00059 & 0,00051 & 0,00052 & 0,00043 & 0,00051 & - \\
\hline \multirow{2}{*}{$\begin{array}{l}\text { Deformação } \\
\text { especifica } \\
\varepsilon(\mathrm{mm} / \mathrm{mm})\end{array}$} & $\varepsilon_{1}$ & 0,00058 & 0,00049 & 0,00056 & 0,00053 & 0,00048 & 0,00048 \\
\hline & $\varepsilon_{2}$ & 0,00059 & 0,00051 & 0,00052 & 0,00043 & 0,00051 & - \\
\hline \multirow{2}{*}{$\mathrm{E}_{\mathrm{cs}}(\mathrm{GPa})$} & $E_{1}$ & 26,70 & 29,06 & 27,40 & 26,99 & 26,77 & 26,19 \\
\hline & $\mathrm{E}_{2}$ & 26,65 & 27,60 & 29,20 & 33,03 & 25,08 & - \\
\hline \multicolumn{2}{|c|}{$\mathrm{E}_{\mathrm{cs}, \text { médio }}(\mathrm{GPa})$} & 26,68 & 28,33 & 28,30 & 30,01 & 25,93 & 26,19 \\
\hline
\end{tabular}

